UNIVERSIDAD NACIONAL DE LA PLATA

FACULTAD DE HUMANIDADES Y CIENCIAS DE LA EDUCACIÓN

SECRETARÍA DE POSGRADO

\title{
Eugenesia y Revolución Sexual. El discurso médico anarquista sobre el control de la natalidad, la maternidad y el placer sexual. Argentina, 1931-1951
}

Nadia Florencia Ledesma Prietto

Tesis para optar por el grado de Doctora en Historia

Directora Dra. Adriana María Valobra, UNLP-CONICET

Codirectora Dra. Karina Inés Ramacciotti, UBA-CONICET

La Plata, 29 de mayo de 2014 


\section{Resumen}

Nuestro interés por recuperar trayectorias discursivas que se ocuparon de lo que hoy denominamos derechos (no) reproductivos y sexuales y de las mujeres en Argentina, nos condujo al análisis de las locuciones del movimiento anarquista. En nuestras primeras pesquisas, las voces de dos médicos anarquistas se destacaron en el tratamiento del problema que nos interesaba abordar. Asimismo, la presencia de ideas provenientes de la eugenesia en los planteos de estos profesionales para el desarrollo de un discurso emancipatorio para las mujeres en relación del derecho a la autodeterminación sexual y reproductiva, nos condujo a focalizar en las distintas apropiaciones de la eugenesia dentro del campo médico. Ante este panorama, nuestra investigación tiene por objetivo general analizar, fundamentalmente, el discurso médico del movimiento anarquista referido al control de la natalidad, la maternidad y el placer sexual en la Argentina durante el período 1931-1951. En este sentido, nos interesa ocuparnos del debate sobre estos temas -más o menos explícitamente enunciados- en el campo médico y, a partir de allí, desprender la particularidad libertaria. La hipótesis general que demostrará esta tesis sostiene que, a partir de la consolidación del pensamiento eugénico anarquista local a través de su propuesta de control de la natalidad, se fortaleció y se legitimó el discurso sobre los derechos de las mujeres a decidir sobre su capacidad de gestar y su derecho al placer sexual sin que interviniera la reproducción como único destino.

\section{Palabras Clave: Anarquismo- campo médico- eugenesia- Revolución Sexual}




\begin{abstract}
Our interest in recovering discursive trajectories that dealt with what today we call sexual and (non-) reproductive rights and women rights in Argentina, lead us to the analysis of the speech of the anarchist movement. In our fist inquiries the voice of two anarchist doctors stood out from our treatment of the previous problem. Likewise, the presence of eugenic ideas in those professionals arguments for the development of a emancipatory discourse for women in relation to the right of sexual and reproductive self determination lead us to focus on different appropriations of eugenics within the medical field. In accordance with this setting, our investigation has for general objective to analyze the medical discourse of the anarchist movement in reference to birth control, motherhood and sexual pleasure in Argentina during the 1931-1951 period. Our interest is to center on the debate around these issues - more or less explicitly enunciated- in the medical field and from there highlight the libertarian stance. The general hypothesis demonstrated by this thesis argues that the women's right to decide over gestation and sexual pleasure, without reproduction as a sole destiny, was strengthen and legitimated by the consolidation of the local anarchist eugenic thinking, particularly through its birth control initiative.
\end{abstract}

\title{
Key words: Anarchism- medical field- eugenics- Sexual Revolution
}


$\underline{\text { Índice general }}$

Agradecimientos........................................................ 1

Introducción............................................................... 3

\section{Capítulo 1}

Posiciones en el campo médico y orden social del discurso.............. 12

\section{Capítulo 2}

Derivas libertarias: tensiones entre sexo y género.................... 47

\section{Capítulo 3}

Los usos de la eugenesia:

La propuesta anarquista sobre el control de la natalidad.

\section{Capítulo 4}

Otras maternidades posibles. La propuesta ácrata de maternidad consciente y voluntaria como herramienta emancipadora

\section{$\underline{\text { Capítulo } 5}$}

El discurso médico anarquista sobre la Revolución Sexual. .171

Conclusiones 204

Bibliografía General. 


\title{
Agradecimientos
}

\begin{abstract}
Los dragones aman las cosas inútiles. Sienten una especial ternura por todo lo que no sirve para nada. Y una secreta admiración. Si las cosas inútiles están ahí, algún mérito deben tener. Como las hojas secas. En especial las hojas secas que tienen un agujero para mirar y descubrir lo que antes no se había visto. No es que las cosas no estuvieran, pero miradas a través del agujero de una hoja seca son otras cosas. Por eso los dragones esperan el otoño con entusiasmo. Saben que va a ser una época de descubrimientos.
\end{abstract}

(Gustavo Roldán, 1997)

Cuando empecé a escribir la tesis compré un cuaderno grande, muy grande, con hojas finas. En ellas iba a dejar registro de todas las búsquedas, ideas y lecturas que conformarían mi investigación. Pero antes de eso, estrené mi cuaderno redactando los agradecimientos, con el tiempo, por suerte, se llenaron más renglones. En estos últimos días vertiginosos, me alegro de haber escrito allí los nombres de quienes hicieron posible que yo haya llegado hasta aquí.

Comienzo agradeciendo a Indi Valobra, mi directora, pues -sin ella en mi caminopensar en que podía investigar, ni siquiera hubiese sido un anhelo. La pasión con la que envuelve cada cosa que hace, contagia. Su confianza y su acompañamiento constante fueron recursos indispensables para lanzarme y recorrer este camino. En esta tarea, resultó invalorable el acompañamiento y la guía de mi co-directora Karina Ramacciotti. A ambas, les reconozco no sólo haber asumido sus roles acabadamente, sino el hacerlo con amor, generosidad y alegría.

Esta tesis contó con el apoyo material de las becas doctorales I y II de CONICET (2010-2015) y el respaldo institucional del Centro Interdisciplinario de Investigaciones en Género (CINIG) del Instituto de Investigaciones en Humanidades y Ciencias Sociales (IDIHCS), Facultad de Humanidades y Ciencias de la Educación, Universidad Nacional de La Plata. Agradezco a las personas que confluyen allí, el apoyo y los intercambios producidos.

A mis amigas y a las compañeras que conocí mientras cursaba la carrera de grado, que con el tiempo se han vuelto amistades confidentes, mi reconocimiento. A Gisela Manzoni, quien me regaló el párrafo del cuento de Gustavo Roldán con el que encabezo esta tesis cuando comenzó esta aventura compartida; y desde entonces, nunca soltó mi mano. A Anabella Gorza, por sus palabras de aliento y confianza cuando mis 
inseguridades me atrapaban. A María Eugenia Bordagaray por el apoyo y los intercambios anárquicos, el acompañamiento de Claudia Molina, en el último tiempo a la distancia, y a Romina Rodríguez, por el soporte y ánimo para continuar.

En el último tiempo, Paula Salguero y Sol Calandria me incentivaron cuando las fuerzas ya flaqueaban. A Magui Tirabassi, por su dedicación y por sobrellevar los tiempos acelerados.

Al personal de las Bibliotecas y Archivos que me ayudaron a conseguir materiales indispensables para esta investigación. En particular, a las personas que sostienen el Archivo de la Federación Libertaria Argentina. A Helena Andrés Granel por los intercambios lazartianos; a Héctor Daniel Guzmán, por los aportes virtuales desde la provincia de Santiago del Estero; y a los familiares y amigos de Lazarte y Martín Fernández que fueron generosos con sus recuerdos sobre estas figuras centrales en mi trabajo.

Mi familia ha sido un sostén constante, su amor y su preocupación por mi felicidad me hacen sentir afortunada. A mi mamá Gladys, además de su amor infinito, por el recuerdo de su voz contándome historias, al igual que papá, antes de dormir. A mi papá Raúl por abrazarme fuerte cuando, a veces, las palabras no alcanzan. A mi hermana Noelia, porque "cada recuerdo de lo que soy lleva impregnado tu nombre...". A mi abuela Eva, mi matriarca, por la historia de su vida que me lleva a otros mundos, que narraba para mí y hoy narra con voz baja y pausada, ante mis preguntas curiosas. A mi tío Félix, el vagabundo, por la poesía y sus historias de los siete mares. Agradezco, también, el apoyo y el amor de mi tía, primas, cuñadxs, suegrxs y sobrinxs que renuevan mi capacidad de asombro y me obligan a no perder la imaginación.

Agradezco a mis amigxs, quienes hacen que todo tenga sentido, su compañía ha sido fundamental para que yo realizara esta tesis. A Jesi, Lauri y Lea, a mis amigxs de Bellas y a la familia "Paranoia".

Dedico las últimas líneas a quienes vivieron diariamente en una casa tomada por libros y fotocopias. A Lola por distraerme en el momento justo. Y a mi gran amor, Adrián, gracias por todo y más. Por poner a prueba todas mis hipótesis. Por motivar todos mis sentidos, por estar a mi lado y rescatarme cuando me pierdo en este laberinto. Gracias por llenar los días de risas y canciones hace tanto tiempo, pero que el descubrimiento diario hace que parezca poco. 


\title{
Introducción
}

\begin{abstract}
"Aunque pese a todos los revolucionarios, voy a osar también en una afirmación, que algún día, será puesta en el rol de las profecías.

Repito: ¿El sexo degradó al hombre y a la mujer? Es por el sexo que vendrá la redención de la humanidad.

El problema humano es un problema sexual" (María Lacerda de Moura, 1935:XVI)
\end{abstract}

El interés de esta investigación surge a partir de un problema, hasta ahora no resuelto: la autonomía de las mujeres sobre sus cuerpos, particularmente a decidir sobre el ejercicio o no de la maternidad.

Desde este presente, cada nuevo debate, es un volver a empezar de cero y cada nuevo caso de aborto no punible judicializado es una muestra de la feroz resistencia de todos los poderes del Estado, de las instituciones religiosas y de amplios sectores de la sociedad. Entonces, el debate legislativo sobre el aborto, se vuelve una ilusión paralizante que mantiene el statu quo, convirtiéndose en una instancia recortada en el tiempo y en el espacio sin reconocimiento de trayectorias discursivas y prácticas.

Este procedimiento de ocultamiento ha impedido establecer una genealogía de las ideas que sustentaron la emancipación femenina, defendiendo su capacidad de decidir cuándo y cómo ser madres o no serlo. También ha excluido los debates, las tensiones y las disputas que, en distintos momentos desde la conformación moderna del Estado en la Argentina, se produjeron en cuanto a la conceptualización de las mujeres como sujetos autónomos.

Entendemos que estas maniobras sustentaban y sustentan aún la política sexual del sistema patriarcal. Si bien las mujeres han visto ampliadas las dimensiones de ciudadanía luego de su lucha por conquistar sus derechos políticos, civiles y sociales, los derechos (no) reproductivos y sexuales todavía siguen pendientes. ${ }^{1}$ Esto demuestra

${ }^{1}$ Esta noción ha sido elaborada por Josefina Brown para poner de relieve con un no entre paréntesis "la posibilidad semántica de que las mujeres pudiésemos elegir voluntaria y libremente no procrear" (Brown, 2014:10) 
la pervivencia del sistema de dominación que conlleva relaciones de poder de los varones hacia las mujeres.

Siguiendo a Joan Scott (2011), la categoría de género es y ha sido útil para el análisis histórico de estas relaciones de poder pues nos permite cuestionar cómo se construye la diferencia sexual, cómo se definen a partir de esta construcción roles y espacios de sociabilidad femeninos y masculinos y nos permite historizar cómo ciertos discursos se vuelven dominantes e invisibilizan otros discursos.

En este sentido, nuestro interés por recuperar trayectorias discursivas que trataran sobre lo que hoy denominamos derechos (no) reproductivos y sexuales y de las mujeres en Argentina, nos condujo al análisis de las locuciones del movimiento anarquista. En nuestras primeras pesquisas las voces de dos médicos anarquistas se destacaron en el tratamiento del problema que nos interesaba abordar. Asimismo, la presencia de ideas provenientes de la eugenesia en los planteos de estos profesionales para el desarrollo de un discurso emancipatorio para las mujeres en relación del derecho a la autodeterminación sexual y reproductiva, nos condujo a focalizar en las distintas apropiaciones de la eugenesia dentro del campo médico.

Ante este panorama, nuestra investigación tiene por objetivo general analizar, fundamentalmente, el discurso médico del movimiento anarquista referido al control de la natalidad, la maternidad y el placer sexual en la Argentina durante el período 19311951.

Nos interesa ocuparnos del debate sobre estos temas -más o menos explícitamente enunciados- en el campo médico y, a partir de allí, desprender la particularidad libertaria. El campo médico no se presenta como una unidad homogénea sino que dentro de este campo se encuentran posiciones dominantes y dominadas, que delinean diversas apropiaciones de las ideas que atraviesan al campo, en este caso nos interesa evidenciar las modulaciones eugénicas.

La mayoría de los estudios locales han centrado su interés en la eugenesia pensada e implementada por los miembros de la "cultura científica" de principios del siglo XX, con especial énfasis en los provenientes del sector médico, jurídico y político que se desempeñaron en lugares de poder, como el ámbito académico como así también en las 
estructuras estatales y en los procesos de institucionalización de la eugenesia. Desde los estudios de la eugenesia dominante, la frontera temporal recreada por el sentido común historiográfico (Nieto, 2010) que le resta continuidad al análisis del anarquismo después de las primeras décadas del siglo $\mathrm{XX},{ }^{2}$ hizo que pareciera imposible encontrar vestigios de la eugenesia ácrata en períodos posteriores.

Así, el interés de la mayoría de las investigaciones se ha concentrado en la fuerte intervención de los postulados eugénicos en el diseño de políticas públicas, en su incidencia en la delineación de leyes y en la participación de la élite médica y jurídica en el poder estatal para llevar adelante estas intervenciones.

Asimismo, el discurso, podríamos decir casi exclusivamente analizado, ha sido el de Juan Lazarte. Sus ideas sobre el control de la natalidad y la maternidad consciente o voluntaria, han sido vinculadas, principalmente, a estrategias eugénicas de mejora de la "raza" o a estrategias políticas y económicas de resistencia al capitalismo. Si bien se menciona el carácter vanguardista y las posibilidades para la emancipación sexual de la mujer, no se ha indagado en esta cuestión y tampoco se han situado estas ideas en relación al campo médico y al movimiento anarquista.

Nuestra lectura considera que la particular modulación que el anarquismo hizo de distintas tradiciones -fundamentalmente de los postulados eugénicos- lo convirtió en un discurso conceptualmente disruptivo respecto de la noción de maternidad como destino único para las mujeres y la diferenciación de reproducción y sexualidad recreativa que originó el surgimiento de la noción de Revolución Sexual como piedra angular de su propuesta.

Asimismo, el abordaje de los discursos de los profesionales médicos que actuaron dentro del anarquismo después de los años '30, nos permite superar no sólo la frontera temporal, sino también la frontera dimensional que presentan los abordajes sobre el

${ }^{2}$ El SCH, señala Nieto "refiere a aprehensiones de varios historiadores de centralidad destacada en el campo, con la idea de un 'acuerdo universal' respecto a ciertas 'verdades' que se suponen aceptables para todos y autoevidentes. Debido a que este tipo de conocimiento se basa en la tradición o consenso de la mayoría, en el acuerdo común de quienes lo comparten y utilizan, y del que es guardián; por lo tanto, hacer entrar una nueva 'verdad' en él es verdaderamente difícil (...)Así el SCH se vuelve una concepción general absorbida acríticamente por diversos ambientes historiográficos en los cuales se moldea el historiador medio" (2010: 226) 
anarquismo en Argentina abocados en su mayoría al análisis del movimiento obrero. Según nuestra lectura, la dimensión cultural cobra relevancia para analizar el período posterior a 1930 pues se convierte en una estrategia de intervención para dar continuidad al movimiento. La multiplicación de proyectos editoriales y revistas llevada adelante por militantes provenientes de sectores medios y profesionales compensaba la contracción del agenciamiento anarquista en movimiento obrero.

Estas iniciativas permiten expandir sus intervenciones a nuevos espacios sociales donde la inserción de figuras referentes del anarquismo en diversos ámbitos profesionales resulta relevante $y$, en particular, se destaca en el campo médico y dentro de este Juan Lazarte y Manuel Martín Fernández.

En suma, la hipótesis general que demostrará esta tesis sostiene que, a partir de la consolidación del pensamiento eugénico anarquista local a través de su propuesta de control de la natalidad, se fortaleció y se legitimó el discurso sobre los derechos de las mujeres a decidir sobre su capacidad de gestar y su derecho al placer sexual sin que interviniera la reproducción como único destino. La matriz de derechos no es estrictamente la del liberalismo aunque retoma la noción de individuo de éste e incluye a la mujer en ella. Más aún, desde la lógica libertaria, los derechos sexuales de las mujeres -así denominados en los documentos anarquistas- son más importantes que otras facultades sean las políticas o las civiles. Vale decir, que esta concepción rompe también con la primacía de los derechos tradicionalmente vinculados a lo público y trae a discusión una serie de problemáticas invisibilizadas como parte de ese debate.

La tesis está organizada en cinco capítulos que permiten desarrollar el objetivo general y demostrar la hipótesis general. La estructura de los mismos está delineada por el análisis de las posiciones dentro del campo médico que hemos seleccionado a partir de la perspectiva relacional que asume este estudio. Esta mirada nos permite construir el orden social discursivo en el que se ubican las locuciones de los médicos anarquistas (Martín Rojo: 1996-1997). Así, sorteamos lo que Richard Cleminson (2008) llamó la lectura "internalista" de los estudios que se enfocan en las dimensiones culturales en particular en la sexualidad y el género del anarquismo. El autor crítica esta mirada “...que lee las actuaciones del anarquismo como si emanaran dentro del propio movimiento sin dar cuenta de las condiciones en que se realizaban..." (Cleminson, 
2008:11). Así la mirada relacional resulta un gran aporte para tensionar y desnaturalizar concepciones tanto sobre el anarquismo como de la eugenesia.

A lo largo de la tesis, utilizaremos algunas de las herramientas proporcionadas por el Análisis Crítico del Discurso (ACD). Considerado una teoría y un método al mismo tiempo, el ACD nos permite considerar al discurso como una práctica social, que debe ser situado en el contexto del que la/o acciona y del que la/o recibe y que tiene como fin analizar cómo se manifiestan a través del lenguaje las relaciones de dominación, discriminación, poder y control (Fairclough, 2003) La perspectiva de Norman Fairclough señala que el ACD comprende tres dimensiones de análisis: en el nivel micro, la dimensión "texto" que corresponde al análisis lingüístico del texto en sí. La "práctica discursiva", segunda dimensión, comprende los procesos de producción e interpretación de los textos que producen la "interacción". Por último, la dimensión "práctica social" que se ocupa del contexto social en el cual se dan los procesos de producción e interacción, las circunstancias institucionales sociales e históricas de aquella interacción. El discurso se considera una construcción. Su creación está determinada por la existencia de textos previos (pre-textos) y debe ser interpretado teniendo en cuenta esos textos. Como señala Julia Kristeva - a través del concepto de intertextualidad - "todo texto se construye como mosaico de citas, todo texto es absorción y transformación de otro texto" (Kristeva, 1978:190). En este sentido si la intertextualidad no es manifiesta la coherencia del texto estará provista a partir de los esquemas interpretativos del analista. Las referencias intertextuales "revelan el proceso de producción de un texto, indicando los pre-textos que el productor incorpora en su construcción y los tipos de discurso con los que este texto está de una forma u otra relacionado" (Luzón Marco, 1997:148). Si en cambio es manifiesta, las marcas de cita evidenciaran las otras voces presentes en el texto.

Asimismo, el ACD más allá de ser una herramienta de análisis metodológico, nos interesa la posición "crítica" de esta perspectiva. Más allá de la vigilancia epistemológica y la autocrítica, la noción a la que se refiere el adjetivo "crítico" es que quien investiga asume una posición explícita de compromiso con ciertas cuestiones sociales y políticas “...y lo hacen no sólo como ciudadanos, sino también en tanto que, precisamente, investigadores" (van Dijk, 1999: 23-24). 
Nos apoyaremos, también, en la crítica feminista la cual, lejos de ser incongruente con el ACD, resulta compatible ya que presentan nociones comunes sobre el poder, el papel de la cultura en la construcción de significados y la necesidad de hacer explícitas las posiciones socio-políticas de los sujetos que investigan.

Estas perspectivas nos permiten situarnos como sujetos con capacidad de intervención política desde nuestras prácticas académicas, que al hacer explícita nuestra subjetividad asumimos que los conocimientos son situados. Como señala Donna Haraway, la objetividad feminista es una objetividad construida a través de la encarnación y la parcialidad que se propone, "luchar por una doctrina y una práctica de la objetividad que favorezca la contestación, la deconstrucción, la construcción apasionada, las conexiones entrelazadas y que trate de transformar los sistemas del conocimiento y las maneras de mirar"(Haraway, 1995:329)

En esta perspectiva de investigación situamos nuestro análisis, que pone el foco en las imbricaciones políticas, sociales y médicas que dan por resultado diversas manifestaciones de la eugenesia. Para ello, analizamos las distintas voces dentro del campo médico, las cuales categorizamos con fines analíticos, en posiciones dominantes y dominadas. Dentro de las posiciones dominantes del campo médico, situamos a la/os profesionales que han ocupado espacios de poder y de decisión en el ámbito universitario, en agencias estatales y en instituciones que han tenido incidencia en el diseño e implementación de políticas que desde una apropiación singular de la eugenesia incidían en la capacidad reproductiva de las mujeres y su sexualidad. En las posiciones dominadas situamos por un lado, los discursos de las médicas feministas que configuraron narrativas particulares a partir de su defensa de los derechos de las mujeres. Por otro lado, ubicamos los discursos de los médicos anarquistas que responde al objetivo de nuestra investigación.

El período de análisis que abarca este estudio está delimitado por las producciones anarquistas en las cuales se tratan los temas a analizar. El punto de partida es el año 1931, cuando aparece la revista Nervio y su editorial en el ámbito local y Lazarte publica en la revista Estudios de Valencia. El año de finalización de la periodización es 1951, cuando culmina la edición de la última publicación en la cual tenemos constancia del tratamiento de las cuestiones a analizar, la revista Luz. Durante ese lapso de tiempo, 
algunos temas se destacan en un momento, otros pierden espacio en la prensa anarquista y, también, cambian las estrategias de difusión y las voces que las promueven.

El núcleo central de nuestro corpus comprende las publicaciones en las cuales participan los médicos anarquistas y en las que se manifiestan sus ideas por otras voces ácratas. Trabajamos con las revistas Nervio, Estudios de España; Cultura Sexual y Física; Hombre de América Fuerte y Libre y Luz. También, analizamos el periódico Reconstruir y las obras de Juan Lazarte sobre el tema. Además para dar cuenta de los discursos dentro del campo médico hemos analizado la obra de: Theodor $\mathrm{H}$. van de Velde; Gregorio Marañón; la producción científica y cultural de Josué Beruti, algunas producciones de Mercedes Rodríguez de Ginocchio, la revista Iatría del Consorcio de Médicos Católicos y la producción referida al tema de Alicia Moreau de Justo, entre otros materiales.

A continuación realizaremos un recorrido de nuestro estudio a través de la descripción de cada capítulo y la hipótesis específica a trabajar en cada uno de ellos a fin de demostrar nuestra hipótesis general.

En el Capítulo 1, exploramos la conformación del campo médico a partir de situar las posiciones dominantes y dominadas que se reflejan en el orden social discursivo a fin de dar cuenta de las diversas trayectorias. La hipótesis de este capítulo apunta a demostrar la presencia de las voces médicas anarquistas en el período estudiado en discusión con otras del campo y, a su vez, enunciar que la dinámica del movimiento anarquista desde el punto de vista político condicionó no sólo los vaivenes y estrategias desplegadas sino también el contenido de las ideas.

En el Capítulo 2, nos proponemos analizar las construcciones discursivas sobre los roles de género de las diversas posiciones dentro del campo médico. Nos interesa evidenciar los puntos en común y las inflexiones discursivas de las distintas apropiaciones. A partir del análisis de distintas locuciones, encontramos la propuesta las voces dominantes que construyeron la maternidad como destino de las mujeres a partir de la imposición e indisolubilidad del binomio mujer-madre. Luego, las médicas feministas cuestionaron las jerarquías implícitas en los roles, mas no la sexualización. Finalmente, los médicos anarquistas, si bien compartieron la idea de maternidad como capacidad propia de las mujeres, no la consideraron destino. Asimismo, al igual que las 
otras posiciones en el campo, sí aceptaron la diferencia sexual como algo dado, no construido. La hipótesis de este capítulo sostiene que si bien los médicos anarquistas cuestionaron y evidenciaron al carácter construido de los roles femeninos y masculinos no hicieron lo mismo con el sexo, pues hacerlo era cuestionar los fundamentos propios de su profesión.

En el Capítulo 3, proponemos recortar los problemas vinculados al modo de pensar el control de la natalidad. Se demostrará que el pensamiento eugénico integró la matriz conceptual de las diversas posiciones en el campo, pero se resignificó el mismo según las matrices ideológicas en las que se inscribe. El pensamiento eugénico dominante reforzó la idea maternal sobre las mujeres; el feminismo, por su parte, osciló en estas relaciones entre maternidad y eugenesia mostrando matices respecto de las miradas dominantes. Los médicos anarquistas, finalmente, utilizaron la eugenesia de manera distintiva respecto de la maternidad. Precisamente, la hipótesis es que, en el anarquismo, el control de la natalidad a través de la difusión de las herramientas anticoncepcionales propició la emancipación femenina al otorgarle conocimiento sobre cómo intervenir su propio cuerpo para decidir sobre el ejercicio o no de la maternidad sin renunciar al placer sexual.

En el Capítulo 4, nos abocamos a analizar cómo a partir de las ideas sobre control de la natalidad, aparece en el anarquismo un discurso sobre la maternidad consciente y voluntaria. Nuestra hipótesis es que, contraria a una política pronatalista y promaternalista, la maternidad consciente y voluntaria, resultado de la aplicación de métodos anticoncepcionales y como parte de la propuesta eugénica ácrata, al mismo tiempo sustentó la emancipación femenina en cuanto a la capacidad volitiva de las mujeres para decidir cuándo y cómo ser madres.

En el Capítulo 5, derivado de las ideas de control de la natalidad y de la maternidad consciente y voluntaria del anarquismo, reconstruimos cómo surge el concepto de Revolución Sexual que incluye, entre otros aspectos, la diferenciación entre sexualidad y reproducción. El placer y autodeterminación sexual, señala nuestra hipótesis, fueron componentes sustantivos de la prédica libertaria que, también conllevó limitaciones que condicionaron uno de los núcleos más importantes de la Revolución Sexual: el cuestionamiento a la heterosexualidad obligatoria. 
La frase que abre este trabajo fue tomada del prólogo del libro de Juan Lazarte Sociedad y prostitución escrito por la militante anarquista brasileña María Lacerda de Moura, quien compartió lazos de amistad y camaradería con Juan Lazarte. La misma condensa las ideas de un período anterior al establecimiento de lo que se llamó la Revolución Sexual en los años '60 y '70. En este sentido, este recorrido que proponemos transitar en las siguientes páginas, que surgió de un interés por analizar las genealogías discursivas en relación a los derechos sexuales y (no) reproductivos, demuestra que el discurso médico anarquista a partir de una singular apropiación de la eugenesia en relación al control de la natalidad legitimó y propició la conquista de aquellos derechos. 


\section{Capítulo 1}

\section{Posiciones en el campo médico y orden social del discurso}

Como hemos mencionado en la introducción, las elecciones teóricometodológicas de nuestro enfoque tienen un carácter relacional que consideramos que permiten poner el acento en las distintas apropiaciones de la eugenesia y las intertextualidades entre las distintas posiciones del campo médico. Por ello, el recorrido de este estudio requiere, en primer lugar, presentar las distintas posiciones que relevaremos para analizar el orden social discursivo en el que se insertan las narrativas de los médicos anarquistas. Recurrimos a la noción de campo, entendido como un sistema de relaciones entre distintas y jerárquicas posiciones que, como señala Luisa Martín Rojo "se proyectan sobre el universo discursivo" (1996-1997: 4). El principio de desigualdad que fundamenta el orden social de los discursos produce discursos autorizados y legitimados y discursos des-autorizados y des-legitimados. Asimismo, el control social sobre la producción y la circulación de discursos también contribuye a la conformación de aquel orden a través de diversos procedimientos de exclusión (Foucault, [1970] 1992).

El campo médico como campo profesional se distingue en el espacio social de los demás campos por el capital cultural y simbólico que allí se vinculan. Las distintas posiciones se definen a partir de la distribución los capitales en juego que estructuran relaciones de poder entre sí (Bourdieu y Wacquant, 1997). Ahora bien, las relaciones de las posiciones de este campo con el campo de poder y el Estado, como así también sus trayectorias, nos permiten distinguir diversos intereses dentro del mismo provenientes de posiciones dominantes y dominadas, pero que conforman un campo a partir del acuerdo fundamental que las reúne en la disputa: la legitimidad de la ciencia médica.

Para recrear el orden social discursivo sobre los temas bajo estudio, nuestro abordaje se estructurará, por un lado, atendiendo a las posiciones médicas dominantes que ocuparon espacios de poder en el ámbito universitario y fueron legitimados desde el Estado y la Iglesia. Por otro lado, abordaremos las posiciones dominadas de las médicas feministas que, si bien contaron con el capital cultural para formar parte del campo, veremos cómo sus intereses en relación con la defensa de los derechos de las mujeres las colocaron por fuera de las instituciones de poder y sus discursos fueron 
subordinados por los discursos dominantes. Finalmente, nos ubicamos en el que consideramos el aporte principal de nuestra investigación y analizamos las posiciones médicas anarquistas, que si bien comparten con las médicas feministas el lugar subordinado y conforman el campo médico a partir de su interés en la legitimidad de la ciencia médica, su trayectoria los ubica en posiciones alejadas de las demás. Asimismo, sus discursos han sido objeto de los procesos de exclusión, no sólo por las posiciones médicas que analizamos, sino también por la historiografía, en la cual ha primado el interés por el análisis de las posiciones dominantes y aquellas que participan de la arena política a través de estructuras partidarias.

A continuación, presentaremos cada una de las posiciones que aborda este estudio para recrear el orden social discursivo, señalaremos los espacios de acción, las redes de sociabilidad y su inclusión dentro del campo médico a fin de mostrar el escenario que recorreremos a lo largo de los capítulos siguientes.

\section{Los médicos dominantes}

Como ha señalado Ricardo González Leandri, la profesionalización de la elite médica a mediados de siglo XIX "dependió fundamentalmente de su legitimación estatal" (1996: 26). La reglamentación de la Facultad de Medicina de la provincia de Buenos Aires, los espacios de sociabilidad allí recreados y la participación de los profesionales médicos en diversas agencias estatales y en la diagramación de políticas públicas, vincularon desde el inicio de su proceso de profesionalización a la elite médica con el Estado.

La participación en las cátedras universitarias también fueron fuentes de legitimidad y autoridad. En este sentido, el médico obstetra Josué Beruti, quien se había doctorado en medicina en 1907 en la Universidad de Friburgo, Alemania, ingresó como adscripto a la Cátedra de Clínica Obstétrica de la Facultad de Medicina de la Universidad de Buenos Aires (UBA) en 1911 y llegó al cargo titular de la Cátedra en 1931. El interés por abordar el discurso de este profesional parte, por un lado, de su autoridad y legitimidad no sólo dentro del ámbito universitario, sino en los diversos espacios institucionales de los que formó parte, como la Asociación Argentina de 
Biotipología, Eugenesia y Medicina Social y su reconocimiento desde la esfera estatal. Por otro lado, desde este posicionamiento, Beruti abogó por la instauración de la eugenesia como prisma a través del cual debían cristalizarse las intervenciones en la sociedad, en particular, en relación a las mujeres. Su preocupación por la educación femenina y la maternidad fueron centrales en su discurso y su práctica llevada adelante en la Clínica Obstétrica y Ginecológica "Eliseo Cantón” y la Escuela de Madres que creó allí.

Se dedicó intensamente a su profesión, contribuyó al conocimiento científico de su especialización y llevó a cabo un programa dirigido a la protección de la maternidad, a través de la Asociación Argentina de Biotipología, Eugenesia y Medicina Social (1932). En esta institución, estaba a cargo de la sección de Eugenesia, Maternidad e Infancia. Sus publicaciones tuvieron amplia difusión en la prensa médica (La semana médica, El día médico). Asimismo, su labor fue divulgada entre un público amplio a través de medios periodísticos comerciales tales como La Nación y La Razón y la denominada prensa femenina como la revista El Hogar. Sus discípulos compilaron la vasta producción de Beruti, escrita entre 1903 y 1942, con motivo del festejo de las bodas de plata que el médico cumplía en la labor en la Cátedra de Clínica Obstétrica de la Facultad de Ciencias Médicas de Buenos Aires.

Hijo de una familia perteneciente a la elite porteña, su formación en universidades alemanas le permitió, a su regreso a la Argentina en 1908, iniciar rápidamente su carrera en el ámbito de la ciencia, la labor hospitalaria y la docencia. Los lazos con Alemania continuaron a través de diversos intercambios académicos y científicos los cuales dieron origen a la creación de la Institución Cultural Argentino Germana en 1922. El médico Gregorio Aráoz Alfaro ocupó el cargo de presidente y Beruti fue el Secretario General hasta 1939. Luego, ocupó el cargo de vicepresidente primero. La institución se proponía difundir la cultura alemana través de intercambios como los viajes de estudio. Según Andrés Reggiani, "eran las cuestiones de índole «técnica» las que inspiraban el interés en la medicina alemana" (2005: 64). La admiración por la medicina del régimen nazi, contribuía "a legitimar la política del régimen o al menos abstenerse de cualquier opinión” (Reggiani, 2005: 67). Asimismo, Beruti admiraba también las políticas implementadas por el fascismo, en particular, las destinadas a delimitar a las mujeres al espacio doméstico y a la maternidad. Los lazos con la biotipología italiana se 
canalizaron a través de la Asociación Argentina de Biotipología Eugenesia y Medicina Social -entidad civil pero con apoyo estatal-que fue central en los años 30 en la difusión de la eugenesia y la biotipología de Nicola Pende (Vallejo y Miranda, 2005). Allí, además de la sección que ya mencionamos, Beruti estaba a cargo también de la materia Maternidad e Infancia en la Escuela Politécnica creada por la asociación en 1934, donde se formaban asistentes sociales, escolares y hospitalarios.

Desde su práctica médica, Beruti fue creador de algunas técnicas aplicadas al control del embarazo como los métodos de cardiotelefonía y fonocardiografía fetal, el tacto rectal para la conducción del parto; investigó sobre el uso de anestésicos en el parto y diseñó diversos instrumentos como el "fórceps polimorfo" y el "taponador y un aspirador traqueal para el recién nacido" (Sala y León, 1943: X). En el ámbito universitario, participó del Consejo de la Facultad de Ciencias Médicas y fue presidente de la Sociedad de Obstetricia y ginecología de Buenos Aires entre 1937 y 1938.

Sus antecedentes y su participación en los distintos espacios institucionales legitimaron su actuación, en particular, en relación con los problemas vinculados a la maternidad. Ello se evidencia en el reconocimiento que recibió Beruti como especialista cuando fue consultado por las agencias estatales sobre el diseño de diversos proyectos de ley en relación a aquellos temas.

Dentro de este posicionamiento del campo médico dominante hemos situado también a los médicos que integraron el Consorcio de Médicos Católicos. Ésta institución surgió en la ciudad de Buenos Aires, en 1929, por iniciativa del jesuita Guillermo Furlong. En el acta de fundación figuran los médicos Miguel Petty, José L. Molinari, Luis Corbi Rodríguez, Enrique Vallaza, Juan J. Murtagh, Gabriel O'Farrell, Francisco E. Radrizzani, Luis Ayerza, Juan Robbio y Ernesto Dillon (Carranza Casares, 2008). Rápidamente, se organizaron filiales en diferentes puntos del país y, hacia 1944 , las corporaciones regionales conformaron una Federación.

Como señala Ana María Rodríguez, a comienzos de los años 30 la Iglesia católica se propuso "conformar un referente cultural/ideológico que marcó una impronta en las políticas estatales cuyo destinatario fue el cuerpo de la mujer" (2003: 203). El Consorcio participó en la concreción de aquellos objetivos aportando legitimidad 
científica a la empresa moral de la Iglesia. Desde sus inicios, se propuso armonizar la ciencia y la moral católica a través de acciones como:

organizar los vínculos entre los médicos católicos de todo el país con el objeto de: investigar las relaciones entre teorías y prácticas médicas y la teología y filosofía católicas; defender los principios de la moral católica contra el materialismo y la seudociencia (sic); proveer mutua ayuda en los intereses religiosos y profesionales de unos y otros; y, en general, promover entre los miembros católicos de la profesión médica tal solidaridad que el conocerse y tratarse sea ventajoso para todos, así en lo relativo a la moral como a la profesión. (Iatria, 1931, en Rodríguez, 2008: 261)

El Consorcio se preocupó por conquistar un lugar relevante dentro del campo médico, como así también, obtener el reconocimiento desde el ámbito clerical (Rodríguez, 2008). Para ello, impulsó la inserción de sus miembros en el cuerpo docente de la Facultad de Medicina de la Universidad de Buenos Aires -referente en el país en la disciplina- y la ocupación de cargos directivos en diversos hospitales. En este sentido, en un discurso inaugural de las sesiones del Consorcio de Médicos Católicos en 1944, su presidente, el médico Luis Ayerza señalaba los alcances de aquel objetivo. En ese momento, el Consorcio estaba conformado por doscientos médicos, de los cuales ocho eran académicos pertenecientes a la Academia Nacional de Medicina, treinta eran profesores en la universidad y once se desempeñaban como directores en hospitales (Rodríguez, 2008).

En este contexto, quien cobra relevancia para nuestro estudio es el médico ginecólogo Carlos Alberto Castaño. Participó en la consolidación del Consorcio y ocupó la presidencia del mismo entre 1934 y 1944 y fue profesor honorario de la Universidad Nacional de Buenos Aires. También fue miembro de la Sociedad de Obstetricia y Ginecología, primero como Secretario General (1916-18918) y luego ocupó la presidencia entre 1942 y 1943. 
En su labor como presidente del Consorcio, sus colegas destacan los retiros espirituales periódicos para médicos y el reconocimiento oficial por parte del Decano de la Facultad de Medicina de Buenos Aires para que se instituyera el día de San Lucas 18 de octubre- como el día del médico (Carranza Casares, 2008). Asimismo, como autoridad dentro del ámbito, fue un referente en el tratamiento médico de las lesiones tumorales del útero por afecciones de las enfermedades venéreas. Brindó cursos de perfeccionamiento para médicos sobre Clínica Ginecológica y dictó conferencias en el ámbito local e internacional. Entre otras, participó de las Jornadas de la Real Academia Nacional de Medicina el 11 de febrero de 1950 en las cuales disertó sobre "patología del neo-malthusianismo" (Matilla y Gómez y Luque y Beltrán, 1951: 13). Castaño es una figura relevante para nuestro trabajo pues fue quien llevó adelante con más ahínco la afrenta a cualquier intento de emancipación femenina, en particular, en relación con la sexualidad y la reproducción. La mayoría de sus intervenciones en la revista Iatría, órgano de difusión del Consorcio que comenzó a publicarse en 1930 y se mantuvo en circulación a través de suscripciones hasta el año 2008, trataban sobre la condena del aborto, la prohibición de los métodos anticonceptivo y la preocupación por la dentalidad.

Por último, dentro de posición que hemos delineado a los fines del análisis, en algunos capítulos abordamos el discurso de la hermana del médico Germinal Rodríguez, la médica la Mercedes Rodríguez de Ginocchio, quien también desde sus diversos espacios de acción se abocó al igual que Beruti, a los problemas relacionados con la maternidad, en relación al trabajo y las madres solteras. Como señalan Carolina Biernat y Karina Ramacciotti (2013), la médica se preocupó de manera marginal por la salud de las mujeres, dado que el interés, desde una perspectiva eugénica, estaba puesto en la capacidad de gestar hija/os sana/os. Estuvo a cargo de la Secretaría de Previsión e Higiene Social del Museo Social Argentino (Becerra Solá y Becerra, 2009) y fue la vice-presidenta del Congreso de Población realizado en 1940. La médica acordaba con las ideas dominantes en relación a las mujeres y se ocupó de legitimar desde la ciencia médica que el lugar de realización de la mujer era el hogar y su única actividad la maternidad. Podríamos conjeturar que la defensa de estas ideas le permitió acceder a ciertos espacios de decisión que eran vedados para la mayoría de las mujeres y, en especial, a las que no comulgaban con esas propuestas -como en el caso de las médicas feministas-. 


\section{Las médicas feministas}

El arribo a la educación universitaria de las mujeres comenzó a fines del siglo XIX, cuando algunas de ellas se empeñaron en sortear los obstáculos que les impedían acceder a ese nivel educativo (Barrancos, 2007). Esta presencia femenina se concentró en la Facultad de Ciencias Médicas de las universidades nacionales de Buenos Aires y Córdoba. Cecilia Grierson fue quien inauguró los egresos femeninos en la UBA, en 1889, seguida por Elvira Rawson de Dellepiane, en 1892. Ambas fueron apadrinadas por el decano de su casa de estudios el Dr. Mauricio González Catán. En Córdoba, Margarita Zatzkin hizo lo mismo, apadrinada por su esposo Elías Fernández de La Puente, en 1909 (Kohn Loncarica y Sánchez, 1997). Durante el período comprendido entre 1900 y 1965, egresaron de la carrera de Medicina un total de 10.631 mujeres de las cuales, un $37,18 \%$ se recibieron de obstetras y un $9,79 \%$ corresponde a kinesiólogas. $^{3}$

Si bien la llegada de mujeres fue resistida por estudiantes y profesores que, imbuidos de las ideas sobre los roles sexuales, creían que era una desviación o anormalidad de la mujer la actividad intelectual considerada propia del varón (Ramacciotti y Valobra, 2011), las mujeres ocuparon un espacio de acción dedicándose en su mayoría a los problemas relacionados con la salud de las mujeres y la niñez (Lorenzo, 2010).

Sus voces fueron marginadas dentro del campo médico y se las excluyó de la docencia universitaria. En este sentido, un caso paradigmático que muestra la resistencia hacia la participación de las mujeres en la docencia universitaria fue la lucha establecida por María Teresa Ferrari de Gaudino para acceder a la cátedra de Clínica Obstétrica Obstetricia en 1927 (Zuppa, 2008).

\footnotetext{
${ }^{3}$ Los datos son aportados por el Boletín Evolución en las profesiones liberales en Argentina 1900- 1965 elaborado por la Oficina Nacional de la Mujer (Dirección nacional de Recursos Humanos, Secretaría de Estado de Trabajo) en el año 1970. De la carrera de medicina de la UBA egresaron 6.326 mujeres desde 1902 a 1950; en la Universidad Nacional de Córdoba egresaron 1.318 mujeres entre 1909 y 1960, sin embargo, de ese total, 1.032 corresponden a egresadas de Obstetricia.
} 
La elección de la carrera de Medicina por parte de las mujeres sobre otras carreras, según los estudios sobre el tema, se produjo por un conjunto de factores. Algunos trabajos enfatizan la decisión de las mujeres de acceder al conocimiento de su cuerpo para poder tener control sobre el mismo, en particular sobre la reproducción (Palermo, 2005). Otros estudios lo relacionan a la incidencia de la feminización de la orientación obstétrica (Lorenzo, 2010) y al predominio de la diferenciación sexual que designaba para las mujeres "las funciones de cuidado y asistencia" (Barrancos, 2007: 118). No obstante la idea que subyace a algunas lecturas que consideran que la especialización en el área de la pediatría y la obstetricia fue una opción que naturalizaba aún más sus pericias como médicas, acotando sus intervenciones, es importante señalar que para poder ejercer en esos rubros, en especial a comienzos del siglo XX, las mujeres debieron disputar los espacios en los que los varones eran las únicas voces autorizadas para hacerlo.

Cecilia Grierson, en la introducción de su tesis titulada "Histero-ovariotomías efectuadas en el Hospital de mujeres desde 1883 a 1889", manifestaba que:

las condiciones de mi sexo, me han puesto naturalmente en más relación con el Hospital de Mujeres y que dedicada por deber de conciencia á (sic) las enfermedades de mujeres, aspiré y obtuve ser encargada de las salas de Ginecolojía (sic). (Grierson, 1889: 9)

En este mismo sentido, pero haciendo hincapié en la crítica del papel de la mujer en la sociedad, desde una reivindicación de la maternidad como justificativo para la adquisición de derechos, Elvira Rawson explicitó a los jurados los motivos que originaron su trabajo de tesis "Apuntes sobre higiene en la mujer":

la mujer destinada á (sic) cumplir el rol más importantes en la reproducción de la especie; con una organización más delicada y reducida por esta elevada misión y las costumbres á (sic) desempeñar un papel secundario en 
la vida activa de los pueblos; privada de las libertades que goza el otro sexo; sofocando sus pasiones; con una educación casi siempre insuficiente y causa de sus errores; exenta de ejercicios y llena de peligros que comprometen su vida y su destino, encuentra en la higiene la guía salvadora para recorrer ilesa las diversas etapas de su evolución. (Rawson de Dellepiane, 1892: 9)

Si bien, como señala Nari (2004), los médicos a través de la medicalización de la vida de las mujeres, fundamentalmente de la reproducción, controlaron y deslegitimaron los saberes populares y, en particular, embistieron sobre el trabajo de las comadronas, las mujeres médicas que se unieron a las luchas feministas abrieron otras perspectivas para sus congéneres.

En esta tarea, además de las médicas anteriormente mencionadas, descollaron también figuras como Julieta Lanteri y Alicia Moreau de Justo, entre otras. La primera se destacó en la lucha por los derechos femeninos aunque es más recordada por la conquista de los derechos políticos. En efecto, Lanteri puso en evidencia los vacíos y las contradicciones en las legislaciones vigentes y logró votar a nivel municipal en 1911. Fundó el Partido Feminista Nacional desde el cual lanzó su candidatura a diputada en 1920, apoyada por el Comité Pro derechos de la Mujer presidido por Elvira Rawson de Dellepiane y la Unión Feminista Nacional, dirigida por Alicia Moreau de Justo (Valobra, 2008).

Alicia Moreau de Justo se recibió de médica con honores, en 1914, cuando expuso su tesis sobre la función endócrina del ovario (Valobra, 2012). Para entonces, ya había publicado varios estudios vinculados a su formación médica los cuales han sido omitidos. Moreau de Justo integró la cultura científica de principios del siglo XX. Para Valobra, no obstante, el repaso por sus producciones médicas evidencia que "su perspectiva imprimió una impronta ciertamente menos biologicista a sus consideraciones que la que los cánones sociales expresaban por entonces” (2012: 146). Sin duda, Moreau de Justo se había servido de sus conocimientos científicos para posicionarse ella misma como palabra autorizada en estas producciones que como joven estudiante formulaba. Sin animarse a cuestionar los fundamentos de su propia legitimidad, Moreau de Justo evidenciaba una mirada aguda y crítica que iba dejando 
pinceladas a lo largo de sus escritos científicos sembrando, en muchos casos, las dudas sobre los conocimientos existentes en distintas materias.

Su tesis, en particular, evidenció esa agudeza. Rompió con las analogías entre los seres humanos y los animales al afirmar "si en las especies animales estudiadas parece evidente que la presencia del cuerpo amarillo es necesaria para la gestación, no está demostrado que igual cosa suceda en las especie humana" (Moreau, 1914: 72, en Valobra, 2012: 145). A partir de la casuística, afirmaba que el intento de establecer correlaciones entre el ciclo menstrual y ovulatorio no respondía a los hechos constatados pues era posible que se presentaran esos ciclos en "mujeres que nunca habían tenido períodos menstruales" (Valobra, 2012: 145).

En este sino, Moreau de Justo tuvo también sus singularidades en otros campos. En efecto, esas particularidades se evidencian también en su apropiación de la eugenesia que la diferenciaron de la propuesta de la primer médica uruguaya (1909), Paulina Luisi, quien fue una figura relevante en nuestro país por su lucha contra la prostitución. La adscripción de Luisi respecto de las ideas eugénicas permearon en todas sus propuestas en relación a la educación sexual (Lavrin, 2005). Junto a Alicia Moreau de Justo participó de la Liga Argentina de Profilaxis Social y sus ideas fueron publicadas en la revista Nuestra Causa (1919) editada por mujeres socialistas y del Partido Feminista Nacional.

El acercamiento de las médicas feministas a la eugenesia podría comprenderse como parte de la amplitud y apropiación que tuvo aquel paradigma y las similitudes con algunos de los postulados médicos dominantes en relación con el control de la natalidad ponen de relieve los diversos usos de la eugenesia. Sin embargo, como veremos en el capítulo tres, Moreau de Justo tuvo un aporte diferencial en su comprensión eugénica.

Alicia Moreau de Justo, además, se caracteriza por el hecho de que, además de ser una médica, tuvo un compromiso político temprano. Su militancia feminista y su relación con el ideario socialista habían comenzado años antes. En su participación en la Revista Socialista Internacional ya se destacaba como una intelectual comprometida. Allí, su producción se orientó especialmente a la educación, aunque también, escribió artículos que le permitieron combinar sus conocimientos médicos con posturas higienistas y una condena al capitalismo. En 1910, ocupó la dirección de la revista que 
cambia su título por el de Humanidad Nueva. En ella, Alicia Moreau escribió artículos en relación con la educación y los derechos de las mujeres. Décadas más tarde, en una entrevista realizada por Sara Papier (Papiermeister) en la revista Cultura sexual y física, la entrevistadora recordó los motivos que condujeron a Alicia Moreau por los caminos del feminismo, trayendo a escena una entrevista anterior realizada en Tribuna Libre. Allí, Alicia Moreau había relatado, según Sara, que siendo todavía una estudiante, pasó frente a un prostíbulo y vio por la ventana "la cara pálida y desencajada de una mujer joven" (Papier, 1938: 580). En ese momento, "una indignación incontenible llevó a la futura médica a prometerse formalmente poner todo su esfuerzo y toda su inteligencia en beneficio de la vindicación femenina" (Papier, 1938: 580). Esta preocupación delineó su actividad en diversos espacios, como docente en el Ateneo Popular (1913), en su consultorio, su labor en el ámbito hospitalario y en el partido. Aunque fue una

figura destacada dentro del socialismo, como señala Barrancos (2008), no tuvo el reconocimiento de su propio partido, ya que su trascendencia estuvo dada por su relación con Juan B Justo.

A lo largo de este estudio, abordaremos los discursos de Moreau de Justo en relación a la eugenesia y la maternidad. En general, las alocuciones de la médica feminista fueron incluidas bajo la denominación de maternalismo político, definición bajo la cual Marcela Nari identificó la visión de las sufragistas feministas, muchas de ellas médicas, de principios de siglo XX. Expresión histórica del feminismo, el maternalismo político, señala la autora, "intentó emancipar y liberar a las mujeres a partir de su condición biológica y social de madres" (Nari, 2004: 103).

Sin embargo, como veremos en el desarrollo de los capítulos, la perspectiva de Moreau de Justo nos permite evidenciar las singularidades de su propuesta respecto de sus contemporáneas, como así también de los médicos dominantes y los médicos anarquistas.

\section{La dimensión cultural del anarquismo en Argentina después de los 30}

A comienzos del siglo XXI, Juan Suriano analizó y aportó algunas conceptualizaciones sobre el anarquismo. La primera, la más abarcativa, es analizar y 
comprender el anarquismo como un "movimiento cultural, político, ideológico y social" (2001: 16). Para el autor, el concepto de movimiento identifica "un conglomerado de tendencias (grupos e individuos) inmersos en un verdadero caos doctrinal" (Suriano, 2001:20), lo cual evidenciaría la existencia de varios anarquismos que confluirían en un movimiento a partir de un punto en común: "la negación de la autoridad encarnada en el Estado" (2001: 21).

También, utiliza el concepto de "movimiento alternativo", para diferenciarlo de un movimiento contracultural o autónomo, del cual no brinda más especificaciones (Suriano, 2001: 27). En este sentido, son interesantes los aportes de Arturo Roig y Hugo Biagini sobre el pensamiento alternativo en Argentina. Los autores brindan una conceptualización del mismo que podría ampliar el concepto anterior. Para ellos, en un "sentido abarcador u omnicompresivo", el concepto sirve para "designar tanto las actitudes contestatarias como postulaciones reformistas - de cambios evolutivos $-\mathrm{y}$ a los encuadramientos que postulan cambio de estructuras - al estilo de quienes plantean la idea de un nuevo mundo, hombre o sociedad-" (Biagini y Roig, 2008: 11). Aquí también podríamos situar al anarquismo.

En otros estudios, el concepto utilizado para identificar al anarquismo ha sido el de "movimiento político". ${ }^{4}$ En este sentido, Fernando López Trujillo identifica como "político" "a cualquier grupo u organización anarquista que se conforme para incidir en las relaciones de poder de la sociedad" (2005: 17).

Siguiendo la teorizaciones de Alberto Melucci sobre los movimientos sociales como forma de acción colectiva, podríamos decir que al identificar al movimiento anarquista sólo desde su dimensión política y las relaciones de poder, caemos en un "reduccionismo político" que ignora "aquellas dimensiones específicamente sociales de la acción”. Esta conceptualización, según el autor, “descuida y menosprecia todos aquellos aspectos de esa acción que consisten en la producción de códigos culturales". En ese sentido, debe comprenderse que la "elaboración de significados alternativos sobre el comportamiento individual y colectivo constituye la actividad principal de las

\footnotetext{
${ }^{4}$ El historiador Juan Suriano toma la referencia de Pasquino, quien utiliza el concepto de movimiento para diferenciarlo de partido, "indica la no institucionalización de una idea, de un grupo, de una actividad [...] Político: se refiere a los objetivos del movimiento, actuar en la arena de las decisiones colectivas, a su intento de poner en el banquillo a los detentadores de poder" (Suriano,2002: 168).
} 
redes sumergidas del movimiento, además de la condición para su acción visible" (Melucci, 1999: 109). Por ello, nos parece interesante retomar estas ideas para comprender la dimensión cultural del anarquismo después de 1930, en la cual participan los médicos ácratas que analizamos. También, consideramos que las vinculaciones entre la estrategia política y la estrategia cultural no deben ser descuidadas y, como veremos más adelante en este capítulo, estas cuestiones incidieron en el contenido discursivo sobre los tópicos bajo estudio.

En relación a la frontera temporal los discursos dominantes dentro del ámbito académico local sobre el desarrollo del anarquismo en Argentina, han extendido el desarrollo del movimiento hasta las tres primeras décadas del siglo XX (del Campo, 1971; Oved, 1978; Bilsky, 1985; Godio, 1987; López, 1987; Suriano, 2001; Barrancos, 1990). Este límite ha sido señalado como una de las características principales del "sentido común historiográfico" $(\mathrm{SCH})$ sobre el anarquismo argentino. Se planteó como una de las razones predominantes de esa oclusión la represión que el Estado ejerció de manera directa y a través de leyes de exclusión sobre quienes integraron el movimiento ácrata. Otras razones que se esgrimieron para argumentar la declinación del anarquismo local fue la estrategia integradora del Estado a través de la "ampliación política" (Suriano, 2001:17) y el diseño, por parte del movimiento, “de una estrategia inadecuada para una sociedad en proceso de modernización y democratización” (Acha, 2009:95). Después de 1930, según el autor, el movimiento se volvió anacrónico para la clase obrera. Esta lectura reafirma otra de las características del sentido común historiográfico: la identificación del anarquismo como una ideología pre-moderna, que captaba a quienes ejercían actividades económicas artesanales y organizadas por oficio.

Esta mirada sobre el carácter pre- moderno del anarquismo, se vio influenciada por la historiografía marxista, en particular por las elaboraciones de Eric Hobsbawm (Migueláñez Martínez, 2010), para quien la teoría anarquista era de carácter primitivo y sólo podía aportar una visión crítica sobre la autoridad y la burocracia, algo que no era significativo, según el autor, para la teoría socialista (Hobsbawm, 2000).

Asimismo, en los análisis vinculados a las temáticas que nos interesa abordar, esta frontera se repite. Si bien la caracterización del anarquismo como vanguardia en cuanto a la locución de la sexualidad en el espacio público ha sido señalada y analizada por los pioneros trabajos de Dora Barrancos (1990), Mabel Bellucci (1990) y por nuevas 
investigaciones (Fernández Cordero, 2007; 2011), estos estudios no se extienden más allá de 1930 .

Nuestra investigación se propone extender la frontera temporal y se inserta en la nueva línea de trabajos que dan continuidad al desarrollo del anarquismo (Trujillo, 2005; Ceruso, 2011; Nieto, 2010; Ruocco, 2009; Bordagaray, 2011; Iñigo Carrera 2006; Benyo, 2005; Pérez et al, 2006). Concretamente, junto con estas autora/es, entendemos que el movimiento anarquista no se clausuró en 1930.

Sin embargo, la mayoría de estos abordajes han recuperado experiencias del desarrollo anarquista en ámbitos y procesos relacionados con la estructura económica (conflicto capital- trabajo) y al hacerlo, han obturado la dimensión cultural en el análisis. Es decir, si bien ampliaron ciertos márgenes; otros permanecen en razón de la matriz epistémica desde la cual analizan el movimiento. En particular, las cuestiones relacionadas con la sexualidad no han sido consideradas. Esta cuestión ha sido señalada recientemente por Laura Fernández Cordero, pero para el caso de la historiografía clásica sobre el anarquismo. En este sentido, indica que "pese a la centralidad que esos temas tuvieron para el propio anarquismo, las dimensiones del género y la sexual están presentes en los principales hitos de su historiografía en Argentina, generalmente, sólo como mención” (Fernández Cordero, 2014:55).

Nuestra crítica a la centralidad en el análisis de la relación del anarquismo con el movimiento obrero, advierte que dentro del campo académico esta perspectiva podría asentar nuevas derivas de aquel sentido común en el devenir de la práctica historiográfica.

Esta crítica nos remite a los planteos que se han elaborado en relación a la desestimación y descalificación de lo que se percibe, parafraseando a Judith Butler, como "meramente cultural" (Butler, 1997).

En las actuales perspectivas críticas al "sentido común historiográfico", la diferencia jerarquizada entre la vida material y cultural sigue sin ser revisada. Este anacronismo teórico, como señala Butler, "ignora las contribuciones que se han hecho a la teoría marxista desde que Althusser desplazara el modelo de la base y la 
superestructura, así como las realizadas desde las distintas corrientes del materialismo cultural..." (Butler, 1998:3).

En este sentido, nuestro estudio se inserta en los planteos de las feministas que durante las décadas del `70 y `80 trataron de deconstruir y señalar las implicancias de la reproducción sexual para las condiciones materiales de existencia (Butler, 1998).

Si bien nuestra investigación acuerda con la mayoría de las críticas que se han planteado al "sentido común historiográfico", recuperamos y damos continuidad a los trabajos que han indagado la dimensión cultural del anarquismo sin ampliar los marcos temporales, que ya hemos mencionado. Entendemos que para lograr un análisis sobre el anarquismo como un "movimiento cultural, político, ideológico y social", (Suriano, 2001:16) es necesario indagar en la dimensión cultural y dentro de ella la sexual, como constitutiva también de la economía política y de la política (Fernández Cordero, 2014).

Si bien se ha mencionado que el refuerzo de las persecuciones y la represión del movimiento fue una de las causas de su declinación, López Trujillo ha evidenciado que, por el contrario, las reiteradas medidas represivas y persecuciones sufridas por el movimiento se volvieron el medio natural en que surgían nuevas organizaciones. En este sentido, señala María Eugenia Bordagaray que luego del golpe se produjo un "desbaratamiento del anarquismo tal como se lo conocía hasta ese momento" y, a partir de allí dos estrategias organizativas orientaron su participación política (Bordagaray, 2013: 4). Una, vinculada a la lucha por la liberación de los obreros de la ciudad de Bragado que injustamente detenidos fueron indultados recién en 1942. Otra, el proceso de organización que llevó a la fundación de la Federación Anarco Comunista Argentina (FACA) en el año 1935 (Bordagaray, 2013). Además de estos aspectos mencionados por la autora, consideramos que es necesario considerar otros. En ese sentido, agregamos a estas estrategias la apuesta por la acción cultural a través de la creación de revistas y edición de colecciones y obras de diversos pensadores ácratas para difundir y sostener al movimiento.

Quienes colaboraron en aquella obra posterior a los 30 provenían en muchos casos de los sectores medios profesionales, de la docencia universitaria, la abogacía, la ingeniería, la física y la medicina. En este sentido, nuestra propuesta sostiene que, si bien el movimiento perdió presencia como agenciador de los sectores trabajadores en 
relación a las primeras décadas del siglo XX, no es menos cierto que ello produjo una reactivación de su dimensión cultural e ideológica y su incidencia en nuevos ámbitos (Pérez et. al., 2006) La militancia libertaria, apoyándose en sectores de la clase media profesional, de la que la muchos formaban parte, volcó sus esfuerzos en los circuitos, las relaciones y los proyectos intelectuales como estrategia para conjurar la contracción de su presencia en el movimiento obrero. Entre esos grupos militantes, encontramos a Juan Lazarte y Manuel Martín Fernández.

Asimismo, esta participación de los profesionales médicos también produjo que en el ámbito del gremialismo médico se trasladaran muchas de las propuestas del ideario ácrata. Ambos participaron de la organización del movimiento en los años 30 y 40, aunque Lazarte se acerca tempranamente a las ideas anarquistas. En efecto, ya a fines de la década del 10, luego de su actuación en el movimiento de Reforma Universitaria, Lazarte comienza a publicar en revistas como la Gaceta Universitaria.

Podríamos decir que la trayectoria de este médico rosarino es tan extensa, que sólo señalaremos las posiciones claves para situar su discurso en relación a los temas que vamos a analizar. ${ }^{5}$ Sin embargo, no resta confirmar que fue un intelectual abocado a la crítica del sistema capitalista y el Estado. Nació el 21 de marzo de 1891, en la ciudad de Rosario, provincia de Santa Fe, en el contexto de una familia de clase media. Allí, cursó sus estudios primarios en un colegio salesiano. Luego, cursó en el colegio Nacional de Rosario, donde conoció a Julio Barcos, pedagogo anarquista de la ciudad de Coronda, hasta la década del 20 participó de los círculos libertarios y luego del golpe del 30 apoyó al radicalismo yrigoyenista desde el grupo Concentración de Izquierdistas de la Unión Cívica Radical. Destacado defensor de la escuela racionalista, fuel impulsor de diversos proyectos educativos en la provincia de Buenos Aires. Fundó la Liga de Educación Racionalista y fue director de su órgano de difusión La escuela popular. Asimismo, también fue el impulsor del gremialismo docente creando en 1911 su primer gremio, La Liga Nacional de Maestros. Según Juan Suriano, "su conocimiento del sistema educativo oficial, lo fueron llevando paulatinamente a creer que había que dar batalla dentro de los marcos de la educación estatal” (2001: 252). Por ello, se aleja de la

\footnotetext{
${ }^{5}$ Para consultar un modelo de biografía clásico ver Mastrángelo (2011).
} 
militancia anarquista y se pasa al radicalismo. Más tarde, se convierte en funcionario del Consejo Nacional de Educación, aunque nunca renunció a sus ideas libertarias.

Lazarte luego de terminar sus estudios secundarios viajó a Buenos Aires y se inscribió en la carrera de Medicina, la cual abandonó, para ingresar en el Instituto del Profesorado de Buenos Aires donde se recibió de profesor en Ciencias Biológicas en 1915. También estudió en el Museo Ciencias Naturales de La Plata, donde cursó junto con Florentino Ameghino, allí obtuvo el título de profesor en Ciencias Naturales. Luego, viajó a Estados Unidos, donde amplió sus estudios de genética con el genetista Thomas Hunt Morgan (1866-1945) y trabajó como redactor de un Diccionario de Sudamericanos Ilustres.

Cuando Estados Unidos ingresó en la Primera Guerra Mundial, Lazarte volvió y se instaló en Córdoba para estudiar Medicina. Allí, según sus compañeros se convirtió en un "militante activo" (Casella, 1932: 34) y se distinguió como uno de los líderes de la Reforma Universitaria. Su militancia social fue destacada y se lo recuerda como "el primer dirigente de la Reforma que intentó vincular el movimiento estudiantil con el movimiento obrero" (Rama y Cappelletti, 1964: 60). En este sentido, Lazarte se desilusionó tempranamente del rumbo que tomó la lucha. En 1919, señalaba que las universidades eran instituciones de privilegio que formaban privilegiados (Lazarte, 1919).

Luego de recibirse de médico en 1923, se instaló en el pueblo de San Genaro, en la provincia de Santa Fe, junto con su familia, su compañera Juana Del Signore (Nina), su hija Alma y su hijo Omar. En ese lugar, además de ejercer su profesión en el consultorio, fue médico escolar y visitador comunal de dos prostíbulos de la zona. También, incentivó la organización de cooperativas de salud, educación y de servicio telefónico. A partir de la década del 30, comenzó su actividad intensa en el anarquismo local e internacional y en el gremialismo médico. Asimismo participó activamente en las redes de solidaridad anarquistas durante la Guerra Civil Española, lo cual evidencia la transnacionalidad del movimiento. Sobre esta cuestión avanzaremos más adelante.

En relación con la organización del movimiento anarquista local, en 1932, participó del 2do. Congreso Anarquista Regional de la República Argentina, como asistente individual, sin representar ninguna organización, biblioteca o centro. Más 
tarde, participó de la creación de la FACA en la ciudad de La Plata. En aquel contexto, la FACA se abrió a acciones conjuntas con otros movimientos sociales a través de las agrupaciones que la conformaban (López Trujillo, 2005: 130). Por un lado, para denunciar y accionar contra el fascismo local e internacional y, por otro, para contrarrestar su pérdida como agencia de las/os trabajadoras/es, frente al avance de otras agencias.

En los años 40, Lazarte continúa participando en el movimiento anarquista. Sus actividades se repartían entre el ejercicio de su profesión, su actividad gremial y cultural. Sus redes de sociabilidad se extendían en el ámbito gremial, médico-científico y en la militancia social. Sin ser discordantes estos ámbitos de acción, en ellos conjugaba distintas intervenciones sobre la realidad social.

Más tarde participó en la creación de la Unión Socialista Libertaria de Rosario en mayo de 1946, dedicada a la propaganda del socialismo libertario, definición que buscaba atraer a simpatizantes de la izquierda que no adhirieran con el socialismo y el comunismo (Reconstruir, 1946).

Como hemos mencionado, su objetivo en el ámbito gremial profesional fue, precisamente, la implementación de un conjunto de ideas que había abrevado en el ideario ácrata. El núcleo conceptual más importante heredado del anarquismo estipulaba aplicar un freno al avance del Estado sobre su autonomía y basar sus principios profesionales dentro de lo que él consideraba la Medicina Social.

Desde la inicial Asociación Médica del Departamento San Gerónimo hasta la Federación Gremial Médica de la provincia de Santa Fe creada en 1935, impulsó sus ideas para una medicina socializada y federalizada y centró sus demandas en la promoción del seguro de salud bajo la organización de la corporación médica y no del Estado.

En 1951, llegó a la dirección de la revista de la Confederación Médica de la República Argentina, desde la cual, junto a Martín Fernández, defendió la autonomía de los médicos frente al gobierno peronista, el cual consideraba totalitario y asfixiante de las libertades (Lazarte, 1953). 
Después del golpe de Estado de 1955, fue convocado, por las nuevas autoridades de la Universidad Nacional del Litoral, a presentarse al concurso para la cátedra de Introducción a las Ciencias Políticas y Sociales en la Facultad de Ciencias Económicas, Comerciales y Políticas; cargo que ocupó entre 1956 y 1963. Siendo médico, es interesante que lo hayan convocado para una cátedra de problemas teóricos y políticos, lo que nos proporciona un indicio del reconocimiento que tenía como intelectual en el ámbito académico. El 19 de julio de 1963 falleció en la casa de un paciente al que había ido a atender. ${ }^{6}$

La trayectoria de Manuel Martín Fernández es la menos transitada por la historiografía; podríamos decir que ha permanecido inexplorada. Sólo se encuentran algunas referencias en las obras escritas por los propios militantes como Fernando Quesada (1974). Oriundo de la provincia de Jujuy, después de estudiar un tiempo en el Liceo Militar se traslada a Córdoba a estudiar medicina. Allí conoce a su compañera Lucila Quiroga (Lola), quien estudiaba odontología. ${ }^{7}$ Luego de recibirse se trasladaron a la provincia de Santiago de Estero, allí comienza a participar en el sostenimiento del movimiento ácrata a través de la agrupación anarquista Renovación. Como representante de esta agrupación participó del Segundo Congreso Anarquista Regional de la República Argentina en 1932, al igual que Lazarte (López Trujillo, 2005).

$\mathrm{Su}$ actividad profesional la ejercía en su consultorio y en consultorios gratuitos para obreros. Unos años más tarde, participó en la lucha antifascista organizando marchas contra los grupos de derecha en la provincia de Santiago del Estero por lo cual fue procesado judicialmente (Guzmán, comunicación electrónica, marzo 2013). En 1937, formó parte de los sostenedores de la revista Vertical, según Héctor Guzmán, la revista aglutinó a los sectores más contestatarios de la agrupación intelectual "La Brasa" de la que formaban parte Martín Fernández y Lucila Quiroga (Guzmán, 2006).

En 1939, Martín Fernández y Lucila Quiroga ya se encontraban en la provincia de Buenos Aires, estableciéndose en San Fernando, allí tenían sus consultorios. Ambos participaron en la organización de la Unión Socialista Libertaria de Capital en 1946, de

\footnotetext{
${ }^{6}$ En el cementerio de San Genaro donde se han depositado sus restos, su lápida -de mármol negro- lleva unas placas de la COMRA y su epitafio sugerido por sus amigos anarquistas dice: "trabajo por la paz, la libertad y el mejoramiento del hombre".

${ }^{7}$ Los datos fueron aportados por Manuel Martín Fernández (h), nieto del médico que analizamos.
} 
la cual Martín Fernández era el Secretario General. Al igual que Lazarte participó del gremialismo médico como Secretario de Propaganda de la Federación Médica de la República Argentina creada el 22 de mayo de 1941 y compuesta por 3728 profesionales, dos años más tarde pasa a ser Confederación.

A nivel nacional, en la lucha antifascista formó parte de la Junta Ejecutiva Nacional de Solidaridad Internacional Antifascista (SIA) siendo elegido Secretario General en abril de 1939. En este período, la SIA se encargaba de la financiación de la salida de refugiada/os desde Francia hacia América del Sur (López Trujillo, 2005). En esta organización también participó Lazarte como delegado representante de Argentina en el Consejo General, el cual estaba presidido por Federica Montseny y formado además por: “J. Anderson (Suecia) Han Ryner (Francia) Emma Goldman (Inglaterra) Rudolf Rocker (EUA), Luigi Bertoni (Suiza) y Jorge Forteza (Uruguay)” (López Trujillo, 2005: 176). Las vinculaciones con la SIA, las inició la FACA creando primero, la Comisión Organizadora para la Ayuda a España bajo la órbita de la SIA, en la cual también participó Lazarte. A continuación, avanzaremos sobre la caracterización de las redes internacionales en las que, particularmente, participó Lazarte junto con otros médicos anarquistas. Consideramos que, en virtud de sus intercambios en estos espacios, Lazarte y otros colegas del ámbito local, moldearon sus ideas y las incorporaron en una matriz interpretativa propia que, como veremos a lo largo de los capítulos, tuvo singulares consideraciones que se plasmaron en las ideas en circulación a través de distintas estrategias de difusión.

\section{La transnacionalidad y las redes profesionales anarquistas}

La transnacionalidad como característica del anarquismo, como señala María Migueláñez Martínez, retomando a Sean Purdy, ${ }^{8}$ sugiere y hace hincapié en las conexiones e interacciones dadas por la "circulación de todo tipo de bienes, gentes, capitales, símbolos e ideas a través del espacio" (2010b: 2), movimientos que durante la Segunda República, la Guerra Civil y el exilio se exacerbaron.

\footnotetext{
8 Sean Purdy, reflexiona críticamente sobre la relación entre la historia comparada y la historia transnacional, señalando que la misma no es de exclusión sino de complementariedad (2006).
} 
Si bien desde fines del siglo XIX, con la llegada de la inmigración, entre militantes ácratas de España y Argentina se desarrollaron diversas dinámicas transnacionales. Aquellos contextos revitalizaron los circuitos y las redes, que “permitieron la propia supervivencia del movimiento” (Migueláñez Martínez, 2012:1).

Algunos estudios han proporcionado evidencias sobre las redes que se desplegaron durante el periodo de la lucha antifascista y las estrategias organizativas del anarquismo local para llevar adelante la cruzada (Quijada, 1991; López Trujillo, 2005; Rama y Cappelletti, 1990). ${ }^{9}$ Los mismos, fundamentalmente, han contribuido a visibilizar al movimiento ácrata en períodos posteriores a 1930 y han señalado la heterogeneidad de posicionamientos dentro del anarquismo local a través del análisis de las confrontaciones internas. Los trabajos biográficos de militantes ácratas que han recuperado su accionar en el contexto del apoyo a la causa republicana (Cimazo, 1979; Rouco Buela, 1964) han servido de base para el análisis de esas trayectorias, la reconstrucción de repertorios organizacionales y la ubicación del movimiento ácrata en procesos políticos y sociales que no habían sido abordados (Bordagaray, 2011).

En relación con la transnacionalidad de ideas, particularmente las propuestas de control de la natalidad del movimiento ácrata arribaron a nuestro país a través de la llegada masiva de inmigrantes que a fines de siglo XIX, configuraron nuevas cartografías sociales principalmente en las ciudades portuarias como Buenos Aires y Rosario. La mano de obra extranjera haría realidad el proyecto modernizador que liberalismo argentino se propuso desarrollar. Empero, prontamente, quienes habían llegado al país y junto con ellos habían traído sus ideas políticas, pusieron de manifiesto los límites de aquel proyecto. Así, rápidamente, aquella inmigración bienvenida, se volvió "extranjera" peligrosa para el Estado, como lo evidencian las represivas "ley de Residencia" N4.144 de 1902 y la "ley de Defensa Social” N 7.029 sancionada en 1910 que pretendían, por exclusión, superar la alta conflictividad social y, especialmente, se enfocaban en eliminar al elemento anarquista de la sociedad (Rodríguez Molas, 1990).

\footnotetext{
9 En particular, el accionar de la organización local de Solidaridad Internacional Antifascista (SIA) impulsada por la Federación Anarco Comunista Argentina (FACA) ha sido puesto de relieve en estas aproximaciones y llama la atención, la ausencia, no ya como objeto de estudio, sino la individualización de esta organización, por parte de las pesquisas sobre el antifascismo en la Argentina.
} 
La mayoría de quienes adherían al movimiento anarquista, defendieron las ideas neomalthusianas. Estas ideas se basaban en una adaptación de la teoría de Thomas Malthus (1776-1834) esbozada en su obra Ensayo sobre el principio de la población de 1798 sobre la oposición entre el crecimiento exponencial de la población y el crecimiento lineal de los recursos. El neomalthusianismo anarquista reconfiguró esta teoría para luchar por una mejora en las condiciones de vida de la/os trabajadores. Para evitar la miseria de la sobrepoblación, propusieron el control de la natalidad, pero no a través de la abstinencia o los matrimonios tardíos como planteaba Malthus, sino a través del conocimiento y uso de medios anticonceptivos.

Estas ideas habían arribado primero a España desde Francia a través de La Liga de la Regeneración Humana liderada por Paul Robin. (Masjuán Bracons, 2002). Dora Barrancos (1990) ha analizado las ideas pedagógicas de Paul Robin y ha señalado su participación en lo que llamó “eugenismo social” (Barrancos, 1996a).

En el país se difundieron revistas como Salud y Fuerza y diversos libros a través de Bautista Fueyo -representante de la Biblioteca y Editorial Salud y Fuerza en Argentina-, quien comenzó a distribuir a través de la Librería Fernández obras sobre el control de natalidad, entre otros, Huelga de Vientres de Luis Bulffi, Generación Consciente de Frank Sutor, ambos de 1910. Luego, comienzan a editarse a través de La Protesta y otras editoriales que incitaron a que tempranamente se locutara sobre el control de la natalidad (Masjuán Bracons, 2003).

Hacia la década del 20, el neomalthusianismo, que fue el puente que facilitó la entrada de la eugenesia a los circuitos ácratas se vio superado y absorbido por este paradigma (Cleminson, 2008). Es interesante señalar que la adscripción a la eugenesia por parte del anarquismo en España ha generado un debate historiográfico sobre el modo de considerar al movimiento. Por un lado, Masjuán Bracons $(2004 ; 2008)$ ofrece un estudio del neomalthusianismo en la península ibérica y su área de influencia. En él presenta una imagen homogénea del discurso libertario, progresista e internalista, sin fisuras, que lo hace rechazar el apoyo que alguna/os anarquistas concedieron a las medidas extremas de la eugenesia, como la esterilización. Por otro lado, Richard Cleminson (2008), al estudiar la sexualidad y la eugenesia en el ideario ácrata, propone una mirada polifacética y contextualizada de los discursos ácratas, haciendo hincapié en 
las tensiones y contradicciones dentro del movimiento y la adscripción de algunos elementos del paradigma eugénico como herramientas de emancipación.

Así, a través de publicaciones como Generación Consciente (1923-1928) y Estudios (1928-1937), editadas en España y difundidas ampliamente en Argentina, las voces médicas fueron las autorizadas para señalar todas las dimensiones en las cuales la eugenesia se manifestaba, entre ellas con mayor énfasis, la sexualidad y la maternidad.

Uno de los más fervientes impulsores de estas ideas fue el médico Isaac Puente. ${ }^{10}$ $\mathrm{Su}$ militancia anarquista comenzó en la década del 20 a partir del acercamiento a sindicalistas de la Confederación Nacional del Trabajo (CNT) y fue el promotor de la sindicalización de los profesionales de la salud a los Sindicatos Únicos de Sanidad de la CNT (Martí Boscá, 2007). Otro de los médicos que también impulsó estas ideas fue Félix Martí Ibáñez. Desde muy joven Martí Ibáñez se vinculó a organizaciones libertarias (Martí Boscá, 2007) y participó del gobierno revolucionario de Cataluña como director general de Sanidad y Asistencia Social en 1936. Brevemente, también ocupó el cargo de Subsecretario de Sanidad de la República, al cual renunció para ocuparse de su actividad en Cataluña. Dos años más tarde fue enviado a Estados Unidos por la CNT para participar del Congreso Mundial de Juventudes por La Paz y luego participó en diversas conferencias en ese país organizadas por SIA buscando apoyo para los republicanos. Más tarde regresó a Barcelona y se incorporó al puesto de oficial médico en la defensa antiaérea. Tras la derrota, cruzó los Pirineos y desde Francia se exilió en Estados Unidos. Allí comenzó una destacada carrera profesional incorporándose a diversos laboratorios farmacéuticos y como profesor y director del Departamento de Historia de la Medicina en el New York Medical College. Su obra más relevante fue la creación de la revista médica $M D$ y editorial $\mathrm{MD}$, que se destacó en el campo de las publicaciones médicas. Muere en Estados Unidos en 1972.

Estos profesionales participaron activamente en el movimiento ácrata español y difundieron sus ideas en las revistas locales, que anteriormente mencionamos. En particular la revista Estudios de Valencia fue el escenario en el cual los médicos se destacaron. La revista es considerada la más prestigiosa revista cultural del anarquismo español que se difundió no sólo entre anarquistas. Este prestigio y atractivo, según

\footnotetext{
${ }^{10}$ Se puede consultar una biografía de Isaac Puente en Francisco Fernández de Mendiola (2007).
} 
señala Diez, se obtuvo por el estilo ecléctico de la publicación y el acento puesto en la cuestión sexual desde una mirada científica. Siendo una continuación de la revista Generación Consciente de Alcoi, la revista, con el nuevo título, editada desde Valencia, comienza en diciembre de 1928, con el número 64 (Diez, 2007). Se editaron 102 números hasta 1937 y contó con una tirada de 25 mil ejemplares en promedio (Navarro, 1997). El director administrativo era Juan José Pastor, que también dirigió Generación Consciente $y$ el director editorial, un anarquista individualista, era Antonio García Birlán.

En Estudios, Puente publicó con su nombre o bajo el seudónimo "un médico rural" en casi todos los números de la revista, aun estando preso entre 1932 y 1934 hasta su muerte ocurrida luego del levantamiento de julio de 1936, cuando es apresado y fusilado el 1 de septiembre en 1936.

Félix Martí Ibáñez se incorporó más tarde a la revista Estudios, en octubre de 1934. Al comienzo publicaba una columna llamada "Eugenesia y moral sexual" que permaneció hasta septiembre de 1936. En ella, sostenía la necesidad de una nueva moral sexual que aceptara el control de la natalidad y el ejercicio de la sexualidad no reproductiva entre varones y mujeres (Nash, 1984). Así, también desde octubre de 1936 el médico Félix Martí Ibáñez se ocupó del "Consultorio Psíquico sexual” en ella señalaba "vamos a contestar a aquellas consultas que planteen un conflicto espiritual o sexual y que requieran consejo o tratamiento psicológico" (Martí Ibáñez, 1975: 15, en Llavona y Bandrés, 1998: 671)

Según el apartado del programa de la revista en relación al control de la natalidad, escrito por Isaac Puente bajo el seudónimo "un médico rural”, se señalaba que

El hombre debe evitar los hijos que no desea. El hijo, además debe ser previamente deseado, concebido en la mente antes que en la matriz, y realizado con las garantías de sanidad que nos aconseja la eugenesia. (un médico rural, 1931, en Nash, 1984: 325) 
Estas ideas fueron argumentadas también por la pedagoga brasileña anarquista, amiga de Lazarte, María Lacerda de Moura (1887-1945). Se le considera una de las más destacadas autoras libertarias de Brasil, defensora del neomalthusianismo y la libertad sexual de la mujer. Colaboró en la prensa obrera de Brasil y en revistas culturales de ese país, como así también en la revista Estudios de España y la revista Nervio de Argentina. Entre sus obras se destacan: A fraternidade na escola (1922); A mulher é uma degenerada (1923); Han Ryner e amor plural (1928); Amai-vos e ñao vos multipliqueis (1932) y Fascismo, filho dileto da Igreja e do Capital (1933), entre otras (Martí Boscá, 2007). En este estudio analizamos su discurso a través del prólogo que escribió para el libro Sociedad y Prostitución (1935) de Lazarte. La libertaria criticaba a los compañeros que se oponían a las ideas del control de los nacimientos, diciéndoles que la anarquía que anhelaban era sólo para los hombres. Las mujeres, decía, eran para ellos "tan sólo la matriz fecunda inagotable destinada a producir los soldados burgueses, o bien los soldados rojos de la revolución social" (Lacerda de Moura, 1932, en Nash, 1984: 328).

A través de la revista Estudios, los médicos Puente y Martí Ibáñez se concentraron en divulgar los métodos para controlar la natalidad, más que en participar de debates ideológicos o teóricos sobre el neomaltusianismo y la eugenesia. Su preocupación era que la población llevara a la práctica las ideas que impulsaban. A través de artículos específicos o a través de las consultas del "Consultorio Psíquico Sexual", los médicos divulgaban los distintos métodos y explicaban su utilización como así también aconsejaban cuales eran los indicados según las características de la mujer o el varón. En otra sección de la revista "preguntas y respuestas" a cargo del médico Roberto Remartínez (1895-1977), también se respondían consultas sobre métodos anticonceptivos, pero no de carácter personal sino general. ${ }^{11}$ Esta postura distaba de las prácticas de la mayoría de los profesionales de la salud españoles que se negaban a difundir los métodos anticonceptivos y no asesoraban sobre su utilización a quienes lo solicitaban. Contra estos médicos arremetían los médicos ácratas desde las páginas de Estudios (un médico rural, 1932).

\footnotetext{
${ }^{11}$ Para un análisis de la sección consultar Tabernero-Holgado et. al (2013).
} 
En suma, los médicos anarquistas de un lado y del otro del Atlántico fueron, entonces, quienes con mayor ahínco impulsaron y defendieron las ideas eugénicas del movimiento. En virtud de ello, retomamos las voces de los médicos españoles en el capítulo tres que trata sobre la eugenesia anarquista y el control de la natalidad, dado que además de las ideas, compartieron espacios de difusión con Lazarte. En relación con Martín Fernández encontramos paralelismos en la estrategia llevada adelante para difundir el conocimiento, nos referimos a los consultorios sexuales o psico- sexuales. Consideramos que estos cuatro médicos se abocaron a la tarea de la difusión de la eugenesia y el control de la natalidad en medios libertarios y legitimaron las propuestas de maternidad consciente y voluntaria y el derecho sexual deslindado de la reproducción. Estas concurrencias, como veremos, se reflejan en las intertextualidades manifiestas o implícitas en las que discurren sus discursos.

\section{Revistas culturales y producción editorial, herramientas de difusión médico- libertaria}

Como han señalado los estudios sobre el anarquismo en Argentina la difusión de las ideas a través de la prensa fue una característica compartida con el socialismo (Suriano, 2001). Asimismo, como señala Luciana Anapios, la prensa anarquista “compartió, además, recursos culturales, referencias a autores y tradiciones intelectuales con diversos sectores del liberalismo" (2011: 4) y se diferenció de ellos a partir de "la ausencia de una autoridad centralizada que unificara criterios”, lo cual, señala la autora "favoreció que las diversas tendencias que contenía el anarquismo local tuvieran sus propias expresiones periodísticas y el surgimiento de emprendimientos destinados al combate ideológico interno" (Anapios, 2011:30). ${ }^{12}$

\footnotetext{
$12 \mathrm{La}$ autora analiza los problemas y debates internos durante los años 20, señala que algunos los conflictos se establecían por cuestiones personales, por diferencias en los métodos y prácticas, por el control de la imprenta y por las luchas que debería apoyar la FORA. Por un lado, se encontraba la corriente representada por la FORA y el periódico La Protesta, que se autolegitimaban como los representantes del movimiento anarquista, centralizando bajo su órbita la organización de la prensa, las huelgas y los consejos; por otro lado, los gremios que no estaban bajo la FORA, grupos disidentes y el periódico La Antorcha, Pampa Libre e Ideas que defendían una postura anti-centralista y radicalizada en cuanto al uso de la violencia (Etchenique, 2000; Anapios, 2008).
} 
A través de la difusión de las ideas entre los sectores trabajadores -como los periódicos, por ejemplo, que se leían y debatían individual o colectivamente- se provocan dos efectos. Por un lado, se "terminaba con el concepto de la información noticiosa, la apreciación y la práctica de las artes y la literatura como privilegios y manufactura exclusiva de las clases privilegiadas". Por otro lado, se "proponían una cultura y una información alternativas y revolucionarias" (Litvak, 1990: 283). En este sentido, la edición de un periódico o una revista, señalan Pérez et al. "no es sólo un acto de propaganda, sino también un ejercicio de experiencia, de formación, de elevación y liberación" (2006: 115).

Esta obra fue la que redoblaron quienes sostuvieron el movimiento luego del golpe de Estado del general José Félix Uriburu. Como ya hemos mencionado, la pérdida de base social entre los sectores trabajadores produjo una reactivación de los proyectos culturales desarrollados por militantes provenientes de sectores medios y profesionales que participaron en la creación y el desarrollo de la FACA (Pérez et. al, 2006). En el congreso de 1932, en el cual participaron Lazarte y Martín Fernández, surge el periódico de largo aliento Acción Libertaria que se editó entre 1932 y 1971.

Asimismo, se impulsó la creación de editoriales como Nervio e Imán y se editó desde 1931 la revista Nervio. Su aparición en el medio cultural tenía el objetivo -según sus sostenedores- de "servir lealmente de mentor a todos aquellos que se encuentren desorientados y anhelan iniciarse en la senda que conduce a la Verdad" (La redacción, mayo 1931: 1). En aquel momento de crisis política y social, local y mundial, esta publicación se proponía analizar los obstáculos para el progreso de la humanidad.

En un primer momento, la revista se centraba en su costado más cultural, sin secciones fijas el subtítulo era "Ciencias, Artes y letras". Publicaba obras de teatro, poemas, ensayos, traducciones de libros, ilustraciones de sus colaboradora/es, entre los que se encontraban José Planas, Alfonsina Storni, Elías Castelnuovo. A partir de su segundo año el subtítulo cambia a "Crítica-Artes-Letras" y hasta 1936, dado el contexto político internacional y nacional, se concentró en la lucha contra el fascismo. Si bien la carga ideológica no estuvo ausente en el primer período, en el nuevo contexto la mayor parte de los artículos se concentró en las críticas al régimen fascista y los debates internacionales en torno al fenómeno, ampliando la nómina de sus colaboradoras/es. Así también se ocuparon de dar visibilidad a las persecuciones locales, como por ejemplo el 
caso de los "presos de Bragado". Para evadir esas persecuciones, los articulistas dejaron de firmar los artículos y sólo figuraban sus iniciales, también dejó de aparecer el sumario tanto en la portada como en el interior de la publicación. Se publicaron 48 números entre mayo de 1931 hasta noviembre de 1936. Bajo la dirección de V.P. Ferreria, entre los colaboradores de la publicación se encontraban Alfonsina Storni, Elías Castelnuovo, Costa Iscar, José M. Lunazzi, Edgardo Casella, entre otras/os.

La revista Nervio tenía similitudes estéticas y de contenido con la revista Estudios de Valencia y en ambas publicaciones colaboró Lazarte, a veces reproduciendo un mismo artículo en una y en otra. Si bien comenzó a escribir en 1919 en la prensa libertaria local cuando era estudiante de medicina en Córdoba, posteriormente abordó problemas sociales vinculados a la sexualidad. En 1931 también colaboraba en la revista Metrópolis (1931-1932) de Leónidas Barletta, en la cual publicó un artículo sobre el control de la natalidad que más tarde replicaría en Estudios.

En Nervio, fue un asiduo articulista y fue uno de los primeros impulsores de este proyecto. Sus participaciones se concentraban en problemas sociales; los títulos dan idea de sus preocupaciones: "Derecho de los solteros", "En torno al divorcio" y "Un problema sexual la suegra", entre otros que lo muestran, asimismo, como un intelectual polifacético en cuanto a sus áreas de interés.

En 1932, la revista Nervio creó una editorial a través de la cual publicó libros y colecciones, los cuales salían a la venta mensualmente y -al igual que la revista- se podían conseguir por medio de suscripciones o en quioscos y puestos de diarios. La primera colección que editó fue los Cuadernos “AHORA". Entre los propósitos de la misma se destacaba que trataría sobre los problemas sociales que necesitaban urgente solución, causados por "la ineptitud del Capitalismo y del Estado" (Ediciones Nervio, 1932: s/n) La primera entrega fue una obra de Lazarte vinculada a la sexualidad: $L a$ revolución sexual de nuestro tiempo (1932), donde desarrolló la genealogía del matrimonio, su crisis y su superación a través de las uniones libres. Dos años más tarde, a través de la editorial de la librería Ruiz de Rosario, publicó su producción más conocida La limitación de los nacimientos (1934) y luego publicó Sociedad y prostitución (1935). En estas producciones, se posicionaba en el lugar de enunciación de un científico social. Legitimaba y otorgaba autoridad a sus argumentaciones a través de la elaboración y análisis de estadísticas, entrevistas y citas de autoridad. En efecto, si 
retomamos las concepciones teórico-medológicas de Fairclough, el texto consta con una "intertextualidad manifiesta: mecanismo de despliegue de voces en un texto que permite a quien habla citar a otra persona o representar toda una conversación que mantuvo con algún interlocutor". Así, Lazarte hacía uso de la intertextualidad manifiesta como estrategia discursiva. La inclusión de referencias a otras obras, en algunos casos, le brindaba legitimidad científica a sus planteos y, en otras oportunidades, utilizaba los mismos para refutarlos o criticarlos.(Fairclough, 1992: 117-118)

La sexología fue uno de los campos científicos en el que se destacó Lazarte, así lo señalaban sus colegas médicos (Roque Cano, 1973) y sus compañeros libertarios (Abad de Santillán et al., 1964). El interés por los problemas sexuales, según sus compañeros de militancia, se debía a que "pensaba que una gran parte de la felicidad o la infelicidad humana dependen del sexo" (1964:39).

El reconocimiento de su especialidad en temas de la sexología, lo llevó a publicar en la revista Hombre de América Fuerte y Libre (1940-1945) una columna llamada "curso de sexología" en el cual en las diversas entregas analizaba aspectos esenciales de la cuestión sexual. La revista nació en el contexto de la reciente derrota en España, el arribo de exiliada/os -actividad que involucraba a Martín Fernández por su participación en la SIA-, y el avance del nazismo y el fascismo en Europa. El comité de dirección estaba conformado por Juan Lazarte, Edgardo Casella, Aarón Cupit, Manuel Martin Fernández y Jorge Hess. En ella podemos encontrar las colaboraciones de Julio Barcos, Jacobo Prince, Fernando Quesada, Horacio E. Roqué, José M. Lunazzi entre otros. Se publicaron veintisiete números entre enero de 1940 y octubre de 1945.

En la misma revista encontramos al médico Manuel Martín Fernández quien estaba a cargo de la columna "problemas psicosexuales" que contaba con un consultorio psicosexual para que el público lector enviara sus consultas. Esta modalidad de interacción con el público ya la había comenzado a practicar la revista Cultura Sexual y Física (1937-1941). ${ }^{13}$ La publicación editada por Claridad y dirigida por el médico cercano al sindicalismo revolucionario Bartolomé Bosio contaba en sus últimas páginas con una columna titulada "contestando a los lectores" que se dedicaba a contestar las preguntar sobre "temas sexuales y físicos" (Cultura sexual y física, 1937: 191). Con el

\footnotetext{
${ }^{13}$ Un estudio preliminar de la revista en Fernández Cordero (2013).
} 
tiempo la columna paso de abarcar una carilla a las dos páginas. En este crecimiento se dividieron y especializaron las consultas en sexuales, clínica general y de manera intermitente también apareció un consultorio sobre cirugía estética. Martin Fernández se hace cargo del consultorio más tarde, cuando se radica en San Fernando. Asimismo, colaboró como articulista. En ambos consultorios, el profesional contestaba las dudas, que se relacionaban con los métodos anticonceptivos, las relaciones sexuales, la masturbación y la anatomía "normal" del pene. También recomendaba bibliografía y en los casos urgentes o complicados invitaba a quien lo necesitara a ir personalmente a su consultorio. En la revista Hombre de América Fuerte y Libre, además del consultorio, también escribió sobre la felicidad sexual de las mujeres, discursos que abordaremos en el último capítulo de nuestro estudio.

Después del golpe de Estado 1943, y con más evidencia con la llegada del peronismo, las publicaciones libertarias dejan de tener espacios dedicados a temas referidos a la sexualidad. La demanda por la emancipación sexual fue obturada y desplazada por cuestiones que eran entendidas como las más apremiantes en aquel contexto. Los médicos anarquistas se volcaron a la organización y Lazarte, en particular, ocupó las páginas del periódico Reconstruir (1946- 1959) con análisis críticos sobre las ideas y las prácticas del peronismo en la economía y la legislación. Ambos médicos desarrollaron también una defensa de la profesión médica frente a la intervención del Estado peronista a través de actividad gremial. Ello se plasmó en la realización de congresos y en las columnas de la revista de la COMRA. Esto conllevó un desplazamiento de núcleos temáticos de interés.

Esta discontinuidad en las publicaciones libertarias se compensó con la edición de una colección de libros en relación con la temática sexual dirigida por Lazarte. La colección Eros de la editorial ácrata Partenón (Abad de Santillán, 1964) estaba conformada por veintiún volúmenes y contó con hasta tres ediciones publicadas entre 1945 y 1953. ${ }^{14}$ Allí se publicaron las obras de Ellen Key, Paul Bourget, Remy de Gourmont, Hannah y Abraham Stone, Honoré de Balzac, Victor Francis Calverton (George Goetz); A. W. Neminlow, Havelock Ellis, Pablo Montegazza, Magnus Hirschfeld, Lázaro Liacho, Agusto Forel, Marguerite Crepón, Edwad Carpender y

\footnotetext{
${ }^{14}$ Sobre un análisis parcial de la colección consultar Cámpora (2012)
} 
Alejandro Lenard, entre otra/os. Es interesante señalar que la obra completa del sexólogo Havelock Ellis se editó en nuestro país por primera vez por bajo esta colección por iniciativa de Lazarte.

Este trabajo editorial al que Lazarte se dedicó junto con otros libertarios fue una de las estrategias asumidas al verse limitado su campo de acción en la prensa periódica y en la publicación de revistas culturales durante el peronismo. Aquel trabajo sería continuado por una enciclopedia de la sexualidad humana, pero el proyecto quedó trunco al fallecer Lazarte en 1963.

En los años 40, Lazarte también se dedicó a publicar obras relacionadas con los problemas de su profesión y su área profesional. En 1943, publicaba a través de la editorial Americalee, de la revista Hombre de América Fuerte y Libre Problemas de Medicina Social, libro en el cual analizaba la situación de los médicos en el país y de los servicios de salud. Para él no había otra opción para resolver los problemas de la salud que la medicina socializada, en este sentido señalaba, "la medicina, como la higiene, no deben ser un patrimonio de uso privado y limitado, sino público y total. Un servicio social. No es el hombre aislado quien debe remunerar al médico, sino la sociedad" (Lazarte, 1943:44). Para ello, consideraba que la medicina social sólo funcionaría en un sistema en donde existiera "la comunidad de medios materiales y riqueza colectiva. Libertad en el sentido de individuo integrado en la sociedad, lo que equivale a negación de toda dictadura" (Lazarte, 1943:45) A través de la editorial de la Unión Socialista Libertaria, publicó dentro de la serie de Cuadernos de Cultura Social, Organización de una Sanidad para la población del país en 1948. Allí, luego de realizar una evaluación del estado sanitario del país, relevando las condiciones materiales de la población y su relación con el padecimiento de enfermedades, hacía hincapié en las soluciones que brindaría la aplicación de la medicina preventiva. En este sentido, proponía el seguro de enfermedad como un primer paso de la medicina socializada. Pero para que sea efectivo, debería estar bajo el control de las agremiaciones médicas y no del Estado. Bajo la forma de editoriales del periódico Reconstruir, publicó un estudio que abarcaba otro de los temas que le interesaban, el federalismo. ${ }^{15}$ Según reconocía Lazarte, el

15 Para paliar la crisis argentina, proponía una organización social basada en la autonomía de los municipios. La descentralización acabaría con las consecuencias nefastas de la estructura estatal burocrática que, según señalaba Lazarte, era costosa y conllevaba la pérdida de la libertad individual y la 
inspirador de estas ideas era Lisandro de la Torre, figura admirada por el médico libertario y a quien dedicó una voluminosa biografía (Lazarte, 1955).

El periódico Reconstruir fue otra gran apuesta del proyecto cultural ácrata, órgano de difusión de las actividades de las USL, en él Lazarte participó no sólo como articulista sino que también conformaba el consejo editorial. El primer ejemplar apareció la primera quincena de junio de 1946. Se editaron noventa números hasta junio de 1959, momento en el cual cambia de formato y se convierte en revista que se publicó hasta marzo de 1976. Entre 1952 y 1955 el periódico fue clausurado y no pudo publicarse. Para contrarrestar esta ausencia los redactores crean la editorial Radar y difunden clásicos de la literatura anarquista y de militantes ácratas locales en formato de libros durante esos años.

Además de difundir las actividades de la USL Reconstruir se ocupó de darle un lugar a la juventud universitaria, los sindicatos y las luchas del sector trabajador, la situación internacional y nacional, con una fuerte crítica al peronismo y todas sus políticas. Se destacó también la relevancia del discurso anticlerical que denunciaba las alianzas entre Perón y la Iglesia. Según entendían, el apoyo eclesiástico a Perón fue fundamental para su triunfo en las elecciones presidenciales. A cambio, Perón habría entregado el sistema educativo a la Iglesia, incluso las universidades, señalaban en este sentido que era "aún más grave [...] la intromisión de la iglesia católica en el plano pedagógico, puesto que la enseñanza en manos de monjas y sacerdotes implica la pérdida segura de la calidad en los contenidos y la enseñanza (Reconstruir, 1946a: 10)

En un acto realizado en Rosario por la Junta Para la Defensa del Laicismo y de la Libertad de Creencias Juan Lazarte señalaba que la enseñanza de la religión católica en las escuelas "provoca[ba] un choque absurdo entre los conocimientos que otorga el progreso de las ciencias, de las artes y de la cultura, y los preconceptos y supersticiones religiosas" (Reconstruir, 1946b : 8) Las denuncias hacia la implementación de la enseñanza religiosa se exacerbaron a partir de 1947, año en el cual se sanciona la ley.

capacidad de iniciativa. Proponía una organización social basada en "una gran confederación de comunas a través también de un sindicalismo federativo que reemplace al Estado moderno" (Lazarte, 1957: 47-48) Para un análisis del trabajo intelectual del anarquismo después de los 30 vinculado a los estudios sobre el capitalismo y la economía consultar Graciano (2012). 
Encontramos dentro del periódico, también, una sección escrita por mujeres titulada "La Página de la Mujer". Herminia Brumana, Ana Piacenza, Emilia Goyena e Iris Pavón (cuyo seudónimo en algunas ocasiones era Alejandrina Serrat) aparecen allí como asiduas colaboradoras. Las escritoras interpelaban desde su columna a mujeres y varones sobre los problemas que las/os afectaban en el contexto del ascenso al poder de Juan Domingo Perón y Eva Duarte. En este sentido, a diferencia de las anteriores publicaciones, "La Página de la Mujer" apuesta a difundirse en un amplio público de lectoras/es, no sólo a quienes tienen afinidades ácratas y tampoco circunscribe su mensaje a la clase trabajadora. Es necesario destacar que el periódico Reconstruir señalaba en su portada que luchaban y difundían el socialismo libertario. Si bien no hablar de anarquía en el contexto del ascenso del peronismo podía ser una estrategia para evitar la represión, podemos decir que esta ausencia también responde a una estrategia de agenciamiento político hacia los sectores de izquierda opuestos al peronismo, que podrían rechazar, por desconocimiento o no, el agenciamiento anarquista.

En los primeros números aparecía Herminia Brumana como editora de la página y parece haber sido también quien escribía las notas no firmadas. A partir de los últimos números de 1947, la página dedicada a las mujeres aparecerá de manera intermitente y se irá convirtiendo en escasos recuadros sobre temas relacionados con la actualidad política. Considerando el período 1946-1952, la última referencia a la mujer aparece en el número inmediatamente posterior a las elecciones del año 1951.

Como ya mencionamos, la columna trataba sobre los problemas en relación al contexto peronista, pero también sobre los problemas de las mujeres de clase media. En este sentido, en su primera aparición, la página trataba sobre un problema que podrían tener las mujeres de clase media profesional: el no tener con quien dejar las/os niñas/os cuando las madres tenían que salir a cenar o al teatro. La solución que Herminia Brumana recomendaba, implementada en Estados Unidos, era el servicio de niñeras (1946: 14).

La mayoría de las mujeres que escribían en la página pertenecían a la Unión de Mujeres Socialistas Libertarias, creada en 1946. Una de las integrantes, Ana Piacenza, había participado en España en el movimiento Mujeres Libres. Quien también participaba de la columna era Iris Pavón, pedagoga, militante anarquista radicada en 
Cruz del Eje, Córdoba. Nació el 15 de septiembre de 1906 en Lobería en un hogar proletario. Se destacó en la prensa escrita, sus primeros escritos fueron poesías que publicaba en periódicos locales. A partir de 1935 participa activamente en el movimiento libertario y fue una vehemente defensora y activista por la liberación de los presos de Bragado. Por su militancia conoció la cárcel en 1944. Tuvo un hijo con su compañero Marcos Dukelsky. Desde Cruz del Eje escribió para el periódico anarquista Reconstruir, siendo una de las más fervientes colaboradoras. Muere el 13 de septiembre de 1951 a causa de una enfermedad (Bordagaray, 2013).

En nuestro estudio volveremos sobre los discursos de estas mujeres anarquistas pues consideramos que los cambios de estrategia en la organización política del movimiento y la apertura del frente gremial profesional, conllevó no sólo la presencia de las voces femeninas en la prensa, sino también un cambio en el contenido que generó giros discursivos respecto de la referencia u omisión de ciertos tópicos así como también un importante cambio en el contenido de los mismos.

Por último, nos queda por presentar la publicación que define el corte temporal de nuestro estudio. Si bien no fue escrita por médicos, consideramos que la publicación Luz de Rosario (1949-1951) dedicada a la juventud, retoma las ideas y las estrategias de difusión de los médicos anarquistas. Por un lado, en la revista planteaba cuestiones sobre la moral sexual, la prostitución y las uniones libres. Por otro lado, contaba con un consultorio de educación sexual a cargo de Ana Piacenza para que quienes quisieran consultaran

\section{Conclusiones}

En este capítulo hemos abordado la lógica de la conformación del campo médico y el modo en que los profesionales libertarios ingresaron en él. Las dinámicas intervenciones de los anarquistas a título individual como colectivo en las empresas del ámbito cultural evidencian nuestra hipótesis respecto de revisitar el período con nuevas miradas a fin de evidenciar las nuevas formas de agenciamiento que este movimiento adquirió y que no han sido auscultadas por la historiografía en la creencia de que concluyeron en el '30. 
Hemos evidenciado los espacios compartidos, en particular los eugénicos, a fin de establecer el sustrato sobre el que operaron los libertarios. Ese sustrato era compartido por otros médicos que lo apropiaron de otros modos y con otros fines como demostraremos en los capítulos subsiguientes.

Asimismo, las tradiciones e ideaciones heredadas por los médicos libertarios evidencian las intertextualidades y el modo en que se nutrieron de ellas tanto a partir de sus compromisos políticos como de su formación profesional.

Los elementos compartidos con sus coterráneos, así como las particularidades de este desarrollo interpretativo que formularon los médicos anarquistas, quedarán condensadas a lo largo de los capítulos de la tesis.

Finalmente, hemos destacado el modo en que la estrategia de organización del anarquismo durante el período influenció en el cambio de voces sobre los tópicos bajo estudio, cuestión que analizaremos en el capítulo sobre maternidad consciente y voluntaria. 


\section{Capítulo 2}

\section{Derivas libertarias: tensiones entre sexo y género}

Los integrantes del campo médico participaron activamente en el proceso de construcción de la idea de la existencia de un sexo biológico y, a partir de esta definición, se propusieron legitimar comportamientos y roles para varones y mujeres, los cuales, además, estaban jerarquizados (Bock, 1991). A través del estatuto de "cientificidad" atribuido a sus postulados, éstos asentaron "verdades" que se reprodujeron en todas las dimensiones de la vida social.

Desde el paradigma positivista, la ciencia se conformó como un ámbito neutral, objetivo y legítimo. Estas características han sido cuestionadas por las perspectivas constructivistas y la teoría feminista, que pusieron de relieve las relaciones de poder que constituyen el discurso científico. En particular, desde esta última perspectiva, los análisis sobre la relación entre género y ciencia han señalado el carácter de categorías socialmente construidas para ambas y han ahondado tanto en los contextos políticos y sociales que determinan el conocimiento científico como en el sesgo androcéntrico de la ciencia (Fox Keller, 1991; Haraway, 1995).

La intervención del discurso médico en la construcción de la dicotomía sexual y la legitimación y la regulación de roles de género dentro de una matriz complementaria y jerárquica fueron analizados desde la historiografía por distintas líneas de investigación que, directa o colateralmente, advirtieron sobre la relevancia que estos tópicos tuvieron para la inclusión o la exclusión de las personas del ejercicio de los derechos de ciudadanía.

Los aportes en el campo historiográfico local que se han ocupado de develar las construcciones del campo médico han evidenciado las tempranas vinculaciones de las discursividades médicas con el poder. Los trabajos de Pablo Ben han contribuido, por un lado, a demostrar la intervención de la ciencia en la consolidación del Estado-nación a través de la imposición de la dicotomía sexual y normas de comportamiento. Por otro, ha contribuido a deconstruir esas aseveraciones a partir del análisis del "hermafroditismo" como desestabilizador de la dicotomía y de su tratamiento médico como una patología (Ben, 2000a). También, a partir del análisis de las construcciones 
del cuerpo femenino, ha puesto en evidencia el establecimiento de comportamientos legitimados a partir de esa construcción anatómica y la exclusión de la identidad femenina a quienes no se ajustaran al esquema binario (Ben, 2000b). En esta misma línea, podemos situar los estudios que han indagado en la influencia del discurso médico, entre otros, para definir sexualidades "normales" y "patológicas" a través de la construcción de la heterosexualidad como norma (Bao, 1993; Ramacciotti y Valobra, 2008; Ben, 2000a, 2000b; Salessi, 1995).

Otros aportes provienen de las investigaciones sobre las normas de género en relación con las mujeres. Las mismas han evidenciado la participación de la medicina en la maternalización de las mujeres (Guy, 1998; Nari, 2004) y en la patologización de aquellas que contradecían los roles asignados, como las mujeres trabajadoras (Lobato, 2000; 2007; Nari, 1995, Armus, 2007) en las primeras décadas del siglo XX.

En menor proporción, los estudios sobre el campo médico han ayudado a deconstruir las discursividades científicas analizando los procesos de medicalización de los cuerpos de las mujeres (Lobato, 1996; Nari, 2004; Di Liscia, 2005, Felitti, 2007; Miranda y Bargas, 2011) y las consideraciones sobre las mujeres desde el discurso eugénico (Miranda, 2005a).

En este punto, interesa señalar que ha habido una intensa producción vinculada a cómo se construyeron los roles para las mujeres aunque sólo colateralmente se ha desnaturalizado el de los varones. Estas obras se concentraron en la cuestión de la maternidad y no hicieron hincapié en el carácter construido de la dicotomía sexual, a la vez que, en menor medida, avanzaron sobre otras dimensiones sobre la cimentación de la feminidad, por ejemplo, la sexualidad. En particular, los estudios se han enfocado sobre el discurso dominante $\mathrm{y}$, dentro de ellos, han ocupado un lugar privilegiado los médicos como sector influyente, considerando -con exiguas excepciones-su discurso como un bloque homogéneo. Las discursividades médicas provenientes de movimientos subalternos, como el anarquismo, no han generado análisis; sólo se ha retomado el discurso de Juan Lazarte para ubicarlo dentro del pensamiento eugénico. Si bien se señala las posibilidades para la libertad sexual de las mujeres, no se avanzó en el análisis de esta dimensión (Miranda y Vallejo, 2005; Felliti, 2012). 
Algunas investigaciones se han ocupado de estudiar los discursos sobre los roles de género que figuró el anarquismo local entre fines del siglo XIX y las primeras décadas del siglo XX. Las investigaciones analizan las intervenciones en la prensa anarquista en relación con las consideraciones sobre la emancipación femenina. Mabel Bellucci (1990) señaló las propuestas en torno a la sexualidad y la mujer, situándolas como antecesora del feminismo de los años 60. El estudio de Dora Barrancos consignó la existencia de dos momentos en el anarquismo local. El primero corre hasta mediados de la década del 20 y evidencia la existencia de un paternalismo en el que los varones ácratas se expresaban sobre la mujer considerándola un instrumento-medio para la emancipación de otros sujetos: su descendencia y su compañero. Por ello, la instrucción era la herramienta para erradicar su ignorancia. El segundo momento, marcado por la influencia del feminismo internacional en las militantes ácratas locales, coloca a las libertarias en escena con su propia voz en la prensa (Barrancos, 1990). En este sentido, Laura Fernández Cordero analiza las intervenciones doctrinarias de las mujeres y la radicalización que produjo en el movimiento libertario al poner de relieve la dimensión del género (Fernández Cordero, 2010).

Estas contribuciones, como hemos señalado, han tenido como límite temporal las primeras décadas del siglo XX y, si bien no se ocupan exclusivamente del discurso médico ácrata, esta frontera ha recreado una lectura parcial del discurso médico. En particular, el discurso de Juan Lazarte es situado dentro de la matriz eugénica y no se explora su participación en la deconstrucción de las posturas dominantes sobre las normativas de género. En este sentido, el estudio de Helena Andrés Granel (2012), concentrado exclusivamente en las obras de Lazarte, ahonda, en particular, en el neomalthusianismo con lo que aporta nuevas interpretaciones próximas a las que defiende nuestro estudio analizando la postura eugénica.

Las intervenciones anarquistas -como las de un amplio espectro de integrantes del campo médico- compartieron las nociones del dimorfismo sexual justificadas por explicaciones biologicistas. Sin embargo, los médicos anarquistas tuvieron un posicionamiento disruptivo respecto de las posturas más acendradas entre 1932 y los primeros años del peronismo. En efecto, a diferencia de la postura dominante que se centraba en la construcción de la mujer-madre, los médicos ácratas promovieron una mirada sobre la emancipación femenina que avanzaba hacia la liberación en la 
dimensión sexual, lo que los llevó -también- a extremar posiciones respecto de algunas médicas feministas que cuestionaban aquella mirada dominante, aunque no alcanzaban a abordar algunas implicancias de sus propios cuestionamientos. Nuestra hipótesis, no obstante, apuntará a reflexionar sobre ciertas ambigüedades en la que incurre el pensamiento libertario al mantener lo biológico como dado.

A fin de establecer esas convergencias y divergencias discursivas de las intervenciones ácratas respecto de otras del campo médico, en este capítulo analizaremos las postulaciones médicas sobre los roles y los comportamientos femeninos y masculinos derivadas de un mismo paradigma sobre la dicotomía sexual. Para ello, en primer lugar, rastrearemos las tradiciones discursivas más influyentes en variados grupos médicos locales internacionales para luego ser reinterpretadas y aggiornadas a nuestro medio.

Tendremos en cuenta, específicamente, las producciones del Theodor van de Velde y Gregorio Marañón, cuya influencia fue notable en estas consideraciones. En segundo lugar, avanzaremos en el análisis del discurso médico dominante en el ámbito local. Para ello, distinguiremos la voz de Josué Beruti y realizaremos algunas breves menciones sobre las elaboraciones de los médicos católicos, considerándolos parte del discurso dominante. Luego, realizaremos un acercamiento al discurso de la médica Alicia Moreau de Justo, a la que situamos como una exponente del feminismo socialista local y en la que escrutaremos el modo en que reformuló la noción de diferencia sexual en favor de objetivos emancipadores en cuanto a los derechos de la ciudadanía femenina. Por último, analizaremos las narrativas de los médicos anarquistas situándolos en el orden social discursivo. Para ello, tendremos en cuenta las trayectorias discursivas en la que se insertan y las intertextualidades con el posicionamiento médico dominante así como las derivas libertarias en relación con las normativas de género sobre la feminidad.

1. Desde el óvulo, el espermatozoide y las hormonas sexuales hasta los roles y comportamientos sociales 
La medicina se constituyó en uno de los soportes fundamentales del sistema patriarcal. Primordialmente, a través de la biología -y luego, de las especialidades médicas (endocrinología, sexología y ginecología)- coadyuvó a legitimar modelos sexuales y genéricos de varones y mujeres. Así, se definieron lo que los profesionales denominaban caracteres sexuales primarios y caracteres sexuales secundarios “correctos" para cada uno. En el mismo proceso, definieron anatomías "incorrectas" y "comportamientos anormales" que se transformaron en "patologías" y supuestas desviaciones que debían tratarse (Ben, 2000 b).

Theodor van de Velde y Gregorio Marañón, por distintas razones, resultan referencias insoslayables de nuestro estudio. Por un lado, las ideas de ambos profesionales tuvieron una gran difusión y circulación en nuestro país desde los años 30 hasta entrada la década del 60. Esta circulación de ideas, señala las redes intelectuales en las que participaban los médicos locales para conocer tempranamente las ideas desarrolladas al otro lado del Atlántico. Las mismas no sólo circularon entre el ámbito médico sino que, como en el caso de van de Velde, sus obras transitaron como literatura de divulgación. Asimismo, la circulación de ideas fue acompañada por visitas a nuestro país en varias ocasiones, en las cuales dictó diversas conferencias que convocaron a intelectuales y médicos. Por otro lado, a través de una intertextualidad manifiesta o implícita, los postulados de estos médicos han sido citados por los profesionales que abordamos en este estudio, tanto para confirmar como para refutar sus argumentos.

En este sentido, es interesante evidenciar cómo los postulados médicos se adaptaban y se moldeaban a fin de sostener diversos fines. En este apartado, entonces, a través la deconstrucción, nos interesa indagar sobre las "verdades" médicas referidas a los comportamientos y los roles de género que formularon las figuras extranjeras más influyentes en el campo médico local.

1. a. "Propter solum ovulum mulier est, quod est” (Sólo por el óvulo es la mujer lo que es) 
El libro El Matrimonio Perfecto del médico alemán Theodor H. van de Velde se editó por primera vez en Suiza, en 1926. A partir de entonces, tuvo una vertiginosa difusión. A fines de la década del 30, integró la Biblioteca Científica de la editorial Claridad. La obra se reeditaba, a un precio accesible, dos veces por año alcanzando las cuarenta reediciones iniciados los años 50 (Barcia : 1981). Incluso, otras empresas editoriales continuaron difundiendo esta obra hasta los años 80. Fue, sin duda, el libro más difundido de una trilogía integrada por dos títulos más: el segundo, llamado Aversión y atracción en el matrimonio, y el tercero, Fertilidad y esterilidad en el matrimonio, publicados entre 1939 y 1940 por primera vez en el país. Los escritos tenían un objetivo central: alcanzar la felicidad conyugal y conservarla.

Como señala Hugo Vezzetti, el discurso sexológico de van de Velde se sitúa entre la medicina y la literatura de divulgación. Por un lado, pertenece al campo médico "por el estilo y las referencias (pero no por los destinatarios ya que posee una débil legitimidad académica)" y, por otro, corresponde al campo literario "porque constituye un género peculiar, por sus condiciones de producción y circulación" (Vezzetti, 1997: 214). A través de estas formulaciones se intentó legitimar y normativizar la sexualidad dentro del matrimonio. Si bien el discurso sexológico es heterogéneo, Vezzetti señala que prevalecieron dos versiones. Una de esas visiones fue conservadora y se preocupó por la educación sexual, la higiene contra las enfermedades venéreas y el combate de la masturbación. Otra, se preocupó por la vida sexual en el matrimonio e intentó incorporar saberes técnicos para alcanzar la felicidad sexual; en esta versión incluye a van de Velde.

Sin embargo, desde nuestra perspectiva, entendemos que cualquiera de las dos versiones que señala Vezzetti han sido conservadoras en cuanto al ejercicio de la sexualidad. En particular en relación con las mujeres, pues, como indica el mismo Vezzetti con respecto al libro El matrimonio perfecto, este discurso sostenía la responsabilidad de la felicidad sexual en el varón. Ello debido a que, según la moral dominante, las mujeres no debían tener ningún conocimiento sobre cómo acceder al placer, sino que era el varón el que debía proporcionarle satisfacción a ella con el fin de lograr un "matrimonio perfecto". Es decir, el modelo de sexualidad que se proponía seguía encorsetado al matrimonio y los roles dentro de él se basaban en relaciones desiguales de poder. 
Algunos estudios que se enfocaron en el control de la natalidad y la sexualidad dentro del matrimonio han destacado el papel de la obra al difundir algunas técnicas para controlar la natalidad en el período de entreguerras (Nari, 2004; Felitti, 2012; Miranda, 2005b). La importante propagación del libro, para otras investigaciones, es un indicador de la "curiosidad acerca de la sexualidad" antes de 1950 y significó un "cambio sustancial" en la vida sexual de las personas (Cosse, 2008: 140; Felitti, 2012: 25). En efecto, con esta bibliografía podían acceder a información que los "médicos locales no estaban dispuestos a aconsejar" para el ejercicio de la sexualidad heterosexual sin que interviniera la reproducción (Nari, 2004: 195). Estudios sobre el discurso católico han señalado la oposición a la divulgación de la obra en el contexto local pues la consideraban inmoral y pornográfica al explicar distintas poses amatorias (Acha, 2001).

Estas perspectivas, si bien no se ocupan del análisis de la obra de van de Velde en profundidad, dejan entrever un impacto disruptivo y novedoso en el contexto local. Al hacer hincapié en las posibilidades que brindó a algunos sectores de la población alfabetizada y con capacidad económica para comprar libros, para informarse sobre el control de la natalidad, estos estudios no consideraron de igual modo los presupuestos ideológicos conservadores y eugénicos que conllevaba. Asimismo, no analizaron críticamente el modo en que se ubicaba el autor en la "neutralidad" del discurso científico, y cómo -a través de un lenguaje ameno que llegó a un público ampliolegitimó un conjunto de ideas con un fuerte correlato moral y normativo sobre el significado de lo masculino y lo femenino. Dado que las referencias han sido, mayoritariamente, al primer tomo de la trilogía y no a la obra en general, la mirada que se recrea es sesgada. En particular, no se ha puesto de relieve que el discurso de van de Velde impuso las desigualdades genéricas y legitimó la inferioridad de las mujeres, por ejemplo, a partir de señalar la correspondencia entre la fisiología del espermatozoide y el óvulo con los comportamientos normativos para varones y mujeres. 
En su segunda obra, Aversión y atracción en el matrimonio, dedicó varios capítulos a analizar y explicar "el contraste entre masculino y femenino". ${ }^{16}$ En su desarrollo, ocupó mayor extensión la descripción de las propiedades femeninas en relación con las propiedades masculinas, las cuales sólo ocupan un capítulo. El interés del médico era otorgarle estatuto científico a las diferencias biológicas establecidas entre varones y mujeres, como así también a las diferencias psicológicas.

Desde el origen, van de Velde señaló características diferenciales, jerárquicas y complementarias del espermatozoide y el óvulo. El médico indicaba que estas diferencias se encontraban de nuevo en "el hombre adulto y en la mujer en completo desarrollo" (van de Velde, 1953: 53). Si bien la característica principal del espermatozoide era el libre movimiento, ante los desarrollos de la ciencia, decía el médico, ya no podía aducirse al óvulo la correspondiente pasividad sino que el óvulo perdía esa peculiaridad "bajo la influencia que la aproximación del elemento masculino ejerce sobre él" (van de Velde , 1953:5 6). Es decir, el óvulo adquiría movimiento no por su propia voluntad, sino a partir de la presencia del espermatozoide. van de Velde también recreaba estas características durante el coito. La mujer debía ser "despertada" y "estimulada" por el varón para sacarla de su conducta "pasiva".

Así, se construían normativas de género atribuyendo características dicotómicas, complementarias y jerárquicas que definían lo masculino y lo femenino. Lo masculino se vinculó con lo objetivo, lo racional, lo universal, lo activo, lo productivo y lo público. Mientras que lo femenino se construyó en oposición a aquellas categorías: lo subjetivo, lo irracional, lo particular, lo pasivo, lo reproductivo y lo privado. Vale decir, pares duales sexualizados y jerarquizados, tal como Frances Olsen delinea respecto del pensamiento occidental en general (Olsen, 1990). Antes de desarrollar estas ideas, van de Velde advertía al público lector que estas diferencias no eran jerárquicas y que tampoco era objeto de su estudio "procurar una representación de los valores que pueda poseer lo masculino y lo femenino para la sociedad humana" (van de Velde, 1953: 55).

\footnotetext{
16 Esta obra está singularmente dedicada "a la memoria de una amiga maternal", como ya hemos mencionado la primera edición a través de la editorial Claridad es del año 1939, nosotras contamos con la quinta edición de octubre de 1953. Las citas son extraídas de esta edición.
} 
Sin embargo, en el desarrollo de sus ideas, contradecía esta advertencia. Para el médico, la naturaleza había impuesto a la mujer su deber de "vivir por completo entregada a la conservación de la especie" (van de Velde, 1953: 56).

Las afirmaciones normativas con relación a los varones también se definían desde el comportamiento del espermatozoide. van de Velde se explayó exiguamente sobre el tema, pero igualmente señalaba que la actividad, la agresividad, la voluntad hacia el poder, entre otras, eran características naturales del "elemento masculino". Desde el inicio, los espermatozoides, señalaba, se enfrentan entre sí para encontrarse con el óvulo, el más apto y fuerte, lo penetra y atraviesa y al mismo tiempo éste se cierra para los demás espermatozoides. Esta analogía, sostenía, "puede demostrarse claramente en todos sus detalles en las relaciones entre el hombre y la mujer" (van de Velde, 1953: $57)$.

Así, de esta lucha entablada entre los espermatozoides se derivaba, sin más explicaciones, la lucha del varón por la mujer, sus ansias de perfeccionarse para proteger y cuidar, su desarrollo intelectual, su racionalidad y su objetividad. Asimismo, estas cualidades conllevaban cierta "egocentricidad", también característica natural del varón. Esta característica congénita se explicaba, según el médico, porque era un comportamiento que se presentaba desde la niñez y no era aprendido durante el desarrollo. La preferencia por juegos de lucha, la competencia, los juguetes como sables o fusiles, la preferencia por profesiones y empleos que les permitieran tener poder sobre los demás devenían y se naturalizaban a partir de aquella lucha que el médico describía e imaginaba entre los espermatozoides.

Los procesos fisiológicos de la ovulación explicaban las características psicológicas de la mujer, entre ellas, señalaba la vulnerabilidad, la labilidad y la emotividad. Destacaba también que en relación con las cualidades del varón, la falta de las mismas se compensaba con otras cualidades complementarias. Por ejemplo, el escaso desarrollo de la función cerebral primaria se complementaba con el mayor desarrollo de la secundaria, lo cual provocaba que la mujer tuviera una mayor capacidad de alcanzar una profunda vida afectiva y su inferioridad sexual se complementaba o sustituía con "su valor aumentado en la propiedad llamada maternalidad que -señalabaes infinitamente más importante y trascendental" (van de Velde, 1953: 91). El concepto de maternalidad era diferente al de maternidad, cuestión que necesitó aclarar el 
traductor del libro el doctor Gregory Warren. Maternidad, decía, refiere a "estado o calidad de madre" y maternalidad refiere al "sentimiento nato de la mujer, de cuidar, interesarse y desvivirse por el prójimo, instinto propio de ella en todas las épocas de su vida" (Warren, en van de Velde, 1953: 95).

Esta última propiedad era central para la definición de la mujer pues, para la medicina, todo su organismo estaba programado para esa función. van de Velde endilgaba a la "Naturaleza" el haber destinado el cuerpo de la mujer "exclusivamente" para parir entendido esto como un deber (van de Velde, 1953: 96). La maternalidad era la cualidad intrínseca de la mujer como para el varón era el trabajo y los negocios.

Nuevamente, van de Velde negaba el papel de las construcciones culturales al sostener la existencia de un instinto maternal anterior a la cultura. En relación con los juegos de las niñas pequeñas, sus "inclinaciones naturales" a cuidar y asumir un rol de madre, maestra, niñera o enfermera en los juegos, demostraban, para el médico, que aquellos comportamientos no habían sido aprendidos ni normativizados, sino que demostraban la maternalidad congénita.

Así, desde el discurso médico se constituyó el binomio mujer-madre y a través de argumentos legitimados en la biología, la identidad femenina quedó encadenada a la maternidad. En este sentido, los estudios de Nari han contribuido a deconstruir los discursos médicos en relación a cómo se cimentó la noción de binomio en el ámbito local. Nari señaló que, desde fines del siglo XIX y a través de la biología, la medicina moderna reformuló la idea de naturaleza otorgándole un carácter presocial y, con ello, el “instinto maternal” se constituyó en "parámetro de la «femeneidad normal»" (Nari, 2004: 18).

El análisis de Nari enfatizó sobre el papel de los eugenistas -en particular del sector médico dominante- que, preocupados por la baja tasa de natalidad y el perfeccionamiento de la raza, se abocaron a la construcción de una ideología maternal. Las mujeres fueron consideradas "esencialmente reproductoras y mejoradoras de la especie" (Nari, 2004: 38). La gestación y la crianza se consideraban procesos que naturalmente la mujer debía realizar pero esta naturalidad se contradecía con la fuerte intervención de los médicos para conseguir la maternalización de las mujeres. Durante el período 1890-1940, señaló Nari, los médicos preocuparon, por un lado, en combatir 
la mortalidad infantil, el aborto, las prácticas anticoncepcionales, el abandono de niños y, por otro lado, en educar a las mujeres para convertirlas en madres. A través de diversas políticas de maternidad, que contaron con el apoyo estatal, el discurso médico logró ubicar a la maternidad como único destino para las mujeres (Nari, 2004).

La preocupación por la salud reproductiva de las mujeres en el ideario de van de Velde estaba inmersa en los presupuestos eugénicos con el fin de propiciar una correcta elección del cónyuge y, con ella, garantizar una correcta reproducción y evitar problemas matrimoniales. Así, el acento estaba puesto en las patologías de los órganos sexuales femeninos en relación con lo cual consignaba que éstos debían ser controlados desde la niñez pues consideraba que podían "aminorar su aptitud para el matrimonio" (Van de Velde, 1953: 230). Para la elección del futuro cónyuge, debía asegurarse que los órganos sexuales no tenían ninguna alteración patológica y que estaban "aptos para realizar una función genésica normal" dado que su función debía "conducir a la fecundación" (van de Velde, 1953: 226).

En este sentido, Pablo Ben examinó estos postulados médicos en el ámbito local en relación con la construcción del cuerpo femenino y señaló las intervenciones médicas diseñadas para corregir lo que ellos consideraban "anormalidades" o "patologías" en personas que poseían genitales ambiguos. El autor señala que el poder médico se imponía con mayor fuerza cuando una persona hermafrodita quería casarse, dado que para los profesionales "no tenía sentido una pareja no fértil, era un absurdo" (Ben, 2000b: 265). Asimismo, antes que admitir la ambigüedad, los médicos se abocaron a negar la identidad femenina de las personas que así se identificaban.

La difusión de estas ideas fue exponencial, tal como lo evidencia la profusa reedición de las obras de van de Velde. Con ella, se legitimaron y naturalizaron diferentes y complementarios comportamientos y roles sociales para varones y mujeres dentro de una matriz jerárquica. Se pregonó, asimismo, un basamento científico que la legitimó en otros ámbitos de la sociedad como una verdad incuestionable y terminó instalando un sentido común sobre los roles de género y su fundamento biológico inapelable.

En la misma línea argumental, pero con un apoyo más denso en la ciencia médica -en particular en la endocrinología-, encontramos a Gregorio Marañón, médico español 
cuyas obras también tuvieron gran circulación e influencia dentro de nuestro país. A continuación, analizaremos algunas de sus ideas, las cuales, en consonancia con las propuestas de van de Velde, conformaron un horizonte de sentido no sólo para profesionales del campo médico, sino que, también, a través de diversas intertextualidades, atravesaron todo el espacio social.

1. b. "Hacer muy hombres a los hombres y muy mujeres a las mujeres". La diferenciación sexual: una cuestión biológica y pedagógica

A diferencia de van de Velde, el impacto de la obra de Gregorio Marañón se circunscribió al campo médico. En efecto, este médico endocrinólogo reconocido en España durante las décadas de 1920 y 1930 mantuvo relaciones directas con los profesionales médicos y políticos a través de diversas visitas al país, entre 1937 y 1939 (López Vega, 2011a). Su llegada produjo algunas manifestaciones de intelectuales antifascistas que reclamaban a Marañón su falta de apoyo a la República española. Si bien en un primer momento Marañón había apoyado la causa republicana, luego se opuso al gobierno del Frente Popular y acusó de antiespañola e internacionalista la propaganda del gobierno republicano (Marañón, 1938). Varios intelectuales, como Elías Castelnuovo, propusieron boicotear la visita mientras que, otras figuras, como la intelectual Victoria Ocampo, lo invitaron a brindar conferencias (Queirolo, 2009). Como veremos más adelante, las ideas de Marañón permearon en todo el campo médico.

La notoriedad de Marañón en el país se registra en las páginas de los Anales de Biotipología, Eugenesia y Medicina Social de la Asociación Argentina de Biotipología Eugenesia y Medicina Social, creada en 1932, de la cual fue miembro honorario (Álvarez Peláez, 2012). También, fue colaborador del diario La Nación y sus obras se editaron en nuestro país, a partir de 1946, a través de las editoriales Espasa Calpe y Claridad (Burgos Ortega, 2001).

Varios estudios, en particular de origen español, se ocupan de analizar la biografía profesional de Marañón como así también sus aportes a la medicina (López Vega, 2011b). Algunos se focalizan en su pensamiento eugénico (Álvarez Peláez, 2012; 
Ferrandiz y Lafuente, 1999) y otros han evidenciado el papel de las teorías marañonianas en las construcciones sobre el género (Nerea, 1998); el papel de la biotipología en el determinismo biológico (Bargas, 2012; Ferla, 2012); la ideología de la domesticidad (Nash, 1993) y la identidad sexual (Castejón Bolea, 2013). Estos trabajos han analizado las teorías de Marañón y han deconstruido los comportamientos sociales bionormativos para varones y mujeres. En esta línea se inserta nuestro aporte a fin de mostrar la intertextualidad de las teorías de Marañón en los discursos de referentes del campo médico en el ámbito local.

La obra más conocida y difundida de Marañón fue Tres ensayos sobre la vida sexual, publicada por primera vez en España, en 1926, luego reeditada en España por Espasa Calpe hasta 1998 (Burgos Ortega, 2001). En ella, el médico planteó sus tesis centrales: la teoría de las secreciones internas y la teoría de la diferenciación sexual. Nos centraremos en explicar estos dos núcleos discursivos y analizaremos las consecuencias sociales en términos de relaciones de poder y definición de los roles de género que atraviesan sus postulados. ${ }^{17}$

Como señala Castejón Bolea, el pensamiento de Marañón reemplazó en España el criterio religioso "como elemento clave en la construcción de la diferenciación de género" y fue un ejemplo de "esencialismo biológico" (2013:2).

A mediados de la década del 20, Marañón institucionalizó la endocrinología como especialidad médica en España y -a partir de ella- formuló que las diferencias entre los sexos tenían su origen en las hormonas sexuales segregadas por los ovarios y los testículos. Las hormonas adquirieron un papel determinante en la diferenciación sexual (Fausto Sterling, 2007), pero también adscribió a la diferenciación a partir de la fisiología del óvulo y del espermatozoide que reproducía "la futura diferenciación de la actividad de la mujer y el hombre” (Marañón, 1951: 69), tal y como, también, había postulado van de Velde. Recordemos que la edición de los trabajos más importantes de los dos profesionales ocurrió en el mismo año: 1926.

\footnotetext{
${ }^{17}$ Utilizaremos para el análisis la edición de Escasa Calpe de Madrid de 1951. Esta edición además de los tres ensayos, "sexo trabajo y deporte", Maternidad y feminismo" y "Educación sexual y diferenciación sexual" agrega un trabajo que había sido publicado anteriormente por separado, "Amor, Conveniencia y eugenesia". Por ello la obra se titula Ensayos sobre la vida sexual.
} 
Si bien las ideas sobre la endocrinología eran debatidas en aquel momento, Marañón no se ocupó de exponer los debates en su obra. Sus postulados se insertaron y se vieron enriquecidos por las ideas de otro endocrinólogo de renombre internacional que también participó activamente de la vida académica y política de nuestro país, Nicola Pende. ${ }^{18}$ Las ideas de este biotipólogo llegaron a España a través de Marañón, quien fue el principal divulgador de la importancia del normal funcionamiento del sistema endócrino para contrarrestar los “desvíos sexuales" (Ferla, 2012: 105). En este sentido, Marañón señalaba que la diferenciación sexual era progresiva. Imbuido de las ideas darwinistas, suponía que la diferenciación sexual se alcanzaría durante el desarrollo. En su teoría, todo ser era al comienzo bisexual: al nacer, "el niño", "por estar aún muy cerca de ese instante en que se decide el triunfo de uno de los sexos, conserva todavía muchos rasgos de la primitiva bisexualidad" (Marañón, 1951: 146). En la niñez, el sexo "elegido" se imponía sobre el derrotado y, durante la pubertad, se producía la batalla que daría paso al predomino de uno sobre otro:

el que prevalece se adueña de todo el organismo e imprime su sello sobre cada función y cada órgano, a más de moldear en forma radicalmente distinta los caracteres sexuales primarios, los órganos de la generación y todo el expresivisimo complejo de los caracteres secundarios. (Marañón, 1951: 145)

Más tarde, señalaba, con el progreso de la edad, "el vigor del sexo triunfante se debilita" y "surge el sexo vencido" que en condiciones patológicas se profundizaba aún más (Marañón, 1951:148). Es decir, con el tiempo, las mujeres se virilizaban y, en menor medida que éstas, los varones adquirían características femeninas.

Si bien Marañón habla de un sexo elegido y de la conformación de la masculinidad y la feminidad a partir de una mixtura de caracteres somáticos y

\footnotetext{
${ }^{18}$ Nicola Pende (1870-1970), según señala Vallejo (2005), se formó en la escuela lombrosiana y adhería al pensamiento tomista. Contaba con gran reconocimiento social y estaba legitimado por la familia real. Creador de la Biotipología, la ciencia se propuso conjugar la biología con la política y participó en la conformación del pensamiento eugénico latino (Miranda, 2005a).
} 
funcionales de los dos sexos, tal "elección" no era individual sino que correspondía a las determinaciones biológicas: el sexo era definido por las características que diferenciales y opuestas- se establecían en función del tipo de órganos genitales, en particular desde la sexualización diferencial de las hormonas producidas por los testículos y los ovarios.

El médico español estaba convencido de que si la diferenciación sexual no era completa, las personas que no podían caracterizarse como el "varón perfecto y la hembra perfecta" permanecían en estados intersexuales que podían conducir a patologías graves. ${ }^{19}$ Cuando en el desarrollo posterior no había correspondencia entre los caracteres sexuales anatómicos primarios y los caracteres funcionales, esto se consideraba una desviación o patología que debía corregirse.

Para ello, Marañón depositaba su confianza en la educación. La persona que había sido definida como varón debía recibir una educación varonil y la mujer debía educarse reforzando los caracteres sexuales funcionales definidos para ella, centralmente, su "instinto maternal". La diferenciación sexual debía perfeccionarse a través de la influencia del medio. Para realizar esto, Marañón aconsejaba tres cosas: "guerra implacable al ocio; matrimonio temprano; y, desde luego, dar al alma lo que es del alma, a Dios, lo que es de Dios" (Marañón, 1951: 181).

Respecto de esta cuestión, es interesante señalar una de las contradicciones constantes del discurso médico que -si bien intenta reforzar que la diferenciación sexual no era producto de la cultura- acuden a la educación a través del medio para corregir aquellas identidades sexuales que el mismo discurso consideraba patológicas y con el objeto de reforzar lo que aparentemente era "natural" para las mujeres y varones.

\footnotetext{
${ }^{19}$ En una obra anterior, Marañón se refirió a los estados intersexuales, en ella señalaba que "el varóntipo" y la "hembra-tipo" son entes casi en absoluto fantásticos; y que, por el contrario, los estados de confusión sexual, en una escala de infinitas gradaciones, que se extienden desde el hermafroditismo escandaloso hasta aquellas formas tan atenuadas que se confunden con la normalidad misma, son tan numerosas, que apenas hay ser humano cuyo sexo no esté empañado por una duda concreta o por una sombra de duda" (Marañón, 1929: 39)
} 
En su tratado sobre "sexo, trabajo y deporte", Marañón estableció los caracteres sexuales anatómicos y funcionales que a su vez clasificó en primarios y secundarios. ${ }^{20}$ Estos caracteres, decía, permitían distinguir "ante un animal dado, cualquiera sea su especie, si pertenece al sexo femenino o al masculino" (Marañón, 1951: 26).

Para el galeno español, los caracteres anatómicos primarios estaban proporcionados por la genitalidad. La magnitud de los aparatos reproductores en el organismo de uno y otro sexo y su ubicación (externa-interna) eran evidencias de la importancia de la función sexual primaria en el cuerpo de la mujer.

Los caracteres anatómicos secundarios correspondían a los detalles que no se relacionaban con la reproducción. Eran la demostración de que "salvo las vísceras más groseras, apenas hay una porción del cuerpo que no tenga «su sexo»" (Marañón, 1951: 31). Así, el predominio del desarrollo pelviano en la mujer compensaba el predominio del desarrollo escapular en el varón. En cuanto al cúmulo energético corporal, los varones tenían mayores niveles que las mujeres, a la vez que el cabello en la mujer era escaso y largo en relación al abundante y corto cabello del varón, entre otras características.

En su propuesta, los caracteres sexuales funcionales eran más importantes para el varón que para la mujer, dado que ella estaba diseñada desde sus caracteres sexuales primarios para la maternidad, en consecuencia no podía alcanzar un gran papel en la actividad social puesto que debía dedicarse exclusivamente a gestar, parir y criar a su descendencia. En cambio, los varones contaban con "instinto para la actuación social (defensa y auge del hogar); menor sensibilidad a los estímulos afectivos y mayor capacidad para la abstracción mental y la creación; mayor aptitud para el impulso motor y la resistencia pasiva. Marcha y actitudes características; voz de timbre grave" (Marañón, 1951: 28). Estas características definieron el rol del varón en la sociedad y fueron legitimadas en razón de la autoridad de la biología, como ciencia objetiva y neutral, ocultando tal como señala Ben "que los procesos biológicos identificados eran una construcción teórica basada en concepciones culturales” (Ben, 2000b: 266).

\footnotetext{
${ }^{20}$ Este esquema suscribía la clasificación de Havelock Ellis (Castejón Bolea, 2013).
} 
Los postulados teóricos de Marañón fueron bien recibidos por algunas corrientes feministas de aquel momento. Haciendo hincapié en la dicotomía sexual entre varones y mujeres, las ideas de Marañón fundamentaron aquellos discursos feministas que luchaban contra la inferioridad de las mujeres en la sociedad a partir de reivindicar, principalmente, la maternidad y todas aquellas características que se establecían como intrínsecas del comportamiento femenino. Marañón señalaba que el feminismo verdadero debía tener como programa reivindicar y acrecentar la diferenciación sexual haciendo "muy mujeres a las mujeres" (Marañón, 1951: 77), cumpliendo las mujeres el deber de "ser madre ante todo [...] por la obligación de su sexo" (Marañón, 1951: 70).

En este apartado hemos relevado algunas de las ideas de dos médicos que tuvieron una fuerte presencia en nuestro país. Uno, con más difusión entre el público en general a través de la literatura de divulgación y otro, con mayor repercusión dentro del campo médico e intelectual. Pero ambos se ocuparon de diagramar la diferencia sexual a partir de la construcción de un modelo biológico. Estas ideas, como hemos mencionado, repercutieron en el ámbito local en diversos ámbitos dentro y fuera del campo médico.

\section{2. "por el simple hecho de ser mujer...". El discurso médico}

\section{dominante y la legitimación de la subordinación}

El campo médico argentino se conformó paralelamente a la organización del Estado nacional, los profesionales médicos participaron activamente en esa tarea y se consolidaron como una corporación dotada con autoridad y legitimidad para intervenir en la vida social. Así, las voces altas dentro del campo "pretendían impactar en la «opinión pública», modelar el «sentido común» de la mayor parte de la gente e influir sobre sus prácticas cotidianas" (Nari, 2004: 105).

El análisis de los discursos de estos profesionales permite acercarnos a las ideas locutadas en relación con las construcciones de la mujer y la feminidad, durante los años 30 y los primeros años de la década del 40; las cuales, sin embargo, fueron reivindicadas por colegas y discípulos posteriormente. También nos permite señalar las intertextualidades con los paradigmas antes reseñados, que evidencia la circulación de ideas y la conformación de un frente discursivo que negaba las relaciones de poder y la 
ideología en la construcción de los postulados y hacía hincapié en la "objetividad” de la ciencia médica.

En el concierto de voces de la elite médica se destacó la voz del obstetra Josué A. Beruti. Dedicado a la docencia universitaria y, a la vez, como miembro de instituciones influyentes en la formación de opinión general y con acceso a medios de comunicación masiva, el médico se esforzó en consolidar el paradigma de la dicotomía sexual. Específicamente, se abocó a definir y legitimar las construcciones culturales en cuanto a los atributos de la feminidad. Para ello, desde todos sus espacios de acción, procuró hacer de la maternidad la característica fundamental y excluyente.

Como titular de la cátedra de Clínica Obstétrica de la Facultad de Ciencias Médicas de Buenos Aires, correspondió a Beruti ocupar la Dirección de la Clínica Obstétrica y Ginecológica Eliseo Cantón. En ella, puso en práctica las ideas que pregonaba en la sección Eugenesia, Maternidad e Infancia. Así, en 1932, fundó la Escuela de Madres de puertas abiertas, a la cual, según datos que aportaba el profesional, diariamente concurrían un promedio de "sesenta madres" (Beruti y Zurano, 1934, en Beruti, 1943, t. III: 580). En ella, las mujeres recibían clases de, entre otras, Asistencia Social; Economía Doméstica; Puericultura, Eugenesia y Profilaxis; Higiene del Embarazo (Beruti y Zurano, 1932, en Beruti, 1943, t. III). La educación femenina fue la preocupación central del profesional y estaba concentrada en convertir a las mujeres en madres desde la niñez. La misma estaba estructurada en principios eugénicos de tinte coercitivo explícito. ${ }^{21}$ Éstos conllevaban, según Marisa Miranda, la "voluntad de acentuar la tradicional división de los roles de género, con airadas críticas a la independencia laboral de la mujer y a la anticoncepción; a la moda femenina y a la ambigüedad sexual explícita” (Miranda, 2009: 161). Como miembro de la elite médica, participó de manera ferviente en la implementación de un nuevo ideal de madre que, como indica Nari, se presentó "como universal, ahistórico, natural. Inscripto en la misma naturaleza femenina" que "reformuló simultáneamente la idea de mujer por lo que la femineidad acabó confundiéndose y reduciéndose a la maternidad: la mujer, a la madre" (Nari, 1996: 154).

\footnotetext{
${ }^{21}$ Concepto desarrollado en Miranda (2003)
} 
Desde argumentos biológicos y heteronormativos que ponían el acento en la diferenciación sexual, Beruti legitimó una "científica división del trabajo" (Beruti, 1941, en Beruti, 1943, t. III: 369). En su modelo, las mujeres, dado que su función primordial debía ser la maternidad, tenían que ocuparse de las actividades reproductivas, exclusivamente; mientras que al varón le correspondían las actividades productivas. La mujer, decía, "por la condición de su sexo, no podrá jamás suplantar con eficacia, muchas de las tareas asignadas en la colectividad al hombre". Definiendo las normas de género, Beruti señaló que la mujer, a diferencia del varón, aportaba "habilidad, paciencia, delicadeza, minuciosidad, ternura, educación filial", (1921, en Beruti, 1943, t. III: 344) entre otras cualidades que podía desarrollar dentro del ámbito doméstico. Asimismo, para exaltar el atributo femenino de la maternidad era necesario "un régimen de instrucción doméstica intensivo y sistemático" (1941, en Beruti, 1943, t. III: 371).

Con esta propuesta, Beruti reforzaba la paradoja de los postulados médicos entre la maternidad congénita y la necesidad de educar a la mujer para la misma. Proponía la conscripción femenina obligatoria como respuesta a la "ignorancia biológica" de la mujer (1934, en Beruti, 1943 t. III: 5). Influenciado por los modelos adoptados en Italia bajo el régimen de Mussolini y en la Alemania nazi, el médico proponía -a través de este servicio que debía ser obligatorio- preparar a las mujeres "para sus verdaderas funciones domésticas y de futuras madres" (1941, en Beruti, 1943: 16). Las políticas de asistencia social llevadas adelante por Benito Mussolini, las cuales se enfocaban en el desarrollo demográfico a través de la tutela estatal de la madre, y las políticas de Hitler sobre educación de la juventud femenina, eran las bases de la propuesta de Beruti. La educación de las mujeres debía estar exclusivamente abocada a su carácter de "futura madre" (1934, en Beruti, 1943, t. IV: 8) y era necesario llevar adelante el ejemplo de la política estatal alemana que, afirmaba:

Tiende a reducir las escuelas superiores, pero permite que prosperen la vocación y el talento; reconoce y no dificulta la labor intelectual femenina ya iniciada, pero no quiere desarrollar en masa la vida académica en la mujer, porque entiende que son tareas más en armonía con su sexo y su misión, el trabajo manual, la economía doméstica, los conocimientos 
prácticos de la vida diaria, los idiomas, la iglesia. (1934, en Beruti, 1943, t. IV: 10)

Estas ideas, además de llevarlas a la práctica en las diversas instituciones en las que participaba y defenderlas en publicaciones médicas y en diarios como La Nación y la revista El Hogar y conferencias radiotelefónicas, entre otras, también las llevó hasta el Congreso de la Nación. En el año 1936, el Ministerio de Relaciones y Culto a cargo de Carlos Saavedra Lamas le solicitó a Beruti colaborar en un Proyecto de ley del Poder Ejecutivo sobre Asistencia y Previsión Social. Allí, expuso sobre la educación maternológica de las mujeres, la asistencia médica de la gestación y el parto y la protección a la maternidad ilegítima como políticas públicas a implementar (1936, en Beruti, 1943, t. II: 585).

Beruti compartía con otros profesionales médicos la admiración del papel propedéutico de la ciencia eugénica como base de la educación de la mujer pues ella era, según esta postura, un ser ignorante de sus deberes de madre así como también de las normativas que el saber médico consideraba apropiadas para la correcta realización de la función maternal. Por ello, la educación femenina se sustentaba en "su carácter de madre y de futura madre" (Beruti y Peralta Ramos, 1935, en Beruti, 1943, t. III: 506). ${ }^{22}$

Estas ideas coincidían con las postuladas por Gregorio Marañón sobre la importancia de la influencia del medio para alcanzar la maternalización de las mujeres. El galeno argentino se refería a su colega como "el ilustre endocrinólogo español" y, tempranamente, manifestó conocimiento sobre su obra (Beruti, 1929, en Beruti, 1943, t. IV: 356). La intertextualidad con el médico español es manifiesta, es decir, explícitamente se incluyen referencias sobre los trabajos de Marañón en los estudios de Beruti y se señalan a través de "marcas de cita" (Fairclough, 1992). Con ellas, Beruti reafirmaba posturas y abría debates, en particular, sobre una cuestión que los médicos consideraban un problema importante en aquel momento: la delgadez femenina, incentivada, decían, por la moda y el feminismo que provocaba el aumento de

\footnotetext{
${ }^{22}$ Subrayado en el original.
} 
enfermedades y la masculinización de las mujeres. El "enflaquecimiento", señalaba, producía "caracteres sexuales menos diferenciados que los normales correspondiendo, al mismo tiempo, a figuras altas, angostas y esbeltas, de rasgos anatómicos pronunciados y capacidad maternal disminuida" (Beruti, 1932, en Beruti, 1943, t. III: 438).

Beruti, con todo, era consciente de la autoridad de su propio posicionamiento, y, desde allí, se permitía disentir con el médico español en los motivos de la difusión de la moda de la "flacura". Marañón, citado por Beruti, señalaba que este fenómeno respondía a la obtención de beneficios económicos y sexuales. Al contrario, el médico argentino refutaba aquel argumento diciendo:

¿Es útil? No, porque, bien que cómoda, resulta, [...] inconveniente para la salud. ¿Es económica? No, porque el ahorro se neutraliza con otros gastos. ¿Es estética? No, porque implica la deformación del cuerpo. ¿Es moral? No, porque propende a la desviación del sexo. (Beruti, 1929, en Beruti, 1943 t. IV: 356)

En esta lucha por convertir a las mujeres en madres y limitar su desarrollo al espacio doméstico, Beruti distinguió enemigos que obstaculizaban su cometido. El principal, al cual interpelaba explícitamente, era el feminismo, llamado "pseudofeminismo" por el médico. Consideraba que el movimiento postulaba una "emancipación mal entendida" pues pretendía colocar a la mujer "al mismo nivel del hombre". Para él, el feminismo "bien entendido" era aquel que bregaba por la dignificación de la mujer en tanto madre o futura madre y que defendía la diferenciación y la complementariedad entre varones y mujeres. Las luchas entabladas por las mujeres para alcanzar su emancipación eran, a sus ojos, evidencia de la incomprensión de las mujeres del papel que la biología les había asignado en la sociedad y culpables del aumento de "plagas sociales", como: 
la restricción voluntaria de los nacimientos, la ilegitimidad, el matrimonio tardío, la soltería, la desnutrición intencional con propósitos de estética, el alcohol, el tabaco y los alcaloides, el abuso de medicamentos, el parasitismo y la explotación del trabajo femenino, la ociosidad y el sedentarismo, el ejercicio físico exagerado o inadecuado y la tendencia absurda y morbosa hacia la masculinidad. (Beruti, 1941, en Beruti, 1943, t. III: 370)

Diversas adjetivaciones fueron las utilizadas por Beruti para definir a las mujeres y al feminismo: movimiento antifisiológico, deforme, mujeres viriloides, feministas furiosas, hombrunas, climatéricas, entre otras.

Con su alocución, el médico pretendía deslegitimar y desautorizar los postulados de las mujeres a través de la neutralización como un procedimiento de exclusión que conforma y reproduce el orden social discursivo. Como señala Martín Rojo, siguiendo a Michel Foucault (1992), la exclusión "como neutralización de los discursos alternativos y disidentes" se produce "mediante la producción y transmisión persuasiva de una imagen negativa y deslegitimadora que se proyecta en tres direcciones: 1) la deslegitimación de la fuente de los discursos y representaciones alternativas; 2) la deslegitimación de otras representaciones e ideologías; 3) la deslegitimación de los propios discursos, en tanto que discursos «inadecuados»" (Martin Rojo, 1996-1997:16). En este caso, las locuciones, no sólo de Beruti sino de gran parte de los médicos del grupo dominante, se proyectaron en la primera dirección. Este procedimiento fue acompañado por otros dos principios de exclusión: uno, separación o deslindamiento; el otro, rechazo (Foucault, 1992). Es decir, al establecer una oposición entre una "emancipación bien entendida" y "emancipación mal entendida", reforzó las dicotomías que "activan en última instancia la oposición «nosotros» (representantes de la normalidad frente a «ellos» (representantes de la anormalidad) y desencadenan inevitablemente en el interlocutor un proceso de identificación" (Martin Rojo, 1996- 1997: 17). Así, el rechazo hacia las mujeres que no reproducían el ideal de femineidad y los movimientos que las albergaban definió posiciones que tanto interpelaron positivamente a quienes aceptaban estas ideas como a quienes las rechazaban y eran excluidas. 
Entre quienes compartieron y legitimaron las ideas de Beruti referidas al rol social de las mujeres, desde una perspectiva médico-religiosa, se encontraban los médicos católicos. Como señala Ana María Rodríguez, a comienzos de los años 30, la Iglesia católica se propuso "conformar un referente cultural/ideológico que marcó una impronta en las políticas estatales cuyo destinatario fue el cuerpo de la mujer" (2003: 203). El Consorcio de Médicos Católicos, institución que congregaba a los profesionales, participó en la concreción de aquellos objetivos aportando legitimidad científica a la empresa moral de la Iglesia. La institución había sido creada en 1929 por iniciativa del jesuita Guillermo Furlong. ${ }^{23}$ Desde sus inicios, se propuso armonizar la ciencia y la moral católica a través de acciones como,

organizar los vínculos entre los médicos católicos de todo el país con el objeto de: investigar las relaciones entre teorías y prácticas médicas y la teología y filosofía católicas; defender los principios de la moral católica contra el materialismo y la seudociencia (sic); proveer mutua ayuda en los intereses religiosos y profesionales de unos y otros; $\mathrm{y}$, en general, promover entre los miembros católicos de la profesión médica tal solidaridad que el conocerse y tratarse sea ventajoso para todos, así en lo relativo a la moral como a la profesión. (Rodríguez, 2008: 261)

Para la difusión de sus ideas, los médicos contaban con su propia publicación, la revista Iatría, que se conseguía por suscripción. A través de ella se pueden seguir los debates y las ideas en relación con los temas relevantes que, en la década del 30 y -con menor espacio en sus páginas- del 40, fueron la denatalidad, el aborto y los métodos anticoncepcionales. Ello, como señala Rodríguez (2008), derivado del influjo de la carta encíclica Casti Connubii que dio a conocer el Papa Pío XI el 31 de diciembre de 1930, la cual proponía una defensa del matrimonio cristiano y se ocupó de aquellos temas.

\footnotetext{
${ }^{23}$ En el acta de fundación figuran los médicos Miguel Petty José L. Molinari, Luis Corbi Rodriguez, Enrique Vallaza, Juan J. Murtagh, Gabriel O'Farrell, Francisco E. Radrizzani, Luis Ayerza, Juan Robbio y Ernesto Dillon (Carranza Casares, 2008).
} 
Como miembros de la elite médica, los galenos agrupados en el Consorcio, también, al igual que Beruti, se preocuparon por la maternalización de las mujeres. Para lograr ese objetivo, no se focalizaron particularmente en la educación maternológica sino que se abocaron a deslegitimar y desautorizar el control de la natalidad a través de cualquier método. Esta preocupación fue central en el delineamiento de la agenda de la institución de la que formaba parte. Esta cuestión la analizaremos con detenimiento en el capítulo cuatro. Aquí sólo nos interesa señalar la concurrencia de este sector en definir las normativas de género, que a la legitimidad de la ciencia médica, sumaban la legitimidad de la moral cristiana. Asimismo, desde la revista, los médicos se ocuparon de prohibir cualquier atisbo de emancipación femenina.

Por ejemplo, la difusión de métodos anticoncepcionales como el método Ogino-Knauss, es decir, el conocimiento de los períodos fértiles e infértiles de la mujer. Para los médicos católicos, la difusión de calendarios sobre los ciclos ovulatorios era peligrosa pues muchos fieles entendían que este método no contradecía la moral religiosa. Carlos A. Castaño, ginecólogo y presidente del Consorcio, manifestó su oposición cuando sostuvo "hay quienes ocultan bajo la práctica indebida del método Ogino el deseo vil, mezquino, inmoral y anticristiano de no tener hijos y para ello encuentran pretextos en la enseñanza de divulgadores inescrupulosos de aquel método" (Castaño, 1939: 39). El problema de la denatalidad era central para los médicos y, desde las páginas de la revista, dieron a conocer una conferencia que Marañón ofreció en Buenos Aires para los miembros del Consorcio de Médicos Católicos, en 1939. Invitado por Castaño, por entonces presidente del Consorcio, el médico español disertó sobre lo que llamó “el magno problema". Recordemos que, en ese momento, Marañón ya se había vuelto un enemigo de la República y era bien recibido por sectores que anteriormente no lo habrían considerado. El médico Oscar Petrarca en el primer número de la revista Cultura sexual y física, editada por Claridad en agosto de 1937, ya había realizado una crítica sobre del cambio radical en el discurso del médico, acusándolo de abandonar sus convicciones.

En aquella conferencia, Marañón reveló lo que él entendía como la causa de la baja tasa de natalidad. Además de la crisis en las costumbres y la inestabilidad de la vida material, sostuvo que el futuro incierto, en aquel contexto de guerra mundial, era lo que llevaba a varones y mujeres a no querer tener hijos. Esta actitud la entendía como una 
reacción defensiva del instinto, por "el temor de crear vidas destinadas a una muerte prematura y arbitraria" (Iatría, 1939: 39). El problema de la denatalidad, para los médicos católicos, a diferencia de Marañón, tenía como causa principal el acto voluntario de controlar la natalidad. Así lo manifestaba el médico Ramón Brandán, profesor titular de Patología Interna en la facultad de Medicina de Córdoba, para quien "la mujer se fecunda y los hijos nacen, con la misma facilidad y las mismas dificultades que en la edad de piedra. No se conocen otras causas del descenso de la natalidad, en la época actual que el aborto provocado voluntariamente $\mathrm{y}$ las prácticas anticoncepcionales" (Brandán, 1939: 5). A través de la reproducción textual, delimitada por marcas de cita, del discurso pronunciado por "una dama socialista de Buenos Aires", el médico señaló los opositores a las ideas por él defendidas que al no otorgarle identidad procedió a desautorizar y deslegitimar ese posicionamiento discursivo. La cita a la que recurrió de esta "dama socialista" que podríamos, hasta el momento, suponer que por la elocuencia y el tono de sus palabras corresponderían a María Luisa Berrondo, directora de la revista Vida Femenina (1936-1943), decía "queremos limpiar la vida, la queremos más fácil, más hermosa, más placentera, más libre. A esto nos conducen la ciencia, el arte, la técnica, la política; ninguna supervivencia del pasado podrá detener ese empuje constructivo del porvenir" (Brandán, 1939: 22). Esta intertextualidad manifiesta fue concebida por el profesional para señalar que el socialismo estaba a favor del control de la natalidad y el aborto voluntario, lo cual él infería de la expresión "limpiar la vida". Las mujeres no podían renunciar al mandato divino de la maternidad y cualquier acto en ese sentido era condenado.

La Iglesia Católica y, particularmente los médicos que profesaban el culto, se encontraban alarmados por la circulación de la literatura popular sobre sexualidad. En especial, la obra de van de Velde, que, si bien se situaba dentro de una perspectiva médico-religiosa, fue calificada de pornográfica y condenada por la congregación del Santo Oficio el 14 de marzo de 1931 (Acha, 2001). Para Castaño, el problema de la difusión de esta literatura era que "disimulado con un cariz científico [...] mezclan sus argumentos con la doctrina católica, revuelven confusamente algunas fragmentarias opiniones de sacerdotes moralistas, etc. engañando fácilmente al lector desprevenido" (Castaño, 1939: 38-39). El psicoanálisis también se conceptualizaba en este sentido y era considerado aún más peligroso por algunos médicos católicos. En su estudio, Acha (2001) también señala este rechazo al psicoanálisis dentro de las páginas de la revista 
Criterio, en la cual también publicaban miembros del Consorcio, creando, con ello, una red interdiscursiva que reforzaba el predicamento católico.

Los médicos católicos, si bien compartía una matriz maternalista con Beruti, dado su posicionamiento ubicado entre la ciencia médica y la moral religiosa, hicieron hincapié en otra cuestión, además de la educación, para imponer las normativas de género. Los profesionales, como veremos en profundidad en los próximos capítulos, se abocaron a combatir el control de la natalidad y disputaron interpretaciones dentro del campo médico utilizando su capital cultural y simbólico, lo cual le concedió respaldo científico a sus planteos religiosos.

El discurso médico dominante mantuvo relaciones intertextuales con las ideas de van de Velde y Marañón. Los argumentos de los médicos del ámbito local, explícita e implícitamente, incorporaron las narrativas de aquellos referentes, tanto para criticarlas como para reforzar sus propios planteos. En particular, Castaño y los médicos católicos se enfrentaron a las ideas de van de Velde en cuanto a la felicidad sexual y adoptaron las ideas de Marañón pues les permitían conjugar su práctica profesional con su práctica religiosa. También Beruti retomó algunas de las ideas del médico español, pero no así las de van de Velde. Dado que su preocupación era la educación de las mujeres para la maternidad, las cuestiones sobre la erótica matrimonial y los métodos anticoncepcionales no fueron preocupaciones centrales. Aunque también el silencio sobre estas cuestiones puede ser un indicio de un procedimiento de exclusión a través de la neutralización de la capacidad disruptiva de estas problemáticas (Martín Rojo,19961997).

En suma, las posiciones médicas representadas por los profesionales analizados hasta aquí construyeron, adhirieron y reforzaron un paradigma de diferenciación sexual biológica y, a partir de ella, una constitución de caracteres sexuales secundarios que definían roles y comportamientos femeninos y masculinos. A excepción de van de Velde, que desde sus primeros textos señaló atributos opuestos, jerárquicos y complementarios entre varones y mujeres a partir de la fisiología del ovario y el espermatozoide, los demás profesionales comulgaban con una diferenciación progresiva de la sexualidad. Las teorías de Marañón, especialmente las vinculadas a los estados intersexuales, habían trascendido el campo médico y así lo podremos observar cuando, a 
continuación, nos concentremos en los posicionamientos discursivos de Alicia Moreau de Justo y de los médicos ácratas.

Esto nos permitirá analizar las adaptaciones y las reformulaciones de los paradigmas dentro de cada posicionamiento político e ideológico y, en particular, nos permitirá analizar cómo desde horizontes de sentido compartidos las narrativas médicas ácratas construyeron un ideario sobre la emancipación femenina que, sustentado en la ciencia, ponía en cuestión las normativas de género impuestas por el discurso dominante. Si bien no cuestionaron el carácter construido de la dicotomía sexual, sí criticaron como atributo excluyente de la mujer la maternidad para las mujeres al ubicar "el instinto sexual" por sobre el "maternal” y rechazaron la reclusión en el espacio doméstico.

\section{Las críticas al discurso dominante. Alicia Moreau y la política como herramienta de emancipación femenina}

Otros discursos sobre miradas de género en el pensamiento socialista han sido recientemente analizados en las figuras de algunos de los líderes más conspicuos (Becerra, 2009). Las de las socialistas, en particular, han estado más dispersas y han encontrado mayor interés en su apuesta sufragista (Barrancos, 2002; Lavrin, 1997). Siguiendo el objetivo de este capítulo, avanzaremos sobre el posicionamiento discursivo de Alicia Moreau de Justo sobre la dicotomía sexual y los roles sociales. La elección de sus postulados nos permite revisar las permeabilidades, las apropiaciones y las readaptaciones de los postulados médicos dominantes, en este caso, desde la mirada de una médica feminista.

Su formación médica incidió en sus explicaciones sobre la exclusión de las mujeres, en particular, de la ciudadanía política. En su tesis (1914), Moreau ya había mostrado su adhesión a los métodos experimentales para realizar aseveraciones sobre la naturaleza humana y comulgaba con las ideas evolucionistas de Darwin, pero haciendo hincapié en la influencia del medio antes que en la determinación biológica. En este sentido, la autora, como señala Valobra, "presentaba un grado de acuerdo respecto de la asociación entre caracteres primarios - como la presencia de glándulas genitales-y los caracteres sexuales secundarios" (2012: 145) pero ponía en cuestión la correlación entre esos dos niveles, dado que las pruebas no eran numerosas ni contundentes como para convertirse en una teoría. 
Yolanda Eraso (2007), explicitó que en ese período existía un acuerdo respecto de cuáles eran las verdades médicas respecto de la mujer y sus funciones. Según la autora, la ginecología definía a las mujeres como portadoras de vida a partir de homologarla al útero como órgano representativo de su esencia ("muller tota in uterus"). Para la endocrinología, no obstante, esa naturaleza definitoria estaba colocada en la noción "muller tota in ovaries". Para Adriana Valobra, el aporte sustantivo que formuló Alicia Moreau en esta tesis fue "repensar la función del ovario sin reducirla a la acción reproductiva" (2012: 146), con ello, cuestionaba esas verdades científicas afirmadas en el campo en el que se posicionaba. "Si para ella el cuerpo constituía un sustrato material inapelable y no quebró las visiones dicotómicas que atravesaron el pensamiento de la época tales como masculino-femenino; naturaleza-cultura; entre otras", la activa médica “intuyó que no había tal reducto de las regularidades armónicas que se esperaban de los cuerpos sanos y que lo patológico, tal cual lo expresaban las posiciones hegemónicas, tenía menos que ver con las herencias que con el medio. De allí que, desde sus primeros pasos por el ámbito de formación académica, desplazó sus miradas hacia lo social y hacia la influencia que podía ejercerse sobre esos cuerpos que requerían, fundamentalmente, educación" (Valobra, 2012:146-147)

Como hemos señalado en un estudio sobre la eugenesia y sus adaptaciones en diversos posicionamientos médicos y políticos, si bien Alicia Moreau adscribía a la existencia de un "sustrato instintivo" determinado por la biología, concedía mayor importancia a la base sentimental de la humanidad y a los procesos de socialización que determinaban su actividad (Ledesma Prietto y Valobra, 2012).

Por ello, y conforme a una mirada materialista de la sociedad, confrontaba con la imposición capitalista de la división del trabajo que orillaba a las mujeres a la domesticidad y a los varones a la productividad. Como ha indicado Gustavo Vallejo (2001), esta autora proponía, a comienzos de los años 10, un método racional de organización de la domesticidad que se ocupara, también, del rediseño arquitectónico de las viviendas. En este nuevo esquema, la autora señalaba la conveniencia de construir una cocina central en un complejo de viviendas en la cual personal contratado se ocupara de la preparación de los alimentos. Las mujeres, así, no sólo las que trabajaban 
fuera de su casa, sino que aquellas que fueran amas de casa podrían ocuparse de la educación de la/os niña/os y participar en la vida social.

Para Moreau de Justo, al definirse de otro modo las tareas vinculadas a la reproducción social, las mujeres podrían ocuparse de aspectos que mejoraran su vida personal y profesional y, al mismo tiempo, exigiría una modificación del reparto de tareas en términos de género pues, según su concepción, las tareas de educación de los hijos debían ser asumidas también por los varones (Valobra, 2012).

Sus intervenciones públicas y su producción entre la década del 20 y el 40 tuvieron como sustrato la demostración de que la condición de las mujeres y su supuesta "inferioridad" no eran sino producto del obligado embrutecimiento social y los roles a los que eran reducidas a través de procesos de socialización que se acendraban históricamente.

Durante la década del 30, sus colaboraciones en Vida Femenina y algunas de sus alocuciones en conferencias y asambleas permiten captar la pluma incisiva de Moreau de Justo en la coyuntura que le tocó vivir. Abocada al análisis político internacional y sus repercusiones locales -primero durante la Guerra Civil Española y luego, en el transcurso de la Segunda Guerra Mundial- sus intervenciones la muestran como una intelectual con un gran conocimiento de la historia política. ${ }^{24} \mathrm{Sin}$ abandonar el reclamo por la ciudadanía política femenina, Moreau de Justo señaló en diversos artículos la compatibilidad existente entre las tareas del hogar y la política. Cuestionando los roles sociales generizados que situaban a las mujeres fuera de la discusión de la vida pública, señalaba que era "querer reducirla al rol de simple fregona" (Moreau de Justo, 1935: 4).

Si bien Moreau de Justo acordaba con la existencia de una esencia femenina y masculina delineada por su constitución biológica, como ha señalado Valobra, ya en 1910 se batía con aquellos detractores de la participación de las mujeres en el ámbito intelectual por considerar que aquello era, en palabras del escritor Leopoldo Lugones, una "monstruosidad biológica". Rechazaba a aquellos que preferían perpetuarla en el rol de "la cenicienta, descuidada o asesinada por la ley, pero robusta, sana y productiva, la

\footnotetext{
${ }^{24}$ Como ha señalado Valobra, retomando las palabras de Dora Barrancos, todavía falta un reconocimiento de Alicia Moreau como "cientista” (Valobra, 2012: 140).
} 
mujer verdadera cargada de hijos". Aunque disputaba con estos intelectuales, Alicia acusaba con profunda aversión a la religión cristiana de la responsabilidad de imponer roles de género que reducían a las mujeres a esa situación. Consideraba, incluso, que atentaba contra la maternidad pues presenta como ideal "el renunciamiento a todo lo que hace la felicidad de la vida, idealizando la virginidad, poblando el mundo de conventos, presentando como horrendos pecados los afectos más puros" (Moreau de Justo, 1910, en Valobra, 2012: 149).

Estas ideas fueron una continuidad en el registro escritural de Moreau de Justo a tal punto que, si hasta los años 20 había reclamado el voto calificado en función de otorgarlo sólo a aquellas que pudieran demostrar sus capacidades intelectuales acreditadas por el sistema educativo formal, luego exigió la igualdad plena tras viajar a Estados Unidos y contactarse con el movimiento sufragista de ese país. Así, al exacerbar su propia lógica respecto al modo en que históricamente las mujeres eran educadas y, al mismo tiempo, al contemplar que los varones en igualdad de condiciones de analfabetismo, por ejemplo, ejercían derechos políticos, Moreau avanzó por la igualdad plena de los roles públicos de varones y mujeres y abogó por el voto universal sin reparos, algo que la diferenció de sus propias compañeras de militancia y la acercó a Julieta Lanteri, fuertemente influenciada por el librepensamiento.

Su libro La mujer en la democracia (1945) constituye, según Marysa Navarro, "un alegato con el doble propósito de demostrar a sus compatriotas la necesidad de defender la democracia y sus principios, atacando toda forma de autoritarismo y también convencerlos de que para que la democracia fuera verdadera tenía que incluir a las mujeres" (Navarro, 1994: 191). En él, podemos encontrar algunas de las definiciones sobre la diferencia sexual que nos permiten analizar los puntos de concordancia con los postulados dominantes y las divergencias que potencian una noción de la maternidad distinta.

Esta noción igualitaria respecto de los roles la expresó con claridad inusitada en los años 40, cuando su pensamiento feminista había madurado sensiblemente. Afirmaba, entonces, que el organismo de la mujer estaba "hecho para engendrar y proteger la vida" (Moreau de Justo, 1945: 24). Apuntaba que “a esta causa orgánica -carácter sexual secundario- se agregan influencias de orden social, por ejemplo, la reclusión en el hogar que impidió durante siglos a la mujer el tomar parte activa en muchas tareas que exigen 
fuerza" (1945: 87-88). Para Moreau de Justo, la función maternal -primordial para la sociedad- era la paradójica justificación que socialmente la había ubicado como un ser inferior: la influencia del medio para hacer de una potencial capacidad un justificativo para la opresión.

La médica confiaba en la educación moderna para "liberar y desarrollar las aptitudes útiles sin distinción de sexos". Confiaba en que una educación de nuevo cuño le permitiría superar aquello que se le habían negado a las mujeres de las generaciones pasadas cuando se redujo "su formación femenina, de acuerdo al canon tradicional" (1945: 175).

El movimiento feminista también era un motor de cambio con el propósito de "reformar la legislación, de abrir carreras, de mejorar condiciones de trabajo y hacer desaparecer los prejuicios y las prácticas que impiden a la mujer desenvolver su vida con libertad y sin más limitaciones que las que nacen de sus naturales condiciones individuales" (1945: 34). A través de una intertextualidad implícita, la autora crítica las interpretaciones que analizamos de los médicos dominantes sobre el feminismo, aclarando que "no es, como equivocadamente suponen algunos, la guerra de la mujer contra el hombre, el desplazamiento de éste o la igualación contraria a la naturaleza misma" (1945: 34). Moreau de Justo reclamaba al feminismo como un movimiento democratizador y repudiaba las ideaciones caricaturescas y reductivas que realizaban algunos médicos.

Moreau de Justo se ubicó en oposición y por fuera del "nosotros" utilizado por los médicos dominantes para señalar lo que ellos consideraban una emancipación "bien entendida". También defendió las ideas que eran designadas por aquellos médicos como indicadores de la "emancipación mal entendida". La médica señaló que la mujer se emancipa a través de la educación, la independencia económica y la conciencia de sus derechos y de su papel en la sociedad. Por ello, debía luchar por su participación en la vida pública para defender su emancipación.

En este punto, interesa señalar que la figura de Alicia Moreau de Justo, poco escrutada en la complejidad de su ideario, aporta ricos elementos para pensar la problemática de los roles y, asimismo, evidencia las limitaciones para pensar algunas problemáticas. En 
efecto, esta médica que disputó con los médicos también fue singular en la lectura de roles respecto de la participación de las mujeres en el espacio público.

Las lecturas sobre los roles de género fueron importantísimas en la dimensión política de la actuación de Moreau de Justo -tanto en el feminismo como en el socialismo-. La igualdad pública de varones y mujeres y la idea de compañerismo tenían especial relevancia y se asentaron en el ideario socialista. Esta lectura de género se exacerbó con la llegada del peronismo. En efecto, el Partido Socialista, y Alicia Moreau de Justo entre sus militantes, denunció el modo en que se vaciaba la lucha sufragista en nombre de lo que tacharon como un gobierno dictatorial y, en particular, cómo ello se realizaba de la mano de visiones tradicionalistas de los roles de género. Como ha señalado Valobra, aun cuando Evita, la primera dama, rompía los moldes atávicos impuestos a la actuación de las mujeres en la política, la oposición en su conjunto, y el socialismo en particular, condenaban la mirada tradicional que en muchos aspectos, Evita transmitía en sus intervenciones. Incluso, aunque no rechazó la sanción de la ley de derechos políticos, Moreau de Justo afirmó, en la Conferencia Nacional de Mujeres Socialistas de 1947, que era necesario "contrarrestar esas acciones evitianas con campañas de distinto alcance cuyo objetivo era «crear a la sufragante» con conciencia y para que reconocieran los malos conductores que -como Perón y su esposa- otorgaban formalmente un derecho planteando viejas jerarquías" (Valobra, 2010: 47). Las viejas jerarquías eran, precisamente, aquellas contra las que Moreau había fustigado desde el feminismo y el socialismo para modificar los roles de género.

Introducir a Moreau de Justo evidencia que la problemática de la normativa de género fue fundamental para la lucha del feminismo local y adquirió en ella singulares pinceladas, menos afectas a ciertos esencialismos. Si bien su producción sobre este particular fue desarrollada en especial a principios del siglo -un comienzo secular menos pacato que los que vendrían luego, en especial en los 30-, fueron esas ideas en las que persistió pues eran el fundamento de su propio lugar en el mundo, disruptivo de los roles generizados.

Al pensar a Moreau de Justo en relación con los médicos dominantes es evidente la confrontación en relación con las exclusiones establecidas por aquéllos para el desarrollo de la vida pública de las mujeres. Sin embargo, aunque era un pilar del feminismo y el socialismo local, su voz se levantó desde los márgenes del campo 
médico - hasta los años 30, cuando aún tenía vinculación profesional con el mismo-. Ella no procuró profundizar sus debates, aunque era una conocedora ávida y sumamente crítica de muchos de los postulados de su tiempo. Luego, desde los 30 en adelante, ya fuera del campo profesional, propició lecturas vinculadas a esos debates en el campo político, en el que esas miradas no estuvieron ausentes. Por otro lado, sus intervenciones no eran retomadas por el discurso médico dominante, cuya estrategia de descalificación incluía la omisión y la sobregeneralización al referirse a las feministas locales, unificadas como un todo sin fisuras y sin denominación de personas.

Las médicas feministas, con todo, no fueron las únicas voces marginales en el campo. Las de los médicos anarquistas, precisamente, fueron marginales -por disruptivas- en su contenido y sus espacios de acción. Precisamente, un núcleo discursivo sobre el que se distinguieron de manera alarmante del discurso médico dominante, fueron sus consideraciones sobre los roles de género. Fueron, incluso, más allá de los planteos de las feministas, irrumpiendo con sus visiones aun cuando, como veremos a continuación, hubiera un sustrato común que muchas veces compartían. En relación con la dicotomía sexual, la confianza en la ciencia médica para modificar el desarrollo de la sociedad y la importancia de la eugenesia para lograr ese objetivo.

\section{Perturbando la normativa de género. El discurso médico ácrata y la emancipación integral de las mujeres}

Diversas alocuciones ácratas, desde fines de siglo XIX, como hemos señalado en la introducción, cuestionaron las relaciones de poder existentes entre varones y mujeres y defendieron la emancipación femenina. Con ello, pusieron de relieve el carácter construido de los roles sociales generizados (Barrancos, 1990; Fernández Cordero, 2010; 2012) El análisis de los discursos de las mujeres anarquistas sobre las consecuencias sociales de la diferencia sexual permitió avanzar en la comprensión de la crítica a la desigualdad entre varones y mujeres. Las disputas con los compañeros de ideas se hizo presente reiteradamente en las páginas de los periódicos escritos por mujeres, como así también las polémicas con las feministas contemporáneas (Barrancos, 1996b; Calzetta, 2005; Molineaux, 2002; Ledesma Prietto y Manzoni, 2009; Andrés Granel, 2008). Sin desconocer el papel de las mujeres ácratas como hacedoras políticas del movimiento (Fernández Cordero, 2012), sino entendiendo su participación en la 
prensa escrita como una acción política emancipadora, la palabra de las mujeres nos permite acercarnos a las prácticas de los militantes ácratas que, a veces, no coincidían con sus discursos en relación con la emancipación femenina.

La literatura ha señalado con énfasis la importancia que tuvieron en esa ruptura de roles impuestos generizados las anarquistas que escribieron a fines del siglo XIX. Dado el impacto que esas posturas alcanzaron, me interesa resaltar esas intervenciones por el modo en que gestaron una postura respecto de los roles de género.

Las anarquistas de aquel período tempranamente cuestionaron las ideas dominantes sobre los roles femeninos y masculinos. Así, ya en La Voz de la Mujer ${ }^{25}$ encontramos críticas a la opresión de las mujeres por parte de los varones en los diversos espacios y roles sociales, en su relación con ellas como jefes, esposos, hermanos o padres. En sus propósitos, reconocieron que en su experiencia como mujeres no sólo como trabajadoras, su lugar había sido el "de ser el juguete, el objeto de los placeres de nuestros infames explotadores o de viles esposos" (La Voz de la Mujer, 2002: 43).

En sus páginas, una colaboradora que firmaba como "una Stiratrice" (una lavandera) denunciaba que en la sociedad en la que vivían la mujer era la víctima de los caprichos, las pasiones y la tiranía del hombre y señalaba la construcción de la desigualdad sobre la base de las diferencias genéricas: "Nada más injusto es la desigualdad artificialmente establecida entre el hombre y la mujer" (La Voz de la Mujer, 2002: 48), expresaba. La educación limitada, la vida doméstica al servicio del hombre, su valor inferior en la escala social con respecto al varón, todo ello, señalaba la autora, concordado para mantener a la mujer en un estado de dependencia económica y moral del hombre. ${ }^{26}$

\footnotetext{
${ }^{25}$ Se publicaron nueve números del periódico entre el 8 de enero de 1896 y el 1 de enero de 1897 , de aparición irregular, se sostenía a partir de suscripciones voluntarias. La impresión del periódico oscilaba entre mil y dos mil ejemplares de cuatro páginas. En la reedición del periódico en 1997, de los ejemplares encontrados en el Instituto de Historia Social de Ámsterdam, no se halló el número 6, del cual hasta el momento no hay datos.

${ }^{26}$ Sin elaboraciones teóricas, consideramos que a partir de sus experiencias las mujeres pudieron comprender y establecer las características del sistema sexo/género mucho antes que los postulados de las teóricas feministas. Nos referimos a las contribuciones de las teóricas feministas que elaboraron argumentaciones sobre el sistema sexo/género, entre ellas, Simone de Beauvoir con su obra El segundo sexo, editado por primera vez en 1949; Kate Millet con su libro Sexual Politics, publicado en 1969 y Gayle Rubin con su ensayo El tráfico de mujeres. Notas sobre la "economía política" del sexo de 1975.
} 
Las acusaciones de estas mujeres hacia sus compañeros anarquistas se basaban en que en la práctica en el hogar, en el sindicato y en el trabajo sus actos no respondían a las ideas que propiciaban. ${ }^{27}$

Para las mujeres de La Voz de la Mujer, la emancipación femenina era uno de los ideales que defendía y constituía a la Anarquía y a través de ella se alcanzaría la igualdad entre el hombre y la mujer con lo cual se eliminaría la supremacía de las privilegios masculinos en la sociedad (La voz de la mujer, 2002: 71). Adhiriendo a las diferencias biológicas y entendiendo la maternidad como una función natural de la mujer, sin embargo, criticaron los roles jerárquicos devenidos de aquella diferencia sexual.

Más tarde, en 1922, desde la ciudad de Necochea un grupo de mujeres organizadas por Juana Rouco Buela ${ }^{28}$ se propusieron lanzar Nuestra Tribuna, ${ }^{29}$ un periódico para -como señalaban los dos epígrafes que se mantuvieron en treinta y seis de los treinta y nueve números- señalar que la inferioridad mental de la mujer es una mentira teológica y que "no hay emancipación de la mujer. La emancipación que nosotras mujeres libres, propiciamos, es social, netamente social" (Nuestra Tribuna, septiembre de 1922: 1). Con ello, se posicionaron en un espacio social opuesto al de los reclamos sufragistas y reformistas y reafirmaron su lugar de enunciación como mujeres anarquistas. También, fue un posicionamiento respecto de sus propios compañeros y los cuestionamientos que pudieran formular a su participación.

\footnotetext{
${ }^{27}$ Los consideraban falsos anarquistas y así los interpelaban: "a pesar vuestro, ya lo veréis, haremos que «La Voz de la Mujer» se introduzca en vuestros hogares y que diga a vuestras compañeras que no sois tal leones, ni siquiera perros de presa [...] que hablan de libertad y sólo la quieren para sí, que hablan de anarquismo y ni siquiera saben... [...] vosotros los que habláis de libertad y en el hogar queréis ser zares" (La voz de la mujer, 2002: 58).

${ }^{28}$ Juana Rouco Buela fue una militante ácrata hasta sus últimos días que participó en la organización sindical de las trabajadoras a través de la Federación Obrera de la Republica Argentina (FORA) del quinto congreso, que proclamó defender los principios económicos y filosóficos del comunismo anárquico. Una biografía política de Juana en Nadia Ledesmo Prietto y Gisela Manzoni (2009). Uno de los primeros análisis sobre la FORA, realizado por Abad de Santillán en 1933, se puede consultar la reedición del año 2005.

${ }^{29}$ El periódico contó con treinta y nueve números, publicados entre 1922 y 1925 , que alcanzaron un tiraje de cuatro mil ejemplares a través de suscripciones. De alcance internacional, el periódico fue reeditado en 2005 en la versión de facsímil encontrada en el Instituto de Historia Social de Ámsterdam por Elsa Calzetta. Las referencias a Nuestra Tribuna provienen de esta reedición.
} 
Al igual que sus compañeras de La Voz de la Mujer, a través de su experiencia como mujeres trabajadoras, reconocían y denunciaban las desigualdades con respecto al varón pero haciendo hincapié en la ignorancia en la cual se mantenía a las mujeres como causa de esa desigualdad, que impedía su educación racional y, con ello, su emancipación (Nuestra Tribuna, septiembre de 1922).

Desde sus prácticas cotidianas en el ámbito familiar y laboral, las mujeres ácratas realizaron una anticiparon el concepto de patriarcado. Además de la noción de construcción cultural de los roles genéricos, la noción de patriarcado aparece en esta publicación definida como un sistema instaurado para negarle los derechos a las mujeres, sometiéndola a una vida de humillación y sumisión, negándole un lugar en el espacio público (Nuestra Tribuna, septiembre de 1922). Sentenciaban que hasta el momento, negando la legitimidad de las teorías médicas, no se había demostrado científicamente por qué causas naturales o de otra clase la mujer era inferior al hombre, develando el carácter construido de la desigualdad.

Al igual que sus antecesoras de La Voz de la Mujer, sostenían que la vida familiar sometía a las mujeres a la servidumbre y, por ello, rechazaban el matrimonio y levantaban la bandera del amor libre. Pero a diferencia de las libertarias de La Voz de la Mujer, que estaban en contra del aborto y el control de la natalidad, las mujeres de Nuestra Tribuna defendieron la maternidad consciente y voluntaria desde una perspectiva neomalthusiana.

Para alcanzar la emancipación, las mujeres de Nuestra Tribuna señalaban que la mujer debía dejar de ser la esclava y sirvienta incondicional del hombre y no debía dedicarse exclusivamente al hogar, sino que, para modificar las ideas y prácticas imperantes debía participar -al igual que el varón- en las luchas y en los sindicatos. Estas nociones se oponían a las que, por entonces, Beruti defendía desde su cátedra y en publicaciones periódicas como La Nación.

Los conflictos con los compañeros, como hemos mencionado en el caso de La Voz de la Mujer, se desarrollaron en las páginas del periódico Nuestra Tribuna en las que las trabajadoras periodistas señalaron las contradicciones que los atravesaban: "hay muchos anarquistas y muy buenos compañeros, pero, que teóricamente aceptan la libertad de la 
mujer y que en la práctica obran de distinta manera en vez de educar a la compañera, no lo hacen..." (Nuestra Tribuna, noviembre de 1922: 4).

El periódico Nuestra Tribuna culminó en 1925. Años después, su impulsora, Juana Rouco Buela, reflexionaba sobre este emprendimiento como un sueño hecho realidad que tuvo como fin "demostrar con hechos que la capacidad de la mujer es exactamente igual que la del hombre, y solo le falta ejercicio y estímulo, ya que siempre se la ha ido colocando en un plano inferior de condiciones" (Rouco Buela, 1964: 83). En este sentido, la apuesta por la educación de las mujeres para salir del lugar subordinado y la influencia del medio para hacer de la diferencia sexual el argumento de esa subordinación se asemejaba a las ideas de Alicia Moreau de Justo, aunque las diferencias entre las anarquistas y las posiciones representadas por la médica socialista eran mayores que las coincidencias, particularmente en torno de la defensa de las instituciones de la democracia liberal que la socialista defendía (Barrancos, 1996b)

A medida que transcurrían los años 20, la perspectiva médica-higienista sobre la sexualidad cobró protagonismo, "si bien la preocupación no es nueva -desde 1914 comienza a difundirse la cuestión higienista-, hay una intensificación del tratamiento médico sobre la sexualidad" (Barrancos, 1990b: 32). Entre las nuevas contribuciones, adheridos a la propuesta eugénica y señala los trabajos del médico Juan Lazarte (Barrancos, 1990) pero señala que esta perspectiva no se ocupa del placer.

En las primeras participaciones de Lazarte en la revista Nervio (1931-1936), introduce concepciones sobre la diferencia sexual y los roles sociales que retoman, implícitamente, el ideario pregonado por las libertarias que lo antecedieron y lo legitima a través nuevos argumentos médicos.

La postura de Lazarte estaba atravesada tanto por las ideas eugénicas como por las perspectivas sexológicas europeas y estadounidenses. En particular, Havelock Ellis fue frecuentemente citado en su obra, como así también Marie Carmichael Stopes, Ben Lindsey y Gregorio Marañón. Recurría, además, a las ideas de Alejandra Kollontai, Ellen Key, Hildegart Rodríguez y de sus dos amigas y camaradas Emma Goldman y María Lacerda de Moura. 
En relación con las diferencias sexuales, Lazarte suscribía las ideas de Marañón sobre una diferenciación sexual progresiva, la existencia de estados intersexuales y la importancia de la pubertad como etapa evolutiva decisiva para el establecimiento de esas diferencias. Así, lo exponía en su columna "Curso de sexología" dentro de la revista Hombre de América. En la lección cuatro "La intersexualidad y los estados intersexuales" sobre la base de las ideas de Marañón, se ocupo de "El problema de los homosexuales". Adhiriendo al esquema de la diferenciación sexual progresiva, sostenía que "el homosexualismo no es una excepción ni una monstruosidad: es un estado por el cual pasan numerosos individuos; unos quedan por evolución retardada y otros avanzan por el camino natural, saliendo de él. Todo esto es evolución sexual" (Lazarte, 1940: 36). No obstante, Lazarte se apropiaba de estos planteos para sostener sus ideas que, en cierto modo, eran críticas a las expresadas por Marañón. En este sentido, también señalaba la influencia del medio en relación con las connotaciones sociales sobre la homosexualidad. En ese momento, considerar al homosexual como invertido, decía, ya no podía sostenerse, dado que "las prácticas homosexuales son perversiones desde el punto de vista social y ético, porque la moral no las acepta" (Lazarte, 1940: 36).

Igualmente, en uno de sus primeros artículos en la revista Nervio, sugerentemente titulado "el provenir del macho en la humanidadseñalaba que, no obstante "la función biológica fundamental corresponde a la madre", las mujeres, en aquel contexto, avanzaban "en un sentido biológico de liberación" a través de las primeras medidas: "igualdad sexual; contralor de los nacimientos, independencia económica, etc." " (Lazarte, 1931a: 2-4). Estas ideas eran las que cuestionaban las normativas impuestas por Marañón.

Con notable confianza, el médico rosarino afirmaba que en los próximos años la civilización "ser[í]a femenina” y el problema sexual estaría resuelto (Lazarte, 1931a: 3). Por un lado, vislumbraba una sociedad regida por los principios eugénicos que delinearían la calidad y la cantidad de la población y, por otro, la reproducción se haría de manera artificial, sin explicar de qué manera. Seguidamente, publicó otro artículo titulado "Un problema sexual: la suegra" (Lazarte, 1931b), en el cual hacía referencia a las teorías de Marañón sobre la virilización de la mujer entre los 45 y los 50 años. Este proceso, decía Lazarte, alteraba los caracteres sexuales secundarios pero no así los primarios. El crecimiento de vello en la cara, el engrosamiento de la piel, la voz gruesa, 
eran algunas de las características. A diferencia de Marañón -al cual citaba explícitamente- que señalaba que la libido de las mujeres virilizadas no cambiaba, Lazarte sostenía que en esas condiciones, aparecía en las mujeres una inclinación homosexual "desaparecen los instintos maternales, aparecen otros y sucede que el sexo en su ocaso se dirige hacia la mujer" (Lazarte, 1931b: 18). Para sustentar sus ideas, recurrió a las teorías psicoanalíticas sobre el complejo de Edipo y explicar las relaciones entre yerno y suegra. A través de una mixtura teórica poco ortodoxa, Lazarte intentaba legitimar científica y biológicamente el lugar de la suegra en la sociedad, específicamente, las mala relaciones con sus yernos, pero no así con las nueras, o entre éstas y los suegros. Este problema se resolvería cuando el matrimonio fuera superado por las uniones libres y la ciencia, decía, que "por medio del rejuvenecimiento la transformará en mujer" (Lazarte, 1931b:19).

La Naturaleza, según Lazarte, había definido para las mujeres "la tarea de la reproducción y el deber del amamantamiento y creación del niño", coincidiendo con las narrativas dominantes, y sobre esa característica decía, al igual que Alicia Moreau de Justo, “se fundamentó la desigualdad” (Lazarte, 1936 [1934]: 8).

A través de la misma base científica, Lazarte se propuso legitimar la emancipación femenina a través de la maternidad consciente y voluntaria alcanzada por el control de la natalidad mediante los conocimientos anticoncepcionales que les permitirían practicar la "sexualidad recreativa" (Lazarte, 1936[1934]: 20). A diferencia de las ideas médicas dominantes, para el médico, al igual que los varones, las mujeres deseaban "el amor sexual" antes que "el amor maternal” (Lazarte, 1936 [1934]: 19). Así, entendía la maternidad como un derecho y no como un deber. En este sentido, se oponía a las políticas llevadas adelante por el fascismo y el nazismo, tan celebradas por Beruti, como el servicio obligatorio que valoraba a las mujeres sólo como "productora de hijos" (Lazarte, 1936 [1934]:89). Para Lazarte la revolución sexual estaría completa cuando la mujer fuera "política, económica y fisiológicamente libre" (Lazarte, 1936 [1934]: 154).

La emancipación de las mujeres también sería impulsada por las uniones libres que harían caer en desuso las instituciones del matrimonio y la prostitución. Acusaba a los 
"tratadistas del matrimonio perfecto que se entretienen en los olores". 30 Con esa referencia, hacía alusión -a través de una intertextualidad implícita- a van de Velde, quien no ponía en discusión el carácter construido de la monogamia (Lazarte, 1932: 8). Del mismo modo, incluía también una cita textual de la obra de van de Velde Aversión y atracción en el matrimonio. La cita se refería a la caracterología, pseudociencia que clasificaba el carácter de los varones y mujeres según su constitución. El médico rosarino rechazaba esa disciplina. A lo largo de este artículo, las marcas de cita manifiestan la intertextualidad explícita con la obra de van de Velde quien afirmaba:

Después de todo cuanto llevo expuesto, más de uno de mis lectores se hallará ante la siguiente pregunta: ¿debe, pues, elegirse un esposo (o una esposa) pícnico-ciclotímico de este grupo constitucional, o será preferible que pertenezcan a los leptosoma-esquizotímicos? (van de Velde, 1953 [1939]: 270, en Lazarte, 1932: 60) ${ }^{31}$

Para Lazarte la caracterología era falsa, no existía como ciencia y sólo era utilizada por "apologistas y neosalvadores del matrimonio". Para el médico, esto resultaba peligroso "porque a algunos legisladores "ignorantes" se les podía ocurrir “elevar a leyes obligatorias o compulsivas, hipótesis fantásticas y líricas" (1932: 60). La ciencia no debía responder a cuestiones religiosas sino que debía dedicarse a crear y “destruir lo viejo" (1932: 63).

María Lacerda de Moura, pedagoga anarquista brasileña, amiga de Juan Lazarte, prologó un libro del médico titulado Sociedad y prostitución, editado en 1935, en el cual puso de manifiesto aquellas resistencias que encontraba, entre los compañeros de ideas, la emancipación femenina. Para Lacerda, "el hombre, aún el más avanzado ideológicamente, siente dificultad en romper los lazos de autoridad que la sujetan a la

\footnotetext{
${ }^{30}$ Subrayado en el original.

${ }^{31}$ Lazarte sólo a veces incluía las referencias bibliográficas de los autores que citaba por lo que a través de una lectura cruzada pudimos identificar la referencia de van de Velde.
} 
mujer, subyugándola" (Lacerda de Moura, 1935: 12). Recuperando las palabras de Emma Goldman con las que Lazarte había concluido su trabajo, Lacerda sostenía una postura contraria a la de Goldman: la mujer no tiene "la «noción» ridícula de que ser amada, amante y madre es sinónimo de esclava y subordinada", sino que la causa de esa noción es "la vida social, y la agresividad masculina y la dulzura femenina, es el egoísmo del hombre y el altruismo de la mujer" (Lacerda de Moura, 1935: 14-15). A partir de un reconocimiento de la diferencia sexual, comprendida como un antagonismo entre varones y mujeres, la anarquista brasileña reclamaba derechos femeninos criticando la desigualdad generada por los "derechos patriarcales" (Lacerda de Moura, 1935: 15)

En la revista Cultura Sexual y Física (1938-1941), editada por Claridad y dirigida por Bartolomé Bosio, Manuel Martín Fernández escribió respecto de los roles de género y las conductas expectables para las mujeres. En un artículo llamado "El prejuicio de la virginidad" situaba a la sexualidad como un instinto natural, biológico que no debía reprimirse. Criticaba la falsa moral que exigía a las mujeres algo que para los varones estaba permitido, señalando la influencia de la cultura para determinar derechos y deberes diferenciados genéricamente, interpelaba a sus congéneres:

¿Qué derecho tenemos de exigir a las mujeres la conservación de lo que no somos capaces de conservar intacto en nosotros mismos sin tener que sufrir las consecuencias de haber contrariado la naturaleza? ¿Qué poder podemos invocar, sino el de las leyes bárbaras y absurdas, para pretender, con autoridad de tiranos, que nuestra futura compañera llegue al lecho nupcial "con la pureza de un lirio", mientras nosotros lo hacemos después de habernos cansado de revolcar en las inmundas camas de todos los prostíbulos? (Martín Fernández, 1938: 587)

Dirigiéndose a sus colegas, Martín Fernández les recordaba que, como “médicos "conscientes", si no podían cambiar las bases de la sociedad tenían la responsabilidad de “darles la posibilidad equitativa de gozar del máximum de felicidad y tranquilidad en 
este mundo infeliz" a las mujeres (Martín Fernández, 1938: 588). Estas ideas también las desarrollaba en las consultas sobre temas sexuales. La castidad que pretendían los médicos como Beruti y los que formaban el Consorcio de Médicos Católicos era para él contraria a la Naturaleza y estaba dictada por un presupuesto de roles generizados.

A diferencia de Lazarte, entre las lecturas que exhortaba a leer Manuel Martín Fernández era recurrente la referencia a van de Velde y su libro El matrimonio perfecto. En particular, era recomendado para los varones, para aprender sobre cómo relacionarse sexualmente con las mujeres. También, les aconsejaba Secretos del matrimonio, de Gabriel Mac Hardy y El Matrimonio Moderno, de Edward Griffith, ambos editados por la editorial Claridad. Si bien puede pensarse la recomendación de estas lecturas como una estrategia de venta, lo cierto es que más adelante, en el consultorio Hombre de América, no vuelve a recomendar a ninguno de esta/os autora/es y recomienda otra/os opuestos a las ideas de van de Velde, como Hildegart Rodríguez o Humberto Salvador, que hacían hincapié en la dimensión del placer sexual por fuera de los límites del matrimonio. Estos cambios en las lecturas nos permiten conjeturar alguna influencia de Juan Lazarte en el discurso de Martín Fernández o nuevas incorporaciones en su acervo. Sobre los roles sexuales suscribía a las teorías de Humberto Salvador, abogado ecuatoriano que escribió Esquema Sexual en 1934, sobre la base de su tesis para alcanzar el grado de doctor en jurisprudencia. Es curioso que Martín Fernández recurriera a un abogado y no a un médico como Marañón, al que igualmente conocía y citaba en relación a los estados intersexuales. Podemos pensar que, en ese momento, Marañón ya no era defendido por los sectores progresistas, sino que había buscado refugio en sectores conservadores, debido a su posición política.

La tesis que retoma Martín Fernández describía las diferencias anatómicas de varones y mujeres haciendo hincapié en la distinción entre sexualidad y genitalidad, dándole importancia a la libido y el orgasmo. La influencia del psicoanálisis era más notoria en el médico santiagueño que en Lazarte, pues consideraba que la falta de satisfacción sexual, generaba en las mujeres problemas de histeria y neurosis. En cuanto a los roles de las mujeres, sostenía que si bien era necesario "un cambio en la concepción social de la mujer” (Martín Fernández, 1940f: 36), que hasta el momento había progresado en cuanto a libertades y se encaminaba "cada vez más a la igualdad" con el varón, no debería perder la "femineidad propia de su constitución biológica") 
(Martín Fernández, 1941b: 36). Adhería, así, a visiones cercanas a los roles normativos dominantes. Establecía que las mujeres eran "eminentemente" amorosas, pasionales, sentimentales, delicadas y susceptibles. Por ello, desde la infancia hasta su madurez, eran más proclives a las "manifestaciones sentimentales" (Martín Fernández, 1941b: 37). Consideraba que éstas no eran inferiores a las aptitudes de los varones sino "equipotenciales", aunque "la carga biológica" se encontraba "desigualmente repartida" (Martín Fernández, 1942b: 17). La sociedad y la "educación domesticadora y esclavista" las deshumanizaba y las desnaturalizaba imponiéndole "obligaciones morales" (Martín Fernández, 1942a: 23). Entre ellas, aceptar la maternidad aunque no quiera, la vida sedentaria en el hogar y el desconocimiento de la vida sexual. Contra estas exigencias afirmaba:

Pero la mujer, equipotencial al hombre, tan humana como él, es un ente social que tiene derechos propios que la sociedad debe reconocer y que, si ésta no reconoce, ella, consciente de su valor, de su dignidad, de sus posibilidades, debe conquistar. Derechos a sí misma sus más íntimos satisfacciones, a su equilibrio psico-orgánico, a todos los aspectos de su posible felicidad. Derechos primordiales que, en el estado actual de las cosas, en que hay que empezar por lo primero, son mucho más importantes que todos los otros derechos, sociales y políticos. (Martín Fernández, 1942b: 18).

En esta lógica, Martín Fernández recuperaba las críticas de las libertarias -como Juana Rouco en sus diatribas contra las feministas sufragistas de su época- para con los derechos vinculados a una lógica liberal a los que ellas se contraponían por considerarlos secundarios frente a otros que eran principales. Entre esos derechos de mayor jerarquía, los vinculados a romper con los estereotipos de género y a garantizar a las mujeres la facultad de autonomía sobre sí, ocupaban un lugar relevante en el ideario médico libertario. Al mismo tiempo, encontraban justificación en teorías como la eugénica que encontró -como veremos en el próximo capítulo- sus reflexiones culminantes en torno al control de la natalidad. 
Llegados a este punto, podemos considerar que, tempranamente, desde fines de siglo XIX, las críticas de las libertarias hicieron hincapié en la arbitrariedad de la asignación de roles y la subordinación de las mujeres. Ya en el siglo XX, y desde la década del 30 con el viraje de las estrategias libertarias, estas ideas fueron tamizadas y legitimadas por el discurso médico. En suma, si bien estas alocuciones ácratas no cuestionaron las diferencias biológicas como construcciones discursivas y tomaron al sexo como un dato biológico, sí cuestionaron la jerarquización de esas diferencias y señalaron el carácter construido de las derivaciones sociales que se establecían a partir de ellas. Vale decir, parafraseando a Olsen, no cuestionaron la sexualización biológica, atacaron los parámetros de sexualización social y la jerarquización implícita en ellos.

\section{Conclusiones}

A lo largo del capítulo hemos señalado los desplazamientos que encontramos dentro del campo médico en relación con la diferencia sexual y los roles sociales a través del repaso de diversos posicionamientos discursivos. Primeramente, revisamos las teorías imperantes en cuanto a la diferencia sexual a través de los discurso de van de Velde y Marañón, que desde su incidencia en la literatura popular y médica motivaron acuerdos y rechazos por parte de la elite médica argentina. En este sentido, para analizar estas intertextualidades, nos ocupamos del discurso de los médicos dominantes representados por Josué Beruti, autoridad médica reconocida desde el ámbito universitario, entre otros y algunos médicos del Consorcio de Médicos Católicos. El repaso por estas narrativas nos permitió ir ubicando en el orden social discursivo las posiciones dominantes y las excluidas, a través de los diversos procesos de neutralización, como así también admitió avanzar sobre las diversas adaptaciones y apropiaciones de los postulados médicos según los posicionamientos políticos e ideológicos que evidencian el carácter construido y subjetivo de la ciencia.

Para ello, seguidamente, repasamos las ideas de una médica feminista a través de los discursos de Alicia Moreau de Justo que fueron conformando el orden social discursivo sobre la diferencia sexual y los roles desde la perspectiva médica, lo cual nos permitió analizar la incidencia de la agencia feminista para plantear la diferencia sexual como fundamento legitimador de la emancipación femenina. 
Por último, nos enfocamos en los discursos de los médicos ácratas que nos permitió situarlos discursivamente dentro del campo médico y señalar las intertextualidades con los discursos dominantes en relación con la adscripción al paradigma de la dicotomía sexual.

El análisis de las narrativas de los profesionales de la salud que participaron del movimiento y la aceptación y la difusión de esas modulaciones por el anarquismo nos permite, por un lado, evidenciar las construcciones sociales que intervienen en los significados que adquirieron la diferencia y desigualdad sexual. En este sentido, compartimos las ideas de Joan Scott, cuando señala que:

las discusiones sobre el significado conllevan la introducción de nuevas oposiciones, la inversión de jerarquías, el intento de exponer términos que se han suprimido, de desafiar el estatus natural de los aparentes pares dicotómicos, y la presentación de su interdependencia e inestabilidad internas. (Scott, 2008: 26)

El análisis de los discursos ácratas permite deconstruir ciertas nociones establecidas nos permiten mostrar las adaptaciones, las intertextualidades, las inflexiones y las continuidades de los paradigmas científicos. Las mismas adquieren diversas representaciones según las posiciones ideológicas de quienes las presentan y las relaciones de poder que los atraviesan.

A lo largo del capítulo hemos afirmado lo disruptivo del discurso médico anarquista respecto de las voces dominantes e, incluso, de sus propias compañeras de militancia. Sin embargo, retomando a Judith Butler, nuestra hipótesis considera que al no refutar "el carácter invariable del sexo"-que implicaba cuestionar los propios fundamentos de su intervención en el campo médico legitimados en la biología- los médicos libertarios quedaron entrampados en la falta de cuestionamiento al anclaje cultural de la construcción de los sexos. Al hacerlo, no lograron quebrar, tampoco, las imposiciones heteronormativas que iban asociadas a aquel dimorfismo sexual. Asimismo, aunque dislocaron el par binario "mujer-femenino" tal como había sido 
expresado por las visiones dominantes, no lograron conmover aquello que se consideraba como "prediscursivo": "la superficie políticamente neutral sobre la cual actúa la cultura"; es decir que, al igual que las feministas, no lograron concebir el sexo como construcción de género (Butler, 2007: 56-57).

Lejos de pretender incurrir en un anacronismo al exigirle al anarquismo giros que sólo se han desplegado en décadas más recientes en torno a la consideración de lo biológico como constructor, nos interesan señalar, más bien, las tensiones implícitas que se generaron en el discurso anarquista al avanzar sobre un eje de esa problematización. Ese recorrido significó un punto de quiebre insoslayable, pero, a su vez, su propia limitación en el aporte que pretendían formular respecto de los roles de género. En este camino, también, nuestra lectura exige corrernos de una mirada romántica que invisibilice estos aspectos problemáticos que tuvo un discurso que, en relación con estos temas, ha sido más bien exaltado por la positiva que explorado en sus contradicciones. 


\section{Capítulo 3}

\section{Los usos de la eugenesia: La propuesta anarquista sobre el control de la natalidad}

Hacia fines del siglo XIX la intervención en la reproducción de la población se legitimó a través de un nuevo paradigma que adquirió carácter de cientificidad. Eugenesia fue el término elegido por el inglés Francis Galton (1822-1911) para expresar "la ciencia de la mejora de la materia prima" que, para su aplicación, tomaba:

conocimiento de todas las influencias que tienden, aunque sea en el grado más remoto, a dar a las razas o linajes de sangre adecuados, una mayor posibilidad de prevalecer, con más rapidez que lo que normalmente pudieran hacer, sobre los menos adecuados. (Galton, 1883, en Álvarez Peláez, 1988: 104)

Dos estrategias fueron indicadas para lograr la mejora de la raza: 1) "facilitar" la reproducción de los que más se ajustaran al ideal racial, y 2) “frenar" la reproducción de los que se desvían del modelo, hasta donde esto puede ser posible y practicable (Galton, 1883: 95). A partir de esta distinción y la polémica entre nature-nurture (naturalezacrianza), iniciada por Galton a partir de sus investigaciones en historiales de gemelos, en las cuales sostuvo "la vasta preponderancia de los efectos de la naturaleza sobre los de la crianza" (Galton, 1883: 126) la eugenesia adquirió diversas características según los paradigmas ideológicos que la idearan o la practicaran (Stepan, 1991).

A partir de su enunciación, la difusión de la eugenesia fue vertiginosa y en la Argentina se materializó, entre otros medios, a través de las redes de intercambio científico (Miranda y Vallejo 2005; 2007; 2012). Dentro de estas redes, los profesionales médicos cumplieron un rol destacado. Ellos formaron parte de la 
intelectualidad moderna, que se fue conformando en el proceso de institucionalización y profesionalización de la vida cultural nacional.

Si bien el campo médico no se presenta como una unidad homogénea sino que en su interior se encuentran posiciones dominantes y dominadas (Bourdieu, 1990), en el caso de las investigaciones nacionales sobre el despliegue de la eugenesia, esta diversidad de posicionamientos no se ve reflejada. Las pesquisas, aunque reconocen aquella adscripción variada de las ideas eugénicas, en su mayoría han centrado su interés en la eugenesia pensada e implementada por los miembros de la "cultura científica" de las primeras décadas del siglo XX, con especial énfasis en los provenientes del sector médico, jurídico y político que participaron en los procesos de institucionalización de la eugenesia desde lugares de poder, como el ámbito académico como así también en las estructuras estatales (Terán, 2000).

En los diversos estudios sobre el desarrollo de la eugenesia prevalecen dos perspectivas interpretativas. Por un lado, las investigaciones que, tomando como nivel de análisis las prácticas efectivamente realizadas, concluyen que la eugenesia que primó fue positiva. Es decir, la preocupación por perfeccionar la población se evidenció a través de medidas de reforma social que se abocaron a producir mejoras en el medio y a combatir las enfermedades incidiendo en la modificación de comportamientos.

Por otro lado, otro grupo de investigaciones, desarrolladas en la última década, han complejizado aquella mirada y han indicado que la eugenesia no se define por sus medios sino por sus fines. En el caso del discurso dominante, el fin perseguido era el control social. Así esta perspectiva, relaciona los discursos locales con las prácticas desarrolladas en el contexto europeo fascista.

Ambas posturas han indicado - para evidenciar el alcance de la eugenesia- la participación del anarquismo en este horizonte de sentido, pero estas menciones no han derivado en análisis exhaustivos sobre esta vertiente eugénica. Igualmente, cuando se trae a escena la propuesta ácrata es para señalar el contraste con los discursos dominantes en relación con las ideas sobre el control de la natalidad y el carácter voluntario de sus proposiciones eugénicas. 
Las investigaciones señalan que debido a la "neutralización" del anarquismo en tanto movimiento, dentro de un contexto represivo, también, se habría visto opacada su impronta eugénica por la hegemonía de la biotipología hacia la década del 20. El proceso de "derechización" de la eugenesia, entre las décadas del 20 y 30, sostienen estos trabajos, produjo la reducción de las propuestas de reforma social, las cuales iban feneciendo al igual que las manifestaciones anarquistas que las sustentaban (Vallejo y Miranda: 2004; Stepan, 1991; Miranda, 2005a). Esta escasa pervivencia de las ideas anarquistas y su desaparición anterior al período considerado de consolidación de la eugenesia en la Argentina, según estos análisis, tornan poco atractiva la indagación sobre la eugenesia ácrata. Asimismo, teniendo en cuenta la teoría crítica de los estudios subalternos, este escaso interés se explica por la pervivencia de una ideología que pone en el centro de la escena al Estado.

Según Ranahit Guha, la ideología para la cual la vida del Estado es central para la narración histórica, que denominó "estatismo", es "la que autoriza que los valores dominantes del Estado determinen el criterio de lo que es histórico" (Guha, 2002:17). En este sentido, podemos decir que las investigaciones nacionales han seguido este modelo de análisis y se han ocupado de la eugenesia interpelada desde el Estado y sus agencias de poder. Así, el interés de la mayoría de las investigaciones se ha concentrado en la fuerte intervención de los postulados eugénicos en el diseño de políticas públicas, en su incidencia en la delineación de leyes y en la participación de la élite médica y jurídica en el poder estatal para llevar adelante estas intervenciones.

Los trabajos que de manera tangencia o integral analizan la propuesta anarquista en relación con el control de la natalidad son aportes relevantes. Sin embargo, en su mayoría sus análisis se concentran en la figura de Juan Lazarte y su obra La Limitación de los nacimientos ${ }^{32}$ (1934) y remarcan el cariz político-eugénico de la propuesta (Barrancos, 1990; Nari, 2004; Biernat, 2005a). Si bien algunos estudios señalan que el control de la natalidad garantizó una "mayor autonomía a las mujeres" (Barrancos, 2007: 478) no se profundiza en este aspecto. Del mismo modo, cuando se señalan las ideas de libertad sexual, estas miradas se concentran en las primeras décadas del siglo XX y le restan continuidad al movimiento (Miranda y Vallejo, 2003). Otros aportes

\footnotetext{
${ }^{32}$ Luego en las sucesivas ediciones el título cambió a El contralor de los nacimientos.
} 
evidencian la eugenesia anarquista, señalando el apoyo de Juan Lazarte a la práctica de esterilizaciones (Armus, 2007), diferenciándolo de las prácticas nazis (Miranda, 2011).

Estos ineludibles aportes han hecho hincapié en el vínculo entre las ideas sobre el control de la natalidad con los intereses eugénicos, pero no han avanzado en las ideas en relación con la libertad sexual que también conllevaba la propuesta eugénica de control de natalidad. En este capítulo nos interesa indagar las ideas sobre el control de la natalidad de los médicos ácratas vinculadas a las premisas eugénicas que postularon para legitimarlo. También nos importa señalar, las vinculaciones con un discurso de emancipación sexual, el cual indagaremos en los sucesivos capítulos. Entendemos, desde una perspectiva de género, que a partir de la consolidación del pensamiento eugénico anarquista local, a través de su propuesta de control de la natalidad, fortaleció y legitimó el derecho de las mujeres a decidir sobre su capacidad de gestar y su derecho al placer sexual sin que interviniera la reproducción. Estas cuestiones se indagarán en profundidad en los dos capítulos siguientes sobre la maternidad consciente y voluntaria y el placer sexual.

Nuestra hipótesis en este capítulo apunta a resignificar las miradas sobre las distintas dimensiones del concepto control de la natalidad y, a su vez, evidenciar no sólo las semejanzas y las diferencias que el anarquismo tuvo respecto de otras miradas en el ámbito médico, sino, también, evidenciar sentidos interpretativos distintos respecto del uso que los libertarios hicieron de las nociones eugénicas para justificar la facultad de las mujeres de decidir sobre su propio cuerpo y su capacidad reproductiva.

Para ello, nos proponemos, en primer lugar, siguiendo nuestra perspectiva relacional y atendiendo al orden social discursivo que pretendemos recrear para situar en él las lociones ácratas, explorar las ideas y las prácticas en torno al control de la natalidad del discurso dominante dentro del campo médico. A través del repaso de la bibliografía específica y el análisis de algunas fuentes representativas indagaremos el discurso eugénico sobre los métodos anticoncepcionales y el aborto. En segundo lugar, señalaremos, brevemente, las argumentaciones provenientes de las voces médicas feministas en relación con el control de la natalidad y su vinculación con la eugenesia. Por último, nos centraremos en los discursos médicos ácratas en relación con los temas a trabajar y apuntaremos los puntos de acuerdo y las divergencias con las demás posiciones dentro del campo médico. En este sentido, siguiendo a Richard Cleminson, 
consideramos al anarquismo no como un movimiento progresista, racional y científico sino "como un conjunto de prácticas y discursos posiblemente contradictorios o en vías de construcción bajo múltiples influencias" (2008: 14). Un movimiento polifacético, donde las contradicciones y los procesos sociales en los cuales se desarrolla son elementos constitutivos e intrínsecos de su devenir. De manera que el apoyo a medidas coercitivas de la eugenesia, como las esterilizaciones, debe entenderse dentro de ese marco.

\section{El discurso eugénico dominante}

La mayoría de los estudios sobre la eugenesia en Argentina acuerda que la vertiente eugénica latina-neolamarckiana ${ }^{33}$ fue la que primó en el país. Señalan, asimismo, que casi todo el espectro médico, adhiriendo a esta perspectiva, propuso "medidas de profilaxis, higiene y saneamiento ecológico, más acordes con la tradición y la sensibilidad de la cultura itálica y católica" (Biernat, 2005a: s/n), frenando los alcances de medidas negativas, como esterilizaciones y abortos eugénicos (Nari, 1996).

\footnotetext{
${ }^{33}$ Juan Baptiste Pierre Antoine de Monet, caballero de Lamarck (1744-1829), a principios del siglo XIX sostuvo su teoría del "transformismo". Ésta señalaba, principalmente, que los cambios inducidos en el organismo desde afuera podían producir cambios sobre las futuras generaciones, causando así la transmutación. Más tarde, cuando Darwin publicó The origin of Species (1859), el lamarckismo cobró popularidad siendo una explicación alternativa a la teoría de la evolución de Darwin. Otras teorías compitieron con la explicación lamarckiana. En 1890, el trabajo del biólogo alemán Augusto Weismann sobre la continuidad del "germ plasm", afirmaba la transmisión de material hereditario de una porción de la célula de una generación a otra, sin alteración por influencias externas. En 1900 el redescubrimiento de las leyes de Gregorio Mendel sobre la segregación independiente y la recombinación de los caracteres heredados en las plantas, que demostró la estabilidad de los caracteres durante los cruzamientos genéticos y su reaparición en las sucesivas generaciones, parecía confirmar las tesis de Weismann. Las disputas con estas teorías, en particular la de "germ plasm", forzaron al Lamarckismo a experimentar con más precisión para contrastar las leyes de la herencia. Así, a principios del siglo XX, el lamarckismo se transformó en neo lamarckismo y continuó siendo empleado dado que era una alternativa razonable en el contexto de incertidumbre de los conocimientos genéticos (Stepan, 1991). Empero, a diferencia de lo que proponía Wiesmann, el lamarckismo, siguió sosteniendo que los cambios, eran sutiles, internos, de adaptación del organismo al medio.
} 
La influencia del pensamiento católico, entre las elites en particular, a partir de la relevancia otorgada a la encíclica Casti Connubi ${ }^{2}$ (1930) promulgada por el papa Pío XI -en la cual expresó su oposición a cualquier prohibición matrimonial, a cualquier método anticonceptivo y el aborto- provocó que quienes promulgaban la eugenesia preocupados por el aumento de la cantidad de la población sin desestimar la calidad de la misma, diseñaran diversas estrategias para superar la contradicción. En ellas, las mujeres fueron el eje central de las propuestas al ser consideradas como las responsables directas de la reproducción de la especie, así como instrumento imprescindible para mejorar y educar en los saberes eugénicos a sus descendientes.

Igualmente, otros estudios han indagado, otras voces dentro de la elite médica menos influenciadas por el pensamiento católico, que practicaron medidas consideradas negativas, como la esterilización o el aborto por razones eugénicas (Eraso, 2007).

En esta línea, se encuentra Josué Beruti, que sin explicitar la puesta en práctica de sus ideas, sí tenía un posicionamiento discursivo que simpatizaba, por ejemplo, con las prácticas esterilizadoras llevadas a cabo en la Alemania nazi. Sin embargo, este profesional se concentró en llevar adelante una campaña de maternalización de la mujer desde un programa de educación eugénica. Así se alcanzaría el perfeccionamiento de la raza sin intervenir directamente en la capacidad reproductiva de los cuerpos.

En el próximo capítulo ahondaremos en las políticas diseñadas e implementadas por este profesional que, como parte de la ecología institucional, intervenía en la planificación de las políticas públicas. En este capítulo nos interesa señalar la eugenesia profesada Beruti y sus argumentaciones en torno al control de la natalidad a través de su posicionamiento sobre la utilización de métodos anticonceptivos, la esterilización y el aborto. Este repaso nos permitirá analizar las adaptaciones de la eugenesia según los posicionamientos ideológicos de quienes la sustentaban.

\section{1.a El control de la natalidad}

Dentro del programa de Beruti, el perfeccionamiento de la raza se llevaría a cabo a través de la estrategia pedagógica, sin embargo, también apoyó estrategias para controlar la natalidad, para alcanzar aquel ideal. Reconocía que los temas de control o 
regulación eran tópicos problemáticos, que no debían locutarse para el conocimiento de la población en general, sino que, indicaba, "no deben salir, a mi juicio, del círculo silencioso y discreto de los investigadores científicos" (Beruti, 1932, en Beruti, 1943 T. III: 489). Las mujeres no tenían derecho a acceder a la información anticonceptiva. Sólo los profesionales médicos, si podían argüir una razón eugénica, autorizaban el control de la natalidad.

La vigilancia sobre las mujeres era fundamentado en la "la ignorancia de su vida biológica”. El control voluntario de los nacimientos era la prueba de ello según Beruti, quien expresaba que "si la mujer comprendiera alguna vez cuál es su exacta posición biológica entre los individuos", muchos problemas sociales estarían resueltos, entre ellos "la restricción voluntaria de los nacimientos". La solución a éste y otros problemas estaría dada por la aplicación de los principios de la eugenesia junto con la "educación sanitaria" (Beruti, 1941, en Beruti, 1943, t. III: 370) Para ello, hacía un llamado a llevar adelante una "campaña maternal" eugénica que tenía como principio fundamental establecer "el binomio indestructible" -madre-hijo- (Beruti, 1934a, en Beruti, 1943 T. III: 573).

El foco estaría puesto en las madres pobres, "sin ética sexual", débiles, que transmitían esa debilidad a su descendencia. Con estas madres, decía "no es posible hacer obra eugénica" que era una cuestión fundamental primero, "porque la situación de ignorancia y de falta de educación de las madres lleva aparejado la contemplación del más grande de los problemas médico-sociales: el de la miseria y todos sus derivados". En segundo lugar, sostenía, "porque aparece de inmediato el problema tan debatido y tan complejo de la propagación de la especie, problema éste que en todo plan de protección materna debe estar en la primera fila" Esta última cuestión "escabrosa" (Beruti, 1934a en Beruti, 1943 T. III: 578) lo llevaba a sostener que había que ocuparse:

más que en disminuir la especie y en limitar la procreación, en procurar los medios y luchar en pro de la obtención de todo aquello que nos lleve a la modificación de las causas influyentes o determinantes, contribuyendo así a la solución del dilema maternal, en cuanto a la indestructibilidad del binomio y a la relación del número de hijos se refiere, y a la ley eugénica, en 
su principio de mejoramiento de la especie. (Beruti, 1934a, en Beruti, 1943, t. III: 577-578)

Sin embargo, invitado a responder una encuesta sobre el tema de la limitación de la fecundidad por la revista Acción Médica, Beruti puso de manifiesto su posición en relación a los motivos que podrían incidir en su puesta en práctica. A la primera pregunta: “¿Hay casos en los que el médico esté obligado a indicar la limitación de la fecundación y evitarla?”, el profesional afirmó que se debía intervenir, sin discusión, en caso de que la salud o la vida de la mujer corrieran algún riesgo a causa de un embarazo. El segundo cuestionamiento avanzaba en revelar los métodos que debían prescribirse en caso de que la primera respuesta hubiera sido afirmativa. En este punto, la seguridad con que se expresó el médico anteriormente, se vuelve en un discurso evasivo. A través de circunlocuciones, demora la respuesta y finalmente la deja sin contestar, aduciendo que el tema es "complejísimo" dado el problema de la “interrupción deliberada de la concepción”. Hasta el momento, afirmaba, no hay ningún método "infalible", sólo la castración o la abstinencia, por ello, el médico no puede prescribir un solo procedimiento. La elección, decía, dependerá de la "oportunidad” y de los "factores individuales" que rodean el caso, y al no haber, según él, pruebas suficientes sobre la efectividad de algún método, lo que corresponde es "proceder con mucha cautela" e intercambiar experiencias entre colegas (Beruti, 1934c, en Beruti 1943 T. III: 452).

Por último, la encuesta interrogaba “¿Entraña un peligro o es un bien social la prescripción de esos métodos para evitar la fecundación?”. Aquí nuevamente era enfático y afirmaba que la indicación médica para limitar la fecundidad era "un bien social porque no sólo se salvaguarda la salud de muchos seres, sino que se evita el nacimiento de muchos otros condenados casi siempre a una vida orgánica precaria" (Beruti, 1934c, en Beruti, 1943 IV: 452-453) Sin embargo, se apresuraba a aclarar que si la limitación gestacional tenía origen en cuestiones sociales y económicas esas causales eran discutibles. Primero, había que ocuparse de "los problemas médicosociales positivos antes de entrar en el escabroso y peligrosísimo terreno de los neomalthusianos" (Beruti, 1934c, en Beruti, 1943 T. III: 453). No obstante, consideró 
que el momento histórico no hacía oportunas aquellas intervenciones por indicación médica:

en Argentina, la eugenesia negativa no tiene, por el momento, razón de ser. La eugenesia positiva que tiende, no a eliminar lo malo, sino a buscar y a superar lo bueno con paciencia, perseverancia y sabiduría, abre [...] un enorme campo de acción práctica. (Beruti, 1934c en Beruti, 1943: 453)

Otras cuestiones eran más urgentes, como la higiene de la raza, la educación eugénica femenina y masculina y la protección maternal. Según evaluaba, el país no estaba "en el crepúsculo biológico de una raza" sino que por el contrario, vivía "en su amanecer" (Beruti, 1934c, en Beruti, 1943: 453-454). Junto a Alberto Peralta Ramos, reafirmaba que todavía no era el momento para debatir sobre "el problema de la licitud o de la ilicitud de los medios anticonceptivos y, por ende, la grave controversia sobre cantidad", porque, decían, la eugenesia no se había asentado como paradigma (Beruti y Peralta Ramos, 1935 en Beruti, 1943: 507).

Dentro esta perspectiva, también se encontraban mujeres, como la médica Mercedes Rodríguez de Ginocchio, que secundaban las propuestas eugénicas de Beruti a través de la defensa de una "educación sexual eugénica maternológica". La misma comprendía controlar los instintos sexuales para prevenir las enfermedades venéreas con el fin de impedir la degeneración de la raza y la exaltación de la maternidad. Retomando las resoluciones del Primer Congreso de Población, realizado en 1940 bajo el auspicio del Museo Social Argentino, señalaba que se debían combatir las prácticas y la propaganda anticoncepcional que provocaba un estado psicológico de pánico a la maternidad y de abandono del hogar (Rodríguez de Ginocchio, 1941).

Como señala Marisa Miranda, estas posturas eugénicas intentaban eliminar el azar en la reproducción, pero "ante la indisolubilidad del vínculo matrimonial y la impugnación al birth control" (2011: 55) debían poner en práctica recursos anticipatorios para alcanzar aquel objetivo, como el certificado prenupcial. El mismo se proclamó en 1936, mediante la ley $\mathrm{N}^{\mathrm{o}} 12331$ de "creación del instituto de profilaxis de 
las enfermedades venéreas", sancionada el 17 de diciembre de 1936 y publicada en el Boletín Oficial el 11 de enero de 1937. En el artículo 13 decía:

Las autoridades sanitarias deberán propiciar y facilitar la realización de exámenes médicos prenupciales. Los jefes de los servicios médicos nacionales y los médicos que las autoridades sanitarias determinen, estarán facultados para expedir certificados a los futuros contrayentes que los soliciten. Estos certificados, que deberán expedirse gratuitamente, serán obligatorios para los varones que hayan de contraer matrimonio. No podrán contraer matrimonio las personas afectadas de enfermedades venéreas en período de contagio. (Boletín Oficial, 1937: 258)

Las mujeres no estaban obligadas a realizar el examen para contraer matrimonio pues se consideraba que ellas -fieles a las prescripciones de los mandatos sociales- no habían tenido relaciones sexuales antes de casarse y, en ese caso, sería una ofensa a la moral obligarlas a ellas también a ser inspeccionadas (Biernat, 2007b; Grammático, 2000; Guy, 1998). El mismo se extendió para ellas en 1965 mediante la ley Nº16.668.

Otro sector dominante del campo médico estaba conformado por los católicos que, si bien no contradecían la mayor parte de los argumentos de los médicos como Beruti, tuvieron divergencias en este punto a raíz del sesgo que lo confesional producía en torno a su mirada sobre la eugenesia y el control de la natalidad.

En relación con el control voluntario de la natalidad, los médicos católicos coincidían con los planteos de Beruti, pero la cuestión que marcaba las tensiones dentro del campo médico dominante era su oposición al aborto o la esterilización por razones terapéuticas y eugénicas.

Para hacer frente a la "degeneración” de la especie, los médicos católicos -como señala Ana María Rodríguez- se ocuparon de fortalecer "la familia cristiana" que "sería la garantía de los intereses de la nación y de la raza" (2009: 3). Para ello, como veremos en el capítulo siguiente, entre otras estrategias morales, se abocaron a convertir a la 
maternidad en una obligación divina de las mujeres a través de la prohibición de cualquier acción que atentara contra la reproducción.

La utilización del "wording” (Fairclough, 1992: 76) "esterilización temporaria” en lugar de "métodos anticoncepcionales", "métodos restrictivos" o "interrupción gestacional" -como expresaba Beruti-, ponía de manifiesto la posición ideológica y política de los médicos católicos en el debate sobre el control de la natalidad. En este sentido, el médico Benjamín Galíndez (1939), señalaba que no se condenaban los fines de la eugenesia, sino los medios a través de los cuales se ponía en práctica. La descripción de los diversos "métodos de esterilización temporaria" incluía la esterilización por cirugía, rayos $\mathrm{X}$ y dosis de Radium. Como métodos todavía en estudio se encontraba el método Ogino-Knauss y la esterilización biológica a través de inyecciones de esperma. Cada uno de ellos era legítimo si su uso estaba indicado por una cuestión médica. Pero indicaba:

va de suyo que para recurrir a ella, se requiere haber agotado otros medios terapéuticos sin obtener resultado o bien que la gravedad de las circunstancias no permitan una mayor dilación y a juicio del médico sea el único recurso de que se pueda echar mano. (Galíndez, 1939: 34-35)

En el capítulo anterior hemos mostrado la prohibición, a través de la voz de Castaño, de la difusión del método Ogino-Knauss, invocando cuestiones morales anticristianas y egoístas. Pero también otra estrategia de neutralización discursiva fue la deslegitimación del procedimiento. Para ello se recurrió a poner en duda o negar su efectividad desde una perspectiva científica. Así lo hicieron -además de Galíndez-, los médicos Enrique Linzoain y Emilio Colombo (1939) del Instituto de Maternidad de la Sociedad de Beneficencia. Ambos profesionales, desde su experiencia, indicaban que la utilización del método no había impedido los embarazos, sus estadísticas lo demostraban. Los análisis sobre el ciclo menstrual de las mujeres indicaban que por cada ciclo maduraba más de un folículo y no se podían definir claramente los períodos de fertilidad e infertilidad de la mujer. 
La utilización de algún método para controlar voluntariamente, sin prescripción médica, la capacidad reproductiva era cuestionada por médicos como Beruti y los católicos. Sin embargo, las mayores divergencias dentro del campo médico dominante surgieron en relación al aborto terapéutico y eugenésico y la esterilización definitiva.

\section{El aborto por razones terapéuticas y eugénicas}

Entre las prácticas anticonceptivas más comunes entre los años 20 y 30, como señalan Marcela Nari (1996) y Dora Barrancos (2007), se encontraba el coito interruptus y la utilización de preservativo masculino. Es decir, métodos que dependían de la voluntad del varón. El aborto era la "la única instancia que poseían las mujeres, especialmente de las clases trabajadoras, para controlar su fecundidad" (Nari, 1996: 65). Si bien la práctica se encontraba penalizada desde fines de siglo XIX, en 1921, la sanción de la ley 11.179, sobre la modificación del Código Penal de la Nación, establecía dos incisos en los cuales implantaba los abortos no punibles por razones terapéuticas (peligro de vida o de la salud de la madre) y por razones eugénicas (violación de una mujer "demente o "idiota"). Ambos fueron modificados en diferentes momentos en el transcurso de los años, lo que evidencia, por un lado, las tensiones y conflictos en torno a los derechos de las mujeres $\mathrm{y}$, por otro, la influencia de la eugenesia en los discursos legislativos.

El primer inciso aborda los abortos terapéuticos y el segundo, los abortos eugénicos. La comisión formada por los senadores Joaquín V. González, Enrique del Valle Iberlucea y Pedro A. Garro, propuso modificaciones al proyecto tratado en la Cámara de Diputados en el informe elevado a la cámara el 23 de septiembre de 1919 y tratado el 23 de septiembre de 1920. Los senadores, tomando como ejemplo el código suizo, retomado por el reconocido penalista español Jiménez de Asúa, recomendaron la incorporación de los abortos no punibles, que no figuraban en el proyecto original. Las razones que se esgrimían para argumentar el primer inciso (aborto terapéutico), decían, no tenía más explicación que "cuando el aborto es indispensable para la salud o la vida de la madre, no constituye delito" (González et al., 1919, en Diario de Sesiones cámara de Senadores, 1920: 958). El segundo inciso, que avanzaba sobre la despenalización en caso de la violación de cualquier mujer y el incesto, era justificado a través de razones 
eugénicas. Adhiriendo a las ideas planteadas por Jiménez de Asúa, los legisladores señalaban que "es indiscutible que la ley debe consentir el aborto cuando es practicado con intervención facultativa, a los fines del perfeccionamiento de la raza". Este problema, decían, se planteó en Europa cuando, durante la guerra, muchas mujeres belgas fueron violadas por soldados "ebrios, desenfrenados o criminales" (González, et al. 1919, en Diario de Sesiones cámara de Senadores, 1920: 958). ${ }^{34}$

Si bien la aprobación final de las reformas al código penal restringió las posibilidades de abortos no punibles a los casos de violación de una mujer "demente" o “idiota", la cuestión generó debates subsiguientes. Por ejemplo, Barrancos (2007) ha señalado la realización de un aborto no punible en 1945 a una mujer que había sido violada en el hospicio de alienados Colonia Oliva en la provincia de Córdoba, lugar donde estaba internada. Los profesionales que realizaron la práctica fueron denunciados por el capellán del hospicio. Luego, fueron llevados a juicio y condenados a tres años de prisión e inhabilitación profesional por seis años. Las razones aducidas eran que la mujer, al ser mayor de edad, debía autorizar su propio aborto y el padre no había hecho una presentación legal para decidir por ella. Sin embargo, luego de asumir como presidente, Juan Domingo Perón concedió el indulto a los tres médicos. Este hecho refleja, según Barrancos, que las políticas del peronismo no fueron pronatalistas.

Ahora bien, en ese contexto, las voces de los médicos dominantes como Beruti y Alberto Peralta Ramos, apoyaron estas medidas a diferencia de los médicos confesionales. Para Beruti, el problema en relación al aborto se presentaba cuando era producto de un acto voluntario, al que se catalogaba como "aborto provocado criminal". $\mathrm{Su}$ práctica -junto con "el aumento de mujeres solteras, matrimonios tardíos, enfermedades esterilizantes, prácticas neomalthusianas"- era la causa de la baja en la tasa de natalidad (Beruti, 1922 en Beruti 1943 T. III: 528). En este sentido, consideraba que todas las mujeres abortaban "casadas y solteras" y entre ellas, decía, las hay “pudientes y menesterosas". Pero si "la casada pudiente" decidía abortar, según el

\footnotetext{
34 Algunas investigaciones han distinguido las intervenciones de Del Valle Iberlucea dentro de la Comisión, en particular en lo atinente a que propició la emancipación femenina a partir del aborto (Becerra, 2009). Sin embargo, consideramos que esta figura estuvo lejos de involucrar en su ecuación los términos eugenesia, aborto y emancipación femenina. Más bien, se ocupó de eugenesia y aborto, por un lado y, por el otro, de emancipación femenina. El tándem entre esa tríada, como se verá más adelante en este capítulo, fue explícitamente enunciado por Juan Lazarte.
} 
médico, no modificaría su decisión por más que le ofrezcan la posibilidad de abandonar a la niña o niño bajo el amparo del torno libre. Igualmente, "la casada pobre" que perdía generalmente su primer embarazo por razones de salud, en el segundo embarazo, si no podía hacerse cargo, no iba a aceptar la entrega de su hija/o porque en ella, señalaba el profesional, ya había "germinado" el "sentimiento maternal", entonces preferiría abortar antes que entregarla/o.(Beruti, 1922 en Beruti 1943 T. III: 528). Las mujeres solteras eran las únicas que podrían hacer uso del torno libre.

Los abortos provocados por indicación terapéutica o no y los abortos espontáneos tenían una gran incidencia en la salud de las mujeres y así lo hizo notar cuando Beruti y su equipo diseñaron la "ficha eugénica de valuación de fecundidad individual" (Beruti, 1934d, en Beruti, 1943 T.III). En ella se indagaba en profundidad sobre la práctica abortiva, para poder hacer una evaluación de la "calidad" de la descendencia.

Yolanda Eraso ha indicado las prácticas llevadas a cabo por el médico Alberto Peralta Ramos en relación con los abortos. A través del análisis de los congresos médicos de la especialidad obstétrica y ginecológica, señala que el citado médico, en el año 1928, realizó un aborto terapéutico seguido de la esterilización de una mujer con lepra justificado por razones eugénicas $\mathrm{y}$, asimismo, intervino en 16 abortos terapéuticos seguidos de la esterilización definitiva, entre 1928 y 1939, también fundados en motivos eugénicos (Eraso, 2007).

Los profesionales que formaban parte del campo médico dominante señalaban la dificultad de desentrañar si las mujeres que llegaban al hospital habían tenido un aborto espontáneo o si se lo habían provocado. Así lo expresaba el médico Edmundo Ries, en el año 1947. A través de la elaboración de estadísticas elaboradas sobre la base de más de tres mil casos de aborto en el Instituto de Maternidad Alfredo Legarde del Hospital Pirovano, atendidos entre 1936 y 1947, el profesional indicaba, que ante la falta de sinceridad de las "enfermas" tenía "la impresión" de que la mayoría de los abortos eran “criminales" (Ries, 1947: 24). Las maniobras más comunes eran la introducción de una sonda a través del cuello del útero por parte de un tercero o de la propia mujer, el uso de purgantes, quinina y diversas infusiones. En menor medida, se encontraba en las estadísticas el aborto provocado con un tallo de perejil (Ries, 1947). 
La principal complicación que sufrían las mujeres que habían abortado al llegar a la internación eran las infecciones que podrían provocarles la esterilidad permanente (Stábile, 1946) o la muerte por septicemia. En la estadística realizada por Ries sobre un total de 3.377 mujeres que habían abortado, 52 habían muerto por septicemias y peritonitis y 240 habían tenido abortos sépticos. El médico reclamaba una campaña pública de divulgación científica en la cual se advirtiera sobre la peligrosidad de la práctica abortiva y, también, señalaba la capacitación especializada de los médicos para intervenir rápidamente luego del aborto para evitar otras complicaciones.

Quienes se oponían a estas ideas y prácticas de manera enardecida eran los médicos católicos. En el siguiente capítulo ahondaremos en sus discursos en relación con el aborto, pero aquí nos interesa abordar un debate interesante que se manifiesta en las páginas de Iatría a través de las críticas del médico Ángel M. Centeno (h), militante de la Acción Católica, a la postura de Beruti. El conflicto se suscitó por la práctica de un aborto a una mujer con rubeola. Nos resulta significativo este ejemplo para mostrar las diversidades discursivas dentro de la posición dominante.

Beruti, consultado por la revista Roche, señaló la necesidad de la práctica de un aborto terapéutico en aquel caso dada la gravedad para la salud de la mujer y de su hija/o que podría nacer con malformaciones y sordomudez. Sin desestimar la autoridad científica de Beruti en el ámbito médico como profesor y especialista, Centeno, retomando los dichos de Beruti en la revista, señaló la ausencia de principios morales y religiosos en la decisión:

Justamente el aborto terapéutico o profiláctico, la muerte del feto, constituye con más razón un problema que desborda los límites de la medicina e ingresa en el campo moral; las consideraciones médicas no pueden en manera alguna caer en el absurdo de que la moral representa un algo aparte y que no tiene relación con ellas. (Centeno, 1952: 196)

Para el conjunto de los médicos confesionales era inadmisible la práctica abortiva bajo cualquier justificación, para Centeno, haciendo alusión a las palabras de Castaño, 
aseveraba "tan criminal es matar un feto o un óvulo fecundado como degollar a un niño de 5 o 7 años"(Centeno, 1952:197)

Si bien quienes formaban parte de la elite médica acordaban con los principios eugénicos de "perfeccionamiento de la raza" y rechazaban cualquier intento voluntario de controlar la natalidad, las diferencias se encontraban en los medios utilizados para llevar adelante el fin eugénico. Hasta aquí, hemos prestado atención a la cuestión del aborto. A continuación señalaremos algunas cuestiones en relación a la esterilización.

\section{Esterilización definitiva}

En la historiografía local sobre la eugenesia, en los últimos años han surgido nuevas investigaciones críticas de las relecturas formuladas por Nancy Stepan. Esta perspectiva, en su mayoría, analiza el desarrollo de la eugenesia en Argentina a través de la consolidación de una disciplina derivada de aquélla, la Biotipología, que arribó al país de la mano del endocrinólogo Nicola Pende en la década de $1930 .{ }^{35}$ La indagación se concentra en la eugenesia pensada desde las elites, la que "dotada explícita o implícitamente de coercitividad" tiende "a modificar el patrimonio genético hereditario de una población” (Miranda, 2009: 142). Quienes visibilizan el control social de las teorías eugénicas sostienen que los aspectos coercitivos fueron desestimados pues "a causa del horror de la experiencia del Tercer Reich, la historiografía desestimó aproximaciones hacia experiencias eugénicas que tuvieron un final distinto al del Tercer Reich" (Vallejo, 2005: 235). Anne Carol ha señalado que "la eugenesia, de hecho, expone al historiador que se acerca a un constante peligro de anacronismo, el peligro de una reinterpretación a la luz del genocidio" (Carol, 1995: 12). En este sentido, los trabajos que adhieren a la eugenesia positiva en el país desestiman la presencia de discursos y prácticas a favor de medidas "negativas".

${ }^{35}$ Según el endocrinólogo la Biotipología era una disciplina que se orientaba al "estudio unitario, poliédrico y correlacionista de los fenómenos morfológicos exteriores e interiores, funcionales, reaccionales, humorales, volitivos, afectivos e intelectuales, que en su conjunto y en sus relaciones recíprocas constituyen la persona humana sintética e individual” (Miranda, 2003: 232). 
Diego Armus señala que la eugenesia dominante rechazó medidas negativas como limitar la reproducción de las personas enfermas y que se abocaron a prescribir conductas a través de la educación, medidas encuadradas dentro de la eugenesia positiva. Igualmente, indica que hubo voces que alentaban "medidas que apuntaban a prevenir e impedir por medios segregativos la reproducción de los considerados no aptos” (2007: 249), como el abogado Carlos Bernaldo de Quirós, pero señala que esta posición no fue dominante, aunque estas ideas estuvieran circulando desde fines del siglo XIX.

Entre quienes apoyaban medidas consideradas "negativas" también se encontraba Beruti. Admiraba las políticas llevadas a cabo por el régimen nazi con relación a la reproducción y, en particular, sobre el rol de la mujer en la vida social, como hemos analizado en el capítulo anterior. Su vinculación con el campo científico alemán era directa desde su formación en la Universidad de Friburgo y, luego, se evidencia en su participación en la creación del Institución Cultural Argentino-Alemana, a través de la cual se seleccionaban médicos que quisieran especializarse en las universidades de ese país.

Para Beruti, las leyes de esterilización nazis impuestas desde 1933 eran "notables y valientes”, permitían la realización de la obra eugénica a través de la esterilización de "inaptos, de los asociales, de los inferiores, de ciertos alienados, de ciertas (sic) enfermos y de ciertos delincuentes" (Beruti, 1934c, en Beruti,1943 T. III: 453). Esta política oficial debía dirigir, controlar y legalizar racionalmente la procreación.

Sin cuestionar el régimen nazi, Beruti señalaba que la aplicación de aquellas medidas en nuestro país no era posible, porque no había necesidad de "discutir todavía si la procreación es un deber o un derecho" (Beruti, 1934c en Beruti 1943 T. III: 454).

Como hemos mencionado, el trabajo de Yolanda Eraso (2007) pone de relieve las pruebas esterilizadoras practicadas por diversos médicos, entre los cuales se destaca A. Peralta Ramos. A través del análisis de la disertación del profesional en el 4to Congreso Argentino de Obstetricia y Ginecología realizado en 1940, Eraso señala que el profesional practicó entre 1928 y 1939 en el Instituto de Maternidad del Hospital Rivadavia 86 esterilizaciones justificadas por razones terapéuticas. En su mayoría, el diagnóstico que justificaba la esterilización era la estrechez pelviana y el 
intersexualismo. Sin embargo, señala la autora, llama la atención que las mujeres esterilizadas por estrechez pelviana ya se habían practicado cesáreas para tener hija/os, es decir, las razones eran eugénicas antes que terapéuticas, lo mismo se puede señalar sobre la esterilización de las intersexuales.

En suma, en este apartado relevamos las voces de los médicos dominantes en relación con la eugenesia y el control de la natalidad. Para ello, diferenciamos las posturas entorno a los métodos anticonceptivos, el aborto y la esterilización. Al hacerlo pudimos establecer puntos de convergencia y divergencia dentro de la elite médica y, al mismo tiempo, pudimos abordar sus ideas y prácticas para alcanzar la propuesta eugénica de "perfeccionamiento de la raza".

Por un lado, los médicos no confesionales no tuvieron reparos en proponer y practicar intervenciones quirúrgicas y químicas en los cuerpos de las mujeres para eliminar los factores "disgénicos" que podían obstaculizar el progreso de la salud y la nación. Por otro lado, los médicos confesionales adherían a los planteos eugénicos, pero reprobaron cualquier intervención en la capacidad reproductiva. El mejoramiento de la salud de la raza se llevaría adelante por reformas en el medio, a través de la inculcación de principios morales y religiosos.

A continuación, para complejizar y diversificar aún más la apropiación de la eugenesia, abordaremos las ideas de las médicas feministas sobre el control de la natalidad.

\section{Las médicas feministas, la eugenesia y el control de la natalidad}

Si bien en otros temas es posible analizar las posturas críticas que otros grupos tuvieron respecto de las posiciones dominantes, y en particular nos enfocamos en las médicas feministas, en este período, y en relación con el control de la natalidad en cualquiera de sus dimensiones, encontramos un enorme silencio de esta posición. No obstante, existen algunos indicios de que el tema les preocupaba y estaba influenciado ese interés por ideas eugénicas de mejoramiento de la raza (Nari, 2004; Lavrin, 2005; Barrancos, 1999; 2007), aunque con matices sensibles sobre este aspecto (Valobra, 2012). Por esta razón, en este capítulo, desarrollaremos brevemente esta postura. 
El movimiento feminista del que las médicas formaban parte se preocuparon por los derechos civiles y políticos, pero la cuestión del control de la natalidad como un derecho no apareció como un reclamo, ni consagraron "ninguna agenda a la anticoncepción" (Barrancos, 2007: 483). Particularmente, las socialistas no locutaron sobre el tema (Barrancos, 1999), diferenciándose de las intervenciones de los legisladores de ese partido que antes mencionamos.

Las primeras médicas feministas que adhirieron a las ideas eugénicas, como Cecilia Grierson y Elvira Rawson de Dellepiane, procuraron alcanzar el mejoramiento de la salud de la población, apostaron por la demanda de la acción estatal para la protección de la maternidad y la infancia (Barrancos, 2007). La tesis de Elvira Rawson de Dellepiane, presentada en 1892, se llamó "Higiene de la mujer". En ella, señalaba que la mujer tenía una "misión reproductora" y que "de ella depende la virilidad de la raza, la moralidad de un estado, el valor de sus hijos" (Rawson de Dellepiane, 1892: 12). En su disertación, se ocupó de la pubertad, el embarazo y el parto, pero no de las cuestiones sobre el control de la natalidad.

La historiadora Asunción Lavrin señala que la preocupación por el comportamiento sexual de las feministas "no nació del deseo de liberar la sexualidad femenina, sino de la preocupación por el doble criterio moral, en el cual veían uno de los orígenes de la desigualdad de los sexos" (Lavrin, 2005:165). En este sentido, la figura de la primera médica uruguaya Paulina Luisi evidencia la conjunción del feminismo y la eugenesia. La médica que tuvo una actuación importante en la lucha contra la prostitución en nuestro país, apoyó la implementación de la educación sexual como parte del programa eugénico, es decir, al igual que el conjunto de médicas feministas, la preocupación no estaba en el placer sexual o la emancipación de la mujer a través del control de los embarazos, sino que el interés estaba puesto en la buena procreación como un deber eugénico (Lavrin, 2005). Con este objetivo, Luisi aceptó la intervención en la reproducción a través de la realización de abortos eugénicos y esterilizaciones al igual que los médicos dominantes no confesionales. Según la médica, "la restricción de la natalidad debería ser orientada útilmente de manera de obtener que los nacimientos respondieran a las condiciones de excelencia deseada" (Luisi, 1919, en Armus, 2007: 250). 
Las personas que estuvieran enfermas de tuberculosis, sífilis o que eran alcohólicas deberían abstenerse de procrear o deberían ser esterilizadas y abortar, si se producía un embarazo. El aborto se presentaba como un deber y no como un derecho para todas las mujeres que no quisieran llevar adelante un embarazo. En estas mujeres "sanas", el aborto deterioraba la salud, cuestión que se utilizaba para justificar la práctica en las mujeres con alguna patología (Sapriza, 2011). Para Luisi, el feminismo debía demostrar que la mujer "es algo más que una máquina para fabricar hijos y cuidar la casa [...] que si es su misión la perpetuación de la especie, debe cumplirla más que con sus entrañas y sus pechos: con la inteligencia y el corazón preparados para ser madre y educadora" (Luisi, 1917 en Lavrin, 1992:161)).

Alicia Moreau de Justo no adhería a las medidas eugénicas intervencionistas y cuestionaba la maternidad como destino. Sin embargo, se acercaba a las ideas de Luisi en relación con la misión educadora de la mujer. En este sentido, señalaba que la difusión de los conocimientos científicos habían indicado a la mujer "que debe preparar su organismo y su espíritu para transmitir una herencia limpia y ser además capaz de formar el alma de su hijo como ha formado su cuerpo" (Moreau de Justo, 1945:193194). Como hemos señalado junto a Valobra, el desarrollo de las ideas eugénicas en el socialismo han sido consideradas por estudios como el de Barrancos (1996) sobre la Sociedad Luz, en el cual se indican los solapamientos de aquellas con el higienismo. La mirada sobre la relación de las mujeres socialistas y la eugenesia han puesto de manifiesto la participación de Moreau de Justo en el sostenimiento de principios eugénicos hasta mediados de los años 30 (Becerra, 2009; Lavrin, 2005). No obstante, la misma Lavrin inflexiona esa idea y señala que la propuesta de la dirigente socialista, en realidad, entendía la eugenesia como una “perspectiva ideal” (Lavrin, 2005: 214).

Asimismo, también hemos señalado que, en su vocabulario, el término eugenesia no ocupó un lugar importante. La médica socialista se opuso a la manipulación genética y concibió la educación como medio para difundir los ideales eugénicos. Ella desplazó su atención hacia los procesos de socialización y demostró cómo eran éstos, y no los supuestos condicionantes biologicistas, los que inhabilitan a las mujeres en la vida política (Ledesma Prietto y Valobra, 2012). El control de la natalidad no fue un tema abordado. Si bien la médica apostaba a una maternidad consciente, no se explayaba sobre los medios anticonceptivos para alcanzarla. En este sentido, señalaba que varones 
y mujeres se enfrentaban al problema sexual de diferente y desigual forma; decía "el hombre ha resuelto hoy con facilidad su problema sexual; no tan simple para la mujer, pues la Biología no puede ser descartada, y ésta cumple su ciclo matemáticamente" (Moreau de Justo, 1938, t. 1: 580-581). La descarga de los “instintos” para los varones se solucionaba con "una «amiga» que «resuelve su exigencia sexual»", pero para las mujeres conllevaba otro problema: "el de los hijos, que se combate en parte con el aborto, solución peligrosa y nociva". Sin embargo, en lugar de apostar por la difusión de los métodos anticonceptivos, exigía una ley de paternidad que haría más responsable al varón “o por lo menos, más cauto" (1938, t. 1: 581).

En esta misma línea, podemos situar los discursos de la médica Thelma Reca, en relación con la educación sexual. Si bien reclamaba una educación amplia, que no se redujera a la prevención de enfermedades venéreas, la amplitud no abarcaba el conocimiento de los medios anticonceptivos (Reca, 1936).

El acercamiento de las médicas feministas a la eugenesia podría comprenderse como parte de la amplitud y apropiación que tuvo aquel paradigma. Las coincidencias con los postulados médicos dominantes en relación con el control de la natalidad evidencian los diversos usos de la eugenesia. Mientras unos hicieron uso de la eugenesia para legitimar la subordinación de las mujeres a través del maternalismo, las médicas feministas lo hicieron con el fin de sostener la estrategia política de la maternidad como fuente de derechos. Esta estrategia limitó el cuestionamiento de la maternidad como destino que proponía el conocimiento sobre el control de la natalidad como herramienta emancipadora.

Caso contrario sucede con el discurso médico libertario argentino que tuvo una notable expresión sobre estos temas. Estas ideas estuvieron profusamente influenciadas por las corrientes españolas y por ello nos interesa puntualizar algunas cuestiones al respecto. En este caso, también, estas consideraciones están teñidas de un conjunto de supuestos teórico metodológicos. A continuación, avanzaremos sobre la mirada anarquista sobre la eugenesia y el control de la natalidad. 


\section{Eugenesia y emancipación sexual: una conexión libertaria}

Los estudios sobre eugenesia en la Argentina, especialmente enfocados en la década del 30, ofrecen escasas menciones sobre el eugenismo anarquista, con lo cual refuerzan, a su vez, el límite temporal impuesto al estudio de la expresión anarquista en el país y, al hacerlo, pierden de vista el rescate de la singular apropiación de las ideas eugénicas que profesaron. Podemos decir que la influencia del modelo propuesto por Nancy Leys Stepan en su libro "The hour of Eugenics": Race, Gender, and Nation in Latin America (1991) en el cual definió como eugenesia "positiva", concentrada en las modificaciones del ambiente, la que imperó en la Argentina a través del estudio de la eugenesia dominante, también obturó, en parte, la mirada sobre el discurso anarquista eugénico. Dora Barrancos, pionera en el estudio del anarquismo en la Argentina, advierte en el análisis de Nancy Stepan la ausencia de mención sobre el "eugenismo social" de la Liga de la Regeneración Humana en Francia, cuyo origen se remonta a 1896 y que se propagó por varios países de la mano del anarquismo, entre ellos, la Argentina. ${ }^{36}$ Según Barrancos, esta omisión fue reproducida por los sucesivos análisis sobre la eugenesia en el país.

Las menudas referencias a las ideas eugénicas en la cultura de izquierda anarquista dentro de los estudios sobre la eugenesia institucionalizada concuerdan, como hemos mencionado, en que el anarquismo local participó en el clima de época de adopción de la ciencia eugénica, pero la frontera temporal que desde la historiografía se le ha impuesto al desarrollo del anarquismo local deja fuera del análisis las manifestaciones que nos interesa analizar, en las cuales encontramos más explícitamente el devenir de las ideas de emancipación sexual de las mujeres vinculadas al discurso eugénico.

La adopción de métodos para controlar la natalidad por el movimiento ácrata fueron considerados herramientas de resistencia al capitalismo, para no entregar mano de obra para el sistema y una solución para mitigar la miseria entre las/os trabajadoras/es (Barrancos, 1990b; Masjuán Bracons, 2008; Nari, 2004). Así, del mismo modo, también se perseguía el mejoramiento de la raza, ya que la multiparidad era

\footnotetext{
${ }^{36}$ Propiciado por los anarquistas franceses Paul Robin y Charles Chaughi su programa era: "Un buen nacimiento, una buena educación, una buena sociedad" (Barrancos, 1996: 189).
} 
considerada una de las causas de la degeneración de los cuerpos femeninos y de sus hijas/os (Nari, 2004). En este sentido, Carolina Biernat señala que la defensa del control de la natalidad de Lazarte se apoya en justificaciones eugenésicas dado que "defiende la procreación consciente, puesto que considera a la multiparidad, especialmente presente entre los sectores económica y socialmente más desvalidos, como un factor fundamental de «degeneración»" (Biernat, 2005a, s/p).

En su mayoría, la bibliografía sobre el tema ha rescatado el discurso del médico Juan Lazarte como el más representativo de una postura eugénica y neomalthusiana que defendió la maternidad consciente y las esterilizaciones "por otra vía a la utilizada por la ortodoxia eugénica" (Miranda, 2011: 130). Para Miranda, retomando las distinciones de Carol, Lazarte se ubica en la perspectiva "democrática" de la eugenesia. Desde esta mirada, aunque conlleve medidas extremas como las esterilizaciones que lo acercarían a las posturas dominantes, la eugenesia anarquista adquiere un carácter progresista en comparación con el carácter autoritario y represivo con el que se ha caracterizado la eugenesia profesada por los médicos dominantes, pues el mejoramiento social era una cuestión de eugenesia voluntaria.

Por ello, según Nari, frente a las posiciones poblacionistas y antimalthusianas dominantes, sólo algunos libertarios, como el médico Juan Lazarte, señalaban la necesidad de la "«procreación consciente», desde justificaciones eugenésicas", pero al mismo tiempo que apostaba por una emancipación biológica de la mujer "se reforzaba por otros caminos- una idea de maternidad no contradictoria con la hegemónica", puesto que el ejercicio de la maternidad conllevaba "mayor dedicación física y afectiva", recreando un modelo "absorbente y excluyente de maternidad" (Nari, 2004: 195).

Nuestro trabajo intenta abordar una línea interpretativa que fue esbozada por Dora Barrancos, pero que no ha sido explorada. Si bien la autora ha señalado que "only anarchists defended women's right to limit the number of their pregnancies and supported women's right to control their bodies. In fact, the anarchists were the first to spread the news of birth control techniques and to approach the idea of equal sexual freedom for both sexes" (Barrancos, 2006: 136), esta cuestión no ha sido estudiada en relación con el impacto de la eugenesia en el movimiento ácrata, en particular, entre profesionales de la salud. La adopción de las ideas eugénicas sobre el control de la 
natalidad se refieren, según la autora, "they championed limiting births in order for the proletariat to have a better standard of living" (2006: 136). Aunque cita la obra de Lazarte, La Revolución sexual de nuestro tiempo (1932) y el libro de Julio Barcos, La libertad sexual de las mujeres (1921), como ejemplos de la idea de "right to one's body" (2006: 149), sus análisis no abordan la relación entre eugenesia, control de la natalidad y libertad sexual en los discursos médicos anarquistas posteriores a 1930.

Otro aporte interesante es el estudio de Helena Andrés Granel (2012) sobre la obra de Juan Lazarte, aunque, a diferencia de la autora, sostenemos que el paradigma eugénico en las narrativas médicas fue el que configuró y otorgó legitimidad a las ideas de libertad sexual y no así las ideas neomalthusianas, que ya dejan de tener peso, aunque las técnicas que proponían perviven.

A continuación, teniendo en cuenta las dimensiones que hemos seleccionado del control de la natalidad, avanzaremos sobre las ideas eugénicas de Lazarte y Martín Fernández que conllevaron ideas de libertad sexual a través de la maternidad consciente y voluntaria y el derecho al placer sexual. Asumiendo el carácter transnacional del movimiento, en cada dimensión señalaremos las ideas esbozadas por los médicos libertarios españoles, indicando los puntos en común y las divergencias con los médicos locales. Entendemos que la circulación de ideas reforzadas por la Guerra Civil Española nos permite tejer las redes de un lado y del otro del Atlántico en relación con estos temas.

\section{3. a La eugenesia en clave liberadora y el control de la natalidad}

La recepción de la eugenesia por el anarquismo evidencia cómo la ciencia eugénica fue el paradigma imperante para enfrentar los problemas de la "degeneración de la raza" y atravesó a diversos posicionamientos políticos e ideológicos que se apropian de aquellos postulados y los integran a su programa. En el movimiento ácrata, las ideas eugénicas fueron herramientas que se adaptaron para alcanzar la emancipación social (Cleminson, 2008).

Así, a fines de la década de 1910, Lelio Zeno, médico anarquista de Rosario, amigo de Juan Lazarte - por entonces estudiante de medicina-, se manifestaba a favor de 
la eugenesia en la revista Prometeo. ${ }^{37}$ Sin embargo, realizaba una distinción: criticaba a quienes a través de legislaciones imponían políticas eugénicas que se inmiscuían en cuestiones de la vida privada, como el certificado prenupcial. Remarcaba que en este caso "el eugenismo" se volvía un "instrumento de tiranía” (Zeno, 1919: 5). Así, citaba al propio Galton que ante ésta situación sostuvo que era la opinión pública la que debía consagrar y controlar las prácticas eugénicas. Asimismo, señalaba que:

no hay un solo ser cuya salud sea perfecta e impecable. En general la humanidad está tarada. Hemos llegado al estado miserable de nuestros días, en virtud de siglos y siglos de ignorancia crasa, penurias negras y costumbres puercas. Por eso el ideal eugénico se conseguirá gracias a la obra lenta y progresiva de la educación y selección racional y espontánea, pero no con imposiciones violentas y en un medio degradado. (Zeno, 1919, 5)

También cuestionaba a quienes adherían al neomaltusianismo creyendo que sólo a través de la reducción de los embarazos se podrían resolver problemas sociales como la miseria.

Lazarte en la revista Estudios de Valencia, entre febrero de 1933 y febrero de 1934, publicó una sección titulada "Significación cultural y ética de la limitación de los nacimientos". Estos artículos fueron editados en formato de libro en Argentina a través de la librería Ruiz de Rosario. Se tituló La limitación de los nacimientos (1934).

El carácter científico de la obra estaba dado por el respaldo de citas de autoridad y la elaboración de estadísticas propias y de otra/os colegas. Su posición en relación con

${ }^{37}$ Lelio Zeno (seudónimo Dr. L. OZ./ LOZ), médico cirujano egresado de la UBA en 1915. En 1929, junto con su hermano Artemio Zeno, padre de la Dra. Ana María Zeno (quien sería luego una reconocida ginecóloga y educadora sexual libertaria, fallecida en el año 2011), dirige la Cátedra de Clínica Quirúrgica. Precursor en el desarrollo de la cirugía plástica en Argentina a partir de sus especializaciones en los centros de investigación de la Unión Soviética, funda el sanatorio Británico de la ciudad de Rosario. Fue un activo partícipe y organizador de los círculos intelectuales y artísticos de esa ciudad (Tarcus, 2007). 
el neomaltusianismo y la eugenesia lo ubica en la misma senda que su colega y amigo Lelio Zeno, es decir no consideraba que sólo el control de la natalidad alcanzaría para la revolución social y se oponía a las imposiciones oficiales. En este sentido, en la cuarta edición de la obra El contralor de los nacimientos (1936), a fin de sortear las disputas y las discusiones que podía generar no sólo dentro del anarquismo, llevaba en la contraportada la siguiente aclaración, "este libro no está escrito con fines de propaganda neomalthusiana, sino desde un punto de vista que pretende ser científico y humano. Creo con ello contribuir a la defensa de la salud de las madres y a la protección de la vida de los niños" (Lazarte, 1936).

Los beneficios del control de los nacimientos se producían en dos dimensiones según Lazarte: la individual, ligada al derecho a decidir los embarazos, y la social, vinculada a la eugenesia y el perfeccionamiento de la raza. Teniendo en cuenta estas dos dimensiones, el médico anarquista se ocupó de evidenciar que la multiparidad era un factor de degeneración de la raza al provocar el debilitamiento de la salud de las mujeres y su descendencia. Señaló los beneficios del uso de los medios anticonceptivos, realizó una descripción de los mismos e hizo hincapié en la revolución sexual que provocaría acceder a los conocimientos y las herramientas para diferenciar el placer sexual de la reproducción. El control de los nacimientos era entendido por el médico "un movimiento de liberación, que si tiene por fundamento el femenino, no deja de tocar también al masculino" (Lazarte, 1936:9).

El parto era considerado "una catástrofe fisiológica" para el cuerpo de las mujeres maduras, enfermas y mal nutridas (Lazarte, 1936: 11). Asimismo, el empleo en trabajos insalubres multiplicaban las posibilidades de abortos, partos prematuros y la muerte de las mujeres embarazadas. Por ello, señalaba que un embarazo para la mujer trabajadora junto con el problema de la debilidad de su "constitución orgánica", también se convertía en un problema para su "liberación económica y social" (Lazarte, 1936: 14).

La ausencia de conocimientos anticoncepcionales producía en las mujeres enfermedades nerviosas por el miedo al embarazo, señalaba que "las mujeres que no llegan a la posesión de anticonceptivos sufren una autopersecución cotidiana", que repercutía en su equilibrio mental. Para Lazarte, el embarazo no deseado hacía que las mujeres recurrieran a una gran variedad de prácticas contracepcionales, "desde el aborto para arriba". Ello podía orillarlas a que cayeran "en manos inexpertas y delincuentes 
(por falta consciente de idoneidad) productoras de más mal que bien, pero que para el legislador, el sociólogo y el higienista demuestran una marcha evidente de la humanidad femenina" (Lazarte, 1936: 28-29). También, interpelaba a sus pares que mantenían a las mujeres en la ignorancia de los conocimientos de su cuerpo. La educación sexual era, para el médico, un medio de “defensa y liberación psicológica” (Lazarte, 1935a: 121).

Estos conocimientos, sostenía, eran legítimos para todas las mujeres, no sólo para las "solteras y recién casadas", sino que también las casadas y las madres que luchaban, entre otros obstáculos, contra "la estupidez de los «Maridos», el consenso de que los anticonceptivos son condenados por la Iglesia, la dificultad de una información seria y científica, la pobreza y demás” (Lazarte, 1936: 28).

En este mismo sentido, Manuel Martín Fernández -en los diversos consultorios sexuales y psicosexuales que dirigió en la revista Cultura Sexual y Física (1937-1941) y la revista Hombre de América fuerte y libre (1940-1945)- se ocupó, entre otras consultas, de proporcionar la información sobre el control de la natalidad. Las justificaciones eugénicas para evitar los nacimientos estaban presentes en su discurso, pero con mayor densidad su preocupación estaba en la liberación sexual. Esto se evidencia también en sus artículos sobre la felicidad sexual de las mujeres, además de sus respuestas en los consultorios.

Para el médico jujeño era necesaria y urgente la educación sexual pues ésta era la herramienta básica para llevar adelante un cambio en la moral sexual. Indicaba: "se hace indispensable una educación sexual amplia que permita por el perfecto conocimiento de la verdad, el ejercicio libre, sereno y tranquilo de la más bella y potente de nuestras fuerzas creadoras" (Martín Fernández, 1940c: 38).

Esta estrategia interactiva para la divulgación de la información sobre los métodos anticonceptivos se reproduce más tarde en la publicación Luz (1949-1951) editada desde la ciudad de Rosario, que tenía como público destinatario la juventud. La sección "Educación sexual" estaba a cargo de la abogada Anita Piacenza. La publicación, en general, se preocupaba por la difusión de una nueva moral sexual. Aquí, las justificaciones eugénicas ya no tenían peso y el interés estaba orientado a liberar a la sexualidad de las costumbres que la circunscribían a la prostitución, el matrimonio y la reproducción. 
Para desarrollar las ideas anarquistas sobre el control de la natalidad en relación con la propuesta eugénica y las ideas emancipadoras para las mujeres que profundizaremos en los próximos capítulos, analizaremos las dimensiones que trabajamos con los médicos dominantes. Ello nos permitirá establecer las confluencias y divergencias discursivas surgidas de la apropiación de un paradigma.

\section{Los métodos anticonceptivos}

Como hemos mencionado, en primer lugar, la multiparidad era considerada un factor de degeneración de la especie por la debilidad que producía en la salud de las mujeres y las volvía más proclives a enfermarse. La descendencia de estas madres heredaría los deterioros de su salud, lo cual era considerado una falta a su derecho de ser engendrados "por padres sanos y en buenas condiciones mentales, económicas y morales" (Lazarte, 1936: 319).

A partir de la elaboración de estadísticas propias sobre la base de los datos que recogía de hospitales de algunas localidades de la provincia de Santa Fe, Lazarte mostraba el aumento de la mortalidad infantil a partir del tercer parto: de 1256 niñas/os nacidos en el tercer parto vivían, después del primer año de vida, 732; vale decir, un porcentaje del 58.3\% (Lazarte, 1936). Las estadísticas elaboradas por la médica Marie C. Stopes, en Londres, reforzaban su argumento y los reproducía pues llegaban a la misma conclusión. Asimismo, Lazarte señalaba que el promedio de vida de una mujer que había tenido 8 ó 9 partos era muy inferior a la que tenía 2 ó 3. A los cuarenta años, eran "piltrafas de mujer, ruinas de ser humano" (Lazarte, 1936:34). Igualmente, esta cuestión estaba atravesada por las condiciones educativas y económicas y eran las mujeres pobres analfabetas las que se veían más afectadas por la multiparidad. Por esto se hacía urgente el conocimiento de los anticonceptivos.

Los progresos científicos en la físicoquímica y la biología habían mejorado la eficacia de los diversos métodos. Ello, para Lazarte, hacía de la ciencia "un gran instrumento de liberación humana en lo tocante al amor" (Lazarte, 1936: 138). En este mismo sentido, Martín Fernández, a través de sus consultorios sexuales, se proponía combatir la ignorancia sobre los métodos con educación sexual. 
Algunos de los métodos anticoncepcionales enumerados por Lazarte podían producir la esterilización definitiva, pero en su clasificación esa variable no fue considerada. Los métodos se dividían en medios mecánicos, cirugía, rayos X y medios químicos. Los mecánicos correspondían a los elementos llamados pesarios o capacetes diafragmas- que se introducían en la vagina antes de la relación sexual. Los primeros fueron la marca comercial "Mensinga" y la médica Stopes aconsejaba los "Pro-race" que no causaban ninguna molestia y su resultado había sido relativamente satisfactorio. Los métodos quirúrgicos descriptos por Lazarte producían esterilización definitiva, como la histerectomía y la resección de las trompas. La exposición a rayos X tenían la ventaja de que su efecto no era permanente, pero señalaba que era costoso e incómodo. Por último, los métodos químicos se encontraban en proceso de experimentación con animales y mujeres. Lazarte citaba diversos estudios realizados con animales y también traía a escena la experimentación con mujeres realizadas por Alberto Peralta Ramos y Mario Schteingart en nuestro país. Si bien no citaba la fuente, Lazarte describía los resultados de la investigación. Se experimentó en 141 mujeres, a las cuales se les inyectó 4 dosis de espermatozoides de carnero en forma creciente, el resultado fue -que sobre 62 mujeres, supuestamente enfermas, que fueron controladas- el $80 \%$ no tuvo embarazos entre los 6 y 15 meses siguientes. Por ende, se concluía que ese método era practicable, que producía la esterilidad temporal y que no se presentaron reacciones en la salud de las mujeres por la aplicación de ese método. Sin realizar ningún comentario sobre la experimentación en mujeres, Lazarte concluía la necesidad de poner estos conocimientos al alcance de las "clases pobres" como ya lo habían hecho en Inglaterra, Rusia y Estados Unidos, países en los cuales existían clínicas anticoncepcionales (Lazarte, 1936: 146). Este reclamo lo sostuvo posteriormente en las Primeras Jornadas Eugénicas Argentinas, de 1956, auspiciadas por el Museo Social Argentino (Lazarte, 1956).

Mientras tanto aquello sucediera, para Lazarte, el método Ogino-Knaus les brindaba a varones y mujeres la posibilidad de controlar los embarazos sin la intervención de tecnologías contraceptivas, que demandaban ciertas condiciones tales como recursos materiales para adquirirlas, cercanía a un centro de salud o a un profesional de la medicina para que se las recomendara; por ello Lazarte le dedicó un apartado. Allí explicaba los descubrimientos en relación a los períodos fértiles e infértiles o tiempos genésicos y agenésicos en los ciclos ovulatorios de las mujeres. 
Asimismo señalaba los debates que se establecían entre los profesionales en relación con el período de tiempo que transcurría entre la menstruación y la ovulación. Este debate también se había desarrollado en las páginas de la revista Estudios, en el cual Lazarte participó, sin polemizar explícitamente, pero sentando su posición favorable a la utilización del método publicando un artículo titulado "los tiempos agenésicos" (Lazarte, 1935b), que era la reproducción del capítulo homónimo de su libro.

Para dilucidar los problemas en torno a los períodos del método el médico Isaac Puente hizo un llamado a la/os lectora/es de Estudios para que compartieran sus experiencias. A la convocatoria respondieron cincuenta personas, de las cuales cuarenta habían tenido resultados favorables en períodos que iban de cuatro meses a tres años y diez habían fracasado luego de un año de práctica (Puente, 1936, en Tabarnero-Holgado et. al, 2013: 62).

Desde sus consultorios, Martín Fernández recomendaba el método, señalando que era muy bueno si se realizaba con aplicación, sin confundir u olvidar las fechas (Martín Fernández, 1939b; 1940d). Su colega español, Félix Martí Ibáñez, quien también dirigía un consultorio psíquicosexual en la revista Estudios, ante las inseguridades que presentaba todavía el calendario de días fértiles e infértiles no lo recomendaba (Nash, 1984). Estas discusiones y discrepancias demuestran los ajustes sobre los conocimientos científicos y las diversas apropiaciones que los médicos hacían de él construyendo, a su vez, nuevos conocimientos a través de su práctica.

Otros métodos recomendados por Martín Fernández eran las inyecciones intramusculares de esperma que esterilizaban a la mujer durante más o menos un año según las pruebas que habían presentado Peralta Ramos y Schteingart. Señalaba que esta práctica estaba poco divulgada y sólo algunos médicos la realizaban (Martín Fernández, 1940b). También, aconsejaba el uso de preservativos masculinos y femeninos; estos últimos eran mejores, como por ejemplo el capacete era el más recomendado que obturaba el cuello de la matriz; en cambio el tapón uterino era para el médico "malísimo" porque una vez introducido producía irritación y podría provocar trastornos graves como el cáncer (Martín Fernández, 1940b: 25).

Sin asegurar un resultado absoluto, recomendaba también la introducción de un supositorio en la vagina media hora antes de la relación sexual. El supositorio debía 
estar compuesto por “Calomel al vapor 0,10 gr.; ácido cítrico 0,10 gr., acido bórico 0,10 gr., sulfato de quinina 0,10 y manteca de cacao, cantidad suficiente para un supositorio" (Martín Fernández, 1940d: 40). Entre los métodos desestimados se encontraban los lavajes con soluciones acéticas o alcalinas como el bicarbonato de sodio. Señalaba que si bien "la reacción ácida de la vagina puede impedir la fecundación", no era correcto pensar que "acidificando la vagina" se podía llegar al mismo resultado (Martín Fernández,1939b: 187).

En las narrativas de Martín Fernández, la estrategia eugénica del control de la natalidad, como hemos mencionado, está presente pero en forma más atenuada en relación al discurso de Lazarte. A través de su consultorio, recomendaba evitar los embarazos a las mujeres que habían tenido muchos hijos en corto tiempo, por ejemplo, una mujer había tenido cuatro hija/os en seis años y también a las mujeres enfermas. En este caso, decía, los médicos estaban en lo correcto en prohibir los embarazos, pero junto con ello tenían que brindar las herramientas para evitarlo sin que las mujeres tuvieran que resignar su vida sexual (Martín Fernández, 1940d). En su apropiación de la eugenesia, ciertas patologías no eran hereditarias como consideraban otros médicos, incluso Lazarte, pero perjudicaban a la descendencia. En este sentido, un lector preguntaba si el alcoholismo se heredaba, Martín Fernández señalaba que no tenía un carácter hereditario, pero igualmente sus descendientes, al haber sido concebidos por un padre o madre no saludable, en general, nacían "más o menos débiles mentales", por lo cual estaban predispuestos a "adquirir ese vicio u otros" (Martín Fernández, 1940e: 33). Asimismo, en su consultorio aclaraba que las enfermedades venéreas no eran hereditarias pero que hasta no se haya terminado el tratamiento no debían practicarse relaciones sexuales. Aclaraba, también, que los lavajes con permanganato luego de la relación sexual no impedían la transmisión de la enfermedad y eran aconsejables colocarse las pomadas preventivas antes del coito.

En una consulta, un lector pregunta si él podría haberse contagiado de blenorragia de una mujer con la que tuvo relaciones sexuales cuatro veces por semana durante dos años y estaba enferma. Aparentemente, la mujer le había dicho al consultante que ella había adquirido la enfermedad por una llaga en el útero que había tenido, cuestión que, rápidamente, el médico, con lenguaje mordaz, rechazó, diciéndole “«ninguna llaga en el útero»", de cualquier origen que sea, si no era blenorrágica, puede ocasionar, por sí sola, 
la blenorragia, por la misma razón que ningún gato, por nada del mundo, puede convertirse en perro" (Martín Fernández 1940h: 58).

El coito interruptus, la práctica más extendida, también era cuestionada por Martín Fernández, no porque no diera resultados sino por los trastornos que causaba en el sistema nervioso de las mujeres. Ante una consulta de una mujer por sus problemas nerviosos, el médico señalaba que eran producto de "«esa retirada a tiempo» de su esposo" que "dejándola insatisfecha, después de la excitación provocada, la mantienen en un estado de enervamiento constante que, lógicamente, debilita su sistema nervioso" (Martín Fernández, 1940b: 25).

Como señala Mary Nash, en la revista Estudios, también por motivos de salud psíquica y física, se rechazaba el coito interruptus y el uso del preservativo masculino. Este sólo lo aconsejaba cuando la mujer "no consciente en el empleo de los anticonceptivos o no puede contarse con su colaboración" (un médico rural, 1931 en Nash, 1984: 330). Su uso estaba aconsejado cuando las condiciones de sanidad no eran óptimas y había riesgo de contagio venéreo. Para Nash, la mayoría de los métodos recomendados eran para el uso femenino: pesario, obturador, esponja, capacete, irrigaciones vaginales, óvulos, pomadas, esterilización mediante rayos $\mathrm{X}$, operaciones quirúrgicas, inyección de esperma, método Ogino-Knaus, entre otros (Nash, 1984). Al contrario de lo que se planteaba sobre las consecuencias del uso del preservativo masculino, para las mujeres no se consideraba que hubiera problemas psíquicos o físicos causados por el uso de algún método, sino que se creía que se beneficiaban al poder controlar los embarazos y su salud mental. Señalaba el especialista Puente, así, dejarían de sufrir de problemas de frigidez causados por el temor al embarazo (un médico rural 1934, en Nash, 1984: 331).

En este mismo sentido, Lazarte señalaba que a causa de la presión social del ambiente, que vedaba la obtención de los conocimientos anticoncepcionales, la unión sexual producía en las mujeres sentimientos contrarios al placer. Para Lazarte, la incertidumbre y el miedo al embarazo las conducían a un desequilibrio mental (Lazarte, 1936).

Asimismo, sostenía que el control de los nacimientos era un derecho que el varón se había apropiado cuando a ellos "no le correspondía la función del parto". Para el 
médico la "libertad de embarazo" conseguida a través del conocimiento de los métodos anticonceptivos, también hacía que "la responsabilidad" de la (no) reproducción involucrara a las mujeres (Lazarte, 1936: 32).

En suma, el conocimiento de los métodos anticonceptivos para controlar la natalidad, además de ser una estrategia eugénica, facilitaría la salida de las mujeres del sistema de maternidad continua, la cual - para estos libertarios-era una de las causas de subordinación social de las mujeres, como veremos en el próximo capítulo. Asimismo, al limitar la función reproductora y regular la potencial capacidad de gestar de las mujeres, el control de la natalidad fue concebido también como un medio de liberación.

Los médicos ácratas eran las voces disonantes en relación con los posicionamientos antes evidenciados. Por un lado, hemos analizado que los médicos dominantes se habían opuesto al control voluntario de la natalidad y sólo Beruti había legitimado el control de los nacimientos en casos de enfermedad, pero bajo exclusiva dirección del médico. Los conocimientos de los métodos anticonceptivos por parte de la población era un tema que, los médicos confesionales o no, se habían dispuesto a combatir. En cambio, los médicos ácratas a través de diversas estrategias como la publicación de sus obras, los consultorios sexuales en las revistas e incluso cotidianamente en su práctica profesional, estaban abocados a la difusión de los conocimientos de las herramientas anticoncepcionales para evitar la degeneración y mejorar la población pero también como instrumento de emancipación femenina. Esta última cuestión es la que los distingue tanto de los médicos dominantes como de las médicas feministas, quienes no se habían explayado sobre este tema. A continuación abordaremos el aborto y la esterilización, punto éste en que los planteos de Lazarte se acercan a los de los médicos dominantes.

\section{Abortos legales y gratuitos}

El problema de las prácticas abortivas no ha tenido un espacio considerable en las narrativas de Lazarte y Martín Fernández. Éste en particular, no se ha referido al tema en ninguna de sus consultas ni en sus artículos. En este punto, los discursos de los médicos ácratas argentinos se distinguían de las apuestas de los médicos ácratas españoles, que explícitamente abordaron el tema y también lo llevaron a la práctica 
cuando José Antonio Martí Fernández, como Ministro de Sanidad de Cataluña, legalizó el aborto en 1936.

Sin mencionar la palabra aborto, Lazarte se refirió al derecho de las mujeres a limitar los nacimientos y a "las perspectivas de una acción sobre el embarazo", si la misma no afectara "la esencia moral" de la "colectividad, ni la vida de la madre corra un peligro serio". En la etapa embrional, señalaba, la maternidad estaba bajo la acción de "la conciencia, inteligencia y ciencia" y no bajo "la religión” (Lazarte, 1936: 32).

En el Segundo Congreso Médico Gremial Argentino y Primer Congreso de Medicina Social, realizado en 1936 en Rosario, en cual Lazarte había participado, sobre el problema del aborto se había realizado una declaración que más tarde la revista Cultura Sexual y Física traía a escena. Para luchar contra el aborto "provocado y clandestino" era necesario mejorar la calidad de vida de las clases trabajadoras; brindar protección a la maternidad y la infancia; difundir los métodos anticonceptivos a través de la educación sexual; luchar contra el aborto clandestino y eliminar el concepto legal de hija/os ilegítima/os (Cultura Sexual y Física, 1938:196).

Más tarde, en su libro Problemas de medicina social editado en 1943, al describir la nueva organización de la medicina socializada, Lazarte planteaba la necesidad de establecer "institutos de aplicación y estudio de las leyes de la herencia, las escuelas prácticas de la técnica de la concepción" las mismas, debían difundir los conocimientos a toda la población, sin privilegios (Lazarte, 1943: 140-141). A su vez, para complementar aquellas instituciones, se establecerían clínicas anticoncepcionales y agregaba “demás está decir que aparecerán bajo la dirección de expertos y en hospitales o dispensarios apropiados, clínicas quirúrgicas interruptoras de gestaciones cuando los interesados o la sociedad y los médicos así lo crean conveniente” (Lazarte, 1943: 141).

En este sentido, Lazarte ponía como ejemplo de organización y coordinación de la sanidad el Consejo de Sanidad y Asistencia Social de Cataluña, el cual estuvo bajo la dirección de Martí Ibáñez entre 1936 y 1939 (Lazarte, 1943). Como director general del Consejo promovió diversos programas sociales para luchar contra la tuberculosis, la lepra, las enfermedades venéreas (Martí Boscá, 2007; Pardo Tomás, 2006) e impulsó la reorganización del servicio psiquiátrico (Llavona y Bandrés, 1998). Empero, la medida más destacada de su experiencia como director fue el "decreto de interrupción artificial 
del embarazo", en el marco de lo que llamó la "reforma eugénica del aborto", en diciembre de 1936. Esta medida, indicaba Martí Ibáñez, incorporaba el aborto a "los dominios de la medicina científica". El decreto señalaba "la libertad de practicar el aborto, sea cual fuere la causa que lo motive, [...] practicado antes de los tres meses [...] siempre que la madre lo solicite y su estado de salud permita garantir el éxito de la intervención" (Martí Ibáñez, 1937a: 11). Esta reforma estaba sustentada sobre cuatro razones que el médico las situaba dentro del campo médico social: 1) causa terapéutica: enfermedades de la madre que ponían en riesgo su salud si se llevaba adelante un embarazo; 2) motivo eugénico: incesto paterno o taras que podían transmitirse al hijo; 3) factores neomalthusianos: deseo de limitar voluntariamente la maternidad, y 4) factor sentimental y ético: maternidad indeseable por diversas razones amorosas o emotivas. En este sentido, Martí Ibáñez señalaba las consecuencias positivas para la vida sexual de la mujer al adquirir "el derecho a disponer de sí misma y a decidir sobre su maternidad" y al liberarse de lo que llamo "la tiranía egoísta masculina” (Martí Ibáñez, 1937b: 38).

La decisión sería acompañada por la creación de centros de difusión de recursos anticoncepcionales para que la mujer recurriera al aborto como último recurso, esto llevaría a una reducción de los abortos al acceder las mujeres a los conocimientos anticoncepcionales. Por otro lado, al salir de la clandestinidad se reduciría la mortalidad femenina. La maternidad era, para el médico, una actividad suprema que involucraba aspectos sociales y espirituales y no podía reducirse a parir hijos "sino a entablar un vínculo espiritual eterno con los mismos, y a convertir al hijo en un trabajador sano, consciente y culto" (Martí Ibáñez, 1937a: 12). La medida tuvo vigencia hasta la instauración del régimen franquista, el cual en el año 1941, a través de la Ley de Represión del Aborto, volvía a la clandestinidad la práctica del aborto y lo penalizaba con prisión para quienes lo causasen.

Si bien los médicos anarquistas locales no lo abordaron o lo hicieron con menor impulso, el tema del aborto estuvo presente a través del pedido explícito de la legalización de su práctica y a través de la aprobación de lo que estaba sucediendo en España. 


\section{Esterilización eugénica}

Algunas de las ideas sobre la eugenesia, como hemos señalado en el capítulo 1, que conformaron el discurso de Lazarte provenían de su relación con Georg Nicolai, de quien fue discípulo. Las ideas de Nicolai sobre la eugenesia fueron editadas mucho tiempo después en 1957, sobre la base de una conferencia dictada en la Facultad de Medicina de la Universidad de Chile, el libro se llamó La eugenesia como gloriosa culminación de la medicina. En él, a través de un repaso por la historia de la medicina, el médico alemán consideraba a la eugenesia como el "conjunto de las medidas que sirven ya para limitar la natalidad, ya para excluir en la masa hereditaria, los genes indeseables, por esterilización de los portadores" (Nicolai, 1957: 129).

Para plantear estas ideas, luego de la experiencia nazi, diferenció la eugenesia defendida por él de la que se aplicó bajo el régimen de Hitler. Señalaba que la confección de historias clínicas familiares era una herramienta eugénesica, pero que bajo el nazismo éstas se llevaron a cabo por razones político-racistas más que por objetivos eugenésicos, y apenado, indicaba que "desgraciadamente el solo hecho de que Hitler se haya mezclado con la eugenesia, la ha[bía] desacreditado en vastos sectores de la población” (Nicolai, 1957: 130).

A través de la limitación de la natalidad, se alcanzaría una nueva moral que sustituiría el amor al prójimo por un sentimiento más universal. Planteaba la primacía de la sociedad sobre el individuo en la cuestión eugénica, por ello argumentaba a favor de la esterilización obligatoria de "mujeres imbéciles" (Nicolai: 1957: 194) dado que su descendencia afectaría a la sociedad y al mejoramiento del "material humano" (Nicolai: 1957:103). Este avasallamiento sobre los derechos individuales estaba justificado:

pensando individualmente, nadie podría ser eugenista, pues, naturalmente, la esterilización forzada significa una restricción de los llamados "derechos del hombre", cuyo alcance, empero, la sociedad tiene que determinar; y si ella dice que el hombre no tiene el derecho ilimitado de procrear a su gusto, ya no tiene tal derecho. Sin eso no sería factible ninguna reforma social, que siempre restringirá a ciertas categorías de individuos el uso de sus 
cualidades, sean éstas físicas, espirituales, económicas o de otra índole.

(Nicolai, 1957: 233)

En esta misma línea, Lazarte apoyó desde la década del 30, y en la siguiente, la práctica de esterilizaciones en "los débiles mentales, locos, etc." (Lazarte, 1948: 26) sin que esto provocara cuestionamientos morales. Debe considerarse que luego de la experiencia del nazismo y sus intervenciones en la reproducción de la especie humana, las prácticas esterilizadoras se relacionaban con aquella barbarie. Lazarte defendía las ideas eugénicas y su preocupación era lograr el mejoramiento de la raza, entendida ésta como toda la especie y no en un sentido "racista" (Lazarte, 1936: 69). Por ello, decía, en su plan de medicina socializada "la esterilidad de los seres nocivos e incurables se hará corrientemente, sin llamar la atención y la mala publicidad”. En este punto aclaraba que "la esterilización debe ser considerada como un derecho y no como un castigo" (Lazarte, 1943:140).

A través del conocimiento de las leyes mendelianas sobre la herencia recesiva o dominante, Lazarte enumeraba las enfermedades que se consideraban hereditarias, mencionaba, la ceguera, la miopía, la demencia, la sordera, el alcoholismo, la lepra, entre otras. Citaba diversos estudios, en particular el caso de Estados Unidos sobre las familias "Juke" y "Kallikak", ${ }^{38}$ pues evidenciaban "las relaciones entre degeneración y herencia, de cuanto reporta a la colectividad el desconocimiento de los medios anticonceptivos, la facultad ilimitada que tienen los degenerados en su procreación y las consecuencias que paga por su ignorancia la sociedad" (Lazarte, 1936: 113).

A través del reclamo de acciones más contundentes, para enfrentar el problema en nuestro país donde señalaba que el número de degenerados llegaba a 100 mil personas, interpelaba a sus pares que por creencias religiosas impedían la

38 Lazarte hace una descripción de los casos citando textualmente párrafos de la obra de Paul Popenoe y Roswell Johnson, Applied Eugenics editada en 1918. Aunque aclara que no está de acuerdo con todo lo que escriben los autores. Esta obra se encuentra disponible para su lectura en http://www.gutenberg.org/files/19560/19560-h/19560-h.htm. El estudio de la familia "Jukes" se editó en 1874. La obra de Richard Dugdale se tituló The Jukes: a study in crime, pauperism, disease and heredity. Más tarde, en 1912, Henry Goddard publicó The kallikak family: a study in the heredity of FeebleMindedness. 
anticoncepción y cuestionaba: “¿qué quieren los higienistas hacer con sus calditos y su asistencia social y demás terapéutica reformista y contemporizadora?” (Lazarte, 1936: 116).

La esterilización de los “degenerados" era justificaba por Lazarte, al igual que su maestro, en tanto no perjudicaba a las personas esterilizadas y proveía "ventajas colectivas que producía (Lazarte, 1936: 119). Para mostrar el panorama de las prácticas esterilizadoras de ese momento, tomaba los casos de Estados Unidos y Alemania. Sobre las prácticas en Estados Unidos no realizaba ningún comentario, pero sobre la situación de Alemania se explayó siguiendo la línea argumentativa de Nicolai y criticó el carácter "reaccionario" que la eugenesia había asumido allí (Lazarte, 1936: 122).

A diferencia de Beruti que, como hemos mencionado, no realizó ninguna crítica sobre el régimen nazi y admiró las políticas esterilizadoras implementadas, Lazarte, que si bien estaba a favor de la esterilización, se permitía disentir y cuestionar. En este sentido, señaló que: "bajo la férula de una dictadura de clase, ha devenido un arma de lucha política, un instrumento de intereses partidarios y un medio de venganzas esgrimido contra los que no participan de la barbarie hitlerista. Se esteriliza a judíos, a comunistas, a socialistas" (Lazarte: 1936: 122).

El peligro que conllevaban las prácticas eugénicas en manos del poder imponía la necesidad de que nunca "la Salud Pública o la Sanidad, estén confinados a las fuentes de pasiones políticas" (Lazarte, 1936: 123). Para ello, señalaba, sólo aquellos médicos que no estaban al servicio de la autoridad y tuvieran como misión el beneficio de la humanidad podrían estar a cargo de la aplicación de la eugenesia. Asimismo, también era primordial eliminar el problema de la pobreza para evitar que los gobiernos legitimándose en la "degeneración”- esterilizaran a campesinos y obreros que, por sus ideas, incomodaban.

A estas medidas drásticas sumaba normas de mejoramiento social dado que "ningún país quiere tener una población débil, tarada, con sectores amplios de la familia Juke o Kallikak". Por lo tanto, era necesario implementar una "medicina integral que se ocupe de los niños mal nutridos, de las mujeres abandonadas, de los hombres desocupados, de los alcoholistas, de los sifilíticos y tuberculosos sin tratamiento, del régimen de trabajo y del buen régimen sanitario" (Lazarte, 1943: 21). 
Es decir, consideraba que la cuestión social no podía reducirse a una cuestión eugenésica hereditaria, biológica. Así, la mortalidad infantil también se debía a la influencia del medio ambiente, denunciaba que "el hambre, la desocupación, la miseria, la ignorancia, el conventillo o el rancho actúan poderosamente en el niño y en la raza" (Lazarte, 1936: 87).

Como mencionamos en relación con el aborto, hay un silencio en las narrativas de Martín Fernández también en este tema. Su preocupación central fue la libertad sexual, en particular de las mujeres, y a través de los consultorios se ocupó de los métodos anticoncepcionales para alcanzarla. Sobre esta cuestión profundizaremos en el último capítulo sobre la libertad sexual.

Lazarte, en cambio, fue un decisivo defensor de las prácticas esterilizadoras, aunque nunca describió a través de qué procedimientos se llevarían a cabo, quiénes participarían de la decisión y dónde se realizaría. Este apoyo a la esterilización por motivos eugénicos lo acerca a las posturas de los médicos dominantes, el "perfeccionamiento de la raza" atraviesa en este punto a dos posiciones médicas disímiles pero que quedan reunidas bajo el paraguas de la eugenesia. Sin embargo, aunque el procedimiento sea compartido, las divergencias aparecen cuando se observa el contexto dado por las otras dimensiones del control de la natalidad que aquí hemos analizado.

\section{Conclusiones}

En este capítulo nos propusimos indagar las ideas sobre el control de la natalidad en el discurso médico ácrata en relación a la eugenesia y a la emancipación sexual.

Para ello, ahondando en la perspectiva relacional que asumimos en este estudio, repasamos los discursos de los médicos dominantes y las médicas feministas. Sistematizamos tres dimensiones del control de la natalidad que nos interesó analizar: los métodos anticonceptivos, el aborto y la esterilización. En cada una de ellas pudimos establecer coincidencias y divergencias entre los distintos posicionamientos que evidencian las diversas apropiaciones o usos de la eugenesia, que también nos permite 
mostrar el carácter construido de las narrativas científicas y la influencia de la ideología en las distintas modulaciones.

El control de la natalidad fue, en las voces de los médicos dominantes, un tema del que sólo estaban autorizados a hablar y practicar los profesionales. Las mujeres, en particular, no podían acceder a ese conocimiento pues ellas no eran (son) dueñas de su cuerpo.

Las médicas feministas también callaron sobre esta cuestión. Su interés no estaba dado por pretender un control sobre el cuerpo de las mujeres para subordinarlas, sino que -abocadas a la estrategia maternalista en la lucha política y estructuradas dentro de una matriz clásica de derechos en la cual los sexuales y reproductivos no estaban expresamente incluidos- no se preocuparon por el control de la natalidad como un acto emancipatorio.

Para los médicos ácratas, el control de la natalidad era una apuesta eugénica y emancipadora. La multiparidad era considerada un factor de degeneración y al mismo tiempo, era la muestra de la falta de conocimientos anticoncepcionales, herramientas que permitirían seguir con la vida sexual heterosexual, sin preocuparse por la reproducción.

La eugenesia en clave liberadora, al mismo tiempo que propició ideas que apuntaban a la limitación de la reproducción de ciertos elementos considerados patológicos y perjudiciales para el futuro de la sociedad anarquista, brindó herramientas y conocimientos sexuales para garantizar el disfrutar de las uniones sin preocuparse por la reproducción y entregarse al placer sin miedo. En los siguientes capítulos ahondaremos en la maternidad consciente y voluntaria y el placer sexual, dos vertientes que se originan en la propuesta de control de la natalidad. 


\section{Capítulo 4}

\section{Otras maternidades posibles. La propuesta ácrata de maternidad consciente y voluntaria como herramienta emancipadora}

La transición demográfica ocurrida en el país, comparada con Europa y América Latina, ha sido caracterizada como un "modelo no ortodoxo". El modelo clásico presenta primero una baja en la tasa de mortalidad como resultado del proceso de modernización. La tasa de natalidad se mantiene alta por un período prolongado, provocando un crecimiento demográfico hasta que, a partir de cambios sociales y culturales, la tasa de fecundidad comienza a disminuir. En Latinoamérica, la tasa de fecundidad se mantuvo alta hasta fines de los años 60, en cambio en la Argentina disminuyó tempranamente, coincidiendo con la baja en la tasa de mortalidad. Esto es lo que caracteriza la peculiar transición demográfica del país (Otero, 2004; Flores Cruz, $\mathrm{s} / \mathrm{f})$.

La tasa de fecundidad general (número de hijos por cada mil mujeres en edad reproductiva) disminuyó de 201, a principios del siglo XX, a 103 entre 1935-1939 (Pantelides y Moreno, 2009). El conocimiento y el uso de las herramientas anticoncepcionales y las prácticas abortivas por parte de la población fueron considerados los responsables de esta baja en la tasa de fecundidad y las mujeres se volvieron objeto de las medidas para revertir la situación al considerar, exclusivamente, su real o potencial capacidad reproductiva, invisibilizando la capacidad del varón (Nari, 1996; Barrancos 1991, 2007). Así, se convirtieron en sujetos de algunos derechos, y otros les fueron vedados, debido a su capacidad potencial de ser madres (Nari, 2004).

Las estrategias del pensamiento poblacionista han sido distinguidas como promaternalistas y pronatalistas según los anclajes teórico-metodológicos de las investigaciones (Biernat, 2005b). En particular, las políticas del gobierno peronista han generado diversas interpretaciones (Valobra, 2004).

Las indagaciones sobre la eugenesia en el país han señalado el carácter selectivo del pronatalismo en el país (Miranda, 2005a), que se preocupó por revertir la baja en la tasa de natalidad definiendo quiénes eran aptos para reproducirse y quiénes no. En esta 
misma línea, pero orientada al análisis del discurso católico, se señaló la preocupación por combatir la denatalidad a través de la prohibición del control de la natalidad, la defensa de la castidad y la reproducción dentro de la matrimonio, encuadrada dentro de un discurso eugénico (Rodríguez, 2009a; 2009 b).

Los estudios sobre la maternalización de las mujeres han hecho hincapié en las estrategias promaternalistas del discurso médico para combatir la despoblación y la “degeneración de la raza” (Nari, 1996; 2004).

El panorama sobre las políticas implementadas, así como los discursos que le dieron origen, nos muestra el dominio de un discurso que promovió un modelo de maternidad que obturó y excluyó otros modelos posibles, entre ellos, la propuesta de maternidad consciente y voluntaria en el discurso anarquista.

En los abordajes reseñados se destaca la excepcionalidad del discurso de Juan Lazarte dentro del campo médico. Específicamente, su obra El contralor de los nacimientos (1934) ha sido la única fuente relevada para analizar las posiciones del anarquismo local. Así, la propuesta de maternidad consciente y voluntaria, resultante del uso de herramientas anticoncepcionales, fue vinculada y analizada como parte de la propuesta política y eugénica primordialmente (Barrancos, 1990; Nari, 2004; Miranda y Vallejo, Miranda, 2011; Biernat, 2005a) y no se profundizó en la influencia que tuvo este discurso para promover la emancipación sexual de las mujeres. Aun cuando se señala que desde este posicionamiento la maternidad se consideró un derecho, se pone el acento en las limitaciones que conllevó la mirada ácrata pues, al mismo tiempo, promovió un modelo tradicional de madre (Nari, 2004). Del mismo modo, como hemos indicado en relación con la eugenesia y el control de la natalidad, cuando se señalan las ideas de libertad sexual, al restarle continuidad al movimiento, estas miradas se concentran en las primeras décadas del siglo XX (Miranda y Vallejo, 2003).

Como hemos señalado, las diversas fronteras temporales, dimensionales e interpretativas que analizan el anarquismo en Argentina han recreado una imagen sesgada de las propuestas anarquistas, en particular de las voces médicas en el marco de esas propuestas, principalmente las ideas de Juan Lazarte. 
En los capítulos precedentes, hemos advertido, por un lado, que las ideas sobre la diferencia sexual y los roles determinados a partir de aquélla desde el discurso médico han hecho hincapié en la maternidad como elemento constitutivo de la feminidad, otorgándole diversas significaciones según el posicionamiento político e ideológico desde el cual locutaban. Por otro lado, hemos evidenciado las múltiples adaptaciones del discurso eugénico en cuanto a las ideas sobre el control de la natalidad. En continuidad con esta línea argumentativa, nos interesa analizar y situar los discursos provenientes del movimiento anarquista a través de las voces médicas y de las mujeres ácratas.

En este capítulo, nos abocamos a analizar cómo, a partir de las ideas sobre control de la natalidad, aparece en el anarquismo un discurso sobre la maternidad consciente y voluntaria, que lo diferencia de las posturas promaternalistas y pronatalistas extremas del discurso dominante y de las posiciones cercanas al maternalismo político que promovieron, con matices, las feministas. Señalaremos la propuesta de maternidad consciente y voluntaria como resultante de aquellas ideas analizadas anteriormente. Entendemos que esta apuesta propició la demanda de derechos sexuales y reproductivos.

Afirmada en la perspectiva teórico-metodológica en la que se inscribe este estudio, abordaremos otras posiciones del campo médico-político en relación con la maternidad. Por un lado, analizaremos el discurso promaternalista y pronatalista de los médicos dominantes que tuvieron injerencia en el diseño de políticas públicas sobre el tema. Avanzaremos sobre las ideas de quienes representaron este posicionamiento, entre ellos, Beruti y los médicos católicos. Por otro lado, relevaremos las ideas de Alicia Moreau de Justo que nos permitirán acercarnos a otra perspectiva de la maternidad. Por último, nos abocaremos al estudio de la noción de maternidad consciente y voluntaria enunciada desde el anarquismo a través de los médicos y de las mujeres ácratas. Analizaremos sus posicionamientos discursivos en relación a las ideas circulantes sobre la maternidad y a las políticas públicas que las sustentaban. Nuestra hipótesis es que, contraria a una política pronatalista y promaternalista, la maternidad consciente y voluntaria, resultado de la aplicación de métodos anticoncepcionales y como parte de la propuesta eugénica ácrata, al mismo tiempo sustentó la emancipación femenina en cuanto a la capacidad volitiva de las mujeres para decidir cuándo y cómo ser madres. 
La periodización de este capítulo está definida a partir de la mayor intervención estatal para promover un ideal de maternidad en los años 30 que delineó las disputas en relación con las concepciones sobre la maternidad que nos interesa abordar en el campo médico. Así, avanzaremos hasta los primeros años del peronismo dado que quisiéramos considerar, más allá de las voces médicas anarquistas, las ideas de las mujeres ácratas en cuanto a la maternidad y las críticas sobre las políticas peronistas en relación con aquella. Ello nos permite señalar también los cambios en el tratamiento de los temas de nuestra investigación dentro del movimiento ácrata ante la llegada del peronismo.

\section{Entre educar y prohibir. Las estrategias del discurso dominante para imponer el modelo de mujer-madre}

El contexto de denatalidad, motivó la preocupación por aumentar el crecimiento de la población. Por ejemplo, durante el Primer Congreso de Población realizado en 1940 auspiciado por el Museo Social Argentino se propusieron medidas para fortalecer la institución familiar, demandando una mayor intervención estatal (Ramacciotti, 2005). Por medio de un sistema de premios y castigos, al igual que en el régimen fascista italiano (Miranda, 2011), se impuso un modelo familiarista en el cual las mujeres debían cumplir su deber maternal.

Los esfuerzos del discurso dominante en sus diversos campos se concentraron en imponer, promover y mantener la maternidad -junto con la heterosexualidad- (Rich, 1985 [1980]) como características innatas de la mujer, obstaculizando la posibilidad de elegir. En el caso del discurso médico oficial, que sustentó la enunciación e implementación de políticas públicas para la maternalización de las mujeres, las estrategias principales fueron educar y prohibir.

En el caso de Beruti, representante del discurso médico oficial, como señalamos en el capítulo dos, la contradicción establecida en relación con la necesidad de educar la vocación congénita de las mujeres a la maternidad se vinculaba con la preocupación eugenésica del médico. Si bien intentaba justificar que la exclusiva función social de la mujer era ser madre, para lograr la mejora de la raza, debía enseñarse a las mujeres, como ser la mejor madre. La preocupación no eran las mujeres en sí, sino la salud de sus posibles descendientes. En este sentido abocó todos sus esfuerzos desde los distintos 
espacios institucionales en los cuales se desempeñaba para imponer y reforzar un ideal para todas las mujeres a través de la educación.

La estrategia del discurso de los médicos católicos, en cambio, se orientó a la prohibición de cualquier discurso, conocimiento y práctica que brindara la posibilidad de tomar control sobre el proceso reproductivo y así elegir voluntariamente el ejercicio de la maternidad. Legitimando su acción en las directivas emanadas por el Vaticano, los médicos del Consorcio entablaron disputas explícitas con quienes apoyaban y difundían los conocimientos para controlar la natalidad y reclamaban la intervención estatal para combatir la difusión de aquellos discursos. Asimismo, también se esforzaron en legitimar desde el paradigma médico y religioso la constitución de familias numerosas para revertir el problema de la denatalidad.

\section{1. a. Educar la maternidad congénita. El pensamiento médico eugénico dominante}

Entre los protectores oficiales de la maternidad, el médico Josué Beruti fue un destacado promotor de las políticas destinadas a la maternalización de las mujeres. A través de sus diversos espacios de acción, en la cátedra de Clínica Obstétrica, la sección Eugenesia, Maternidad e Infancia de la Asociación Argentina de Biotipología, Eugenesia y Medicina Social y la Escuela de Madres que creó dentro de la Clínica Eliseo Cantón, llevó adelante un programa de educación con el objetivo de construir a las mujeres-madres.

La preocupación de Beruti se relacionaba con las ideas eugénicas que analizamos en el capítulo precedente. Si las mujeres aprendían cómo ser mejores madres aun antes de decidirlo, podrían tener los cuidados necesarios para que su progenie fuera saludable.

Algunas de las ideas de Beruti con referencia a la maternidad fueron analizadas en el segundo capítulo de este estudio, en el cual se explica la conceptualización de la diferencia sexual y los roles de género que fundamentaban los planteos maternalistas del profesional. En este capítulo, avanzaremos sobre las propuestas de Beruti implementadas en dos instituciones en cuya creación intervino: la sección de Eugenesia, Maternidad e Infancia y la Escuela de Madres. Nos interesa ahondar en este punto pues 
consideramos estas instituciones antecedentes de la Dirección de Maternidad e Infancia, repartición estatal creada posteriormente. Durante estos años, como señala Marisa Miranda, las "elites políticas se mantuvieron fuertemente amalgamadas con los miembros representativos del campo de las Ciencias de la Salud" que, bajo el paradigma "de la Eugenesia y la Biotipología, demandó profundas restricciones a las libertades individuales" (Miranda, 2003: 234). Estas iniciativas privadas contaron con el respaldo del gobierno de Agustín P. Justo, aunque no se tradujo en apoyo económico, pero otorgó legitimidad a estas iniciativas.

Al acceder a la titularidad de la cátedra en 1931, a Josué Beruti le correspondió la dirección de la Cínica Obstétrica y Ginecológica Eliseo Cantón del Hospital Ramos Mejía. Bajo la influencia de la obra llevada a cabo por su colega, con quien compartía espacios institucionales e ideales, Alberto Peralta Ramos en el Instituto de Maternidad del Hospital Rivadavia, inaugurado en 1928, y por el trabajo de asistencia a la maternidad realizado por el médico Augusto Turenne en Uruguay (Pou Ferrari, 2005), Beruti puso en marcha un servicio social con el objetivo de "salvar a la madre, salvar al hijo y propender el mejoramiento de la estirpe"(Beruti, 1932, en Beruti, 1943, t. III: 535) El servicio social estaba a cargo de María E. Zurano, colaboradora de Beruti en los temas de protección de la maternidad, en particular, de las madres solteras. El plan se diseñó en dieciséis etapas; entre ellas, se destacaba la formación de las visitadoras del Servicio Social, su desempeño en las salas de internación y en consultorios externos, la creación de un hogar para embarazadas y puérperas, la realización de talleres, la educación primaria para las internadas y la creación de una escuela de madres de puertas abiertas. En el balance de los primeros años, Beruti señaló las resistencias y la desconfianza de las mujeres internadas ante el nuevo servicio social y las dificultades de establecer la continuidad de la acción de las visitadoras dado que ellas trabajaban ad honorem. ${ }^{39}$ La falta de recursos económicos, señalaba Beruti, podría solucionarse con la creación de una cooperadora pero, para él, esa modalidad era característica del pasado y no de la moderna asistencia social. Criticaba las sociedades de beneficencia compuestas

\footnotetext{
${ }^{39}$ Las visitadoras eran estudiantes o egresadas del Museo Social Argentino, institución privada con gran influencia en el poder político que incorporó como institución de extensión universitaria de la Universidad de Buenos Aires en 1927 y crea en 1930 la Escuela de Servicio Social a cargo de Germinal Rodríguez y Alberto Zwanck (Becerra Solá y Becerra, 2009).
} 
por señoras pues su accionar conllevaba "prejuicios religiosos" (Beruti, 1932, en Beruti, 1943, t. III: 535)

El hogar contaba con 14 camas para puérperas y 11 camas para madres menores solteras, primordialmente. En los talleres se confeccionaba la ropa que utilizaba la Maternidad y se enseñaba a tejer. También contaban con una biblioteca y clases a cargo de maestras normales. Pero lo más destacado de la obra del servicio social era la Escuela de Madres de puertas abiertas, creada en diciembre de 1932. En ella se evidencia la puesta en práctica de la ideología maternalista. Las mujeres que concurrían a los consultorios podían asistir de 8.30 a 9.00 hs. a distintas clases prácticas de: Asistencia Social y Economía Doméstica, a cargo de la señorita Zurano; Puericultura, a cargo del Dr. Galdi; Eugenesia y Profilaxis, a cargo del Jefe de Clínica Dr. Palazzo; Higiene del Embarazo, a cargo del Dr. Cabello y Primeros Auxilios e Higiene en general y del Puerperio, a cargo de las visitadoras Celín y Casademont (Beruti, 1932, en Beruti, 1943, t. III: 535). El programa se proponía "proteger a la mujer antes del embarazo, durante el embarazo, durante el parto y después del parto, conjuntamente con el nuevo vástago" (Beruti, 1932, en Beruti, 1943, t. III: 536).

Dirigida a educar, principalmente, a las mujeres indigentes y obreras, la obra impulsada por Beruti, por un lado, intentaba reforzar el binomio madre-hijo. Por otro lado, su interés estaba puesto en la mejora de la raza a través de la vigilancia y el control de esas mujeres que podrían tener mayores problemas de salud y que, por ende, podían transmitir esos males a su descendencia. Asimismo, estos intereses fueron reforzados a través de la Asociación Argentina de Biotipología, Eugenesia y Medicina Social de la cual Beruti era miembro. Dentro de ella, se inauguró en 1934 la sección Eugenesia, Maternidad e Infancia bajo su dirección. Desde allí se propuso, a fin de aumentar las acciones que venía implementando en la clínica, difundir los principios eugénicos, maternológicos y de higiene infantil a través de la propaganda y la enseñanza. Para ello, la sección se proponía realizar la creación de maternidades escuela, exhortaría la obligatoriedad de cursos sobre maternología y puericultura en todos los niveles de instrucción y llevaría adelante investigaciones científicas que permitieran presentar informes ante autoridades nacionales e internacionales (Beruti, 1934, en Beruti 1943, t. III: 494). 
La maternidad, como ya hemos hecho referencia, era la suprema y única misión para la mujer según este posicionamiento discursivo representativo de la elite médica. Para ello, las mujeres debían recibir una educación oficial orientada a la maternidad y circunscripta al espacio doméstico desde su niñez, al igual que se realizaba en Italia y Alemania, modelos inspiradores de políticas promaternalistas y pronatalistas legitimadas con el fin de contrarrestar la caída demográfica. Contra la/os que consideraban que estas ideas eran humillantes para las mujeres, Beruti, señalaba que lo que se perseguía era "su dignificación". 40 En "armonía con su sexo", decía, las actividades académicas que requerían una actividad intelectual no le correspondían, dado que esa era una actividad definida como masculina. Para llevar adelante su misión, debía dedicarse al "trabajo manual, la economía doméstica, los conocimientos prácticos de la vida diaria, los idiomas, la iglesia" (Beruti, 1934a, 1943t. IV: 10).

Además de la educación como medio para garantizar la maternalización de las mujeres, otras medidas eran necesarias para alcanzar ese objetivo, entre ellas, mencionaba junto a Peralta Ramos:

La investigación de las causas del infanticidio; la represión del aborto criminal; la denuncia obligatoria del embarazo; el reconocimiento médico prematrimonial, el consejo prenupcial, el certificado prematrimonial, el permiso matrimonial y la carta de familia; el estudio de las relaciones entre la Eugenesia y el Derecho [...]; la defensa de los peligros del neomathusianismo, la maternidad consciente, etc. (Beruti y Peralta Ramos, 1935, en Beruti, 1943, t. III: 506-507)

Beruti logró hacer escuela y sus ideas prosperaron y contaron con varias mujeres que lo apoyaron. Podríamos considerar que la defensa de las ideas dominantes le permitió su participación en espacios de poder y de decisión que eran vedados para la mayoría de las mujeres y, en especial, a las que no comulgaban con esas propuestas -como en el

\footnotetext{
${ }^{40}$ Cursiva en el original.
} 
caso de las médicas feministas-. Dos ejemplos de ello son Mercedes Rodríguez de Ginocchio y su colaboradora María Encarnación Zurano.

Mercedes Rodríguez de Ginocchio impulsó ideas maternalistas en sintonía con las propuestas de Beruti y se especializó en los problemas que podrían interferir en la capacidad reproductiva de las trabajadoras, actuó en el Museo Social Argentino donde, en la década del 30, estuvo a cargo de la Secretaría de Previsión e Higiene Social (Becerra Solá y Becerra, 2009). Como señalan Biernat y Ramacciotti (2013), la médica se preocupó de manera marginal por la salud de las mujeres, dado que el interés, desde una perspectiva eugénica, estaba puesto en la capacidad de gestar hija/os sana/os.

El trabajo femenino era considerado uno de los motivos de la baja de la natalidad. A principios del siglo XX, esta preocupación se reflejó en las leyes protectoras sobre el trabajo femenino (Lobato, 2007) y, más tarde, se evidenció a partir de una mayor intervención del Estado a través de la creación de agencias estatales específicas dedicadas a la cuestión de la maternidad (Ramacciotti y Biernat, 2008).

La participación de las mujeres en la creciente producción industrial nacional desarrollada a partir de las consecuencias económicas de la Segunda Guerra Mundial alarmaba a Rodríguez de Ginocchio. Ella sostenía el espacio doméstico como lugar exclusivo de realización de la mujer, el trabajo fuera del hogar era considerado una obligación, una situación transitoria, como señala Graciela Queirolo (2008), que se producía a causa de la muerte o la enfermedad del varón de la familia.

Para hacer frente a este problema, junto al abogado Carlos Bernaldo de Quirós, Rodríguez de Ginocchio planteó:

o la mujer, mayor o menor de 18 años (madre en potencia), queda en la casa con nuevos y firmes estímulos morales, económicos y legislativos que la enraícen al hogar, al servicio de nuestro enriquecimiento demográfico [...] o habrá que crear en el Código Penal una sanción específica ejemplar contra el capitalismo [...], que cometa delitos contra las personas, contra la salud pública y contra el patrimonio biológico humano de la República. (Rodríguez de Ginocchio y Bernaldo de Quirós, 1941: 37) 
Las mujeres que ya habían pasado su edad reproductiva eran las únicas autorizadas a trabajar en las industrias dado que ya "no representan un peligro ni pérdida de valor genético para la nación” (Rodríguez de Ginocchio y Bernaldo de Quirós, 1941: 37). La maternidad se presentaba en este discurso como una obligación o un deber antes que un derecho, en consonancia con las ideas de Beruti y, como veremos, con las ideas de los médicos católicos.

Otra figura que siguió las propuestas de Beruti fue María E. Zurano, egresada de la Escuela de Servicio Social del Museo Social Argentino, quien estuvo a cargo del servicio social de la Clínica Eliseo Cantón. Luego, en 1938 fue docente de Enseñanza Práctica en la Escuela de Visitadoras de la Facultad de Ciencias Médicas de la Universidad de Buenos Aires y, unos años más tarde, en 1940, formó parte del cuerpo docente de la Escuela de Asistencia Social creada por el Instituto de Cultura Religiosa Superior Femenina de la Iglesia Católica (Oliva, 2007).

En su cargo como jefa del servicio social sus actividades se concentraron en la atención a las madres solteras. Junto a Beruti se abocó al análisis del problema y plantearon algunas soluciones. La madre soltera, señalaban, se redimía de su "pecado" a través de su hijo pues él podía "salvarla y nivelar su estado al de todas las madres, cuando el sentimiento materno la sostiene y guía" (Beruti y Zurano, 1934, en Beruti, 1943, t. III: 581). Como señala Nari, las propuestas médicas oficiales hacia las "madres solteras" no se traducían en nuevas consideraciones sobre la mujer y su libertad sexual, como veremos en la prédica médica anarquista, sino que respondían a otras lógicas:

por un lado, la mujer no era considerada sujeto de su destino. Existía un estereotipo definido detrás de cada madre soltera: una mujer joven (en muchos casos, menor de edad) que, por su inocencia o por su profundo amor a un hombre, había sido objeto de seducción, de engaño y de abandono. Por otro, sus intereses abarcaban problemas poblacionales, ligados a la sociedad y el Estado, en las cuales las mujeres no eran sino las intermediarias obligadas. (Nari, 2004: 140) 
La reproducción por fuera de esta institución era criticada; es decir, no todas las maternidades eran aceptables. Las madres solteras, aun cuando sus hijas/os fueran reconocidos por un varón, eran consideradas ilegítimas. Según Isabella Cosse, "la maternidad soltera era concebida una desviación" pues el vínculo matrimonial era considerado como "el rito que permitía la constitución plena de la identidad femenina" al ser esposa, ama de casa y madre y también la identidad masculina "en tanto que convertía al hombre en un jefe de familia con autoridad sobre la esposa y los hijos y la responsabilidad de satisfacer sus necesidades" (Cosse, 2008: 85).

Las consideraciones sociales sobre la madre soltera debían modificarse y, para ello, exigían una legislación que las salvaguardara. Este pedido se materializó el 21 de diciembre de 1936 con la sanción de la ley $N^{\circ} 12341^{41}$ que dio origen a la Dirección de Maternidad e Infancia. Como señalan Biernat y Ramacciotti (2008), la creación de instituciones que se dedicaran a la protección de las madres y su prole se debía a la necesidad de resolver diversos problemas. En primer lugar, la baja del aporte inmigratorio y las bajas tasas de natalidad incidieron en los sectores de poder y su preocupación por aumentar la población. En segundo lugar, la difusión del discurso eugénico puso el acento en alcanzar la mejora de la raza a través del control de la salud de las mujeres-madres. Tercero, la incorporación de las mujeres al mercado de trabajo reforzó la ideología maternal que intentaba reincorporarlas al hogar. En cuarto lugar, se buscaba establecer la protección de las madres y sus hijas/os en el nivel nacional. Las autoras señalan, por último, las demandas de un reconocimiento oficial por parte de los profesionales de la salud especializados en la protección de las madres. La nueva agencia estatal, según el artículo 3 de la ley, tenía como finalidad el “perfeccionamiento de las generaciones futuras por el cultivo armónico de la personalidad del niño en todos sus aspectos combatiendo la morbimortalidad infantil en todas sus causas y amparando a la mujer en su condición de madre y futura madre". Para las mujeres que contradijeran los objetivos de esta política, el amparo se convertiría en sanción a través de una multa o la cárcel. Por ejemplo, a las mujeres que no cumplieran con "el deber de amamantar a su hijo", o lo hicieran con uno ajeno antes que con el propio, o no

\footnotetext{
${ }^{41}$ Disponible en http://www.boletinoficial.gov.ar/Inicio/Index.castle
} 
alcanzasen un período de amamantamiento de cinco meses, les corresponderían aquellas sanciones. El carácter artificial del binomio madre-hijo se manifestaba en la necesidad de obligar a las mujeres que preferían no ser madres a serlo, aunque ellas lo hubieran negado a través del abandono de su hija/o. Las autoridades, señalaba la ley, "podrán ordenar la detención de la misma y su internación en un hospital, clínica o casa de corrección al solo objeto de que cuide a su niño" (Boletín Oficial, 11 de enero 1937: 259).

Los esfuerzos de Beruti dieron sus frutos en la nueva legislación, aunque los alcances prácticos de la misma hayan sido relativos. Ello resulta en sintonía con los resultados expuestos por Biernat y Ramacciotti (2008), que señalan que si bien los discursos pronatalistas sustentaron los proyectos legislativos en relación con el problema de la natalidad, en su aplicación estas políticas cobraron otro sentido. Sobre la base de su análisis sobre la actuación de la Dirección de Maternidad e Infancia, creada en 1936, las autoras pusieron de relieve la importancia que adquirió el binomio madrehijo para la acción estatal, así como las sinuosidades de esta acción según los períodos. El acento estuvo puesto en la protección de las mujeres en tanto madres reales o potenciales. Asimismo, Nari señala que la educación de las mujeres en cuestiones de puericultura, la protección de las embarazadas y del binomio madre-hijo, "se enlazaba al discurso pronatalista y eugenésico, puesto que contribuía al aumento de la población y al «vigor» de la raza" (Nari, 2004: 179).

Con la llegada del peronismo, la intervención y el control que estaban presentes en las políticas de maternidad desde 1930 fueron retomadas por el gobierno, pero con algunos desplazamientos. El interés, como han señalado los estudios sobre la implementación de las políticas públicas durante este período, pasó de las madres a los y las infantes y los esfuerzos se dirigieron a proteger a la niñez. Como señalan Valobra y Ramacciotti (2004) en relación con las políticas implementadas desde el Ministerio de Salud Pública, el Estado reemplazó a la madre en la crianza de sus hija/os a través de diversas instituciones y espacios de socialización. Esta cuestión también se evidenció en la ampliación del número de jardines de infantes y la obligatoriedad del nivel inicial de educación (Ledesma Prietto y Valobra, 2007). 


\section{1. b. La maternidad obligatoria a través de la prohibición del control reproductivo en el discurso médico católico}

Los médicos del Consorcio Católico se preocuparon por la consolidación de la nación católica en el contexto denatalista. Su intervención estuvo guiada, señala Omar Acha, por los tópicos planteados en la Encíclica Casti Connubbi, "el control de la natalidad y la eugenesia" (2001: 169). La carta encíclica que dio a conocer el Papa Pío XI el 31 de diciembre de 1930 trataba sobre el matrimonio cristiano. En ella se ocupó de la indisolubilidad del matrimonio, promulgó su oposición a cualquier prohibición matrimonial, a cualquier método anticonceptivo, al aborto y al divorcio e instaba a los sacerdotes a "aconsejar" a sus fieles en la elección de los cónyuges, evitando que contrajeran matrimonio con quienes "sólo podrían engendrar hijos defectuosos" (Miranda, 2011: 49). Asimismo, justificó la sumisión de la mujer al varón respaldándose en San Agustín, quien decía que "las casadas estén sujetas a sus maridos, como al Señor; porque el hombre es cabeza de la mujer, así como Cristo es cabeza de la Iglesia" (Pío XI, 1930: s/p) y se opuso a la emancipación de la mujer en todos sus dimensiones: económica, social y fisiológica. ${ }^{42}$ Como plantea Rodríguez (2009b), el documento confirmaba la autoridad de la iglesia en cuestiones de la vida privada y la conformación de la familia. Estas cuestiones fueron las que guiaron la práctica discursiva de los médicos, la cual pueden registrase a través de su revista Iatría. ${ }^{43}$

A través del estudio de la construcción de la mujer-madre, Nari señaló que desde el discurso médico "la desnatalización era vinculada a la expansión de las posibilidades públicas de las mujeres: otros empleos, educación superior, la «nueva

\footnotetext{
42 Pío XI señalaba que la sumisión de la mujer "no niega ni quita la libertad que en pleno derecho compete a la mujer, así por su dignidad de persona humana como por sus nobilísimas funciones de esposa, madre y compañera, ni la obliga a dar satisfacción a cualesquiera gustos del marido, no muy conformes quizá con la razón o la dignidad de esposa, ni, finalmente, enseña que se haya de equiparar la esposa con aquellas personas que en derecho se llaman menores y a las que por falta de madurez de juicio o por desconocimiento de los asuntos humanos no se les suele conceder el ejercicio de sus derechos, sino que, por lo contrario, prohíbe aquella exagerada licencia, que no se cuida del bien de la familia, prohíbe que en este cuerpo de la familia se separe el corazón de la cabeza, con grandísimo detrimento del conjunto y con próximo peligro de ruina, pues si el varón es la cabeza, la mujer es el corazón, y como aquél tiene el principado del gobierno, ésta puede y debe reclamar para sí, como cosa que le pertenece, el principado del amor" (Pío XI, 1930: s/p).

${ }^{43}$ La revista Iatría era el órgano de difusión del Consorcio, comenzó a publicarse en 1930 y se mantuvo en circulación a través de suscripciones hasta el año 2008 (Rodríguez, 2009a).
} 
mujer» que aparecía en las calles urbanas, la «mujer moderna»" (Nari, 2004: 191). La relajación de los valores morales y la búsqueda del placer sexual independientemente de la reproducción también eran considerados factores que promovía la desnatalización. Incluso, la sexualidad recreativa dentro de la institución matrimonial era reprendida dado que iba en contra del objetivo principal del matrimonio: la procreación. Como señalamos en los anteriores capítulos, a diferencia de los médicos de la elite como Beruti, que se abocaron a la educación maternalista y demandaron políticas de maternidad en ese sentido, los médicos católicos pusieron el acento en la demanda de políticas represivas de cualquier conducta contraria a la procreación dentro del matrimonio. Si bien el refuerzo del binomio madre-hijo era central para sus objetivos, no hicieron hincapié en la necesidad de construir y tutelar esta relación, sino que bajo el paraguas del problema de la denatalidad solicitaron medidas que obligaran a las mujeres a parir. A través de la represión del aborto, el conocimiento y la utilización de cualquier herramienta anticoncepcional, incluso, como vimos en el capítulo anterior, el método Ogino-Knaus (Castaño, 1939). En relación con este método, que se basaba en la continencia periódica, se señalaba que el problema no era mantener relaciones durante el período de fertilidad y hacer uso de la continencia en el período fértil. La cuestión que penalizaba esta práctica era hacerlo deliberadamente, los profesionales expresaban "querer evitar por este medio toda maternidad, excluir absoluta y definitivamente lo que es el fin principal del matrimonio sería una intención culpable que haría inmoral el uso sistemático de la continencia periódica” (Riquet y Gaucherand, 1939: 42).

Por ello, se solicitaba la prohibición de su divulgación. A estas medidas restrictivas se sumaba el pedido de disposiciones que premiaran a las familias numerosas con mejoras económicas como se había propuesto en el Primer Congreso de Población (Rodríguez, 2009b).

La denatalidad como problema demográfico cuadraba con las intenciones de los médicos católicos y les brindó la justificación para llevar adelante una afrenta contra los derechos reproductivos de las mujeres. En su batalla contra el aborto, aun oponiéndose a las circunstancias contempladas por ley penal, los médicos católicos dejaban al descubierto sus consideraciones sobre la mujer. El médico católico de la Universidad de Córdoba Ramón Brandán señalaba “el feto humano «in utero», desde el 
momento de la concepción, no es solamente una individualidad, es también una personalidad, constituye una persona moral y jurídica, que en el terreno legal tiene derechos por el sólo hecho de existir"44 (Brandán, 1939: 17). Las críticas sobre el aborto habían sido señaladas en la Encíclica Casti Connubii, en 1930, que objetó la práctica bajo cualquier indicación, fuera médica, social o eugénica (Pío XI, 1930). Retomando las críticas de la Encíclica a los planteos jurídicos que conceptualizaban al feto como "injusto agresor" para alegar el acceso a un aborto, Brandán señalaba que "nadie puede equiparar al feto al injusto agresor, a no ser por la única razón de ser éste el más dábil [débil], ya que solo tiene la culpa de existir” (Brandán, 1939:19). Así, el médico dejaba entrever que si había que elegir, se tenía que privilegiar al embrión, los derechos de éste primaban -aún hoy- por sobre los de la mujer. Asimismo, Castaño, entre las razones que argumentaba para penalizar la práctica del aborto, incluía la pérdida del instinto maternal y la consecuente virilización de la mujer, reforzando así la feminidad a la maternidad (1934).

La relevancia de la Encíclica para legitimar sus planteos se evidencia en las páginas de la revista y en las jornadas de estudio llevadas a cabo en mayo de 1939 por el Consorcio. En el transcurso de una semana las diversas conferencias se concentraron en las consecuencias sociales de los métodos anticoncepcionales, el aborto y la esterilización; la importancia del matrimonio para la procreación; la maternidad y la salud de la juventud (Iatria, 1939). Durante los primeros años de la década del 40 y el ascenso al poder de Juan Domingo Perón, la preocupación estuvo centrada en la intervención estatal en la organización de la salud y el papel de los profesionales médicos en el servicio público. Desde diferentes perspectivas ideológicas, como hemos señalado en el primer capítulo, el problema de la defensa de la profesión liberal frente al avance del Estado en las cuestiones de la salud de la población, fue un reclamo que los médicos del Consorcio compartieron con sus colegas de la COMRA, gremio médico en el cual se nucleaban los médicos ácratas.

Aunque los conflictos entre el peronismo y la iglesia católica, como señala Rodríguez (2003), cristalizaron cuando el Estado intervino en cuestiones que la iglesia pretendía controlar de manera exclusiva, en particular la familia, la educación y la

\footnotetext{
${ }^{44}$ Subrayado en el original.
} 
asistencia, el Consorcio de Médicos Católicos se había anticipado en enviar una advertencia a poco tiempo del ascenso de Perón. Luego de la creación de la Secretaría de Trabajo y Previsión a cargo del entonces Coronel Juan Domingo Perón, en 1944, el Consorcio se dirigió a esa dependencia a través de un memorándum en el cual señalaba los límites y atribuciones de la Secretaría y solicitaba que ésta no modificara o alterara con sus políticas las cuestiones éticas por ellos defendidas (Rodríguez, 2008).

El contexto político delineó los temas relevantes a presentar y discutir en la revista, los tópicos sobre la denatalidad, el control de la natalidad, el aborto volvieron a surgir con mayor énfasis en los discursos de los médicos católicos en las Primeras Jornadas Argentinas de Médicos Católicos: Problemas de Higiene Sexual realizadas en octubre de 1953 en Santa Fe. Su análisis excede nuestro período de investigación en este estudio, lo cual no implica dejar de señalar las continuidades discursivas que presentan los médicos católicos, podríamos arriesgarnos a decir, hasta el presente, sobre algunas cuestiones relevadas aquí.

En este apartado hemos abordado las ideas en relación con las estrategias asumidas por el discurso médico dominante para la imposición de un ideal. Ambos se preocuparon por construir una identidad femenina marcada por la maternidad, pero para hacerlo dedicaron sus esfuerzos a distintas estrategias que se complementaban satisfactoriamente. Por un lado, médicos como Beruti se abocaron a la educación de las mujeres para la maternidad. Propiciaron instituciones privadas que contaban con apoyo estatal e influyeron en el diseño de políticas públicas promaternalistas. Por otro lado, los médicos católicos optaron por otras estrategias para convertir a las mujeres en madres. Su preocupación no estuvo centrada en educar a las mujeres para la maternidad, hasta podríamos decir que la mujer no aparece en el discurso como un sujeto relevante. Los profesionales se abocaron a reprimir cualquier intento de evitar la procreación, entendiendo la maternidad como un mandato divino que no podía transgredirse. A través de la prohibición de la difusión de los métodos anticoncepcionales, la condena al aborto y la exaltación del fin procreativo de la institución matrimonial, las mujeres veían coartada la posibilidad de elegir y controlar los procesos fisiológicos de su cuerpo. A diferencia de estas dos posturas, a continuación revisaremos las ideas de Alicia Moreau de Justo, que, junto con otras 
mujeres, abrevó por una maternidad como herramienta legitimadora de su participación en la vida pública.

\section{La maternidad como herramienta política. Cuestionamientos al discurso dominante}

Estas miradas acendradas respecto de la maternidad innata de las mujeres fueron discutidas, con distinta intensidad y refinamiento conceptual por algunos movimientos políticos y sociales. Los ejemplos más elocuentes de ello fueron las posturas del feminismo y el anarquismo.

Respecto de las visiones del feminismo, hay varios estudios vinculados al tema que, a los fines de este apartado, sólo interesa introducir de manera general a fin de ofrecer un contrapunto respecto de la visión dominante. De esa manera, siguiendo a Scott, seguimos el camino de analizar esa visión dominante-normativa no como resultado de un consenso social sino de un conflicto en el que participaron distintas voces invisibilizadas por la Historia (1993).

Las investigaciones han conceptualizado las prácticas de las feministas de comienzos de siglo XX como maternalismo político (Nari, 1994), feminismo maternal (Bock, 1991) o feminismo relacional (Offen, 1991). Con estas denominaciones pusieron de relieve la función social de la maternidad para demandar derechos de ciudadanía femenina (Nari, 2004).

La maternidad fue aceptada como condición de feminidad $\mathrm{y}$, como señala Asunción Lavrin, para el feminismo del cono sur fue "definidor de la misión femenina dentro del hogar y la comunidad, y capacitador para la acción social y política" (Lavrin, 2005). Si bien el feminismo de la primeras décadas del siglo XX no fue homogéneo tenían en común "una formulación más política de la maternidad” (Nari, 2004: 240).

El maternalismo político giró alrededor de dos premisas. La primera, al ser madres las mujeres debían tener derechos sociales, civiles y políticos. La segunda, su participación transformaría la política, la sanearía al llevar al espacio público los atributos morales de la maternidad. Las feministas de las primeras décadas participaron 
del discurso maternalista, pero su propuesta distaba de las consideraciones del discurso dominante que utilizó la cuestión maternal como justificación para tutelar y subordinar la vida de las mujeres y recluirlas al espacio doméstico (Nari, 2004).

Si bien la categoría de maternalismo político posibilitó la visibilización y el análisis de las prácticas de las feministas de las primeras décadas del siglo XX, también, tendió a una generalización que dificultó percibir los matices y la diversidad de posiciones de aquellas mujeres. En este sentido, retomando las cuestiones planteadas en el segundo capítulo, la obra de Alicia Moreau de Justo permite realizar aportes para analizar el lugar de la maternidad como herramienta legitimadora de la participación de las mujeres en la vida pública y, asimismo, la singularidad que expresó respecto de sus contemporáneas.

En particular, nos interesa señalar la importancia otorgada por Moreau de Justo a la capacidad volitiva de las mujeres en relación con el ejercicio de la maternidad. Tradicionalmente, se ha considerado que la médica socialista compartió el ideario sobre la maternidad como "la misión natural" de la mujer (Nari, 2004: 259). No obstante, al acercarnos a sus ideas, es posible establecer los contactos y los distanciamientos entre esta perspectiva de la maternidad y la que nos proponemos abordar en este capítulo, la perspectiva ácrata de maternidad consciente y voluntaria.

Moreau de Justo fue una gran analista política de la situación nacional e internacional, lo cual se evidencia desde sus columnas en Vida Femenina. En su crítica a los regímenes totalitarios europeos subrayó que las políticas en relación con la mujer -admiradas por Beruti- se orientaban a "presentarle como ideal la fecundidad conejil", lo cual para ella, decía en aquel contexto "no es elevar a la mujer ni a la maternidad" (Moreau de Justo, 1945: 94).

Para combatir la situación en la que se encontraban las mujeres en relación con sus derechos y siendo ellas, las que quisieran, futuras madres responsables de la educación de sus hija/os, la práctica maternal se realizaría en mejores condiciones cuando las mujeres a través del ejercicio de sus derechos, en particular los políticos, se emanciparan. Moreau de Justo cuestionaba también los discursos dominantes que determinaban el espacio doméstico como lugar de realización exclusivo de la mujer, al señalar que las actividades dentro y fuera del hogar eran compatibles En este sentido 
indicaba que "pretender que la mujer moderna atienda su hogar desconociendo esos hechos fundamentales, indiferente a la solución de los problemas, es querer reducirla al rol de simple fregona" (Moreau de Justo, 1935: 4).

La médica socialista señaló que todas las personas -varones y mujeres- nacían con una vocación, pero no siempre era ésta la maternidad, para la mujer, o la paternidad, para el varón. Consideraba que "la mujer que no ha nacido para ser madre, será, sin dudas, una mala madre. Lo mismo que el hombre que no tiene el sentido de la paternidad, será un padre desamorado, a quien los hijos fastidien”. Así, la idea de la maternidad como parte constitutiva de la identidad femenina era cuestionada a partir de la elección de esa situación. En este sentido, expresaba "no creo que todas las mujeres tengan latente el deseo del hogar o de los hijos" (Moreau de Justo, 1938: 580). ${ }^{45}$ La maternidad accidental debía reemplazarse por "la maternidad consciente y voluntaria" que se alcanzaría a través de un "proceso de evolución mental” (Moreau de Justo, 1945: 194) que valorizaría la maternidad y, a cambio de ser ésta un obstáculo para la función política, sería “su mayor razón de ser”. Señalaba que "cuánto más alta sea la conciencia de su responsabilidad materna, más querrá la mujer poseer los medios de acción colectiva que permitan sobrellevarla mejor" (Moreau de Justo, 1945: 196).

En cierto modo, las médicas feministas -así como el movimiento feminista en su conjunto- parecían compartir varias de las ideas de las posturas dominantes sobre maternidad y respecto del destino natural de las mujeres en ese sentido, aunque no de manera excluyente. A partir de los años 40 el movimiento feminista sufrió un retroceso en su capacidad de acción. El ascenso del peronismo y el llamado a la movilización política de las mujeres por parte de Eva Perón y el apoyo al sufragio femenino fueron algunos de los sucesos que llevaron a la disminución de las fuerzas del movimiento (Valobra, 2010).

Contraria a los planteos de los médicos oficiales y católicos, Moreau de Justo sitúa la maternidad en otro registro que no es el del deber sino en el de la elección por lo que aquellas ideas le parecían injustas y absurdas. Con ello, matiza también las

\footnotetext{
${ }^{45}$ Entrevistada por Sara Papier en su columna "La voz de la mujer argentina" dentro de la revista Cultura Sexual y Física.
} 
locuciones de las feministas sobre este tema. Sin embargo, ella no se ocupó de desarrollar el modo en que se lograría una maternidad consciente y voluntaria, ni tampoco se explayó en las posibilidades de emancipación sexual de esta propuesta.

Si bien Moreau de Justo se aparta de la perspectiva maternalista reseñada anteriormente, no podemos situarla en la línea defendida por los médicos ácratas. Ella se ubica en la corriente del maternalismo político, pero matizadas o analizadas conjuntamente con sus ideas sobre la maternidad como elección y no como un deber, junto con la incidencia del medio antes que en la constitución orgánica que analizamos en el segundo capítulo, nos permiten situarla en el límite de aquella estrategia política, distanciarla de las posiciones maternalistas y señalar tanto las concurrencias como las diferencias con la perspectiva médica ácrata que veremos a continuación.

Siguiendo con la perspectiva contextualista que estructura nuestro estudio, el repaso de las ideas circulantes en cuanto a la maternidad nos permite situar la propuesta ácrata de maternidad consciente y voluntaria estableciendo las conexiones y las rupturas con aquellos repertorios.

\section{La maternidad consciente y voluntaria como estrategia para la emancipación sexual femenina}

Si consideramos la estrategia del control de la natalidad en el discurso anarquista sólo desde su conexión con las ideas eugénicas y neomalthusianas, o como una política de resistencia al capitalismo, perdemos de vista que también en su origen, y con más fuerza en su desarrollo, abrió nuevas dimensiones de derechos para las mujeres.

La postura anarquista encontró dos estrategias de divulgación. Por un lado, en tanto movimiento político, dentro del anarquismo algunos grupos de mujeres hicieron sus primeras críticas a esas visiones dominantes sobre la maternidad. Esta acción de las mujeres primero, se dio al unísono de las intervenciones en otros campos propiciadas por los médicos libertarios. Sin embargo, la llegada del peronismo marcó una cesura en esa dinámica y colocó a las mujeres como únicas interlocutoras frente al Estado respecto de la problemática de la maternidad. De ese modo, lo que en los años 30 fue 
incipiente, a partir de 1946 se terminó convirtiendo en la estrategia privilegiada para oponerse al peronismo y sus políticas públicas.

La otra estrategia del anarquismo fue la discusión con las visiones dominantes dentro del campo médico. Las mismas fueron impulsadas por galenos como Lazarte y Martín Fernández.

Nuestro aporte se orienta a analizar la propuesta de maternidad consciente y voluntaria. Por un lado, nos interesa señalar el carácter disruptivo de la propuesta, en el contexto promaternalista, al brindar la posibilidad de elegir cuándo y cómo ser madres, legitimando el derecho al placer sexual de las heterosexuales. Por otro lado, a través del análisis de los discursos de los médicos y las mujeres ácratas nos proponemos analizar su conceptualización de la maternidad en relación con los posicionamientos analizados en el capítulo. A diferencia de los estudios antes referidos, ubicamos las ideas libertarias por fuera del maternalismo político y distanciadas de la ideología maternalista sobre la maternidad que analizamos desde aquellas voces en períodos posteriores a 1930, más allá de que compartan algunas nociones sobre el valor de la maternidad o la madre. Para los médicos anarquistas, la preocupación por la maternidad no sólo se concentró en los conocimientos anticoncepcionales, sino que también se ocuparon de los derechos a la maternidad y la paternidad de las personas solteras y el problema de la falta de independencia económica de la mujer, considerada una cuestión que -junto a la carga biológica- la situaba en condiciones inferiores al varón.

Por último, nos interesa señalar los posicionamientos de algunas de las mujeres libertarias que se expresaron en el periódico Reconstruir, que nos permitirá observar cómo el peronismo produjo coincidencias discursivas de posicionamientos políticoideológicos opuestos.

\subsection{Entre la mujer y la madre: la maternidad consciente y voluntaria desde las voces médicas dentro del anarquismo}

Opuestos al discurso pro maternalista oficial y con matices respecto de sus camaradas de lucha política, los médicos anarquistas ofrecieron otra mirada sobre la maternidad que se sustentaba en la mujer como sujeto de derecho. En el capítulo 
anterior hemos analizado el discurso eugénico anarquista y las ideas sobre el control de la natalidad. Los conocimientos anticoncepcionales, además de contribuir a la reproducción de descendencia sana, también constituyeron una herramienta poderosa para la emancipación femenina al brindarles a las mujeres la posibilidad de elegir el ejercicio de la maternidad.

La maternidad consciente y voluntaria como resultado de la práctica del control de la natalidad también fue vinculada principalmente con planteos eugénicos diluyéndose su carácter emancipatorio. Como hemos mencionado, esta interpretación es la que prevalece en el campo historiográfico argentino, algunos con mayor énfasis, otros con matices que deslizan indicios de liberación en las ideas ácratas pero que no trascienden las primeras décadas del siglo XX.

Dos interpretaciones contrapuestas sobre los aportes de Juan Lazarte evidencian las tensiones sobre la cuestión. Por un lado, la mirada de Marcela Nari y, por otro, las consideraciones de Mary Nash.

Los alcances y los límites de propuestas ideas libertarias fueron analizados por Nari, quien señaló que el médico Juan Lazarte "apoyaba el control de la natalidad, la «procreación consciente», desde justificaciones eugenésicas”, pero que al mismo tiempo "se apelaba al «derecho a la maternidad», a la «libertad de embarazo», a la «emancipación biológica femenina»”. Sin embargo, en relación con la maternidad, la autora ponía el acento en que "se reforzaba -por otros caminos- una idea de maternidad no contradictoria con la hegemónica. La «mejor» madre no era la que más hijos tenía sino la que ofrecía a cada uno de ellos mayor dedicación física y afectiva”, recreando un modelo "absorbente y excluyente de maternidad" (2004: 195). Para Nari, médicos como Lazarte representaban la máxima desviación del "discurso médico oficial" aunque lo combinó, señala, con un "modelo de madre abnegada y amorosa" (1995: 163).

Algunos estudios sobre el caso del anarquismo español y sus áreas de influencia sitúan la maternidad consciente y voluntaria como parte de la propuesta eugénica, pero también hacen referencia a las posibilidades de emancipación que ofreció a las mujeres el poder controlar los embarazos (Andrés Granel, 2008; Masjuan Bracons, 2002; 2008). Para los años 30, Mary Nash señala que la maternidad no era cuestionada, pero se limitaba a través de la maternidad consciente que, según la autora, "la adopción de una 
planificación familiar acorde con las condiciones de salud, económicas y laborales de la madre y la familia" (Nash, 1996: 294), matizando el cariz emancipatorio de la propuesta. Pero, igualmente, hace notar que la perspectiva defendida por Juan Lazarte en la revista Estudios anunciaba cuestiones que luego serían problematizadas por el feminismo radical de la segunda ola. Lazarte consideró, al igual que esta corriente, que la carga biológica de la reproducción ponía a la mujer en condiciones de inferioridad en relación con el varón. Desde esta perspectiva, señala la autora, "el control de la natalidad, al permitirle superar su condición biológica, se convierte en arma fundamental de la lucha de la liberación de la mujer" (Nash, 1984: 328)

Nuestra perspectiva, más cercana a la mirada de Nash sobre Lazarte y a la de Andrés Granel sobre el anarquismo en España, propone entender las propuestas de Lazarte y Martín Fernández sobre maternidad consciente y voluntaria, incluso con la carga eugénica, como una forma de consideración de las mujeres como sujetos de derechos.

Bajo este prisma, la maternidad dejó de ser solamente un deber, pues según expresaba Lazarte: “existe, pues un derecho a ser madre, un derecho a la maternidad [...] que implica una libertad de embarazo y su realización en las más óptimas condiciones regladas o en relación con el conocimiento de los anticonceptivos" (Lazarte, 1936: 31). Esta capacidad de las mujeres de controlar los embarazos a través de los conocimientos científicos sobre la reproducción humana y las herramientas anticoncepcionales para poder evitarla, abría nuevas dimensiones de la sexualidad, brindando la posibilidad de independizar el placer de la reproducción. En esta estrategia se ubican los esfuerzos de Lazarte y Martín Fernández que, a través de la edición de libros, folletos, colaboraciones en revistas, consultorios psicosexuales que ofrecían las publicaciones y su práctica médica en los consultorios particulares, difundían estas ideas.

En momentos en que la elite política y médica se alarmaba por la baja en la tasa de natalidad y culpaban a "la mujer moderna" de no querer aceptar su único destino, para Lazarte, estos acontecimientos eran un indicio de la llegada de la sexualidad "por ese avanzar sexual de la mujer hacia la recreación y el olvido un poco de la maternidad. (Esto quiere decir que no todo el contenido del sexo está en la maternidad)" (Lazarte, 1935a: 56). 
Martín Fernández señalaba que la maternidad se convertía en una obligación que la mujer "tiene que aceptar quiera o no, y venga de quien venga" y que todo conspiraba para:

hacer de la mujer un juguete, un ser sin sentimientos ni aspiraciones propias, una persona sin sexo, o mejor dicho una persona a la que el sexo sólo debe servirle por el valor económico que puede representar para conquistar posiciones, para tener hijos y para torturarla con la idea constante de sólo vale y sirve por eso y para eso. (Martín Fernández: 1942b:17)

Para Lazarte, el ejercicio de la maternidad era una actividad que se relacionaba con la calidad y la dedicación. Con el respaldo de las estadísticas presentadas por colegas médicos como Marañón, Enrique Feimann y sus propios cálculos, Lazarte argumentaba que la maternidad prolífica aumentaba la mortalidad infantil, lo cual debilitaba la salud de la raza y producía un estado de tristeza constante en las mujeres (1936). En este sentido, señalaba:

no es la mejor madre la que tiene más hijos; seguramente está entre las peores. La maternidad no es una cuestión de cantidad, sino de conciencia, selección y calidad. La mejor madre es aquella que se identifica con su hijo antes de nacer, estableciendo vínculos de inmortalidad física y psíquica. (Lazarte, 1936: 37-38)

Estas ideas, según Nari, lo acercan a las posiciones maternalistas dominantes. En nuestra perspectiva, si bien la maternidad no fue cuestionada como un instinto natural, al establecer la posibilidad de elección de la maternidad, se ubicó dentro del campo como un discurso subalterno. Cimentado en la eugenesia, pero también en la emancipación de las mujeres. Estas ideas mixturaron posturas esencialistas sobre lo que debía ser una madre con nociones de libertad individual de decidir cómo y cuándo serlo. 
Lazarte señalaba el ideal de maternidad perseguido: "la madre tendrá hijos después de una preparación consciente y una maduración voluntaria, vale decir tendrá el hijo cuando quiera y más lo desee" (Lazarte, 1936: 31).

Las maternidades que proponían las posturas dominantes eran para Lazarte formas de "maternidad continua". Tomaba esta idea de maternidad continua de Margaret Sanger - pionera defensora del control de la natalidad en Estados Unidos- y la entendía como una forma de esclavitud, un trabajo forzado para las mujeres. Esta situación se producía por la ignorancia en que la religión y los médicos mantenían a la mujer en relación a los conocimientos de la reproducción. Esta cuestión también había sido enunciada por Marie Carmichael Stopes quien, citada por Lazarte, criticaba la dependencia de las mujeres a la información que le proporcionara el médico. En este sentido, el médico ácrata señalaba las consecuencias de conservar esa situación "mientras la mujer sea una incubadora de maternidad y una sierva de la ignorancia, miseria, maridos e hijos, no habrá redención humana posible y la condena se perpetuará por los años de los años" (Lazarte, 1936: 44).

La solución era proporcionar a la maternidad otro valor social que permitiera el acceso al placer sexual heterosexual de las mujeres. A través de citas del trabajo "Maternidad Consciente" (1934) de la abogada Hildegart Rodríguez -secretaria de la Liga Española de Reforma Sexual sobre Bases Científicas-, presentado en las Primeras Jornadas Eugénicas Españolas en 1933, Lazarte fundamentaba la necesidad de controlar los embarazos para alcanzar los fines eugénicos y de libertad sexual.

Los médicos ácratas señalaban que para lograr la completa emancipación femenina no bastaba con que la mujer se liberara sexualmente y decidiera sobre sus embarazos. Para que estas condiciones se realizaran sin obstáculos, la mujer debería alcanzar la independencia económica. Manuel Martín Fernández, señalaba, "estamos convencidos de que el día que la mujer pueda resolver independientemente su problema económico podrá ser dueña de su cuerpo y de sus actos y conquistar con ello su libertad sexual" (1939b: 316). De ese modo, Lazarte consideraba que podría "afrontar cualquier 
medio social y en tan buenas condiciones como el hombre por poseer un doble instrumento de liberación económica y sexual". 46

La precariedad laboral de las mujeres pobres del ámbito rural y urbano, entre ellas, campesinas, obreras, "sirvientas", unidas a la primacía del discurso de la domesticidad dejaba abierta la puerta para la prostitución como una posibilidad para aquellas mujeres. Lazarte así lo describía:

Mientras la gente del orden crea que la mujer no debe trabajar y si sólo existir en su casa, como cuidadora del hogar y máquina de proliferar ad infinitum, una vía para el prostíbulo se encontrará siempre abierta, porque el hogar es una condición privada de la mujer de la burguesía y clase media y no de todas, pues una gran parte de las mujeres de la clase media y la inmensa mayoría del proletariado, no llegan al clásico hogar burgués, se pierden en la soltería, el celibato, la miseria, yendo a caer en la prostitución. (Lazarte, 1935a: 150)

Esta crítica era una disputa explícita a los argumentos defendidos por profesionales médicos como Beruti, Rodríguez de Ginocchio y los médicos católicos que negaban la participación de las mujeres en el mercado de trabajo y demandaban políticas públicas orientadas a proteger los cuerpos que gestarían a los futuros ciudadanos. ${ }^{47}$ Las políticas promaternalistas con las que el Estado intentaba reforzar el binomio mujer-madre era objeto de cuestionamiento, pues las mujeres eran consideradas "mujeres-hembras, fábricas de hijos de carne y hueso", Martín Fernández señalaba las intenciones que él percibía en ese discurso:

\footnotetext{
${ }^{47}$ Algunos aportes historiográficos en relación con el trabajo femenino: Lobato, Mirta (2007) Queirolo, Graciela (2006); Palermo, Silvana (2008)
} 
"Es necesario aumentar la natalidad y que las nuevas generaciones sean cada vez más fuertes y sanas" dicen; pero, evidentemente, en la inmensa mayoría de los casos, sólo les interesa aumentar la buena carne de cañónmuchos hombres y muchas mujeres para que puedan producir, para los otros, más y mejor en las fábricas y las trincheras. (Martín Fernández, 1942b: 18)

Ahora bien, si hasta aquí existen puntos de acuerdo entre el pensamiento feminista y el libertario, incluso, hasta un cierto sustrato común con las propuestas de puericultura de los médicos dominantes, una cuestión que refleja las irreconciliables diferencias entre el pensamiento maternalista y el defendido desde el anarquismo a través del discurso médico fue la maternidad ilegítima.

Lazarte llamó "derechos de los solteros" a la facultad de ejercer la sexualidad recreativa, vedado para las mujeres dentro y fuera del matrimonio e incluyó -entre esas potestades- la decisión de la maternidad y la paternidad. Con ello, se contrapuso a los postulados que encorsetaban la reproducción dentro del matrimonio. En este sentido, interpelaba al poder estatal que limitaba el acceso a aquellos derechos "¿con qué sentimientos podrá el Estado discutir la voluntad que tienen un hombre joven de ser padre y una mujer bella de ser madre, cuándo no quieren casarse?, ¿Por qué razones va a calificarse denigrante a los hijos nacidos de esa unión?" (Lazarte, 1932a: 44). Señalaba que tanto la maternidad como la paternidad debían asumirse con responsabilidad. Los varones tenían derecho a la paternidad, pero ello traía aparejado los "deberes de alimentar, sustentar y educar a los hijos" (Lazarte, 1932b: 6). La falta de vínculos legales no se traducía en relaciones laxas con las/os hijas/os. La mención del derecho a la paternidad ponía de relieve la decisión de los varones a convertirse y ejercer su papel de padres, decisión que se invisibiliza(ba) en el énfasis de afirmar el binomio "madre-hijo" y en la noción de masculinidad como ajena a la paternidad.

Por otro lado, criticaba al discurso que veneraba la maternidad sólo si no escapaba a las normas del matrimonio, la religión y la ley. Lazarte señalaba lo que para él era el verdadero fin de esa exaltación: 
así, quiere decir, que cuando esos protectores oficiales y declamadores de la maternidad les entra la inquietud de la protección, lo que sostienen son los puntales de la sociedad y no la esencia misma del fenómeno, que sería tanto la madre, como el hijo; en realidad, sustentan y propagan solamente las bases jurídicas de sus instituciones, y no las raíces instintivas que le dieron origen. (Lazarte, 1932b: 36)

Para Lazarte, las persecuciones morales que sufrían las madres solteras predisponían a las mujeres a problemas psíquicos y enfermedades que influían en la salud del futuro hija/o. Considerar la maternidad ilegítima como un delito, según Lazarte, significaba el "empobrecimiento del organismo materno. Aumento de la proporción de malos partos [...] y por último, la mortalidad de niños ilegítimos por cualquiera de las enfermedades" (Lazarte, 1935a: 37).

Las categorías de "soltero" y "casado" utilizadas para clasificar a la población eran consideradas "artificiales y caprichosos" y consideraba que conllevaban un peligro si de ellas se deducían connotaciones "morales" (Lazarte, 1932b: 5). En este sentido señalaba que las personas solteras eran sujetos de derecho, independientemente de su condición civil. Por ello, podían disfrutar de su libertad sexual, pues tenían "derechos a las uniones libres, sexuales, de recreación o reproducción, transitorias o completas, fuera como es lógico de esa vergüenza humana que es la prostitución" (Lazarte, 1932b: 6). Si bien profundizaremos esta cuestión en el próximo capítulo, en el que nos focalizaremos en la libertad sexual, aquí podemos decir que el anarquismo condenó tanto la prostitución como el matrimonio como instituciones guardianas de la sexualidad, tanto recreativa (prostitución) como reproductiva (matrimonio). ${ }^{48}$

Lazarte tomó el ejemplo de las estadísticas elaboradas en Estados Unidos, donde vislumbraba la llegada de un nuevo matriarcado por el avance de la juventud femenina, Y señalaba que "no puede pensarse que la miseria o la ignorancia causen toda la

\footnotetext{
${ }^{48}$ Consultar Helena Andrés Granel (2008) y Fernández Cordero (2010)
} 
ilegitimidad..." (Lazarte, 1935a: 39). Con ello, se contraponía a lo que señalaban médicos como Beruti. Afirmaba que mujeres y varones que ganaban su propio sustento -el 83 por ciento según la estadística- decidían libremente ser padres fuera de la institución matrimonial. Por otro lado, señalaba que, sin embargo, no había que olvidar que en "numerosos casos de ilegitimidad los padres [varones] son casados" (Lazarte, 1935: 41). Esto era un indicio para el médico anarquista de la debilidad del matrimonio para limitar la sexualidad.

Para Lazarte, los progresos ya estaban en marcha, pues decía que "los solteros, sobre todo las solteras, han entado en una nueva senda; reclamaban y practican sus derechos vitales" (Lazarte, 1932a: 43).

En la difusión de los conocimientos sobre la anticoncepción para alcanzar la maternidad consciente y voluntaria, los médicos tenían el rol protagónico para Lazarte. Con insistencia, en su obra interpelaba a sus pares, en especial a los que respondían a valores religiosos $\mathrm{y}$, en virtud de ellos, consideraba que mantenían a la mujer en la ignorancia de los conocimientos de su cuerpo. Así, proponía en su plan para la socialización de la medicina, el establecimiento de clínicas y escuelas anticoncepcionales que "desparramadas por las ciudades y los campos [...] enseñarán a las masas de mujeres casadas una de las más importantes conquistas de liberación individual y de la civilización colectiva" (Lazarte, 1943: 141). En esta propuesta, Lazarte conjugaba los fines eugénicos y emancipatorios que perseguía.

En esa nueva organización de la medicina que defendía Lazarte, Manuel Martín Fernández y otros médicos libertarios congregados en la COMRA, tenía un lugar importante la "protección de la madre y el niño". Para ello, instaba al establecimiento de:

servicios prenatales, maternales a domicilio, oficinas de protección económica a la madre, lugares de reposo, salas de lactancia, instituciones de protección del niño [...] consultorios y dispensarios, las casas del niño, los institutos de puericultura, los centros de crianza. (Lazarte, 1943: 141-142) 
Instituciones y servicios que estarían organizados y dirigidos por los médicos y no por los políticos, le permitían afirmar las capacidades de los profesionales de la salud para la organización de "una medicina integral” (1943: 87).

La preocupación por la protección del binomio madre-hijo podría señalarse como un punto de acuerdo con el discurso dominante, pero sólo si lo analizamos desde el sustento eugénico que la motivaba. Si consideramos, también, la preocupación por la liberación de la mujer de la maternidad como un deber y su consideración como un sujeto con derecho a decidir el ejercicio de la maternidad sin renunciar a sus derechos sexuales, las divergencias son evidentes y las distinguen igualmente de los planteos de feministas como Moreau de Justo, que no se explayaron sobre la libertad sexual que conllevaba la propuesta de maternidad consciente y voluntaria.

Una de las principales consultas remitidas al consultorio de Martín Fernández, como hemos señalado en el capítulo anterior, versaba sobre los métodos anticonceptivos. En una de esas consultas, una mujer que había tenido cuatro hijos en seis años, preguntaba por sus trastornos nerviosos( Martín Fernández, 1940b)Para el médico, estos se relacionaban con la estrategia que utilizaba su marido para evitar la reproducción. Le recomendaba, dada su maternidad continua, evitar los embarazos, pero sin renunciar al placer sexual. El método recomendado era el preservativo masculino o femenino, el cual, además de un embarazo, le permitiría revertir su problema nervioso. Si bien se perfilaba un interés eugénico en evitar la multiparidad, también se establecía el interés por la libertad sexual de las mujeres.

La llegada de Perón a la presidencia generó un cambio de estrategias dentro del anarquismo, algunas de las cuales se venían ya perfilando en el período anterior. Desde el anarquismo, la homologación del peronismo con los gobiernos totalitarios de Europa obturó otras miradas sobre él que no coincidieran con la matriz fascista de la que estaba formado, según los libertarios. Esta preocupación por la educación de la niñez en manos del Estado y los avances sobre el rol de la familia y la madre fue compartida, como hemos señalado anteriormente, por los médicos católicos. Las locuciones de las mujeres libertarias podrían encuadrarse dentro de una retórica maternalista, como ha sido señalado en los análisis sobre sus antecesoras de los años 20 y 30 . Entendemos que estas variaciones discursivas se produjeron a partir del contexto político y social en el cual accionaban las mujeres de la UMSL y los médicos anarquistas que participaban en la 
Unión Socialista Libertaria. El peronismo se convirtió en el prisma por el cual se descomponían los diversos frentes de lucha para estos militantes ácratas. En este sentido, la demanda por la emancipación sexual fue obturada y desplazada por cuestiones que eran entendidas como las más apremiantes en aquel contexto. Los médicos anarquistas se volcaron a la organización y Lazarte, en particular, ocupó las páginas de Reconstruir con análisis críticos sobre las ideas y las prácticas del peronismo en la economía y la legislación. Ambos médicos desarrollaron también una defensa de la profesión médica frente a la intervención del Estado peronista a través de actividad gremial. Ello se plasmó en la realización de congresos y en las columnas de la revista de la COMRA. Esto conllevó un desplazamiento de núcleos temáticos de interés. Así, se evidencia una discontinuidad del discurso en favor a la maternidad consciente y voluntaria y la emancipación sexual en las publicaciones libertarias que se compensó con la edición de una colección de libros en relación con la temática sexual dirigida por Lazarte. Al mismo tiempo, las mujeres anarquistas, ya no vinculadas al campo médico, asumieron la voz en temáticas relacionadas con la maternidad, pero, si bien reclamaron derechos para las mujeres, no hicieron hincapié en la dimensión sexual. En cambio, apelaron a las mujeres en tanto madres para enfrentarse al avance del peronismo en la educación de la niñez e hicieron, de ese modo, blanco en las políticas peronistas.

\section{3. b. Las mujeres en Reconstruir: una visión de maternidad ¿libertaria?}

Eleonora Ardanaz indica que el anarquismo incorporó a las mujeres en la lucha política pues al estar asociada su identidad a su papel de reproductora de la especie “eran las más importantes socializadoras de sus hijos, por lo tanto, era vital incorporarlas para asegurar su emancipación y el adoctrinamiento de futuros libertarios" (2007: 4). No obstante apelar a las madres, no se las pensaba como lo hacían los discursos maternalistas dominantes, sino que, como señala la autora, "al concebirla como una persona capaz de detentar el dominio pleno de su cuerpo, que podía decidir libremente cuántos hijos deseaba traer al mundo [...], también debía ser una mujer activa en la esfera pública, luchadora y comprometida" (Ardanaz, 2007: 4-5).

Para el período que nos ocupa, ello aparece reflejado en algunas intervenciones de la Agrupación Femenina Antiguerrera (AFA) fundada en 1936, mayoritariamente por 
anarquistas. En el momento en el que se pronunciaban las mujeres de la AFA, el fascismo era el régimen contra el que había que luchar. No sólo en el ámbito internacional, sino dentro de nuestro país. Más adelante, con la llegada de Perón al poder, los peligros del avance fascista, para el movimiento anarquista, se harían realidad.

La AFA cuestionaba el lugar que el régimen fascista les concedía a las mujeres y, al hacerlo, contradecía el ideario de Beruti. Para ellas, el espacio de acción se había reducido al hogar y "se la desplazó de la cátedra, [la] oficina" pretendiendo "de ella que se dedique tan solo a tener hijos", para ofrecerlos, señalaban, al Estado totalitario como soldados (AFA, 1936: 8). Desde esta agrupación, la interpelación hacia las mujeres era a través de su identidad como trabajadoras y como madres.

Cuestionaban el sistema patriarcal que sometía a las mujeres a la autoridad del varón y remarcaban que este sometimiento se intensificaba en el ámbito rural: "¿qué decir de la mujer del campo para quien no existe otra función que trabajar junto a las bestias y tener hijos, muchos hijos, para que compartan y prolonguen su dolorosa vida?". Esta situación resultaba anacrónica, pues para la mujer que tenía "el deber de trabajar, debería existir el derecho a disponer de su vida y su pensamiento" (AFA, 1936: $4)$.

Exigían que las leyes protectoras del trabajo femenino y la maternidad se efectivizaran e incluían entre sus demandas el subsidio a la maternidad, la creación de casas-cunas en los lugares de trabajo y la posibilidad de amamantarlos las horas necesarias. En este sentido, las solicitudes iban en el mismo derrotero que las propuestas médicas.

Asimismo, reclamaban que las mujeres tuvieran los mismos derechos que el varón: a divertirse en los momentos de descanso, a la cultura, a ser respetada en el lugar de trabajo y a organizarse en defensa de sus derechos como trabajadoras en el ámbito gremial, en especial, decían, "en cualquier trabajo que no se considere en nuestro ambiente como esencialmente femenino" (AFA, 1936: 12).

La apelación a las mujeres en tanto madres también fue señalada por Gisela Manzoni (2013) a través del análisis de las voces femeninas dentro del anarquismo 
durante el período de entreguerras. La autora señala que la apelación antimilitarista y antifascista que promovieron las militantes anarquistas en este período discrepa del que formularon a fines del siglo XIX pues tuvo tonos claramente maternalistas que las ubicaron dentro del maternalismo político. Por ello se hace necesario matizar el carácter disruptivo de las locuciones libertarias en relación con los roles de género. En relación con este planteo, Ardanaz agrega que, si bien las representaciones de las madres se asociaban al pacifismo y al antimilitarismo, esta relación cambió a partir de la Guerra Civil Española (1936-1939) cuando las madres debían "arengar a los hijos a participar para salvar a la humanidad del peligro fascista” (Ardanaz, 2007: 8).

La historiografía ha analizado las políticas públicas del peronismo y las resistencias que generaron pero, sin embargo, ha omitido las voces del anarquismo. Dora Barrancos, por su parte, se focaliza en las políticas específicas del primer peronismo y alega que "la única agencia inexorablemente pronatalista en la Argentina ha sido -y continúa siendo- la iglesia católica y los grupos más conservadores en torno de aquella" (Barrancos, 2007: 483). En disonancia con estudios que han argumentado que el interés del gobierno fue aumentar la población sana, y que en razón de ello la mujer tenía un rol central (Di Liscia et al., 2000), la autora indicó que "no puede confundirse «pro maternalismo» $-\mathrm{y}$ alguna retórica pro engendradora que emplean ciertos funcionarios del peronismo- con medidas políticas que impulsaron la obligación de parir durante esos años en los que el Estado tomó el color benefactor. Faltan al primer peronismo las conocidas medidas que lo asimilan a los regímenes pro natalistas" (Barrancos, 2007: 489).

Siguiendo estas explicaciones, la bifurcación pronatalista-promaternalista fue explorada por las autoras Karina Ramacciotti y Adriana Valobra (Ramacciotti y Valobra, 2004) a través del examen de la políticas ideadas por el ministro de salud Ramón Carrillo. En esta lectura se señala que el primer peronismo centró su accionar en educar a las/os niñas/os desde la primera infancia. Por medio de diversas instituciones y en distintos espacios de socialización y formación de la niñez, el Estado limitó y condicionó la influencia de las madres en el desarrollo de sus hijas/os. Conceptualizaron esta mirada sobre el accionar del gobierno peronista como "políticas de crianza estatizada". Las mismas son definidas como las "que el Estado implementa para atender a la infancia desplazando temporal o completamente a la madre y a la célula familiar en 
general" (Valobra, 2005: 81). En este sentido, Isabella Cosse señala que la niñez en el peronismo se resignificó, y se volvió un pilar fundamental para el gobierno pues "la vieja intención de convertir a los niños en ciudadanos capaces de contribuir al desarrollo nacional se trasladó a la necesidad de garantizar la continuidad de la «revolución» y la perpetuidad del régimen del poder" (Cosse, 2004: 520).

Como mencionamos, estos estudios no han analizado las propuestas del anarquismo y, al hacerlo, han omitido dos aspectos: la presencia de un discurso de contrapeso al oficial y, también, la descripción de un cambio de estrategia político que tuvo consecuencias notables en el tipo de alocución respecto de la maternidad expresada por el movimiento libertario.

La Unión de Mujeres Socialistas Libertarias, creada en 1946, cuyas acciones fueron difundidas por el periódico Reconstruir, fue uno de los espacios colectivos de mujeres. Estas libertarias reconocían que los valores que las identificaban, el socialismo y la libertad, se hallaban más difíciles de alcanzar para las mujeres que para los varones “por lo tanto, más dignos de luchar por conquistarlos” sentenciaban (UMSL, 1946: 14).

Pero, como señalamos, a diferencia de las locuciones de los médicos ácratas, estas mujeres no extendieron sus reclamos a la emancipación sexual ni se ocuparon de la difusión de las herramientas anticonceptivas. En su declaración de principios enumeraban la demanda de "igualdad de todos los derechos para hombres y mujeres [...], la protección a la maternidad. Maternidad consciente. Protección a las mujeres que trabajan" (UMSL, 1946: 13), entre otros. Su interés estaba puesto en la lucha contra lo que consideraban el fascismo criollo, el peronismo.

Dentro del periódico, las mujeres contaban con una sección exclusiva, llamada "La página de la mujer", entre las destacadas columnistas se encontraban, Herminia Brumana, Anita Piacenza, Emilia Goyena e Iris Pavón (seudónimo Alejandrina Serrat).

Dentro de esta sección, las autoras interpelaban a mujeres y varones sobre los problemas que las/os afectaban en el contexto del ascenso al poder de Juan Domingo Perón y Eva Duarte.

A través del título “amiga, ¿quiere usted votar?”, Anita Piacenza señalaba que para que la mujer pudiera ejercer los derechos políticos era necesario que primero se 
capacitara y se liberara de la tutela e influencia masculina (Piacenza, 1946). Estos derechos se consideraban secundarios en la lucha, y se colocaban en primer orden los derechos, económicos, civiles, sociales y sexuales.

Desde la página de la mujer, Iris Pavón cuestionó las políticas del Estado y su "justicia social" entre comillas. Como militante anarquista, Pavón sentía que el peronismo se había apropiado del concepto de justicia social por el que se bregaba desde el movimiento libertario y lo había resignificado, ya que para la escritora "desde que no es don que se regala, sino dignidad que se conquista [...] la «justicia social» es peor aún que la limosna; que no sólo no ha terminado con la miseria y el hambre, sino que trafica, especula con las necesidades de la población sufriente" (Pavón, 1946: 9). Las críticas se centraron en las políticas militaristas, como el decreto/ley de preconscripción de 1947, que ponía a disposición del ejército a las/os niñas/os y los/as adolescentes entre 12 y 20 años, durante dos años, las cuales identificaron como un signo del carácter totalitario del gobierno (Reconstruir, 1946). Señalaba "aunque sólo se invoque intentos de educación física, práctica de deportes", lo que se persigue "es el culto de la fuerza bruta, la mística de la violencia, la fanatización del niño por el sentimiento guerrero y belicoso" (Pavón, 1947: 10). Por ello, hacía un llamado a las madres, peronistas y antiperonistas, porque "su sola y suprema condición la ubica por encima de lo circunstancial, a la madre de todos los niños argentinos nacidos y por nacer” a ellas interpelaba, “¿permitiréis vosotros, por ignorancia, por ingenuidad, por cobardía, que con nuestros hijos se repita la experiencia trágica que ha desgarrado a Europa?, ¿permitiréis que para afianzar un régimen de esclavitud y de muerte, se deformen, se corrompan, se envilezcan los sagrados frutos de vuestro amor?". La autora destacaba la especial atención y lugar a "la captación de la niñez y la adolescencia" en las políticas peronistas, pues eran más fáciles de adoctrinar y modelar de acuerdo a sus propósitos (Pavón, 1947:10).

Emilia Goyena, de quien sólo sabemos que fue exiliada en la Argentina después de la Guerra Civil española, señalaba que la clave de superación de la mujer estaría en la educación moral para que, sobre todo a través de su rol de madres, pudieran gestar hogares "revolucionarios" y hombres nuevos. La mujer formaría parte de la nueva sociedad asumiendo el papel de educadora de sus hijos, de su rol revolucionario como madre iluminada e iluminadora. 
Goyena utilizaba una interrogación para el título de sus notas, ¿¿mujer que piensas?', en ellas criticaba las acciones de la iglesia, que mantenía a la mujer en la ignorancia y el sometimiento. Para los que consideraban que la cabeza de la mujer servía para llevar sombreros, Goyena instaba a las mujeres a pensar:

si piensas, mujer, demostraremos que con sombrero o sin él, tu cerebro funciona unido al sentimiento y que la Humanidad puede esperar mucho bueno de ti. Tal vez, todo lo bueno que los hombres nos han sabido dar (Goyena, 1946: 9).

El discurso maternalista de las anarquistas, con las morigeraciones a las visiones más libérrimas que habían propuesto sus pares masculinos médicos en períodos anteriores, puede encontrar su explicación en el contexto político de actuación. Efectivamente, en pos de captar un público que se había subyugado con algunas intervenciones más convencionales -aunque no todas- por parte de Evita, las anarquistas tuvieron que encontrar nuevos tonos a sus postulaciones.

Este discurso sobre maternidad de las anarquistas, significativamente, llega hasta 1948. En efecto, 1949 es un año en que hay coincidencia para marcar un proceso de verticalización política y persecución desde el Estado a los grupos opositores; además, es el año de institucionalización del Partido Peronista Femenino.

\section{Conclusiones}

En este capítulo hemos demostrado cómo la maternidad consciente y voluntaria de raigambre eugénica propiciada por los médicos libertarios -Lazarte y Martín Fernández, en particular-generó una nueva matriz de derechos para las mujeres.

Para situar dentro del orden social discursivo esta perspectiva, siguiendo la estructura general de este estudio, nos abocamos al repaso de otras conceptualizaciones 
de la maternidad. En primer lugar, el análisis de las posiciones médicas dominantes, representadas por Beruti y los médicos católicos, nos acercó a las ideas y prácticas promaternalistas y pronatalistas que los profesionales legitimaron dado el contexto denatalista.

La maternalización de las mujeres a través de la educación o la obligación de gestar a través de medidas represivas fueron las estrategias asumidas por estos profesionales que, algunos en mayor medida, incidieron en la creación de agencias estatales y en la diagramación de políticas públicas. El interés eugénico por el perfeccionamiento de la raza delineó el carácter de estas políticas que intentaron aumentar la cantidad, pero sin descuidar la calidad de la población. Para ello, la protección y la tutela de la maternidad fue central para llevar adelante sus objetivos.

Entendida como un deber, en estos discursos la maternidad se volvió la coartada para limitar y para controlar la vida de las mujeres. Otras actividades estaban vedadas, sus espacios de acción se reducía al hogar y su capacidad económica dependía del varón. Quienes se animaban a contradecir estas disposiciones eran señaladas como las culpables del problema demográfico y su moral era cuestionada. Las mujeres no podían decidir sobre su capacidad de gestar, los médicos eran los únicos autorizados a concluir sobre esta cuestión y, llegado el caso, evaluarían esa opción desde una justificación eugénica.

Luego de esta revisión de las posiciones en el campo médico en relación con la maternidad, nos ocupamos del discurso de los médicos ácratas. La propuesta de maternidad consciente y voluntaria, además de contemplar la decisión de las mujeres, característica compartida con las ideas de Moreau de Justo, posibilitó el ejercicio de la sexualidad sin preocuparse por la reproducción.

Esta cuestión es la que sitúa la propuesta libertaria enfrentada al planteo maternalista dominante y las propuestas del maternalismo político de las feministas, incluso de las más laxas en este posicionamiento, como Moreau de Justo.

El interés eugénico de la propuesta anarquista se conjugó con ideas de emancipación social y sexual. Por un lado, la maternidad era considerada como una carga biológica que situaba a la mujer en condiciones de inferioridad en relación con el 
varón y que le impedía desarrollarse en iguales condiciones en la vida social. Por otro lado, al poder decidir cuándo y cómo ser madres o no serlo, las mujeres heterosexuales podrían liberarse de la preocupación por la reproducción y disfrutar de las uniones sexuales con los varones. Estas ideas resultaban absolutamente disruptivas en el contexto en el cual se locutaban. Mientras la elite política y médica preocupada por la baja en la tasa de natalidad, y ocupada en reforzar el binomio mujer-madre para perfeccionar la raza, demandó, diseñó e implementó políticas públicas en ese sentido; y los esfuerzos de Moreau de Justo se orientaron a demandar la participación de las mujeres en la vida política apelando a la maternidad, la propuesta defendida por el anarquismo ofrece nuevos sentidos.

El repaso por las ideas de las mujeres de la UMSL nos permitió establecer las continuidades e inflexiones discursivas dentro del movimiento. Al utilizar una escala temporal de larga duración hemos observado que un cambio político institucional como el generado por la llegada del peronismo al gobierno significó para un movimiento opositor al mismo un cambio de estrategia política que conllevó, asimismo, la modificación del discurso sobre maternidad consciente y voluntaria. En efecto, tal como han planteado algunos estudios recientes, se evidenció un proceso de maternalización del discurso durante el peronismo propiciado por las mujeres anarquistas que fueron las encargadas de contraponerse a las políticas públicas diseñadas por el peronismo en relación con ese tópico. Los médicos anarquistas que antes habían ocupado un rol preponderante en relación con ese tema, viraron sus espacios de intervención y dejaron de lado esta temática en sus alocuciones. Hemos entendido ese discurso maternalista de las anarquistas, en el contexto de disputa del mismo sujeto político.

Asimismo, desde las locuciones anarquistas, al considerar al gobierno peronista como una tardía extensión europea de los gobiernos fascistas, las acciones diseñadas y aplicadas por él, fueron observadas desde un prisma que reforzaba las coincidencias entre los gobiernos totalitarios europeos y el gobierno nacional.

Ubicar en el campo discursivo las posiciones ácratas sobre la maternidad, nos permite visibilizar, por un lado, una conceptualización de la maternidad silenciada por los discursos dominantes y, por otro, nos posibilita establecer la genealogía de ideas debatidas posteriormente en relación con los derechos sexuales y reproductivos de las mujeres, pendientes aún hoy, que evidencian la incompleta ciudadanía femenina. 


\section{Capítulo 5}

\section{El discurso médico anarquista sobre la Revolución Sexual}

Desde fines del siglo XIX, la sexualidad fue puesta en locución dentro de la expresión ideológica y cultural anarquista en la Argentina, que colocó para su discusión en el espacio público cuestiones de la vida privada con una perspectiva distinta a la de las posiciones dominantes. Como hemos mencionado en el capítulo dos, durante los años 30 el discurso dominante encontró un punto álgido de difusión en la perspectiva sexológica de la obra de van de Velde, El matrimonio perfecto. Esta literatura provocó un cambio dentro del heterogéneo discurso sexológico, pero los límites para el despliegue de la sexualidad femenina seguían firmes (Felitti, 2012). La gran difusión de la obra de van de Velde fue un indicador de la necesidad de saber sobre la sexualidad, pero, aunque tímidamente disruptivo, no alcanzó a cuestionar, como señala Isabella Cosse, entre otros temas, "la valoración de la virginidad femenina, no modificó el cortejo ni la importancia atribuida a la contención del deseo sexual previo al matrimonio" (Cosse, 2008: 140). Así, el placer sexual femenino y la autodeterminación sexual de las mujeres seguían encorsetados al matrimonio y a la reproducción y para alcanzarlo dependían de los conocimientos sexuales del varón.

Sin embargo, en este capítulo nos proponemos demostrar que placer $\mathrm{y}$ autodeterminación sexual fueron componentes sustantivos de la prédica libertaria que, con todo, evidenciaron, también, limitaciones que condicionaron uno de los núcleos más importantes de esta tendencia: la Revolución Sexual.

Según Kate Millet, a fines de los años 60, la expresión Revolución Sexual era una noción extendida en el uso cotidiano y académico, pero no era clara su definición. Por ello, la autora postuló la necesidad de reflexionar e historizar el uso de la misma a fin de evaluar los desaciertos y las posibilidades futuras de la Revolución Sexual. Para ello, distingue una fase que discurre en la centuria que abarca 1830-1930 y que considera las raíces históricas de la Revolución Sexual entendida como un proceso. En ese lapso, la autora rescata los aportes del feminismo en distintas áreas, como la educación y la participación política y el trabajo, pero considera que todo ello no alcanzó a destruir la 
red estructuras sociales del patriarcado. Asimismo, señala que el aumento de libertad sexual en ese período no se produjo por los cambios sociales sino "por las mejoras tecnológicas introducidas en la fabricación de métodos anticonceptivos, así como a su proliferación” (Millet, [1969] 1995: 130). El período siguiente, con todo, reaccionó frente a los atisbos -tímidos, según Millet- que esos movimientos habían enunciado. Así, la autora comprende fenómenos como el nazismo, la experiencia de la Unión Soviética, el freudismo y la perspectiva funcionalista, como elementos de la contrarrevolución.

La intervención de Millet nos permite reflexionar sobre la necesidad de historizar el concepto de Revolución Sexual y establecer más precisamente qué entendieron quienes la reclamaron y lucharon por ella y, asimismo, qué consideraciones elaboraron sus detractores. Es decir, nos interesa restituir el debate en torno a un concepto central en la discursividad anarquista, pero que fue, también, objeto de disputa con otros sectores. Asimismo, nos interesa explicar un fenómeno anterior al período que se considera inaugural respecto de la llegada de la Revolución Sexual, que algunos estudios sobre los años 60 consideran tardía en relación con Estados Unidos (Cosse, 2008).

En los capítulos anteriores, hemos abordado el concepto de derechos sexuales a partir del desglose de la dimensión de las prácticas, según lo conceptualiza Graciela Di Marco (2012). Así, nos enfocamos en el control sobre el propio cuerpo y la autodeterminación reproductiva como problemas centrales en los debates del período bajo estudio que cobraron especial relevancia en la discursividad anarquista. En este capítulo nos concentraremos en otra dimensión de las prácticas: la autodeterminación sexual. La autodeterminación sexual incluye, conceptualmente, una serie de subdimensiones que van desde el modo de definir el placer sexual hasta distintas formas de prácticas sexuales en las relaciones personales.

La idea de autodeterminación sexual no fue estrictamente la que utilizaron los anarquistas en el período, pero analíticamente nos sirve para pensar sobre distintos significados y connotaciones en las alocuciones médicas que indagaremos.

El carácter vanguardista dentro del orden social discursivo anarquista en la Argentina en relación con la sexualidad fue evidenciado por diversos estudios que se 
han ocupado de analizar distintas publicaciones ácratas, revistas, periódicos y folletos, editados en el país o introducidos por quienes migraban al país desde fines del siglo XIX (Barrancos, 1990; Bellucci, 1990; Fernández Cordero, 2007, 2011). Sin embargo, excepto el abordaje de Andrés Granel (2012), no encontramos referencias sobre el discurso anarquista posterior a 1930. En particular, no se han analizado las vinculaciones entre eugenesia y emancipación sexual desde el discurso médico anarquista local, y sobre esa línea nos proponemos realizar nuestro aporte.

En el capítulo anterior, sostuvimos que la propuesta eugénica sobre el control de la natalidad fortaleció y legitimó la propuesta de emancipación femenina. Por un lado, a través de la maternidad consciente y voluntaria. Por otro lado, como sostiene la hipótesis de este capítulo, a través de diferenciar el placer sexual de la reproducción. Aquí, avanzaremos sobre las ideas de autodeterminación sexual en relación con las mujeres como indicador de la Revolución Sexual que pregonaron los anarquistas.

\section{Los médicos dominantes y la negación de la emancipación sexual de las mujeres}

A fines del siglo XIX, el discurso médico tuvo un rol preponderante en la construcción de la definición de la sexualidad. En otras latitudes, el médico austríaco Wilheim Stekel analizó cómo las imposiciones sociales hacían que las mujeres no pudieran expresar su satisfacción en una relación sexual y cómo, por el contrario, a veces llegaban a fingir un orgasmo por vergüenza a expresar de qué modo se sentían satisfechas. Para Steckel, el placer sexual femenino debía ser garantizado por los varones, a quienes el psicólogo invitaba a descubrir las zonas erógenas femeninas para evitar lo que se denominaba la "frialdad sexual de la mujer". En virtud de ello, sin embargo, Steckel no esperaba desarrollar el placer sexual femenino como una forma de emancipación de las mujeres. El hallazgo del placer sexual femenino debía servir para someter a las mujeres a través del predominio de la relación por parte de los varones ( $\mathrm{La}$ frialdad sexual de la mujer. Psicopatología de la vida sexual, 1942). En esta línea, entonces, el placer sexual no era sinónimo de libertad o emancipación sexual sino que, más bien, el placer sexual de las mujeres era la forma de conseguir su mayor sometimiento y dominación. 
Estas ideas se esparcieron en distintas partes del globo y fueron tomadas de diversa manera. En la Argentina, según Ramacciotti y Valobra (2008), la apropiación fue mucho más pacata en virtud de la primacía de las ideas religiosas y otros posicionamientos que privilegiaron el lugar de los roles reproductivos en la sexualidad.

Los profesionales, preocupados por la "degeneración de la raza", imbuidos del pensamiento eugenésico, influyeron en la construcción de normativas que tenían como fin controlar el ejercicio de la sexualidad (Lavrin, 2005). La centralidad del aspecto reproductivo se plasmó en diversas políticas sobre la población que intentaron regular las prácticas sexuales de las personas, imponiendo modelos de "sexualidad normal" para varones y mujeres (Vallejo y Miranda, 2011; Miranda, 2011) y diagnosticando "patologías" que justificaban "intervenciones terapéuticas o de normalización" (Foucault, [1977] 1991: 42). En particular, la sexualidad femenina se vinculó a la reproducción de la especie y el placer sexual se homologó al fin procreativo. En este sentido, los estudios de Nari evidenciaron la negación de los profesionales médicos a aceptar "la existencia y legitimidad del placer sexual femenino" al punto que, cuando éste se manifestaba, fue considerado "una enfermedad (ninfomanía)" (Nari, 1996: 163). Asimismo, la autora pone de relieve la contradicción en la que incurrían los médicos al oponerse al control de los nacimientos "al considerar, por ejemplo, el coitus interruptus poco saludable para las mujeres porque suprimía el orgasmo femenino y los dejaba eróticamente insatisfechas" (Nari, 1996: 163). En cambio, el "instinto sexual" masculino se naturalizó como un impulso irrefrenable que debía ser controlado a través de una educación sexual eugénica. El acento estaba puesto en la profilaxis de las enfermedades venéreas asociadas a la prostitución. Sin embargo, como señalan Gustavo Vallejo y Marisa Miranda, "la urgencia” por combatir la prostitución

no era tanto entonces por la salud del cuerpo de la prostituta ni la de su descendencia (en general, ilegítima), sino por la de quienes, utilizando sus servicios, hicieran peligrar la salud de sus futuros hijos (legítimos) al transmitirles las consecuencias del morbo venéreo adquirido por el contacto sexual. (Vallejo y Miranda, 2012: 96) 
Tampoco encontramos, entre los médicos dominantes, discursos que cuestionaran la prostitución como institución que ponía a disposición de los varones el cuerpo de las mujeres. En este sentido, las mujeres que habían desobedecido las normas -por ejemplo, quienes habían sido madres sin estar casadas- eran objeto de campañas re-educadoras. Así, José Beruti señalaba que:

toda campaña de protección a la madre soltera debe radicar fundamentalmente en aquellas que tiendan al mejoramiento ambiental, a la educación en todo sentido, tratando de modificar instintos y costumbres, a la elevación de la ética sexual, y a fijar el verdadero concepto de la responsabilidad moral del individuo. (Beruti y Zurano, 1934b, en Beruti, 1943, t. III: 587)

Conjuntamente con la educación se utilizaron otras estrategias para controlar la sexualidad. Miranda (2011) ha señalado las alianzas entre el poder político y religioso para intervenir en la cultura a través de la prohibición. A comienzos de los años 40, el intendente de la provincia de Buenos Aires, Carlos Alberto Pueyrredón, prohibió dos números de la revista Cultura Sexual y Física junto con otras treinta y tres publicaciones, entre las que figuraban los libros sobre temas sexológicos publicados a través de la "Biblioteca científica" de la editorial Claridad.

En la tarea de normativizar la actividad sexual a través de la educación, se destacó la médica Mercedez Rodríguez de Ginocchio. Como hemos mencionado en el capítulo tres, su propuesta de "educación sexual eugénica maternológica" intentaba controlar la sexualidad para evitar la degeneración de la raza. En ese caso, Rodríguez de Ginocchio indicaba que:

esta educación civiliza la líbido [...] ennobleciendo el amor y dignificando al individuo (padre o madre en potencia), que controla, así, conscientemente, 
su actividad sexual e higiene mental, por autoafirmación del espíritu de responsabilidad genésica. (Rodríguez de Ginocchio 1941: 68-69)

El momento de inicio de esta educación era en la niñez, a partir de los 6 años de edad, "antes que la líbido" hiciera "eclosión" y se pudieran dirigir los deseos y los instintos antes de que se desarrollasen (Rodríguez de Ginocchio, 1941: 69). En estos planteos, la médica retomaba las recomendaciones de Gregorio Marañón en relación con los caracteres sexuales anatómicos y funcionales -analizados en el capítulo dos-. A partir de ellos, argumentaba que la mujer estaba destinada a la reproducción, lo cual establecía que "su función sexual" fuera "de preponderancia y naturaleza primaria". En cambio, consideraba que el varón satisfacía "esta función de un modo fugaz, generalmente irresponsable y secundario" (Rodríguez de Ginocchio, 1941: 72).

Entre los efectos de la falta de educación sexual, la médica señalaba las aberraciones sexuales, el adulterio, la prostitución, las enfermedades venéreas, el infanticidio y el onanismo -este último, considerado un "síndrome de degeneración mental" (Rodríguez de Ginocchio, 1941:73)-.

En el contexto posterior a la sanción de la ley $\mathrm{N}^{\circ} 12.331$ de creación del Instituto de Profilaxis de las Enfermedades Venéreas (1936), no obstante, Rodríguez de Ginocchio dejaba entrever algunas dudas en su modelo binario y sexualizado. Entonces, denunciaba que los objetivos propuestos no se habían llevado a cabo, en particular, la difusión de la educación sexual a través del Instituto o el Museo de Venereología que hasta ese momento no se había creado. Si bien señalaba que la libido debía educarse y dirigirse, acusaba a la "falsa educación" sexual que establecía frenos "antinaturales" al desarrollo de "las fuerzas de la libido" rodeando "de misterio el vínculo fatal" entre varones y mujeres (Rodríguez de Ginocchio, 1941: 76).

En esta misma línea, el jurista José Ignacio Olmedo, invitado a disertar por iniciativa del médico Juan B. González en la Sexta Sesión Científica Ordinaria organizada por la Sociedad de Obstetricia y Ginecología, deslegitimaba la búsqueda del placer independiente de la reproducción señalando que llevaba "a la degradación, a la molicie, al crimen, a la enfermedad, a la muerte" y sentenciaba que sólo "los débiles, los 
inferiores, son [...] los adeptos incondicionales del sibaritismo, de la vida egoísta, del deleite embriagador que anula la conciencia, seca el corazón y esteriliza las fuerzas superiores del espíritu" (Olmedo, 1940: 363-364). A través de la reivindicación del matrimonio como ámbito en el cual la sexualidad se legitimaba -sólo si el "onanismo conyugal" no desvirtuaba los fines reproductivos-, condenó a quienes comulgaban con un "libertismo sexual" (Olmedo 1940: 366).

Dentro de este posicionamiento, quienes se opusieron firmemente a la legitimidad del placer sexual fueron los médicos confesionales. El placer sexual fue condenado por la Iglesia tempranamente pues éste exponía los bajos instintos, y la debilidad de la carne y rozaba con lo diabólico. Incluso, se consideró que era un dilema moral que se enfrentaba en el matrimonio. Desde el siglo XII hasta la actualidad, la Iglesia cambió la idea sobre el placer sexual y sólo lo considera pecaminoso "cuando es el motivo del sexo marital, pero no como resultado directo del sexo ejercido correctamente, es decir, para la procreación" (Mejía, 2003: 49). En conjunto, como afirman los estudiosos sobre el tema, "esta ética se caracteriza por su hostilidad histórica y contemporánea, por su rechazo a las mujeres, al cuerpo, a la sexualidad y al placer" (Mejía, 2003:48). Estas nociones debían evitar la libertad sexual, en particular, de las mujeres, aunque -según las épocas- no se excluyó a los varones de ella (Mejía, 2003)

Como ya hemos analizado, la estrategia de los médicos católicos se rigió por estos principios y se orientó a la prohibición de la información sobre los métodos anticonceptivos y a defender el valor de la castidad antes del matrimonio. En efecto, el discurso católico, como señala Acha (2001), se dedicó a “destruir la voz de quienes propugnaban la Revolución Sexual" la cual consideraban "la más funesta de las revoluciones" (Criterio, enero 1931, en Acha, 2001: 164).

En este sentido, las disputas con el médico Bartolomé Bosio y la revista Cultura Sexual y Física se plasmaron en las páginas de Iatría y Criterio. Para refutar los argumentos esgrimidos por discursos opositores, los médicos católicos citaban textualmente párrafos, por ejemplo de Bosio, y seguidamente hacían la crítica. En una oportunidad, alguien que firmó el artículo como el seudónimo de C.A.B., que se presenta en el artículo como médico católico, escribió una opinión en contra de un artículo publicado por Bosio en la revista La Semana Médica el 16 de febrero de 1939. En este artículo, el médico cercano al sindicalismo revolucionario se preguntaba si era 
necesario insistir en la castidad de la mujer antes del matrimonio, cuando los hechos demostraban todo lo contrario. En respuesta a esa interrogación, el médico confesional contestaba que la castidad de la mujer era "una exigencia moral elemental que cualquier persona honesta aprueba [y] el hecho de que a pesar de ello no se pueda evitar que haya mujeres deshonestas, e incluso haya habido prostitutas en todos los tiempos, no dice nada en contra de la prédica de la castidad, y sí, mucho a favor" (C.A.B., 1939: 49). Luego, contradecía las palabras de Bosio que expresaba que ninguna mujer acataría el consejo médico de abstinencia sexual:

aunque nosotros no tenemos, como el colega, la valiosa colaboración confidencial de las progresistas lectoras de "Cultura Sexual y Física", estamos tan firme como humildemente seguros de que el tipo común de mujer cristiana en nuestro país es aquella por la que ni sus mismos padres ni sus directores espirituales tienen que hacer gran cosa para que sepa guardar su castidad. (C.A.B., 1939: 49)

Aquí, el médico católico reafirmaba el discurso confesional que, como señala Acha (2001) sostenía que "la búsqueda de placer sexual pertenecía a los hombres" (160). Por último, ante la declaración de Bosio sobre que las mujeres arriesgaban hasta su propia vida con el fin de alcanzar el placer sexual, el profesional católico rebatía el argumento diciendo que "indudablemente, al Dr. Bosio no se le ocurrió nunca que pudiera haber mujeres capaces de arriesgar su vida para salvar su castidad" (C.A.B., 1939: 49).

La apuesta por la virginidad femenina no era sólo una reivindicación de los médicos católicos, sino que en la lucha contra las enfermedades venéreas algunos sostenían que "el concepto moral y religioso de que al menos la mujer debe ir virgen al matrimonio, también desde el punto de vista médico-social, conserva todo su enorme valor" (Stábile, 1946: 316).

En este sentido, para combatir las enfermedades venéreas, la ley $\mathrm{N}^{\circ} 12.331$ de 1936 instauró el certificado prenupcial para varones, reprodujo las distintas nociones 
sobre la sexualidad femenina y masculina en el ámbito legal. Como hemos analizado en el capítulo tres, la obligatoriedad del certificado prenupcial discriminaba a las mujeres. La Iglesia católica se opuso al certificado sosteniendo que la normativa era una intervención del Estado en la vida privada y producía la disminución de los matrimonios oficiales (Rodríguez, 2003).

Si bien los médicos dominantes obturaban cualquier resquicio por el que pudiera cobrar entidad la sexualidad femenina independiente de la reproducción, cuando querían justificar esta postura aparecían las contradicciones. En su estudio sobre la esterilización, el médico Benjamín Galíndez señalaba que la mujer que se esterilizaba de forma definitiva podría sufrir problemas psíquicos y también era común que "ante la seguridad de no quedar embarazadas, se entrega[ra]n al desenfreno de sus pasiones y en no pocas veces v[i]e[ra]n un aliciente para la infidelidad conyugal” (Galíndez, 1939: $11)^{49}$

Estos núcleos discursivos persistieron en el tiempo y se manifestaron de manera más exacerbada en las intervenciones de los médicos de influencia católica. Así se evidencia en las Primeras Jornadas de Médicos Católicos sobre Problemas de Higiene Sexual organizadas en el año 1953 por la Federación Argentina de Consorcios de Médicos Católicos en la provincia de Santa Fe. Estas jornadas, según los organizadores, tenían el objetivo de conciliar la moral cristiana con la investigación científica. En ellas, los profesionales expresaron su interés por la sexualidad desde una perspectiva científica que aportaba a la "educación de la castidad y para el matrimonio, institución clave de los problemas educativos y sociales" (Primeras Jornadas de Médicos Católicos. Problemas de Higiene Sexual, 1954). En este sentido, Luis María Baliña, quien fue secretario general del Consorcio de Médicos Católicos de Buenos Aires y decano de la Facultad de Medicina de la Universidad del Salvador en los años 70, reflexionó en estas jornadas sobre la santidad del matrimonio y consideró al divorcio como un "fraude sexual". También incluyó dentro de estas "estafas" a la homosexualidad, el amor libre y la prostitución (Baliña, 1954). Uno de los expositores, Castaño, quien consecuente con sus ideas la emancipación femenina, la "Libertad Moderna" "50 (Castaño, 1954:259) que

\footnotetext{
${ }^{49}$ Subrayado mío.

${ }^{50}$ Subrayado en el original.
} 
llevaba a la perdida de la virginidad antes del matrimonio, el control de la natalidad, eran la muestra de que, "la esencia general de la mujer moderna engendra una tendencia revolucionaria [que] busca voltear las eternas columnas de granito sobre las cuales reposa la arquitectura general de la vida" (Castaño, 1954: 260).

En síntesis, los médicos dominantes otorgaron entidad a la emancipación sexual de las mujeres aunque para defenestrarla como manifestación deseable para ellas. Dentro de ese esquema, condenaron lo que consideraron en un mismo plano problemático y devenido de aquélla: la homosexualidad, el placer sexual femenino, el amor libre, entre otras dimensiones. Se preocuparon, por vía del interés eugénico, en delinear propuestas para una educación sexual $y$, a través de ella, intentaron normativizar el ejercicio sexual dentro del matrimonio y circunscribirlo a algo ligado exclusivamente a la reproducción. No había para las mujeres lugar para la emancipación, sólo debían preocuparse por la realización de sus roles supuestamente naturales.

\section{La emancipación femenina y la omisión del placer}

Aunque la emancipación femenina fue clave para el feminismo de la denominada primera ola, ésta no tuvo su correlato en aspectos sexuales en el que cuestiones como el placer sexual, la elección sexual o la formación de parejas no formaron parte de las expresiones de este movimiento. Según Linda Gordon, las feministas estadounidenses del período 1870-1890 se ocuparon de temas como el control de la natalidad, pero sólo excepcionalmente lo vincularon con cuestiones relacionadas con la libertad sexual (Gordon, 1984).

En este último aspecto, algunas figuras han descollado dentro de ese universo reactivo a abordar estos temas. Entre otras, la ginecóloga Alice Binker Stockham quien, en 1896, inició una campaña por el control de la natalidad y promovió, en relación con ello, el método de la Karezza aplicado, en igualdad, a varones y mujeres para que lograran una sexualidad saludable. Según la autora, Karezza significa "to express afection in both words and actions" (Stolckham, 1896: 20). En este método, tanto varones como mujeres evitaban el clímax e impulsaban la continencia masculina, lo que 
lo convertía no sólo en un método de control de la natalidad, sino en un sistema sexual total.

Their advocates expected the self-control involved to build character and spiritual qualities, while honoring, refining and dignifying the sexual functions; and Karezza was reputed to be a cure for sterility as well, since its continued use was thought to build up the resources of fertility in the body. (Gordon, 1973: 9)

No obstante, y más allá de algunas excepciones, las médicas feministas argentinas -si bien criticaron y lucharon contra la prostitución y el sometimiento sexual al que conminaba a la mujer- no desarrollaron estas consideraciones fuera de ese marco. Su silencio, en este sentido, lo fue en mayor medida que en el discurso de los médicos dominantes, en cuyos discursos se evidenció la intertextualidad con otras narrativas para, luego, criticarlas. Siguiendo a Lavrin, las feministas se preocuparon por el comportamiento sexual, pero no a partir de un interés por liberar la sexualidad de la mujer, sino "de la preocupación por el doble criterio moral, en el cual veían uno de los orígenes de la desigualdad de los sexos" (Lavrin, 2005: 165). En este sentido, la educación sexual que propiciaban se relacionaba con la implementación de una sola moral para varones y mujeres con el fin de provocar "actitudes más sanas frente a la sexualidad y la procreación" (Lavrin, 2005: 177). El reclamo de las médicas feministas se concentraba en la abolición de la prostitución reglamentada, la profilaxis de las enfermedades venéreas, la protección de la madre soltera a través de la eliminación de la ilegitimidad en el ámbito legal y la igualdad de derechos. Ponían de relieve las desigualdades establecidas en los códigos sociales y jurídicos entre los derechos de varones y mujeres.

En particular, Alicia Moreau de Justo se abocó a la campaña abolicionista integrando la junta consultiva de la Liga Argentina de Profilaxis Social desde 1934. La educación sexual se relacionaba con alcanzar un cambio moral y no realizó comentarios sobre el placer. La médica apostaba a que "la coeducación, la convivencia fraternal en el trabajo, engendra[ra]n una comprensión distinta de los sexos en la cual prima[ra] el aspecto afectivo sentimental". Para contener el desenfreno sexual, señalaba la 
supremacía del amor que "en su forma más alta y exquisita, es el enemigo natural de aquel acercamiento puramente instintivo" (Moreau de Justo, 1945: 187).

Según señala Lavrin, la propuesta feminista de educación sexual fracasó porque “intentó frenar la sexualidad masculina y elevar las relaciones entre los sexos a un nivel espiritual y ético que los varones, en su mayoría, no iban a aceptar" (Lavrin, 2005: 205). Es interesante notar que la autora no discute sino que reafirma que el placer sexual era una cuestión masculina y que era de carácter instintivo. Asimismo, algunas mujeres también podrían haberse opuesto a las propuestas de las feministas.

Coincidimos con Lavrin en que estas mujeres se abocaron a reclamar intervenciones estatales para la protección de la madre y su prole "como medio de resolver los problemas que creaba el doble criterio moral" (Lavrin, 2005: 205). De este modo, la preocupación por el placer sexual no pudo sobrepasar los límites del ámbito privado y la búsqueda de la emancipación femenina no incluyó la libertad sexual como una dimensión asequible.

\section{El placer sexual en locución}

El estudio de Barrancos en el cual abordó la emancipación sexual femenina en el anarquismo local (1990), retomando algunas líneas de análisis de Mary Nash para el anarquismo en España, estableció dos momentos en el discurso anarquista sobre el tema. El primero transcurre entre principios de siglo hasta 1922-1923. En ese período, las discusiones sobre el amor y el placer ocuparon un importante espacio en periódicos y revistas. A través de un lenguaje transgresor, se disputaron los significados del "amor libre" y se arremetió contra el matrimonio y la prostitución. En el segundo momento, que se extiende hasta 1930, límite temporal de nuestro estudio, la sexualidad comienza a analizarse desde una perspectiva médica y eugénica. Lazarte es señalado como el más claro exponente de esta mirada sobre la sexualidad, que, para la autora, no habla de placer. En esta misma línea, Mabel Bellucci, quien se aproximó a las luchas de las mujeres ácratas en el ámbito local, abordó la problemática femenina en el discurso anarquista a través del análisis de los temas más destacados y recurrentes, como el amor y la unión libre, las enfermedades venéreas, los métodos contraconcepcionales, la abolición de la prostitución y la maternidad idealizada en el transcurso del siglo XIX al siglo XX (Bellucci, 1990). 
Siguiendo el límite temporal de las anteriores investigaciones, Laura Fernández Cordero retoma la perspectiva de análisis de Barrancos, desde nuevas miradas teóricometodológicas. La autora señala la centralidad de la cuestión sexual en el ideario ácrata a través de un análisis bajtiano de las fuentes que pone el acento en la polifonía y en la construcción intersubjetiva de los discursos. Esta perspectiva le permite analizar las formas en que las mujeres ácratas recitan la doctrina a través de la prensa y las resistencias de los varones a esta intervención política (Fernández Cordero, 2010), como así también los debates en relación a la emancipación femenina. En este sentido, señala las limitaciones de las anarquistas que pudiendo hacer uso de las herramientas del anarquismo "para analizar la opresión, la sujeción y la explotación de los cuerpos sexuados [...] no lograron articular un discurso de las nuevas corporalidades y el placer" (Fernández Cordero, 2011:2).

Otros estudios locales que de manera tangencial han abordado el discurso anarquista sobre la sexualidad destacan la lucha del movimiento contra la moral sexual burguesa, el matrimonio y la apuesta por las uniones libres y el placer sexual (Lavrin, 2005). Asimismo, de manera colateral, la reconstrucción de biografías o emprendimientos periodísticos de las mujeres anarquistas dieron algunas pinceladas al tema, en particular, sobre la apropiación de la anarquía que realizaron las mujeres y las tensiones que produjeron con sus propuestas emancipatorias en el plano sexual y que pusieron en evidencia las contradicciones entre el discurso público y la actuación en el espacio privado de algunos libertarios (Feijoó y Nari, 1994; Guzzo, 2003; Calzetta, 2005; Manzoni y Ledesma Prietto, 2009; Molineaux, 2002; Vasallo, 2007; Barrancos, 1996).

Como ya hemos mencionado, la transnacionalidad del movimiento que evidenciamos a través de la circulación de ideas, producciones y personas, en particular con el movimiento en España, exige considerar algunos de los aportes provenientes de investigaciones que analizan el discurso anarquista sobre la sexualidad desarrollada allí. Los trabajos de Mary Nash han sido el puntapié inicial para las indagaciones de la dimensión cultural del anarquismo. La autora, a través del análisis de la propuesta neomalthusiana de la reforma sexual anarquista, ha profundizado en los conocimientos para separar la sexualidad de la reproducción (Nash, 1984; 1993). Una renovada perspectiva proviene del trabajo de Cleminson Anarquismo y sexualidad (2008). En él, 
a diferencia de los trabajos de Nash, se analizan las propuestas ácratas situándolas en relación con los discursos científicos reglamentarios provenientes del campo de la sexología, la psiquiatría y la eugenesia, entre otros. En esta misma línea, Helena Andrés Granel (2008), además de explorar el discurso vinculado con el control de la natalidad, avanza sobre el amor libre, las consideraciones sobre el matrimonio, la familia y la prostitución y los debates relacionados con estos temas en las publicaciones libertarias. Asimismo, su tesis sobre el discurso de Juan Lazarte en relación con el neomaltusianismo, la prostitución, el matrimonio y la sexualidad (2012) ha avanzado sobre la dimensión de la emancipación sexual.

En suma, como ya hemos adelantado, podemos decir que -en su mayoría- los trabajos sobre el anarquismo local no han avanzado más allá de los años 30. Asimismo, no se han analizado las vinculaciones entre eugenesia y emancipación sexual, como así tampoco se ha reparado en el discurso médico de quienes participaban del sostenimiento del movimiento anarquista.

Para adentrarnos en el estudio de la emancipación sexual de las mujeres, es útil revisar una literatura precursora que avanzó sobre aspectos vinculados a ella. En particular, nos referimos a la propuesta de reconocimiento de la sexualidad femenina formulada por Julio Barcos, a quien consideramos como el antecedente local más próximo a los postulados de los médicos anarquistas en relación con el derecho sexual femenino.

\section{3. a. La libertad sexual de las mujeres}

Algunos intelectuales anarquistas contemporáneos plantean que Julio Barcos -al igual que Juan Lazarte- fue "uno de los pilares ácratas del feminismo moderno" (Rama, 1990, 48). Asimismo, como ya hemos mencionado, su obra La Libertad sexual de las mujeres $(1921)^{51}$ se considera como un ejemplo de la defensa de derecho al cuerpo (Barrancos, 2006). La publicación adquirió gran difusión y fue reeditada en cinco oportunidades, la última de la que tenemos constancia fue en 1935, fue publicada

\footnotetext{
${ }^{51}$ Luego en el título de la obra desaparece el artículo "La".
} 
también en Barcelona en 1930, sin embargo, anteriormente Barcos había difundido sus ideas en la revista Generación Consciente en 1924.

En el primer capítulo, hicimos referencia a la relación maestro-alumno entre Barcos y Lazarte, así como a los espacios de acción que compartían en las revistas culturales. Asimismo, tenemos constancia del vínculo entre Barcos y Martín Fernández. En el prólogo de la quinta edición del libro Libertad sexual de las mujeres, el autor analizó los alcances de su obra y agradeció a los que lo habían apoyado en la defensa de la libertad sexual de las mujeres, entre ellos, destacó a Manuel Martín Fernández. También, señaló la traducción al portugués por María Lacerda de Moura. El pedagogo santafesino se presentaba como el primer autor en Argentina que "planteó con franqueza el problema social del sexo" (Barcos, 1935: 8).

Estas diversas relaciones nos permiten conjeturar que algunos de los planteos de Barcos pervivieron en las ideas propugnadas por los médicos anarquistas que se destacaron en las décadas posteriores en el tratamiento de estas temáticas.

En el desarrollo de la obra, Barcos examinó los obstáculos que se le presentaban a las mujeres para lograr lo que él denominaba su "libertad sexual". Por un lado, consideró que existía una civilización "unisexual" masculina que había engendrado "dos hijos monstruos: el capitalismo y la guerra”, los cuales esclavizaban al sexo femenino (Barcos, 1935: 6). Por otro lado, se refirió a la doble moral para mujeres y varones. Haciendo hincapié en las contradicciones entre sus compañeros libertarios que luchaban por la liberación de los oprimidos pero que no renunciaban a sus privilegios de sexo, mencionaba: "hay una cruz más pesada que la esclavitud económica de los asalariados: la esclavitud de la mujer, parias entre parias, obrera sin salario y sin relevo que está día y noche al servicio de su amo, llámese éste marido, padre hermano, tutor o amante" (Barcos, 1935: 21).

A través de una intertextualidad manifiesta, podemos reconocer algunas influencias en los planteos del autor. Por un lado, se manifiesta su admiración por las escritoras y militantes feministas, en especial de Charlotte Gilman Perkins, escritora y feminista utópica. Su ensayo Women and Economics: A Study of the Economic Relation Between Men and Women as a Factor in Social Evolution, de 1898, demuestra, para Julio Barcos "que la dependencia económica de la mujer es la que ha producido su 
degeneración física y mental" (1935: 251). Los planteos de la pedagoga y feminista Ellen Key también se encuentran entre sus referencias. De la región rioplatense, Julio Barcos retoma a las escritoras Gabriela Mistral, Herminia Brumana y Juana Fernández Rosales (seudónimo de Juana de Ibarbourou) para situarlas como ejemplo de mujeres que han luchado por la liberación sexual y no se han detenido en reclamaciones sufragistas, en los que considera que se concentraba vanamente el feminismo de la época. Para Julio Barcos, las feministas de la región "llenas de afectación y de remilgos, imbuidas del falso pudor burgués" (1935: 102), no franqueaban la frontera de reivindicar su libertad sexual.

En el libro reflexionaba sobre las consecuencias de la libertad de las mujeres no sólo para ellas, sino también para los varones, pues señala que ellas "saben hacer mejor uso de la libertad que los hombres" (Barcos, 1935: 6). Para Barcos, la doble moral sexual se expresaba en las contradicciones de la "burguesía adúltera" que "odia a la ramera y desprecia a la mujer que practica el amor libre, sin advertir que lo que las honestas hacen, es ejercer la prostitución con el marido y practican el amor libre, clandestinamente, con el amante" (Barcos, 1935: 100). El autor pretendía una sola moral para los dos sexos, sin sanciones ni obligaciones, "lo que queremos es que cada mujer haga libre uso de su cuerpo y alma, sin mendigar su libertad a nadie" (Barcos, 1935: 256).

Asimismo, Barcos acusaba a los defensores de la moral, la familia y el pudor de ser los causantes de la opresión femenina en tanto sostenían:

que las mujeres nacieron para vivir emparedadas entre la superstición y la obediencia, para amamantar y criar hijos, para ser reinas del hogar, teniendo por cetro la escoba, por trono la cocina y por reino la felicidad en el otro mundo (la de éste le ha sido hipotecada por los hombres). (Barcos, 1935, 27)

Sin desmontar el mandato de la mujer-madre, Barcos creía en la educación como instrumento de liberación femenina que aportaría a un mayor conocimiento de las 
mujeres y, así, a una mayor capacidad de decisión. En la década del 20, hacía un llamado a la medicina social y a la eugenesia para que educaran desde temprano a la mujer para la maternidad, reemplazando "la falsa educación del pudor" (Barcos, 1935: 257). Las mujeres sólo debían llevar adelante una vida sexual sin prejuicios y, a comienzos de la década del 20, Barcos consideraba que para ello bastaba y sobraba "con que lo prediquen y lo practiquen desenfadadamente" (Barcos, 1935: 102).

Barcos no se refirió a una Revolución Sexual sino que, bajo la noción de libertad sexual, definió la emancipación de las mujeres de las ataduras sexuales y las invitó a su propia liberación a través de la educación, el desprejuicio y la autonomía de elección de parejas. En esta línea, continuarán -con matices- Lazarte y Martín Fernández en los años 30 .

\section{3. b. La Revolución Sexual}

La idea de Revolución Sexual fue articulada por Juan Lazarte en el folleto homónimo. En 1932, la revista Nervio creó una editorial a través de la cual publicó libros y colecciones. La primera colección que editó fue los Cuadernos "AHORA". Entre los propósitos de la misma se destacaba que trataría sobre los problemas sociales que necesitaban urgente solución, causados por "la ineptitud del Capitalismo y del Estado" (Ediciones Nervio, 1932: s/n). A través de la editorial Lazarte publicó La Revolución Sexual de nuestro tiempo, un folleto en el cual analizó la crisis de la institución matrimonial y su superación a través de las uniones libres. El texto tuvo singular difusión no sólo en la Argentina sino también en España, donde se publicó a través de la editorial Tierra y Libertad, en 1933.

El concepto no era propio de Lazarte. Generalmente, se ha asociado este concepto con la obra de Wilheim Reich. El libro, en realidad y expresado por el propio autor, constaba de una primera versión publicada en 1929 y denominada Geschlechtsreife, Enthaltsamkeit, Ehemoral ("madurez sexual, continencia, moral matrimonial") (Reich, [1949] 1970: 1). Al año siguiente, publicó Die Sexualität im Kulturfampf. Como ha señalado John Levi Martin (1996: 108), en ese título, la palabra "Kulturkampf" hacía referencia a "cultural struggle", es decir, batalla cultural, que era la palabra usada para 
describir la disputa de Bismarck con la Iglesia Católica, "and so does not mean <revolution>". Una versión ampliada de esta obra de Reich, y publicada en 1936, incluyó una segunda parte llamada "La lucha por la < nueva forma de vida $>$ en la Unión Soviética". Allí, había un capítulo denominado "La Revolución Sexual”. Fue en esta versión donde Reich hace referencia a un autor de apellido Baktis que habría escrito un libro, no antes de 1921, llamado La Revolución Sexual. En él, Baktis hablaría de los cambios sexuales habidos en la Unión Soviética. Sin embargo, sobre esta obra no hay más información. Lo cierto es que, desde entonces, el libro de Reich pasó a tener esa traducción en inglés y, luego, la tomaría en castellano.

No obstante, Levi Martin señala que el primer uso del concepto Revolución Sexual -hasta donde puede rastrearlo en el pasado- se produjo en 1921, en el libro Die Sexual Revolution publicado en Leipzig y escrito por el médico Wilhelm Heinrich Dreuw. Según Levi Martin, este texto muestra una alianza entre distintos sectores para propiciar reformas legales y prevenir la prostitución y tratar las enfermedades venéreas (Levi, 1996: 107).

Para Levi, las similitudes entre el uso y las ideas que difunde Dreuw y las que luego retoman otros autores, incluido el mismo Reich, no implican necesariamente que éstos conocieran la obra de Dreuw, sino, más bien, que en un espectro de izquierda radical la expresión Revolución Sexual, o ideas que daban cuenta de ella, fue un fenómeno de paralelismo en distintos países que alcanzó no sólo a Dreuw y Reich en Alemania sino también a Alejandra Kollontai en Rusia, a Alec Craig en Inglaterra y otras figuras y ámbitos nacionales (Levi Martin, 1996: 111).

Para Levi Martin, finalmente, la importancia del concepto antecede a la publicación de Wilheim Reich y ubica en Estados Unidos el lugar de mayor importancia para el ensamble del concepto y su posterior difusión. En particular, pues considera como punto de impulso para el mismo ya que, en 1927, la revista Modern Quarterly, editada por Víctor Francis Calverton y Samuel D. Schmalhausen, utiliza la expresión "Revolución Sexual" para explicar los cambios en la sexualidad americana. Para Levi Martin, esta idea fue articulada a partir de la obra de otro autor bien conocido en la temática, Ben Lindsey, juez que escribió The revolt of youth (1925). Luego, en Schmalhausen escribiría, en 1929, una ponencia con este mismo nombre que presentaría en la Conferencia "The great meeting on sex and civilization". Schmalhausen y 
Calverton editarían esta conferencia como libro y, en la Argentina, sería el mismo Lazarte el que incluiría una traducción de esta obra en la colección Eros bajo su dirección.

A lo largo de sus obras, Lazarte recurría asiduamente a estos autores. A través de aquellas obras, en particular la obra de Calverton y Schmaulhausen, adoptó el término; en efecto, las intertextualidades evidencian esta conexión. Así también, la importancia otorgada por Lazarte a aquella obra se evidencia en la posterior publicación, por editorial Partenon, de aquellos estudios bajo el título "El sexo en la civilización" en tres volúmenes dentro de la colección Eros dirigida por él, en 1947 y reeditados por segunda vez en 1952.

Sin embargo, cabe mencionar también que Levi Martin se limita a los países de habla anglosajona y omite, del mismo modo que lo hace Juan Lazarte, toda referencia explícita a la obra de Hildegart Rodríguez titulada Revolución Sexual, libro publicado en la ciudad de Valencia, en 1931. Lazarte, con todo, conocía la obra de Rodríguez en relación con la maternidad consciente. Para Rodríguez, la Revolución Sexual debía solucionar problemas de distinta índole tales como el divorcio, la prostitución, la homosexualidad, los abortos clandestinos, el adulterio como delito, las enfermedades venéreas -que consideraba que debían tratarse como delitos punibles para quienes las transmitieran-, la regulación de los nacimientos, el problema de los niños anormales, entre otros. En su propuesta diferenciaba la libertad de amor, del amor libre pues para ella, siguiendo a Ellen Key, el segundo era "la tapadera oficial para toda clase de licencias eróticas" (1931: 5).

Para Samuel D. Schmalhausen, la Revolución Sexual no significaba, según Levi Martin, la abolición del ejercicio racional de la autoridad sino la represión del capitalismo cristiano, término acuñado este autor. Según entendía Schmalhausen, el proceso para crear un mundo nuevo implicaba una doble revolución: una, en la esfera económica y la otra, en la esfera de la erótica (citado por Levi Martin, 1996: 129-130). Lazarte se nutrió de las visiones de Revolución Sexual y compartió las ideas de Schmaulhusen sobre la necesidad de un cambio en las relaciones económicas, para lograr la completa Revolución Sexual. 
En el capítulo tres, hemos hecho referencia a las consideraciones sobre "el derecho de los solteros" que Lazarte proclamaba. En particular, los derechos sexuales eran los más relevantes, para que los varones no fueran hacia la prostitución y las mujeres no sufrieran problemas psíquicos y físicos por la insatisfacción” (Lazarte, 1935). Desde una perspectiva eugénica, entonces, el placer sexual y el conocimiento y control del propio cuerpo se volvieron aspectos fundamentales de la propuesta lazartiana.

Como ya hemos señalado, el miedo al embarazo era una fuente de conflictos para las mujeres. La solución era la difusión de una educación sexual que, a diferencia de las posiciones del campo médico que analizamos anteriormente, se ocupara de brindar la información sobre los métodos anticonceptivos. Con estas herramientas, Lazarte anunciaba la llegada de una nueva moral a partir del

esfuerzo hondo de la nueva conciencia en separar proceso reproductor, de ritual de comunicación física y espiritual: placer; en distinguir y disociar, el sexo de multiplicación elevando las alturas del amor y liberando las grandes fuerzas humanas ocultas y prisioneras, por siglos de esclavitud católica capitalista. (Lazarte, 1936: 138)

Por ello, los conocimientos científicos sobre la reproducción humana y las técnicas anticoncepcionales para poder evitarla eran, para Lazarte, las herramientas que ayudarían a las mujeres a apropiarse de su sexualidad. La ciencia "liberadora" otorgaba legitimidad a estos planteos y contribuía a pensar la Revolución Sexual desde otras perspectivas. En este sentido, Lazarte, mencionaba que "todo acto sexual es moral" (Lazarte, 1932c: 19). Asimismo, planteaba que la falta de experiencia sexual de las mujeres traía "por consecuencia la disminución de las facultades eróticas" y "una mujer sin esta riqueza, no puede contribuir a la felicidad de nadie, ni de ella misma" (Lazarte, 1936: 20).

En sintonía con los planteos de Lazarte, Martín Fernández sostuvo que la falta de satisfacción sexual producía enfermedades de carácter nervioso en las mujeres. Otros 
síntomas eran la anemia, el insomnio, la intranquilidad, la distracción y la falta de memoria. Incluso, la imposibilidad de satisfacer su "necesidad" eventualmente "y no cuando la sienten" producía histeria y otras neurosis que afectaban la vida de las mujeres, la desnaturalizaba desviando "todas sus mejores posibilidades intelectuales y de actuación social” (Martín Fernández, 1940c: 34).

La independencia económica, la liberación sexual, a través de la planificación de los embarazos y el conocimiento del propio cuerpo y del placer sexual, conquistado por medio de una educación sexual mixta, de bases eugénicas, llevarían a una emancipación real que retomando a Emma Goldman -otra fuente de inspiración del autor-, comenzaba “en el alma de la mujer” (Lazarte, 1935a: 153).

En el folleto a Revolución Sexual de nuestro tiempo, de 1932, Lazarte consideraba que dicha Revolución se expresaba, en relación a la crisis del matrimonio como institución coercitiva de la sexualidad, en ocho indicadores. Entre ellos, el aumento de las relaciones sexuales extra-matrimoniales y pre- casamentarias y su admisión en el consenso público, algo que compartía con los autores mencionados, incluso Hildegart Rodríguez, y que se correspondía con la existencia del divorcio y las uniones libres. La mayor ilegalidad expresada en uniones de hecho y la desvalorización de los hijos legítimos, eran otros indicadorea de esa revolución, acompañadas por la decadencia de la prostitución, vencida por la juventud femenina y el derecho de los solteros a la sexualidad recreativa y a una maternidad y paternidad por fuera de las instituciones. Estos indicadores tenían como prerrequisito que no sólo los varones sino también las mujeres estuvieran liberados sexualmente para acceder a relaciones sexuales, variadas y múltiples, con una educación higiénica adecuada. Asimismo, para que la Revolución Sexual estuviera completa era necesario, por un lado una nueva moral, por otro lado la libertad sexual y por último "los medios materiales para coadyuvar este progreso" (Lazarte, 1936: 154). Entonces, decía "recién la maternidad será consciente; la prostitución y el venéreo desaparecerán borrados por el verdadero amor" (Lazarte, 1936: 155) que, anteriormente, "las generaciones pasadas perdieron en locas abstinencias o en mortales aventuras" (Lazarte, 1935a: 146).

Por la amplitud que ocuparon en el discurso anarquista, resulta interesante desagregar, algunos de los tópicos que conformaban la Revolución Sexual en los discursos de los médicos ácratas Lazarte, Martín Fernández y otras/os libertarias y 
militantes anarquistas, que continuaron las perspectivas de estos médicos, cuando los mismos se abocaron a la lucha contra el peronismo, desde el anarquismo y el gremialismo médico.

\section{3. b. I. Las Uniones libres}

Dentro del anarquismo, el amor libre "cuestiona toda doble moral, hipocresía o cinismo" (Baigorria, 2006:9). Durante el período en el que la legitimidad de las uniones dependía del poder estatal y el poder religioso y el matrimonio eran de carácter indisoluble, la unión libre fue sinónimo de amor libre. El amor libre era una crítica a las instituciones como el matrimonio, pero no contenía la idea de amor plural o múltiple (Baigorria, 2006). Esta temática fue debatida dentro del anarquismo donde había quienes cuestionaban el significado que en la práctica adquiría el "amor libre" pues se reducía a una crítica del aspecto jurídico y económico del matrimonio burgués. Como señala Andrés Granel, "mantenía intactos [...] los modos de relación que cuestionaba a nivel teórico" (2008: 70).

Así, la propuesta de unión libre adquiría diferentes significados. En la práctica podría haber conservado la asignación de roles femeninos y masculinos del sistema patriarcal. Para las mujeres, podría no haber significado ningún beneficio, pues como criticaba María Lacerda de Moura "la mujer continúa representando el papel de cosa, objeto de placer" (Andrés Granel, 2008: 73).

Una de las consecuencias de las uniones libres era la desaparición del adulterio. Éste desde el punto de vista sexual, decía Lazarte (1932b) "está fundamentado en la esclavitud de la mujer, en la propiedad que considera la esposa como un bien, mueble o riqueza" (19). Por ende, quien daría el golpe final serían las mujeres, particularmente las jóvenes que "miran con desconfianza el matrimonio y defienden encarnizadamente sus libertades". La concepción del adulterio como un delito decía "pertenece a épocas en que amor es reproducción, en las cuales no se concibe ni el amor placer o recreación y camaradería" (Lazarte, 1932c:20). Es interesante señalar que en nuestro país el adulterio estaba considerado un delito por el artículo 118 del Código Penal hasta el año 1995, año en el cual fue derogado por la ley $\mathrm{N}^{\circ}$ 24453. Como señala Barrancos, el carácter 
patriarcal de la legislación se evidenciaba en distinta penalización del adulterio según el género. En relación con las mujeres "comportaba una lesión al honor que debía castigarse"; en cambio, en relación con los varones "se refería a cuestiones patrimoniales" (Barrancos, 2007: 261).

Otro efecto del progreso de las uniones libres era el aumento del número de divorcios. Lazarte, retomando lo sucedido en Estados Unidos a través de las citas de los trabajos de Lindsey y Calverton, señalaba:

la burguesía y el feminismo creo que han dado un gran paso adelante, pero no por el divorcio en sí, que como toda cosa negativa no quiere decir nada, sino como contribución a la disolución del matrimonio, cuyas crisis o muerte trae aparejada la iniciación de la unión libre y libertad de amar. (Lazarte, 1932d: 8)

En la publicación Luz (1949- 1951) se retomaban aquellas ideas cuando se afirmaba: "el matrimonio está muy lejos de ser el basamento de la familia. Nos referimos al matrimonio tal como está legislado y no a la unión natural monogámica entre el hombre y la mujer" (Luz: 1951: 9). Para enfrentar este problema reclamaban una nueva moral sexual, la cual, decían, "librada de todo dogmatismo, permita el desarrollo de las inclinaciones humanas sin ninguna clase de obligaciones, que no sean las nacida del mutuo afecto entre las personas" ( $L u z, 1950: 10)$. En este sentido, apostaban a la defensa del "amor libre", el cual decían, ante los discursos "ignorantes" que vinculaban esa categoría al "libertinaje o la "prostitución", eran ella/os la/os únicos que tenían autoridad para dar "su definición exacta". Así, puntualizaban que "amor libre" era:

el derecho que tiene todo hombre y toda mujer a elejir (sic) en el amor, sin coacciones de ninguna clase, esto es, libremente. Es decir, que cuando un individuo quiere unirse a otro sexo opuesto, debe estar en condiciones de 
hacerlo sin la presión de factores económicos, religiosos, políticos, raciales, domésticos, sociales, etc. (Luz, 1951:7)

Predominó en la publicación, aún con más fuerza que en las narrativas de los médicos ácratas, la prescripción de la heterosexualidad. Además, desde la revista también se evidenciaba un discurso que, desde otra perspectiva, contribuía al mandato del discurso dominante en relación a las mujeres. Criticaban la educación doméstica y mojigata que enseñaba a cocinar, coser, bordar, escribir, vestir elegante, hablar idiomas y tocar el piano, porque no enseñaban lo fundamental: "a ser esposas y madres" ( $L u z$, 1951:7). Como esposa, indicaban, debía ser la mejor amante del hombre. Si no lo era, a causa del aburrimiento, éste recurriría "a la hembra avanzada que le proporciona aquellos placeres que su esposa no sabe darle" ( $L u z, 1951: 7)$. Si bien proponían una nueva moral sexual, los límites de la propuesta se explicarían por la primacía de "la ley del derecho sexual masculino" que, como señala Rich, está instituida "en el mito del irresistible-triunfante-impulso sexual masculino del pene-con-vida propia” (Rich, 1985: 20).

\section{3. b. II. La virginidad, el placer y la felicidad sexual}

La mengua del valor de la virginidad en el ideario de la época fue un aspecto que formaba parte del pensamiento anarquista y era una forma visible de emancipación sexual de las mujeres de los sometimientos sociales de su época y, a su vez, permitiría abrir una nueva dimensión a esa emancipación: el placer sexual.

La caída del matrimonio, y todo lo que esta institución representaba, beneficiaría al conjunto social, pero aún más a las mujeres. Lazarte consideraba sostenía que las instituciones sexuales "elaboradas por la cultura y sostenidas por la organización societaria estatal" representadas en "el matrimonio, la prostitución y el celibato (...) polarizan los instintos sexuales en su acción y reacción sobre el individuo, y es una agitación permanente sobre la civilidad" (Lazarte, 1932b: 5). 
Las uniones libres entre varones y mujeres modificarían las formas de relacionarse. Ellas posibilitarían la llegada de un "nuevo régimen de relaciones e interrelaciones sociales y económicas" basado en un plan de socialización integral (Lazarte, 1932a: 63).

Desde las páginas de Cultura Sexual y Física Manuel Martín Fernández, a través de una estrategia de difusión distinta a la de Lazarte -los consultorios sexuales-, también promovió el derecho al placer sexual de las mujeres. Esta estrategia la replicó en Hombre de América Fuerte y Libre, donde también desarrolló una columna titulada "La mujer: su posible felicidad sexual".

Al igual que Lazarte, el médico Martín Fernández cuestionaba la "falacia de la virginidad" y señalaba que el ideal a alcanzar era que varones y mujeres "pudieran unirse en cuanto sienten en sus organismos los primeros insistentes y patentes llamados del sexo" (1938: 587). Como médico, decía, tenía la responsabilidad de auxiliar a las mujeres en las cuestiones de la sexualidad "para darles la posibilidad equitativa de gozar del máximum de felicidad y tranquilidad en este mundo infeliz" (1938: 588). Por ello, los consultorios que dirigió en las distintas revistas se convirtieron en herramientas para lograr el cambio. Si bien fueron varones los que más consultaban, en sus respuestas, cuando el tema lo indicaba, Martín Fernández hacía mención a la igualdad de las mujeres al derecho del ejercicio sexual. También indicaba lecturas, como por ejemplo el libro de Barcos, el cual calificaba como "un libro de una gran moral, que ha merecido el aplauso caluroso de las más sanas y libres mentalidades" (Martín Fernández: 1939b: 316).

La encuesta fue otro recurso interactivo del médico para presentar los problemas relacionados con la educación sexual y los beneficios que ella traía aparejada en relación con el placer sexual -tanto dentro como fuera del matrimonio-. A través de ella interpelaba sobre "vida sexual, matrimonio y educación sexual" a quienes leían su columna. El cuestionario incluía las siguientes preguntas:

1. ¿está de acuerdo con su vida sexual?, 2. ¿Cree Ud. que la educación que ha recibido lo capacitó suficientemente, para gozar de todas las 
posibilidades físicas y espirituales en la plenitud que nos brinda la vida?, 3. Si está descontento- ¿a qué atribuye sus fracasos?, 4. ¿Qué opina Ud. del matrimonio como institución; significa o no, para Ud. la conquista de la felicidad que todos soñamos?, 5. Si está descontento- ¿Por qué, qué defectos le encuentra, cómo cree que debieran ser las relaciones de los sexos, teniendo en cuenta la felicidad de los que se aman y la de los posibles hijos?, 6. ¿Cómo cree Ud. Que debe ser la educación sexual que hay que dar a los niños y jóvenes?, 7. ¿A qué edad cree que debe iniciarse la vida sexual? (Martín Fernández, 1940a:21)

A través de estas preguntas, el médico no sólo buscaba un dato estadístico sino también que el público reflexionara y pusiera en cuestión la educación sexual que habían recibido, así como las formas de relacionarse sexualmente.

La educación femenina propugnada por los médicos dominantes, la cual era fundamentalmente doméstica, era criticada por Lazarte. La falta de conocimientos sexuales y la castidad también provocaban que las mujeres se orientaran a "prácticas sexuales perversas u onanistas" (Lazarte, 1932a: 19). Si bien Lazarte no se refirió a la masturbación, Martín Fernández, como veremos más adelante, la aceptaba como una práctica pero sólo para los varones.

Lazarte planteó que no alcanzaba con que las mujeres adquirieran independencia económica sino que también debían tener derecho a la sexualidad recreativa para ello debían acceder a una educación sexual que les permitiera olvidarse de la reproducción y la desaparición del valor de la virginidad o la "himenolatría" (Lazarte, 1935a: 69).

En su consultorio, ante los obstáculos que la sociedad interponía a la libre unión sexual, Martín Fernández recomendaba la masturbación como práctica sexual recreativa, para los varones, una vez por semana, evitando que se convirtiera en un vicio (Martín Fernández, 1940b). En cambio, esta práctica no era recomendada para las mujeres, pues a ellas sólo les aconsejaba practicar "relaciones sexuales normales". Así pues, si bien su postura en torno a la sexualidad era de mayor tolerancia, la posibilidad de que la autosatisfacción sexual fuera una práctica habitual generaba dudas y no estaba 
permitida para las mujeres, lo cual -aunque Martín Fernández promovía el disfrute para las mujeres, lo hacían con parámetros distintos en términos de género.

Martín Fernández también apostaba por una educación sexual a través de la cual, las mujeres alcanzaran su felicidad sexual. Como hemos mencionado anteriormente, para este médico, la satisfacción sexual de las mujeres se situaba dentro de la esfera de los derechos primordiales (Martín Fernández, 1942b: 18). Su práctica médica le había demostrado que si las mujeres actuaran en relación con su "constitución animal y humana" y satisficieran sus necesidades desobedeciendo "las obligaciones morales", serían personas "mucho más sana[s]" que pagarían "menos tributos a los trastornos genitales y sexuales” (Martín Fernández, 1942a: 24).

Varias cuestiones obstaculizaban la felicidad sexual, entre ellas, señalaba, el matrimonio por conveniencia, el confort del hogar burgués, las revistas para la mujer, el cine y el teatro (Martín Fernández, 1942b:17). Asimismo, la falta de independencia la convertía "en títere que actúa por reflejo del ambiente", lo cual producía que los trastornos en la salud de las mujeres fueran de índole nervioso o psíquico en su mayoría (Martín Fernández: 1942b:18). Antes, decía, se consideraba que estos trastornos se originaban en patologías ginecológicas pero el avance de la ciencia establecía nuevas verdades, aunque señalaba que nunca eran absolutas (Martín Fernández, 1942c: 21). Tampoco había que considerar a la mujer una enferma en razón de los procesos fisiológicos como la menstruación, la menopausia o el embarazo (Martín Fernández, 1942a: 25). Las relaciones sexuales comportaban, si no se establecían con base a ciertos parámetros, un atentado a la felicidad sexual:

desde el punto de vista puramente sexual, la mujer necesita ser siempre conquistada y nunca violada. La violación es siempre para la mujer, aún para la que cumple sus bodas de oro con el matrimonio, la ofensa que más hiere su sensibilidad interior, la ofensa que mayor resentimiento, conciente (sic) o subconciente (sic), le produce. (Martín Fernández, 1941b: 38) 


\section{3. b. III. La verdadera lucha: suprimir la prostitución}

La crítica a la doble moral burguesa, que sólo permitía los encuentros sexuales dentro del matrimonio, con fines reproductivos para las mujeres y que había instituido a la prostitución para satisfacer las necesidades de recreación de los varones, fue una constante en el discurso anarquista. En su obra Sociedad y Prostitución, Lazarte (1935a) señalaba que la prohibición del placer sexual para las mujeres, la inequidad laboral entre mujeres y varones, que por igual desempeño obtenían diferentes salarios, llevaban a las mujeres a la miseria, la cual las embarcaba en el camino de la prostitución. En este sentido, para lograr la completa emancipación femenina, no bastaba con que la mujer se liberara sexualmente y decidiera sobre sus embarazos. Para que estas condiciones se realizaran sin obstáculos, la mujer debería alcanzar la independencia económica, para estar en iguales condiciones con el varón tanto en la esfera sexual como económica (Lazarte, 1935a). En este mismo sentido, acompañando la perspectiva de Lazarte, el médico Martín Fernández declaraba: "estamos convencidos de que el día que la mujer pueda resolver independientemente su problema económico, podrá ser dueña de su cuerpo y de sus actos conquistar con ello su libertad sexual" (Martín Fernández, 1939a: 316).

Considerando a la mujer la primera esclava de la humanidad, indicaba que "los sentimientos y necesidades de ella no contaban para nada" (Martín Fernández, 1942b: 17) y era necesario que en las relaciones entre varones y mujeres existiera "la mutua libertad" (Martin Fernández, 1941a:38). Por ello también era necesaria, como también señalaba Lazarte,

la independencia económica [...] pues solamente cuando una mujer se siente económicamente libre puede sentirse dueña total de su personalidad y solamente cuando el hombre, dentro de las costumbres y el sistema social en que vivimos, tiene conciencia de tal libertad de la mujer, puede considerar a esta como un ser socialmente igual a él (Martín Fernández, 1941a: 38) 
Como ya hemos mencionado María Lacerda de Moura defendió las ideas de libertad sexual de las mujeres. Invitada por Lazarte, la pedagoga prologó la obra Sociedad y Prostitución. Allí, rescató el valor de publicar un libro sobre "el fenómeno social que es la prostitución" y lo catalogó como "revolucionario" (Lacerda de Moura, 1935: 5). La crítica realizada por Lazarte era aún más autorizada, decía, porque procedía de un médico visitador de prostíbulos, que conocía las experiencias de las mujeres en esa situación.

La relevancia de hablar sobre estos temas aun dentro del movimiento anarquista era algo a destacar por Lacerda de Moura, quien había resistido la ignorancia de algunos de sus compañeros hacia sus ideas, quienes le aseguraban que la emancipación sexual era "el colorario de la emancipación del hombre" (1935: 10). Para la libertaria, "el hombre" de cualquier ideología "siente dificultad en romper los lazos de autoridad que lo sujetan a la mujer, subyugándola" (1935: 12). Al igual que Lazarte, sostenía que la juventud era la que llevaría adelante la emancipación sexual. Sin embargo, también, señalaba los obstáculos, que en ese contexto, identificaba con el nazismo y el fascismo, aunque confiaba en que los regímenes pasarían y la mujer "tenaz [...] una vez despierta, nunca más el patriarcado la colocará en la situación degradante de hembra, para el placer exclusivo del macho y la procreación inconsciente" (1935:13). Si bien reconocía que los varones pelearían para conservar "sus derechos patriarcales" a través del derecho o la fuerza, a través del sexo llegaría la liberación (1935: 15). Lacerda de Moura apostaba, para solucionar los problemas sexuales, a las uniones sexuales bajo el método Karezza, ideado por la ginecóloga estadounidense Alice Binker Stockham en 1896. El sistema consistía en mantener relaciones sexuales "intensas y prolongadas sin depleción y sin orgasmo"; a través de ellas, señalaba, se llegaría a la unión de las almas y la renovación espiritual y a "la sensación inmensamente mayor de placer" (1935: 16).

El posicionamiento de Lazarte en relación con el problema de la prostitución constituía una alternativa al reglamentarismo y el abolicionismo, sistemas discutidos en la década del 30. Ésta era la postura defendida por el movimiento anarquista, la cual apostaba a la supresión total de la prostitución atacando lo que señaló como sus verdaderas causas. A través de un estudio sociológico y antropológico basado en entrevistas y elaboración de estadísticas, Lazarte respaldó y legitimó "la verdadera lucha" que era la erradicación de la prostitución. 
En las primeras décadas del siglo XX, los debates sobre la prostitución irrumpían en la escena pública. Diversos sectores se manifestaban a favor de la reglamentación de la misma o de su abolición, cada uno de los cuales esgrimían distintas motivaciones, ya sea el control de la propagación de las enfermedades venéreas, la homosexualidad masculina, la destrucción de la institución familiar y la pervivencia del amor conyugal como espacio reproductivo, la degeneración social y racial, entre otras razones. ${ }^{52}$

El sistema reglamentarista imperó en nuestro país hasta el año 1936, cuando se sancionó la ley 12.331. Hasta ese momento, los prostíbulos estaban bajo el control del Estado, debían registrarse y tener autorización municipal para funcionar, recibían visitas periódicas de médicos para la supervisión sanitaria de las prostitutas, las cuales también debían registrarse. Este sistema, como señala Donna Guy, "legalizó la prostitución para aislar y controlar -así lo esperaba- las consecuencias sociales y médicas del comercio sexual" (1994: 66)

Algunos médicos higienistas consideraban que la reglamentación era una buena herramienta para combatir la propagación de las enfermedades venéreas y así contener los males que podían causar a las futuras generaciones. ${ }^{53}$ Empero, para otros, como Juan Lazarte, la reglamentación era injusta porque instituía "el proxenetismo y la explotación de la mujer como una función social, útil y moral" (Lazarte, 1935a: 130). Para el médico libertario, el reglamentarismo había fracasado pues no había logrado su objetivo, controlar las enfermedades, al considerar a las mujeres como las únicas responsables del contagio y era el "factor dominante de degeneración racial" (Lazarte, 1935a: 15).

La ley de profilaxis social inauguró el período abolicionista, sin embargo, nada decía sobre erradicar o prohibir el ejercicio de la prostitución, en este sentido Lazarte señalaba "el abolicionismo no consiste en abolir la prostitución, sino en abolir la reglamentación” (1935a: 92).

\footnotetext{
${ }^{52}$ Véase un pormenorizado análisis de los debates acerca de la prostitución en la provincia de Buenos Aires en Donna Guy (1994). También consultar: María Luisa Múgica (2001); Karin Grammático (2000); Marisa Miranda Marisa (2012) y Graciela Queirolo (2013).

${ }^{53}$ Sobre el discurso médico y su accionar, consultar Carolina Biernat (2007).
} 
Desde la mirada de Juan Lazarte, tanto el reglamentarismo como el abolicionismo representan dos maneras de intervención del sistema capitalista a favor de la subordinación de la mujer. Ninguna bregaba por la desaparición de esa institución sino que promovían su existencia. Desde su experiencia como médico visitador comunal (no oficial) de prostíbulos, Lazarte, como ya hemos mencionado, planteaba que la miseria, obligaba a las mujeres a prostituirse, porque "en ninguna parte se trata a la mujer de acuerdo al mérito de su trabajo" (Lazarte, 1935a: 37).

Estos reclamos, más tarde, continuaron en las páginas de la publicación Luz. Al igual que Lazarte, la/os redactores señalaban que los motivos principales de la “existencia y propagación" de la prostitución eran las condiciones económicas y la falta de educación sexual y moral ( $L u z, 1949: 4)$.

\section{Conclusiones}

Dentro de la heterogeneidad del discurso sobre la sexualidad, en este estudio hemos analizado las voces bajas-subalternas que desde una alocución eugénica propiciaron ideas sobre la libertad sexual, en particular, en relación a las mujeres. Si bien en cada uno de los capítulos nos hemos referido tangencialmente a las cuestiones referidas a la Revolución Sexual, en este capítulo ahondamos en este concepto para poner de relieve la deriva eugénica anarquista.

La crítica a la doble moral burguesa se concentró en desacreditar los límites impuestos a la libertad sexual a través de dos instituciones: la prostitución y el matrimonio oficial. Asimismo, se señaló la desigualdad de género en cuanto al ejercicio de la sexualidad. Las mujeres tenían vedado el acceso al placer sexual. Por un lado, el valor puesto en la virginidad de la mujer $y$, por otro, la procreación como único fin legítimo para el ejercicio sexual estrechaban los caminos por donde podían transitar los placeres femeninos.

El discurso médico anarquista postuló el derecho a la libertad sexual femenina al cuestionar esa doble moral sexual. Asimismo, legitimaron el goce sexual femenino desacreditando el valor de la virginidad y la maternidad como único fin de la unión sexual. 
Si bien Julio Barcos, Juan Lazarte y Manuel Martín Fernández, compartían las ideas libertarias, y en especial su interés por la sexualidad femenina, podemos decir que los planteos de Barcos, plasmados en su libro con carácter ensayístico, difieren en la base argumentativa de la de aquéllos, pues los planteos eugénicos son más tenues respecto de la relación con la Revolución Sexual. A pesar de estas diferencias argumentativas consideramos que las ideas de Barcos han sido la punta de lanza para los posteriores planteos elaborados por Lazarte y Martín Fernández.

En su noción de Revolución Sexual, Lazarte legitimaba la necesidad instintiva del ejercicio sexual. Esta idea también era compartida por Manuel Martín Fernández. De este modo, sus horizontes de sentido compartían argumentos con los discursos dominantes. Por un lado, algo a lo que ya hemos hecho referencia: los médicos ácratas tendieron a pensar las relaciones sexuales exclusivamente dentro de la matriz heterosexual.

Por otro lado, al defender un modelo heteronormativo de sexualidad establecían que el placer sexual femenino derivaba exclusivamente de la unión sexual con un varón, específicamente, del coito. En palabras de Carole Pateman, el contrato sexual persistía y legitimaba "el acceso de los varones al cuerpo de las mujeres" a pesar de las críticas a las dos instituciones que con mayor expresividad condensaban ese contrato: el matrimonio y la prostitución” (Pateman, 1995: 11).

Por último, señala la necesidad del divorcio, las uniones libres y el derecho de los solteros, tres cuestiones que amenazaban la existencia de la institución matrimonial y cuestionaban su papel como organizadora de la sexualidad.

Con ello, la propuesta de libertad sexual femenina, Revolución Sexual o felicidad sexual (para Barcos, Lazarte y Martín Fernández, respectivamente) si bien amplió algunos márgenes conservó intacta la estructura patriarcal que invisibilizaba "la existencia lesbiana" (Rich, [1980] 1985: 23) y cualquier otro tipo de relación no heterosexista, del mismo modo que, aunque buscaban demoler las estructuras socioeconómicas que condicionaban a las mujeres y a la sociedad en general, esa heterosexualidad obligatoria persistente de manera latente y manifiesta sobre las mujeres "como medio de asegurar el derecho masculino de acceso físico, económico y emocional" (Rich, [1980] 1985: 22), tensaba aquellos postulados libertarios. 
Con todo, es necesario pensar en el contexto de locución de estas ideas. Locutadas en un marco adverso a las mismas, con discursos dominantes que negaban o invisibilizaban estas temáticas, las voces anarquistas -utilizando algunos argumentos compartidos con este núcleo de médicos dominantes como la eugenesia- imprimieron una afrenta a los postulados que defendían sus colegas médicos, que se desempeñaban en altos cargos de decisión sobre la vida sexual y reproductiva de las mujeres. 


\section{Conclusiones}

A lo largo de esta tesis nos hemos propuesto analizar el discurso médico del movimiento anarquista referido al control de la natalidad, la maternidad y el placer sexual en la Argentina durante el período 1931-1951. Para ello, y asumiendo una perspectiva relacional de análisis, hemos abordado del orden social discursivo en el que se ubicaban sus ideas y las disputas que establece respecto de otras posiciones dentro del campo médico. Esto nos permitió evidenciar intertextualidades manifiestas e implícitas entre ellas y con paradigmas dominantes como la eugenesia. Las diversas apropiaciones de los postulados eugénicos ponen de relieve el carácter construido de la ciencia y cómo los posicionamientos políticos e ideológicos inciden en esas modulaciones. En este sentido, hemos evidenciado la particular apropiación de los médicos anarquistas que conllevó un discurso emancipatorio para las mujeres.

En este recorrido, en primer lugar, presentamos el orden social discursivo construido por las voces médicas dominantes en el campo esgrimido por quienes se dedicaron a la docencia universitaria, colaboraron con agencias estatales en la diagramación de políticas, crearon instituciones civiles y fusionaron intereses religiosos y profesionales. Las voces dominadas de las médicas feministas, que conjugaron la profesión con el reclamo de derechos civiles y políticos para las mujeres, pero que no avanzaron sobre los derechos sexuales, como sí lo hicieron los médicos ácratas. Estos discursos libertarios, también marginales dentro del campo, legitimaron propuestas de autodeterminación sexual.

La pesquisa de estas cuestiones contribuye a la historia del anarquismo al evidenciar el dinamismo del movimiento en momentos posteriores a lo que la Historiografía ha considerado. Así, superamos las fronteras temporales y dimensionales establecidas en relación al desarrollo del anarquismo en Argentina. Este cuestionamiento a la periodización, puso de relieve la reactivación de la dimensión cultural del anarquismo como estrategia de continuidad y sostenimiento representada en las revistas y proyectos editoriales impulsados por militantes provenientes de sectores profesionales. También, explicitamos el carácter transnacional del movimiento a través de las intertextualidades con los médicos anarquistas españoles. 
Seguidamente, abordamos las construcciones de los roles femeninos y masculinos a partir de la construcción de la dicotomía sexual. En relación a las otras posiciones dentro del campo, el discurso de los médicos ácratas fue disruptivo al cuestionar el carácter construido de las determinaciones sociales que intervienen en los significados que adquirieron la diferencia y desigualdad, pero evitó el cuestionamiento del sexo biológico como algo dado, lo que limitó y tensionó su aporte.

Luego, indagamos en las ideas sobre el control de la natalidad en el discurso médico ácrata en relación con la eugenesia y la emancipación sexual, atendiendo a tres dimensiones que seleccionamos: medios anticonceptivos, aborto y esterilización. En cada una de ellas, establecimos puntos de acuerdo y de divergencia entre los posicionamientos que evidencia los diversos usos de la eugenesia. En el discurso médico ácrata sobre el control de la natalidad confluía una propuesta eugénica y emancipadora. La preocupación por la degeneración de la raza se conjugó con la necesidad de conocer y acceder a herramientas anticoncepcionales que permitieron el ejercicio de una maternidad consciente y voluntaria y legitimaron el derecho al placer sexual heterosexual. Estas cuestiones fueron abordadas en los dos últimos capítulos.

Por un lado, hemos demostrado cómo la maternidad consciente y voluntaria de raigambre eugénica generó una nueva matriz de derechos para las mujeres que se diferenció de las propuestas promaternalistas y pronatalistas de las otras posiciones del campo médico que desplegaron estrategias educativas y represiva para lograr la maternalización de las mujeres. Asimismo, ésta era distinta de la estrategia del maternalismo político. La maternidad, desde las locuciones ácratas, era considerada como una carga biológica que situaba a la mujer en condiciones de inferioridad en relación con el varón y le impedía desarrollarse en iguales condiciones en la vida social. Con la posibilidad de decidir cuándo y cómo ser madres o no serlo, las mujeres heterosexuales podrían liberarse de la preocupación por la reproducción y disfrutar de las uniones sexuales con los varones. También, hemos evidenciado el cambio con la llegada del peronismo. Por un lado, los médicos anarquistas se orientaron a otras estrategias políticas y dejaron de lado este tema. Por otro, las voces femeninas ganan lugar en la difusión de esta temática, aunque ellas no provienen necesariamente del campo médico. A partir de este cambio, se evidenció la modificación del discurso sobre maternidad consciente y voluntaria. 
En una mirada general, la tesis procuró aportar en dos sentidos. En uno, a partir de la evidencia de otro discurso sobre la maternidad silenciado por el discurso dominante, nos permite establecer genealogías y trayectorias discursivas de los derechos sexuales y (no) reproductivos. En otro sentido, demostramos que el discurso sobre la libertad sexual -propiciado por el control de la natalidad desde una alocución eugénica de los médicos ácratas- constituyó la Revolución Sexual en un período temprano y anterior al que la historiografía instituyó como el período de la Revolución Sexual, profundamente asociado con los años 60 y 70. El discurso libertario, con su crítica a la virginidad, el matrimonio y la prostitución, legitimó el derecho al placer sexual heterosexual como una necesidad instintiva; aunque tuvo sus limitaciones al no franquear la barrera de la heterosexualidad obligatoria, sostener las relaciones sexo-afectivas entre varones y mujeres y delimitar el placer femenino al coito.

A partir de los esfuerzos de los movimientos de mujeres y el feminismo, las ideas que abordamos aquí ya son parte de un discurso que disputa un lugar en el espacio público, incluso algunas son apropiadas por el Estado en cuanto a las políticas de salud reproductiva. La producción sobre las temáticas abordadas ha procurado historizar las luchas feministas, en especial, desde los años '70. Sin embargo, como demostramos, estos planteos habían sido innovadores desde el discurso anarquista, herencia que ningún feminismo reclamó, aunque se apropió de sus ideas, sin reconocer, la ideología que les había dado origen. En ese sentido, consideramos que hay dos líneas que esta historización que se está llevando adelante adeuda. Una, la que restituya al pensamiento anarquista la impronta en relación con las temáticas de la sexualidad y el control de la natalidad. La otra, la que analice cuáles fueron los derroteros posteriores a la década del 50 que siguieron las ideas de Revolución Sexual que ellos impulsaron. Finalmente, un universo se abre en torno a cómo los actores interpretaron y practicaron aquellas nociones y vivieron los cambios.

Es en torno de esto último que surge una angustia que me lleva a abrir la trama y la temporalidad de mi investigación, por cómo el presente interpela al pasado y el pasado, con los resultados que cristalizaron tras las fuerzas en conflicto, también nos constituye. Durante la corrección de esta tesis, una niña de 13 años fue violada por su padrastro. La práctica del aborto no punible -que la ley actualmente reconoce- le fue negada en un hospital público de la provincia de Buenos Aires alegando cuestiones 
técnicas que se relacionaban con el tiempo de gestación y señalando que la vida de la niña corría peligro si se practicaba la intervención. Asimismo, todos los médicos que podían practicar el aborto, se presentaron como objetores de conciencia. Ante esta situación, una idea negativa se cernió sobre mi pensamiento en tanto consideré que era una evidencia, con cadencia de plomo, de la distancia que aún nos separa en el acceso a derechos que ya están estipulados desde principios del siglo XX y nos coloca frente a lo que aún falta alcanzar. Unos días más tarde, no obstante, la niña pudo acceder a su derecho en un consultorio privado, terminado, luego, en un hospital público fuera de la provincia de Buenos Aires. El movimiento de mujeres y feministas, que desde el primer momento acompañó a la niña y su familia y denunció el avasallamiento de sus derechos, realizó las gestiones para que se llevara adelante la práctica. Ningún poder público intervino en favor de la niña. Si bien, podríamos señalar continuidades en relación a la educación sexual, el conocimiento de métodos anticonceptivos y el aborto, entre otras cuestiones, sin conformarnos, celebramos este ejemplo en defensa de los derechos conseguidos de la mano de la sororidad.

Nuestro interés por establecer trayectorias discursivas sobre temas que son tan sensibles en nuestra actualidad, demuestra que el discurso médico anarquista -a partir de una singular apropiación de la eugenesia en relación al control de la natalidad- legitimó y propició la conquista de aquellos derechos sexuales y (no) reproductivos. Un objetivo político, sin duda, contribuye a esta investigación en afán de restituir a las luchas que hoy emprenden los movimientos de mujeres y feministas contemporáneos. Sin intención de establecer analogías ni caer en anacronismos, consideramos que, al analizar el discurso de los médicos ácratas, podemos establecer genealogías sobre estos derechos y demandas aportando historicidad al reclamo de la soberanía femenina sobre su cuerpo. 


\section{Bibliografía General}

Abad de Santillán, Diego; Invaldi, Ángel y Capelletti, Ángel (1964), Juan Lazarte militante social, médico, humanista, Rosario, Grupo Editor de Estudios Sociales.

Acha, Omar (2001), "Las percepciones de género según el catolicismo argentino plasmadas en Criterio (1928-1943)", Signos Históricos, enero-junio, pp. 141-173.

Acha, O. (2009), Historiografia crítica de la historiografía argentina: las izquierdas en el siglo $X X$, vol. 1, Buenos Aires, Prometeo.

Agrupación Femenina Antiguerrera (1936), La mujer argentina y sus derechos, Buenos Aires, s/e.

Andrés Granel, Helena (2008), "Anarquismo y sexualidad", Germinal: revista de estudios libertarios, $\mathrm{N}^{\mathrm{o}}$ 5, 2008, pp. 65-84.

(2012), Juan Lazarte, anarquismo, neomalthusianismo y emancipación femenina, tesis de maestría, Universidad Nacional de Rosario, Facultad de Humanidades y Artes.

Álvarez Peláez, Raquel (1988), Francis Galton. Herencia y eugenesia, Madrid, Alianza.

(2012), "La eugenesia de las mil caras. Españoles vinculados con la Asociación Argentina de Biotipología, Eugenesia y Medicina Social”, en Marisa Miranda y Gustavo Vallejo (dirs.), Una historia de la eugenesia. Argentina y las redes biopolíticas internacionales, T. I: 1912-1945, Buenos Aires, Biblos, pp. 219-237.

Ardanaz, Eleonora (2007), Madres de rojo y negro: cambios en las representaciones acerca de la maternidad en el discurso anarquista argentino, II Jornadas Hum. H.A. $\begin{array}{lllllll}\text { Bahía } & \text { Blanca, } & 4 & \text { al } & 16 & \text { de } & \text { octubre. }\end{array}$ http://www.jornadashumha.com.ar/pdf/2007/Ardanaz.pdf 
Anapios, Luciana (2011), "Una promesa de folletos. El rol de la prensa en el movimiento anarquista en la Argentina (1890-1930)", en A Contracorriente En Vol. 8, No. 2, Winter, pp. 1-33, [Disponible en http://www.ncsu.edu/acontracorriente/winter_11/articles/Anapios.pdf].

Ardanaz, Eleonora (2005), "Mujeres que levantan sus voces: aportes para el análisis de un discurso contrahegemónico", en Actas del II coloquio Nacional de Investigadores en Estudios del Discurso, 4 al 6 de agosto, Universidad Nacional del Sur, [Disponible en http://www.fl.unc.edu.ar/aledar/hosted/3ercoloquio/213.pdf].

Armus, Diego (2007), La ciudad impura. Salud, tuberculosis y cultura en Buenos Aires, Buenos Aires, Edhasa

Baigorria, Osvaldo (comp.) (2006), El amor libre. Eros y anarquía, Buenos Aires, Libros de Anarres.

Baliña, Luis (1954), "Exposición general del tema de las jornadas”. Primeras Jornadas de Médicos Católicos. Problemas de Higiene Sexual. Buenos Aires, Criterio, pp. 11.

Bao, Daniel (1993), "Invertidos sexuales, tortilleras and maricas machos: the construction of homosexuality in Buenos Aires, 1900-1950", Journal of Homosexuality, San Francisco, v. 24, № 3/4, pp. 183-219.

Barcia, José (1981), “"Claridad», editorial del pensamiento izquierdista”, Todo es Historia, año XV, $\mathrm{N}^{\circ} 172$, septiembre, pp. 8-25.

Bargas, María Luján (2012), "Cada cual en su justo lugar. Diferencias sexuales en las aplicaciones de la Biotipología en la Argentina", en Marisa Miranda y Gustavo Vallejo (dirs.), Una historia de la eugenesia. Argentina y las redes biopoliticas internacionales, 1912-1945. Tomo I:, Buenos Aires, Biblos, pp. 437-458.

Barcos, Julio (1935), Libertad sexual de las mujeres. [1921], Buenos Aires, Araujo.

Barrancos, Dora (2002), Inclusión/ Exclusión. Historia con mujeres, Buenos Aires, FCE. 
(1990a), Anarquismo, educación y costumbres en la Argentina de principios de siglo, Buenos Aires, Contrapunto.

(1990b), “Anarquismo y sexualidad”, en Diego Armus (comp.), Mundo urbano y cultura popular, Buenos Aires, Sudamericana, pp. 17-37.

(1991), "Contraconcepcionalidad y aborto en la década de 1920, problema privado y cuestión pública", Estudios Sociales, $\mathrm{N}^{\circ} 1$.

(1996a), “Mujeres de 'Nuestra Tribuna': el difícil oficio de la diferencia", Mora, № 2, noviembre, pp. 125-143.

(1996b), La escena iluminada. Ciencias para los trabajadores (1890-1930), Buenos Aires, Plus Ultra.

(1999), "Presencia de la mujer en las luchas sociales argentinas de principio de siglo", en Aportes para una Argentina plural, Buenos Aires, Archivo General de la Nación, pp. 117-128.

(2002), Iniciativas y debates en materia de reproducción durante el primer peronismo (1946-1952), Salta, SEPOSAL.

(2006), "Problematic Modernity: Gender, Sexuality, and Reproduction in Twentieth-Century Argentina", Journal of Women's History, vol. 18, $\mathrm{N}^{\circ} 2$, pp. 123-150.

(2007a) "Contrapuntos entre sexualidad y reproducción", en Susana Torrado (comp.), Población y Bienestar en la Argentina del primero al segundo Centenario, T. I, Buenos Aires, Edhasa.

(2007b), Mujeres en la sociedad. Una historia de cinco siglos, Buenos Aires, Sudamericana.

Bellucci, Mabel (1990), “Anarquismo, sexualidad y emancipación femenina. Argentina alrededor del 900”, Nueva Sociedad, No 109, septiembre-octubre, pp. 148-157. 
Bellucci y Camusso, Cristina (1987), “La huelga de inquilinos de 1907: el papel de las mujeres". Cuadernos de CICSO No 58, Buenos Aires.

Ben, Pablo (2000a), "Muéstrame tus genitales y te diré quién eres...", en Omar Acha y Paula Halperín, Cuerpos, géneros e identidades. Estudios de historia de género en Argentina, Buenos Aires, Ediciones del Signo.

(2000b), "Cuerpos femeninos y cuerpos abyectos. La construcción anatómica de la feminidad en la medicina Argentina”, en Fernanda Gil Lozano, Valeria Pita y Gabriela Ini (comps.), Historia de las mujeres en Argentina, T. I, Buenos Aires, Taurus.

Bergallo, P. y Ramón Michel, A. (2009), El aborto no punible en el derecho argentino, CEDES, FEIM, IPPF-RHO.

Beruti, Josué (1922). "Comunicación al II congreso nacional de medicina”, La semana médica, No 4. Cfr. Beruti, J. (1943), Producción cientifica y cultural, Buenos Aires. s/e.

(1934a), "Maternidad y educación femenina", Anales de Biotipología, Eugenesia y Medicina Social, s/n, 15 de noviembre. Cfr. Beruti, J. (1943), Producción cientifica y cultural, T. IV, Buenos Aires.

(1934b), "Respuesta a una encuesta sobre limitación de la fecundidad", Acción Médica, año IV, $\mathrm{N}^{\circ}$ 39. Buenos Aires. Cfr. Beruti, J. (1943), Producción científica y cultural, Buenos Aires, s/e.

(1934c), "Conferencia pronunciada el 6 de noviembre de 1934 en la Asociación de Visitadoras de Higiene Social", Anales de Biotipología, eugenesia y medicina social, 15 de noviembre, Buenos Aires. Cfr. Beruti, J. (1943), Producción cientifica y cultural, Buenos Aires, s/e.

y Zurano, María. (1934), "El problema de la madre soltera en nuestro país", Boletín del Ministerio de Relaciones Exteriores, T. III, Primera Parte, Buenos Aires, 1934. Cfr. Beruti (1943), Producción científica y cultural, Buenos Aires, s/e.

Beruti, Josué (1943) Producción científica y Cultural T. I, Buenos Aires, s/e 
Beruti, Josué (1943) Producción cientifica y Cultural T. III, Buenos Aires, s/e

Beruti, Josué (1943) Producción cientifica y Cultural T. IV, Buenos Aires, s/e

Biagini, Hugo E. (2000), La reforma universitaria, Buenos Aires, Leviatán.

Bianchi, Susana (2000), "Las mujeres en el peronismo (Argentina 1945-1955)", en Georges Duby y Michelle Perrot (dirs.), Historia de las mujeres en Occidente. El siglo $X X$, Madrid, Taurus.

Bilsky, Edgardo (1985), La FORA y el movimiento obrero, II Tomos, Buenos Aires, CEAL.

Biernat, Carolina (2004), "Inmigración, natalidad y urbanización: el poblacionismo argentino y sus contradicciones frente a las preguntas por el desarrollo económico (1914-1955)”, en Hernán Otero (dir.), El mosaico argentino, Buenos Aires, Siglo XXI.

(2005a), "La eugenesia argentina y el debate sobre el crecimiento de la población en los años de entreguerras", Cuadernos del Sur, № 34, Bahía Blanca, pp. 251-273. Disponible en www.bibliotecadigital.uns.edu.ar/scielo.php?script $=$ sci_arttext\&pid=S1668$76042005000100011 \& \operatorname{lng}=e s \& n r m=i s o$ (2005b), "Las dos vías de la imaginación poblacionista argentina: natalismo e inmigración entre 1914 y 1955”, Ciclos, Año XV, vol. XV, n 30, pp. 217 245.

(2007), "Médicos, especialistas, políticos y funcionarios en la organización centralizada de la profilaxis de las enfermedades venéreas en la Argentina (1930-1954)", Anuario de Estudios Americanos, 64, I, Sevilla, enero-junio, pp. 257288.

(2010), "El rol de las mujeres en el debate poblacionista argentino de la primera mitad del siglo XX”, Conferencia en el V Congreso Iberoamericano de Estudios de Género, Universidad Nacional de Luján. 
Biernat, Carolina y Ramacciotti, Karina. (2008), “La tutela estatal de la madre y el niño en la Argentina: estructuras administrativas, legislación y cuadros técnicos (19361955)", História, Ciências, Saude-Manguinhos [online], Vol. 15, N 2, pp. 331-351. Disponible en: http://dx.doi.org/10.1590/S0104-59702008000200006

Bock, Gisela (1991), "La historia de las mujeres y la historia del género: Aspectos de un debate internacional", Historia Social, 9, Universidad de Valencia, Instituto de Historia Social, pp. 55-77. Disponible en: http://www.carlosmanzano.net/articulos/Bock.pdf

Bordagaray, María Eugenia (2011), “Trayectorias, historia y género en el movimiento libertario argentino", Zona Franca, Rosario, pp. 41 - 51.

Bordagaray (2013) Luchas antifascistas y trayectorias generizadas en el movimiento libertario argentino (1936-1955), en Cuadernos de H Ideas; vol. 7, no. 7

- Butler, Judith (1998), "Meramente cultural”, El Rodaballo, Revista de política y cultura, $\quad \mathrm{n}^{\mathrm{o}} \quad 9, \quad$ verano, pp. 52-58, [disponible en http://cholonautas.edu.pe/modulo/upload/butl.pdf].

Butler, Judith(2007) El género en disputa, Buenos Aires, Paidós

Bourdieu, Pierre (1990), “Algunas propiedades de los campos", Sociología y cultura, México, Grijalbo, pp. 135-141.

Brandán, Ramón (1939), "Los grandes males sociales, el aborto", Iatría, año IX, diciembre, pp. 3-28.

Brauner Rodgers, Susana. (1990), "El nacionalismo yrigoyenista, 1930-1943”, EIAL, vol 1, $\mathrm{N}^{\circ}$ 2, julio-diciembre. Disponible en http.//www1.tau.ac.il/eial

Burgos Ortega, Inés (2001), “Gregorio Marañón «sexo, trabajo y deporte»”, Ágora para la Educación Física y el Deporte, $\mathrm{n}^{\circ}$ 1, pp. 97-102. Disponible en http://www5.uva.es/agora/revista/l/agoralinesburgos.pdf

C.A.B. (1939) "Una opinión acerca del neomaltusianismo" en Iatría, año IX, abril4751. 
Calzetta, Elsa (2005), Nuestra Tribuna. Hojita del sentir anárquico femenino. 19221925, Bahía Blanca, Universidad Nacional de Sur - Ediuns.

Casterà, Maria y Moreira, Alfonso (2006), Estudios Revista Ecléctica, Índices, España, [Disponible en http://www.christiebooks.com/ChristieBooksWP/wpcontent/uploads/2010/07/2006-FAXDOC-22.pdf].

Cimazo, Jacinto (1979), Fernando Quesada. Un trozo de historia libertaria, Buenos Aires, Ed. Reconstruir

Cosse, Isabella. (2004), “Entre el estigma y la integración: imágenes, estereotipos y representaciones de la filiación ilegítima en Argentina (1940-1955)”, en Hernán Otero (dir.), El mosaico argentino, Buenos Aires, Siglo XXI.

(2008), "El modelo conyugal en la ciudad de Buenos Aires de la segunda posguerra: el compañerismo de complementariedad y el impulso familiarista", Trabajos y comunicaciones, $\mathrm{N}^{\mathrm{0}} 34$, La Plata, pp. 63-94.

(2010), Pareja, sexualidad y familia en los años sesenta. Una revolución discreta en Buenos Aires, Buenos Aires, Siglo XXI.

Carbonetti, Adrián y González Leandri, Ricardo (eds.) (2009), Historias de salud y enfermedad en América latina. Siglos XIX y XX, Córdoba, Universidad Nacional de Córdoba-Centro de Estudios Avanzados.

Carol, Anne (1995), Histoire de l'eugénesime en France, Éditions du Seuil.

Carranza Casares, (2008), “Consorcio de Médicos Católicos”, Iatria, año 78, №189, $\begin{array}{llll}\text { diciembre, } & \text { 6-7. } & \text { en }\end{array}$ http://medicoscatolicos.org.ar/documents/Iatria_189.pdf

Casella, Edgardo (1932), "Juan Lazarte. Lo que ha sido, lo que es, lo que puede ser", Nervio, $\mathrm{N}^{\mathrm{o}}$ 12, año 1, abril, pp. 33-35.

Castaño, Carlos A. (1934), "El aborto terapéutico y el aborto criminal. Sus causa, sus peligros, sus penas", Iatría, año IV, mayo, pp. 20-41. 
(1939), “Difusión peligrosa de algunas publicaciones”, Iatría, año

IX, abril, pp. 38-41

(1954), "Exposición general del tema de las Jornadas", Primeras Jornadas de Médicos Católicos. Problemas de Higiene Sexual, Buenos Aires, Criterio, pp.259-290.

Castejón Bolea, Ramón. (2013), “Marañón y la identidad sexual: biología, sexualidad y género en la España de la década de 1920", Arbor, Vol. 189 (759), n 759, http://dx.doi.org/10.3989/arbor.2013.759n1004

Centeno, Ángel (1952) “aborto y rubéola” en, Iatría, año XXIII, N 114, septiembreoctubre, pp.194-198

Cleminson, Richard (2008), Anarquismo y sexualidad en España, 1900-1939, España, Servicio Publicaciones UCA.

del Campo, Hugo (1971), Los Anarquistas, Buenos Aires, CEAL.

Diez, Xavier (2007), El anarquismo individualista en España (1923-1938), Barcelona, Virus Editorial, [Disponible en http://www.viruseditorial.net/pdf/anarquismo\%20individualista.pdf].

Di Liscia, Herminia (1997), Maternidad y discurso maternal en la política sanitaria peronista, La Plata, UNLP.

(2005), "Dentro y fuera del hogar. Mujeres, familias y medicalización en Argentina, 1870-1940”, Revista Signos Históricos, no 13, México, Universidad Autónoma de México, enero-junio, pp. 95-110.

Di Liscia, et al. (2000), Mujeres, maternidad y peronismo, La Pampa, Fondo Editorial Pampeano.

Di Liscia, María Silvia (2007), "Los bordes y límites de la eugenesia, donde caen las "razas superiores" (Argentina, primera mitad del siglo XX)", en Gustavo Vallejo y Marisa Miranda (comps.), Políticas del cuerpo. Estrategias modernas de normalización del individuo y la sociedad, Buenos Aires, Siglo XXI. 
Di Liscia, María Silvia y Salto, Graciela Nélida (ed.) (2004), Higienismo, educación y discurso en la Argentina (1870-1940), La Pampa, Universidad Nacional de La Pampa.

Flores Cruz, Ramiro (s/f), "El crecimiento de la población argentina", en Grupo de Estudios de Población, Migración y Desarrollo. Instituto de Investigaciones Gino Germani. Facultad de Ciencias Sociales. UBA. Disponible en

\section{http://webiigg.sociales.uba.ar/pobmigra/archivos/Ramiro Flores/Crecimiento.pdf}

- Ediciones Nervio (1932), "Propósitos", en Lazarte, Juan, La revolución sexual de nuestro tiempo, Buenos Aires, ediciones Nervio, anteportada.

Eraso, Yolanda (2007), "Biotypology, Endocrinology, and Sterilization: the practice of eugenics in the treatment of Argentinian women during the 1930s", Bull Hist Med, 81 (4), pp. 793-822. $\quad$ Disponible en http://www.ncbi.nlm.nih.gov/pmc/articles/PMC2629848/

Fairclough, Norman (1992), Discourse and social change, Londres-Nueva York, Routledge. Disponible en http://www.academia.edu/1217902/DISCOURSE_AND_SOCIAL_CHANGE_By_Norm an_Fairclough

Fausto Sterling, Anne (2006), Cuerpos sexuados, Barcelona, Melusina.

Feijoó, María del Carmen y Nari, Marcela (1994), “Imaginándolas/los lectores de La Voz de la Mujer", en Lea Fletcher (comp.), Cultura y Mujeres en el siglo XIX, Buenos Aires, Feminaria

Felitti, Karina (2007), "El debate médico sobre anticoncepción y aborto en Buenos Aires en los años sesenta del siglo XX”, Dynamis, 27, pp. 333-357.

(2012), La Revolución de la píldora: sexualidad y política en los sesenta, Buenos Aires, Edhasa.

Ferla, Luis (2012) "El determinismo biotipológicos y su red de sustentación a través de eugenistas españoles, brasileños y argentinos" en, Marisa Miranda y Gustavo Vallejo, 
(dirs.), Una historia de la eugenesia. Argentina y las redes biopoliticas internacionales, Tomo I: 1912-1945, Buenos Aires, Biblos, pp. 97-122.

Fernández Cordero, Laura (2007), “Amor y sexualidad en las publicaciones anarquistas (Argentina, 1890-1930)", Entrepasados, n 32, Buenos Aires, pp. 59-75.

(2010), “Queremos emanciparos: anarquismo y mujer en

Buenos Aires de fines del XIX", Revista Izquierdas, año 3, $\mathrm{N}^{\circ}$ 6, s/n. Disponible en http://www.izquierdas.cl/revista/wp-content/uploads/2011/07/6.pdf

-“Una paradoja vital. Cuerpo y autonomía en los feminismos locales contemporáneos”, II Jornadas CINIG de Estudios de Género y Feminismos. “Desde Kate Millet hasta los debates actuales”, La Plata, 28-30 de septiembre 2011. ISBN 978-950-34-0751-6 (2013), "Un ejercicio de lectura sobre el concierto de la prensa anarquista a partir de Mijail Bajtin (Argentina, 1895-1925)", AdVersuS. Revista de Semiótica, Buenos Aires, pp. 68-91.

(2014), "Historiografía del anarquismo en Argentina. Notas para debatir una nueva lectura", A Contracorriente, Vol. 11, N³, pp. 41-67.

Ferrandiz, Alejandra y Lafuente, Enrique (1999), "El pensamiento eugénico de Marañón", Asclepio, LI-2, pp. 133-148.

Disponible en http://asclepio.revistas.csic.es/index.php/asclepio/article/view/314/310

Foucault, Michel (1992) El orden social del discurso,[1970] Buenos Aires, Tusquets

Fox Keller, Evelyn (1991), Reflexiones sobre género y ciencia, Madrid, Alfons El Magnanim.

Galíndez, Benjamín (1939) “La esterilizacipon”, en Iatría, año IX, septiembre, pp3-37

Goyena, Emilia (1946). Mujer ¿Qué piensas? Reconstruir, año I, No 5, agosto 2da.

Quincena, p.9 
Grammático, Karin (2000), “Obreras, prostitutas y mal venéreo. Un estado en busca de la profilaxis", en Fernanda Gil Lozano et al. (dirs.), Historia de las mujeres en la Argentina, T. 2, Buenos Aires, Taurus, pp. 114-133.

Guha, Ranajit (2002), Las voces de la historia y otros estudios subalternos, Barcelona, Crítica.

Guy, Donna (1994), El sexo peligroso. La prostitución legal en Buenos Aires. 18751955, Buenos Aires, Sudamericana.

(1998), "Madres vivas y muertas. Los múltiples conceptos de la maternidad en Buenos Aires”. Daniel Balderston y Donna Guy (comps.), Sexo y sexualidades en América Latina, Buenos Aires, Paidós, pp. 231-256.

Haraway, Donna (1995), "Conocimientos situados: la cuestión científica en el feminismo y el privilegio de la perspectiva parcial". Donna Haraway, Ciencia, ciborgs y mujeres. La reinvención de la naturaleza, España, Cátedra-Universitat de ValenciaInstituto de la mujer, pp. 313-346.

- Hobsbawn, Eric (2000) [1969], "Reflexiones sobre el anarquismo", en Revolucionarios. Ensayos contemporáneos, Barcelona, Crítica.pp. 121-133

Iatría (1939), “Conferencia de Gregorio Marañon”, año IX, abril

Iatría (1939), "Programa de la primera semana nacional”, año IX, abril, pp. 61-62.

- Kristeva, Julia (1978) [1966], Semiótica I, Madrid, Fundamentos.

- Jiménez-Lucena, Isabel y Molero-Mesa, Jorge (2009), "Problematizando el proceso de (des)medicalización. Mecanismos de sometimiento/autogestión del cuerpo en los medios libertarios españoles del primer tercio del siglo XX", en Miranda, Marisa y Sierra Girón, Álvaro (coords.), Cuerpo, bipolítica y control social. América Latina y Europa en lo siglos XIX y XX, Buenos Aires, Siglo XXI, pp.69-80 y 74-76.

Lacerda de Moura, Maria (1935), "Prólogo", en Juan Lazarte, Sociedad y prostitución, pp. 5-18. 
Lavrin, Asunción (1992), "Paulina Luisi: pensamiento y escritura feminista". Lou Charnon-Deutsch (ed.), Estudios sobre escritoras hispánicas en honor de Georgina Sabat-Rivers, España Castalia, pp. 156-172.

(1997), “Alicia Moreau de Justo: feminismo y política, 19111945”. Bárbara Pottast y Susana Menéndez, Cuadernos de historia de América Latina, Málaga, AHILA-Algazara.

(2005), "Feminismo y sexualidad. Una relación incómoda". Asunción Lavrin (comp.), Mujeres, feminismo y cambio social. Argentina, Chile y Uruguay, Centro de Investigaciones Diego Barros Arana, Santiago de Chile, pp. 165206.

Lazarte, Juan (1919), "Las universidades son malas". En Prometeo, 1era. Quincena de septiembre, año I, $\mathrm{N}^{\circ} 2$

(1931a), "El porvenir del macho en la Humanidad", Nervio, año I, N 4, agosto, pp. 2-4.

(1931b), “Un problema sexual: la suegra”, Nervio, año I, Nº 6, octubre, pp. 15-19.

(1932a), La revolución sexual de nuestro tiempo, Buenos Aires, Nervio.

(1932b), "Derechos de los solteros”, Nervio, año 1, N 11, marzo, pp. 5-

7.

(1932c), "Desprestigio del adulterio", Estudios, año X, N 105, mayo,

pp. $19-20$

(1935a), Sociedad y prostitución, Rosario, Librería Ruiz.

(1935b), “Los tiempos agenésicos”, Estudios, N 147, año VIII, noviembre, $\quad$ pp. 14-15. Disponible en http://www.christiebooks.com/ChristieBooksWP/wp-content/uploads/2010/07/1935ESTUDIOS-147.pdf 
(1936), El contralor de los nacimientos [1934], Rosario, Librería

Ruiz.

(1940), “Curso de sexología, Lección 4. La intersexualidad y los estados intersexuales", Hombre de América, año I, № 4, mayo pp. 34-36.

(1943), Problemas de Medicina social, Buenos Aires, Amicalee.

(1948), Organización de una sanidad para la población del país,

Buenos Aires, Unión Socialista Libertaria.

(1956), "Eugenesia y educación demográfica", Estudios

Eugenésicos, t. IV, № 57, Buenos Aires, abril, pp. 85-89.

(1957) La solución federalista en la crisis histórica argentina.

Buenos Aires, editorial Reconstruir.

- La redacción (1931), “antena”, en Nervio, año I, nº 1, mayo, p.1

Ledesma Prietto, Nadia (2010), "Eugenesia, anarquismo y emancipación femenina. Una aproximación a los discursos libertarios. Argentina, (1930-1940)", ponencia presentada

en el Seminario Internacional Fazendo Género 9, agosto. Disponible en www.fazendogenero.ufsc.br/9/resources/anais/1278270454_ARQUIVO_FAZENDO\%2 ONADIA\%20FINAL\%5B1\%5D.pdf

Ledesma Prietto, Nadia y Valobra Adriana(2012), "Eugenesia y derechos: idearios médico-políticos sobre los roles públicos y privados de las mujeres, 1930-1945”. Marisa Miranda y Gustavo Vallejo (dirs.), Una historia de la eugenesia. Argentina y las redes biopolíticas internacionales, T. I: 1912-1945, Buenos Aires, Biblos, pp. 411-436.

Ledesa Prietto, Nadia y Manzoni, Gisela (2009), "Pluma, aguja y barricadas. Desafiando la hegemonía patriarcal". Adriana Valobra (comp.), Mujeres en espacios bonaerenses, 3, EDULP, pp. 65-79. 
Ledesma Prietto, Nadia y Valobra, Adriana (2007), “Algunas consideraciones sobre la política educativa en los gobiernos de Mercante y Aloé, 1946-1955”. Claudio Panella (comp.), El gobierno de Domingo A. Mercante en Buenos Aires 1946-1952. Un caso de peronismo provincial, Tomo III, La Plata, Instituto Cultural de la Provincia de Buenos Aires, pp. 53-73.

Linzzoain, Enrique y Colombo, Emilio (1939), "La ley de Ogino y Knaus frente a la realidad", en Iatría, año OX, abril, pp. 19-31

- Luzón Marco, María José (1997), “Intertextualidad e interpretación del discurso”, en EPOS, XIII, pp.135-149.

Lobato, Mirta (1996), "Lecturas de historia de la salud en la Argentina. Una introducción”. Mirta Lobato (comp.), Política, médicos y enfermedades: lecturas de historia de la salud argentina, Buenos Aires, Biblos, pp. 11-18.

(2000), “Entre la protección y la exclusión: Discurso maternal y protección de la mujer obrera, Argentina 1890-1934". Juan Suriano (comp.), La cuestión social en Argentina 1870-1943, Buenos Aires, La Colmena.

(2007), Historia de las trabajadoras en la Argentina (1869-1960), Buenos Aires, Edhasa.

López Trujillo, Fernando (2005), Vidas en rojo y negro. Una historia del Anarquismo en la "Década infame", Buenos Aires, Letra libre.

López Vega, Antonio (2011a) “Gregorio Marañón: un médico español y la cultura argentina", Seminario lazos educativos y cientificos entre España y Argentina, Buenos Aires, Fundación Ortega y Gasset, 30 de agosto.

(2011b), “La cuestión sociosanitaria en la obra de Marañón en el contexto de la lucha contra las enfermedades infecciosas", Asclepio, LXIII, N²2, julio-diciembre, pp. 477-506.

Luisi, Paulina, (1917), S/t, Acción femenina, 1: 2, agosto Crf Lavrin, Asunción (1992), "Paulina Luisi: pensamiento y escritura feminista". Lou Charnon-Deutsch (ed.), 
Estudios sobre escritoras hispánicas en honor de Georgina Sabat- Rivers, España Castalia, pp. 156-172.

(1919), Por una mejor descendencia, Buenos Aires, s/e. Crf Armus, Diego (2007), la ciudad impura. Buenos Aires, Edhasa.

- Manzoni, Gisela (2012), “Antimilitaristas y libertarias de Nuestra Tribuna. La postura de las mujeres anarquistas ante el militarismo", en Asociación de Amigos del Archivo Histórico de la Provincia de Buenos Aires "Dr. Ricardo Levene", [Disponible en http://www.amigoslevene.com.ar/colaboraciones/25nuestratribuna.html].

Migueláñez Martínez, María (2010a), “1910 y el declive del anarquismo argentino. ¿Hito histórico o hito historiográfico?”, en Congreso Internacional 1810-2010: 200 años de Iberoamérica. XIV Encuentro de Latinoamericanistas Españoles, España, pp. 436-452, [disponible en http://halshs.archivesouvertes.fr/docs/00/52/96/99/PDF/AT5_MiguelaA_ez.pdf].

(2010b) “Anarquistas en red una historia social y cultural del movimiento libertario continental (1920-1930)", en Anales del IX Encontro Internacional da ANPHLAC, Univ. Fed. de Goiás. Fac. de Historia, julio, [Disponible en http://anphlac.fflch.usp.br/sites/anphlac.fflch.usp.br/files/Martinez\%20MM.pdf].

Marañón, Gregorio (1929), Los estados intersexuales en la especie humana, Madrid, Javier Morata.

(1939), Liberalismo y comunismo: reflexiones sobre la revolución Española, Buenos Aires, Oficina de Prensa y Propaganda de la Representación del Gobierno Nacional de España en Buenos Aires. Disponible en http://www.segundarepublica.com/index.php?opcion $=7 \& i d=75$

(1951), Ensayos sobre la vida sexual, Madrid, Espasa Calpe.

Mejía, María Consuelo (2003), "Sexualidad y derechos sexuales: el discurso de la Iglesia católica", Debate Feminista, Vol. 27, abril, pp. 45-56.

Martí Boscá, José (2007), "Estudios: educación sexual, arte, ciencia, cultura general”, Faximil, Faxdoc 23/2007. Documentos de Trabajo de Faximil. Disponible en 
http://issuu.com/faximil/docs/2006-faxdoc23? mode $=$ embed\&layout $=$ http\%3A\%2F\%2Fskin.issuu.com\%2 Fv\%2Flight\%2Flayout.xml\&showFlipBtn=true

- Martí Ibáñez (1937a), “Entorno a la reforma eugénica”, en Estudios, n 160, año XV, enero, pp.11-12.

(1937b), "Sanidad, Asistencia Social y Eugenesia en la Revolución Social Española”, Estudios, n 160, año XV, pp. 34-38.

Martín Rojo, Luisa (1997), "El orden social de los discursos", Discurso, 21-22, pp. 137.

Martín Fernández, Manuel (1938), "El prejuicio de la Virginidad", en Cultura sexual y fisica, T. I, mayo, pp. 587-588.

(1939), "Contestando a los lectores", Cultura Sexual y

Física, 29, TIII, pp 313-316

(1940a), "Problemas psicosexuales", Hombre de América

Fuerte y Libre, I (1), p. 21.

(1940b), "Consultorio psicosexual", Hombre de América

Fuerte y Libre, Año I, № 2, febrero, p. 25.

(1940c) "Consultorio Psicosexual", Hombre de América

Fuerte y Libre, Año I, N³, abril, p.34

(1940d), “Consultorio psicosexual”, Hombre de América

Fuerte y Libre, Año I, № 4, mayo, p 40

(1940e), "Consultorio psicosexual", Hombre de América Fuerte y Libre. Buenos Aires, Año I, N 6, septiembre.

(1940f), "Sobre la obra de Juan Lazarte Psicosociología de los celos", Hombre de América Fuerte y Libre, Año I, Nº7, diciembre, pp. 35-36.

(1941a), "Problemas psicosexuales. El complejo amor: las armonías necesarias”, Hombre de América Fuerte y Libre, Año II, ํ9, pp. 37-38 
(1941b), "Problema psicosexuales. El complejo amor: las armonías necesarias", Hombre de América Fuerte y Libre, año II, N 11, agosto, pp. $36-38$

(1942a), "La mujer: su posible felicidad sexual", Hombre de América Fuerte y Libre, Año III, $\mathrm{N}^{\circ}$ 14, junio, pp. 22-23.

(1942b), "La mujer: su posible felicidad sexual (continuación)", Hombre de América, N 15, agosto, pp. 17-18.

Masjuán Bracons, Eduard (2003), "La antorcha de Cupido: eugenesia, biotipología y eugamia en Argentina, 1930-1970", Asclepio, vol. LV, fasc. 2, Madrid.

(2004), “El pensamiento demográfico anarquista: fecundidad y emigración a América Latina (1900-1914)", Revista de Demografia Histórica, XX, II, España, pp. 153-180.

(2008), "El neomalthusianismo ibérico e italiano: un precedente de la ecología humana contemporánea", Historia Actual Online, № 15. Disponible en http://historia actual.org/ Publicaciones/index.php/ haol/article $/$ view/234

Miranda, Marisa (2005a), "La biotipología en el pronatalismo argentino (1930 1983)", Asclepio, Vol. LVII 1, pp. 189-218.

Miranda, Marisa (2009), "Eugenesia en Argentina: aportes para una comprensión epistemológica". Marisa Miranda y Álvaro Girón Sierra (coords.), Cuerpo, biopolítica y control social. América Latina y Europa en los siglos XIX y XX, Buenos Aires, Siglo XXI, 2009, pp. 139-155.

Miranda, Marisa y Vallejo, Gustavo (comps.) (2005), Darwinismo social y eugenesia en el mundo latino, Buenos Aires, Siglo XXI.

Miranda, Marisa (2003), "La antorcha de cupido: eugenesia, biotipología y eugamia en Argentina, 1930-1970”, Asclepio, Vol. LV 2, España, pp. 231-255. 
(2005b), "Matrimonio y procreación en la ortodoxia eugénica argentina”, Sociohistórica, N 17-18. Primer y segundo semestre. Universidad Nacional de La Plata. Facultad de Humanidades y Ciencias de la Educación. Centro de Investigaciones Socio Históricas, pp. 151-178.

(2011), Controlar lo incontrolable. Una historia de la sexualidad en la Argentina, Buenos Aires, Biblos.

(2012), “Buenos Aires, entre Eros y Tánatos: La prostitución como amenaza disgénica (1930-1955)", Dynamis [online], vol. 32, $\mathrm{N}^{\circ}$ 1, pp. 93-113. Disponible en http://scielo.isciii.es/scielo.php?script $=$ sci_arttext\&pid $=S 0211$ $95362012000100005 \& \operatorname{lng}=e s \& n r m=i s o$

Miranda, Marisa y Bargas, Luján (2011), "Mujer y maternidad: entre el rol sexual y el deber social (Argentina, 1920-1940)", Locus: revista de história, Juiz de Fora, v. 17, n. 2, pp. 75-101.

Miranda, Marisa y Vallejo, Gustavo (2005), Darwinismo social y eugenesia en el mundo latino, Buenos Aires, Siglo XXI

Miranda, Marisa y Vallejo, Gustavo (dirs.) (2012), Una historia de la eugenesia. Argentina y las redes biopolíticas internacionales 1912-1945, Buenos Aires, Biblos.

Molineaux, Maxine (2002), La Voz de la Mujer. Periódico comunista-anárquico [1997], Buenos Aires, Universidad Nacional de Quilmes.

Moreau de Justo, Alicia (1935), "Alrededor del sufragio femenino", Vida Femenina, año III, $\mathrm{N}^{\circ} 26,15$ de septiembre, p. 4

(1938) Entrevista de Sara Papier, "La voz de la mujer argentina”, en Cultura sexual y física, Año I, N¹0, T I, pp580-582

(1945), La mujer en la democracia, Buenos Aires, El Ateneo.

Múgica, María Luisa (2001), Sexo bajo control. La prostitución reglamentada en Rosario entre 1900 y 1912, Rosario, Universidad Nacional de Rosario. 
Nari, Marcela (1995), "La educación de la mujer (o acerca de cómo cocinar y cambiar los pañales a su bebé de manera científica)”, Revista Mora, $\mathrm{N}^{\circ} 1$, pp. 31-45.

(1996), “Las prácticas anticonceptivas, la disminución de la natalidad y el debate médico, 1890-1940". Mirta Lobato (ed.), Política, médicos y enfermedades, Buenos Aires, Biblos, pp. 153-189.

(2004), Políticas de maternidad y maternalismo político. Buenos Aires, 1890-1940, Buenos Aires, Biblos.

- Nash, Mary (1984), "El neomalthusianismo anarquista y los conocimientos sobre el control de la natalidad", en Nash, Mary (comp.), Presencia y protagonismo. Aspectos de la historia de la mujer, Barcelona, Ediciones del Serbal, pp.307-340.

(1993), "Maternidad, maternología y reforma eugénica en España 19001939” en Duby, Georges y Perrot, Michelle (direc.), Historia de las mujeres, el siglo XX: la mujer nueva, Tomo X, España, Taurus, pp.243-261.

Navarro, Marysa, (1994) Evita, Buenos Aires, Planeta

Nieto, Agustín (2010), "Notas críticas sobre el sentido común historiográfico”, $A$ Contracorriente, vol. $7, \quad \mathrm{~N}^{\circ}$ 3, pp. 219-248. Disponible en http://www.ncsu.edu/acontracorriente/spring_10/articles/Nieto.pdf [Consultado: 16 de septiembre de 2011]

Nuestra Tribuna, $\mathrm{n}^{\mathrm{o}} 1,15$ de agosto de 1922.

Oliva, Andrea (2007), Trabajo Social y lucha de clases. Análisis histórico de las modalidades de intervención en Argentina, Buenos Aires, Imago Mundi.

Olmedo, J. (1940), "El problema de la natalidad ante la conciencia jurídica", Boletín de la sociedad de Obstetricia y Ginecología, nº XIX, julio, Buenos Aires.

Olsen, Frances, (1990) “El sexo del derecho”. David Kairys (ed.), The Politics of Law, Nueva York, Panteón, pp. 452-467. Disponible en http://www.derechoshumanos.unlp.edu.ar/assets/files/documentos/el-sexo-delderecho.pdf 
Otero, Hernán (2004), “La transición demográfica argentina a debate: una perspectiva espacial de las explicaciones ideacionales, económicas y político-institucionales". Hernán Otero (dir.) (2004), El mosaico argentino, Buenos Aires, Siglo XXI.

Oved, Iaacov (1978), El anarquismo y el movimiento obrero en Argentina, México, Siglo XXI.

Palermo, Silvana (2008), "El trabajo femenino en el siglo XX: nuevas miradas y planteos de la historia de la mujer y los estudios de género", Trabajos y comunicaciones, Segunda Época, No 34, La Plata.

Palma, Héctor (2002), Gobernar es seleccionar, apuntes sobre la eugenesia, Buenos Aires, Jorge Baudino.

Pantelides, Edith y Moreno Martín, J. (coords.) (2009), Situación de la población argentina, Programa Naciones Unidas para el Desarrollo-PNUD-UNFPA, Buenos Aires.

Pateman, Carole (2005) el contrato sexual, Madrid, Anthropos.

Pavón, Iris (Alejandrina Serrat seudónimo) (1946), "La farsa de la justicia social”, Reconstruir, año I, $\mathrm{N}^{\circ} 10$, noviembre.

(1947), “La madre ante la preconscripción", Reconstruir, año I, No 12, febrero.

Piacenza, Anita (1946), “Amiga ¿quiere usted votar?”, Reconstruir, año 1, № 2, junio.

Piñeiro, Alberto G. (1989), Del radicalismo al peronismo: Hechos e Ideas. 1935-1941, Buenos Aires, Centro Editor de América Latina

"Problemas sexuales" (1950), Luz, III, 8, p. 10.

Purdy, Sean (2006), “A história comparada o desafío de transnacionalidade”, en Anales del VII Encontro de ANPHLAC, PUC-Campinas, São Paulo, octubre, [Disponible en http://www.anphlac.org/periodicos/anais/encontro7/ensaio58.pdf]. 
- Quijada, Mónica (1991), Aires de República, aires de cruzada: la Guerra Civil Española en Argentina, Barcelona, Sendai.

- Rama, Carlos y Cappelletti, Ángel (1990), El anarquismo en América Latina, Caracas, Biblioteca Ayacucho.

Rich, Adrienne (1985) "Heterosexualidad obligatoria y esxistencia lesbiana", en Revista Nosotras, $\mathrm{N}^{\circ} 3$, noviembre.

Queirolo, Graciela (2006), "Mujeres que trabajan: una revisión historiográfica del trabajo femenino en la ciudad de Buenos Aires (1890-1940)", Nuevo Topo. Revista de historia y pensamiento crítico, $\mathrm{N}^{\mathrm{o}} 3$, Buenos Aires, septiembre-octubre, pp. 29-48.

(2009), "Victoria Ocampo (1890-1979): Cruces entre feminismo, clase y elite intelectual", Clío \& Asociados, 13, pp. 135-159. Disponible en http://www.memoria.fahce.unlp.edu.ar/art_revistas/pr.4628/pr.4628.pdf

(2013), “Género y sexualidad en tiempos de males venéneros (Buenos Aires, 1920-1940)", Nomadías, N 17, julio, pp. 67-87.

Rama, Carlos M. y Cappelletti, Ángel, J. (1990), El anarquismo en América Latina, Venezuela, Biblioteca Ayacucho.

Ramacciotti, Karina (2005), "El Museo Social Argentino y el Primer Congreso de Población de 1940", Sociohistórica, Cuadernos del Centro de Investigaciones Sociohistóricas, $\mathrm{N}^{\mathrm{o}} 13$ y 14, La Plata, pp. 231-238.

(2008b), "Las madres y sus hijos en foco". Carolina Barry, Karina Ramacciotti y Adriana Valobra (eds.), La fundación Eva Perón y las mujeres. Entre la provocación y la inclusión, Buenos Aires, Biblos, pp. 51-76.

(2009), La política sanitaria del peronismo, Buenos Aires,

Biblos.

Ramacciotti, Karina y Valobra, Adriana (2004), “«Plasmar la raza fuerte...» Relaciones de género en la propaganda sanitaria de la Secretaría de Salud Pública de la Argentina: 
1947-1949”. Karina Ramacciotti y Adriana Valobra (comps.), Generando el peronismo (1946-1955), Buenos Aires, Proyecto Editorial.

(comps.) (2004), Generando el peronismo.

Estudios de cultura, política y género (1946-1955), Buenos Aires, Proyecto Editorial.

(2008), "El campo médico argentino y su

mirada al tribadismo, 1936-1955”, Estudos Feministas, Florianópolis, 16 (2), mayoagosto, pp. 493-516.

Rodríguez, Ana María (2008), "La perspectiva católica sobre la salud y la práctica médica en la Argentina de los años treinta. La visión de los médicos confesionales", Anuario de Estudios Americanos, 65, 1, enero-junio, Sevilla, pp. 257-275.

(2009a), "Por una raza sana y vigorosa obtenida por los medios morales. La eugenesia católica argentina en los años treinta", Revista Estudios DIGITAL, N ${ }^{\circ}$ 22, Córdoba, Centro de Estudios Avanzados de la Universidad Nacional de Córdoba.

Rawson de Dellepiane, Elvira (1892)"higiene de la mujer". Tesis

Reca, Thelma (1936), Vida femenina, 31, 15 de febrero.

Ries, Edmundo (1947) “el aborto mortal y su relación con el aborto en general” en, Boletín de la Sociedad de Obstetricia y Ginecología, T, XXVI, 10 de abril, pp 23-42

Riquet, R. P. y Gaucherand, Jules (1939), "La continencia periódica en el matrimonio", Iatría, año IX, abril, pp. 42-43.

Rodríguez, Ana María Teresa (2008), "La perspectiva católica sobre la salud y la práctica médica en la Argentina de los años treinta. La visión de los médicos confesionales", Anuario de Estudios Americanos, 65, 1, Sevilla, enero-junio, pp. 257275. 
Rodríguez, Hildegart (1934), "Maternidad Consciente", en Enrique Noguera y Luis Huerta (ed.), Genética, Eugenesia y Pedagogía sexual. Libro de las Primeras Jornadas Eugénicas Españolas, T. 1, Madrid, Morata, pp. 203-244.

Rodríguez de Ginocchio, Mercedes (1941) "Educación sexual eugénica maternológica" en Anales del Instituto de maternidad "Porf. U. Fernández”, º3, pp 68-78

Rodríguez de Ginocchio, Mercedes y Bernaldo de Quirós, Carlos (1941) “Obrerismoginecopatías-legislación. Función del trabajo en la mujer" en, Anales del Instituto de Maternidad Prof. U. Fernández, Nº 3, pp21-44

Romero, Ricardo (2004), "Reformismo y universidad", en Hugo Biagini y Arturo Roig (dirs.), El pensamiento alternativo en la Argentina del siglo XX. Identidad, utopía, integración (1900-1930), T. I, Buenos Aires, Biblos, pp. 233-242.

Rouco Buela, Juana (1964), Historia de un ideal vivido por una mujer, Buenos Aires, s/e.

Salessi, Jorge (1995), Médicos maleantes y maricas. Higiene, criminología y homosexualidad en la construcción de la nación Argentina. (Buenos Aires: 1871-1914), Rosario, Beatriz Viterbo Editora.

Sapriza, Graciela (2011), "Historia de la (des)penalización del aborto en Uruguay. “Aborto libre": la corta experiencia uruguaya (1934-1938)". Niki Johnson y Alejandra López Gómez; Castro, Alicia y Arribeltz, Gualberto, (Des)penalizacion del aborto en Uruguay: prácticas, actores y discursos abordaje interdisciplinario sobre una realidad compleja, Uruguay, Universidad de la República de Uruguay-Comisión Sectorial de Investigación Científica, pp. 19-64.

Scott, Joan (1993), "El género: una categoría útil para el análisis histórico”, en De mujer a género. Teoría, interpretación y práctica feminista en las ciencias sociales, Buenos Aires, Centro Editor de América Latina, p.35

Scott, Joan (2008), Género e Historia, México, FCE 
Scott, Joan. "Género ¿todavía una categoría útil para el análisis?, en La manzana de la discordia, vol. 6, $\mathrm{n}^{\circ}$ 1, enero- junio 2011, pp. 95-101. ( abril 2013) disponible en http://manzanadiscordia.univalle.edu.co/volumenes/articulos/V6N1/art9.pdf

Stábile, Américo (1946) “ Sobre lógicam pedagogía y ética mpedicas aplicadas al estudio de la esterilidad matrimonial" en, Boletín de la sociedad de Obstetricia y Ginecología, T. XXV, 8 de agosto, pp.302-324

Stepan, Nancy (1991), "The Hour of Eugenics": race, gender, and nation in Latin América. Cornell University Press, Ithaca and London.

Suriano, Juan (2001), Anarquistas, cultura y política libertaria en Buenos Aires 18901910, Buenos Aires, Manantial.

Tarcus, Horacio (dir.) (2007), Diccionario biográfico de la izquierda argentina, Buenos Aires, Emecé.

Terán, Oscar (2000), Vida intelectual en Buenos Aires a fin de siglo, Buenos Aires, Fondo de Cultura Económica.

Torrado, Susana (1992), Estructura social de la Argentina: 1945-1983, Buenos Aires, Ediciones de la Flor.

(2003), Historia de la familia en la Argentina moderna (1870-2000), Buenos Aires, Ediciones de la Flor.

Unión de Mujeres Socialistas Libertarias (1946), "Declaración de principios", Reconstruir, año I, $\mathrm{N}^{\mathrm{o}} 1$, junio.

Vallejo, Gustavo (2001), "La casa moderna y los derechos políticos de la mujer en los orígenes del feminismo rioplatense [en línea]", Sociohistórica, 9-10. Disponible e: http://www.fuentesmemoria.fahce.unlp.edu.ar/art_revistas/pr.2945/pr.2945.pdf

(2004), "Los saberes del poder: eugenesia y biotipología en la Argentina del siglo XX”, Revista de Indias, vol. LXIV, № 231, pp. 425-444. 
- (2005), "Las formas del organicismo social en la eugenesia latina".

Marisa Miranda y Gustavo Vallejos, Darwinismo social y eugenesia en el mundo latino, Buenos Aires, Siglo XXI, pp. 233-272.

Vallejo, Gustavo y Miranda, Marisa (comps.) (2004), "Los saberes del poder: eugenesia y biotipología en la Argentina del siglo XX”, Revista de Indias, vol. LXIV, $\mathrm{N}^{\circ} 231$.

(2007), Políticas del cuerpo: estrategias modernas de normalización del individuo y la sociedad, Buenos Aires, Siglo XXI.

(dirs.) (2010), Derivas de Darwin. Cultura y política en clave biológica, Buenos Aires, Siglo XXI.

(e/p), “La recepción del darwinismo en el Río de la Plata a través de fantasías literarias". Palma Héctor (dir.), Darwin y el darwinismo. Cientocincuenta años después, Buenos Aires, UNSAM.

Valobra, Adriana (2005), “«De cronopios y de famas.» La atención del binomio madrehijo en la política sanitaria bonaerense durante la gobernación de Domingo Alfredo Mercante, 1946 y 1952”. Claudio Panella (comp.), El gobierno de Domingo Mercante. Un caso de peronismo provincial, T. I, La Plata, Instituto Cultural y Archivo Histórico de la Provincia de Buenos Aires, pp. 129-172.

(2005), "Public health policies, women's organizations and mothers in the province of Buenos Aires, 1946-1952", (Un) Healthy Interiors: Contestations at the Intersection of Public Health and Private Space, Studies in Social Sciences, vol. XXXVIII, Carrollton, Georgia, University of West Georgia, julio, pp. 79-95.

(2004-2005), "Género y peronismo en la historiografía argentina. Estudio preliminar" [En línea], Trabajos y Comunicaciones, 30-31. Disponible en: http://www.fuentesmemoria.fahce.unlp.edu.ar/art_revistas/pr.314/pr.314.pdf

(2010), Del hogar a las urnas: recorridos de la ciudanía política femenina: Argentina, 1946-1955, Rosario, Prohistoria. 
(2012), "Recorridos, tensiones y desplazamientos en el ideario de

Alicia Moreau", Nomadias, $\mathrm{N}^{\circ}$ 15, julio, pp. 139-169. Disponible en http://www.nomadias.uchile.cl/index.php/NO/article/view/21068

Van de Velde, Theodor (1953), Atracción y aversión en el matrimonio [1939], Buenos Aires, Claridad.

Vezzetti, Hugo (1997), "Historia del freudismo e historia de la sexualidad: el género sexológico en Buenos Aires en los treinta", Prismas, N 1, Bernal, UNQ, pp. 211-218. Disponible en http://saavedrafajardo.um.es/WEB/archivos/Prismas/01/Prismas0126.pdf [Fecha de consulta: marzo de 2013]

Zimmermann, Eduardo, Los liberales reformistas: la cuestión social en la Argentina 1890-1916, Buenos Aires, Sudamericana, 1995.

Zeno, Lelio (1919), “el eugenismo tomado por las patas”, Prometeo, año I, No 4, pp. 46 